\title{
"Identification of the role of Arabidopsis ATAF-type NAC transcription factors in plant stress and development"
}

\author{
Dissertation \\ for the award of the degree \\ "Doctor of Philosophy" (Ph.D.) \\ Division of Mathematics and Natural Sciences \\ of the Georg-August-Universität Göttingen \\ within the doctoral program Biology \\ of the Georg-August University School of Science (GAUSS)
}

Submitted by

Neena Ratnakaran

from Pune, India

Göttingen 2014 


\section{Thesis Committee}

Prof. Dr. Christiane Gatz

(Dept.of Plant Molecular Biology and Physiology)

Prof. Dr. Volker Lipka

(Dept. of Plant Cell Biology)

Dr. Corinna Thurow

(Dept.of Plant Molecular Biology and Physiology)

\section{Members of the Examination Board}

Reviewer : : Prof. Dr. Christiane Gatz

(Dept.of Plant Molecular Biology and Physiology)

Second reviewer: Prof. Dr. Volker Lipka

(Dept. of Plant Cell Biology)

Further members of the Examination Board:

Prof. Dr. Ivo Feussner (Dept. of Plant Biochemistry)

PD Dr. Thomas Teichmann (Dept. of Plant Cell Biology)

Prof. Dr. Andrea Polle (Dept. of Forest Botany and Tree Physiology)

Jr. Prof. Dr. Cynthia Gleason (Dept.of Plant Molecular Biology and Physiology)

Date of oral examination: $16^{\text {th }}$ April 2014 
Dedicated to my loving Family 


\section{Contents}

1. Introduction............................................. 1

$1.1 \quad$ Xenobiotic-stress response in plants................................... 1

1.2 Role of phytohormones in defense responses.................... 3

1.2.1 Salicylic acid pathway.................................................. 4

1.2.2 Jasmonic acid pathway ............................................... 5

1.2.3 Antagonism between different phytohormones............................ 8

$1.3 \quad$ Local and systemic wound response in plants......................... 10

$1.4 \quad$ NAC transcription factors............................................. 11

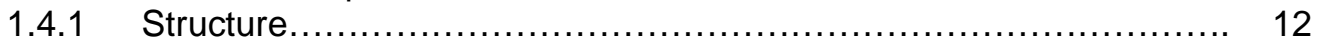

1.4 .2 Classification......................................................... 13

1.4.3 Biological functions of NAC proteins................................... 16

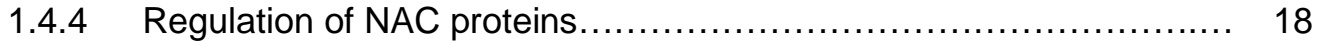

2. Aim of the Study......................................... 19

3. Materials and Methods................................. 21

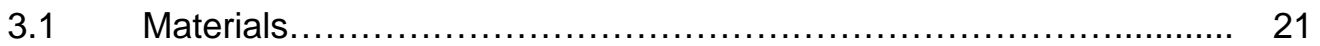

3.1.1 Organisms

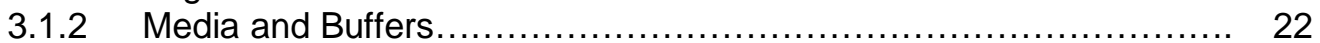

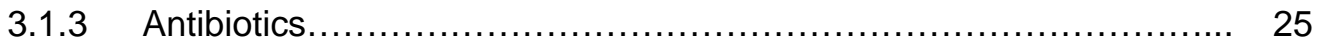

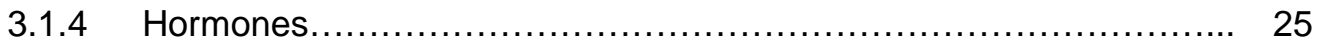

3.1.5 Kits, Enzymes and Standards........................................ 25

3.1.6 Plasmids............................................................. 25

3.1.7 Oligonucleotides................................................ 28

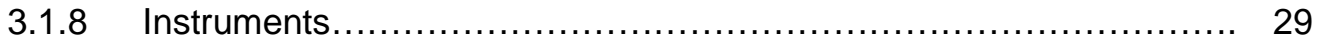

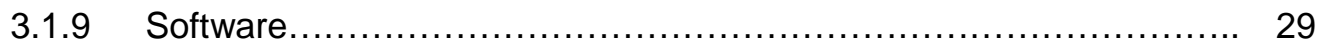

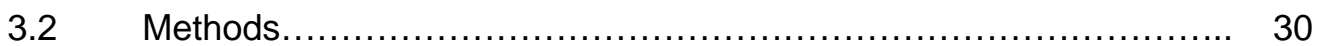

3.2.1 Plant material, growth conditions and treatments...................... 30

3.2.2 Molecular biology methods......................................... 32

3.2.3 Protoplast isolation and transformation................................ 37

3.2.4 Luciferase assay ............................................................ 37

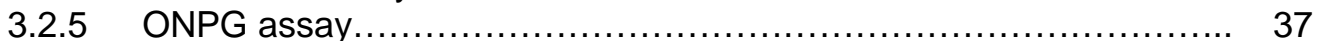

3.2.6 Metabolite measurements .......................................... 38

3.2.7 Quantitative GUS assay ............................................ 38

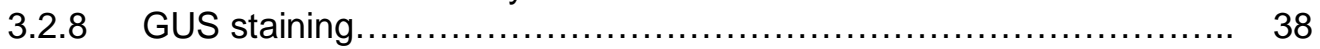

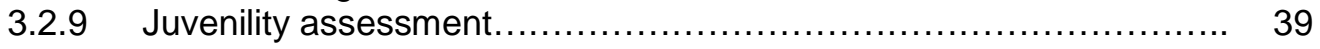

3.2.10 Germination test for seed dormancy analysis.......................... 39

4. Results................................................. 40

4.1 ANACO32 and ATAF1 are downstream target genes of the TGA/SCL14 complex in the detoxification response...................... 40

4.2 AKR4C9, bHLH585 and At3g04000 may be direct downstream targets of ANAC032 in the detoxification response towards xenobiotic compounds................................................... 43

4.3 ANACO32 and ATAF1 and their downstream targets are involved in diverse stress responses.................................................... 50

4.4 ANAC032 plays a JA-independent role in wound response............. 57 
4.5 Over-expression of ANAC032 suppresses JA-, ET- and SA- induced gene expression...................................................... 60

4.6 Over-expression of ANAC032 most likely affects signaling and not biosynthesis of phytohormones.................................... 66

4.7 Over-expression of ATAF1 leads to increased basal levels of

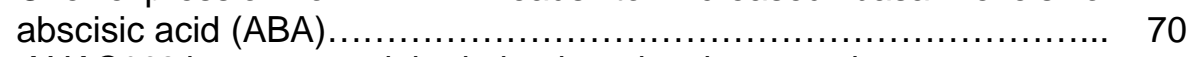

4.8 ANAC032 has a potential role in plant developmental processes..... 71

5. Discussion................................................. 77

5.1 Role of ANAC032 and ATAF1 in the xenobiotic-induced detoxification response......................................... 77

5.2 Role of ANAC032 and ATAF1 in phytohormone-mediated defense responses........................................................ 81

5.3 Role of ANAC032 and ATAF1 in plant developmental processes..... 86

6. Summary 93

7. References............................................. 95

8. Acknowledgement.................................... 114

9. Supplementary Material.............................. 115

10. Abbreviations............................................ 142

11. Curriculum vitae....................................... 145 


\section{Introduction}

Plants being sessile in nature do not enjoy the freedom of movement to escape harsh environmental conditions or pathogen invasions. In order to survive they have evolved efficient means of responding to different stresses that can be encountered. Physical barriers in the form of cell wall, cuticle and surface structures such as thorns, trichomes etc. as well as pre-formed anti-microbial chemicals function as a first layer of unspecific defense response against all kinds of threats. A second layer of induced stress response is activated when the first barrier is insufficient to contain the threat. This induced response involves recognition of pathogens or harmful substances and a response via production of counteractive chemicals/enzymes or even cell death. There have been extensive studies aiming to understand specific defense and stress responses. However, the complexities arising from the interconnection of many stress-induced pathways leaves much to be unraveled.

\subsection{Xenobiotic stress response in plants}

Plants often have to deal with exogenous xenobiotic compounds (e.g. chemical pesticides or toxins secreted by microorganisms and other plants) or endogenously produced toxic molecules. Detoxification and disposal of toxic compounds of both origins is essential for plant survival and is carried out via three main steps (Figure 1.1). The first phase called transformation involves enzymes that oxidize, reduce or hydrolyze the toxic substance thus making them accessible for the next phase. The second phase is conjugation wherein the transformed substrate is conjugated to moieties like glutathione or glucose making them less or non-toxic. Numerous plant species are known that can exhibit tolerance to toxic benzoxazinoids by rapidly metabolizing them to less phytotoxic glucoside derivatives (Baerson et al., 2005). The third and final phase involves compartmentalization of the conjugates into cell vacuoles or deposition into the apoplast (Coleman et al., 1997; Dixon et al., 1998; Li et al., 2002; Sandermann Jr., 1992). For example, it was shown recently that the xenobiotic monochlorobimane is conjugated to glutathione in the cytosol and then 
transported to the vacuole where gamma-glutamyl transpeptidase 4 (GGT4) initiates its further degradation (Grzam et al., 2007).

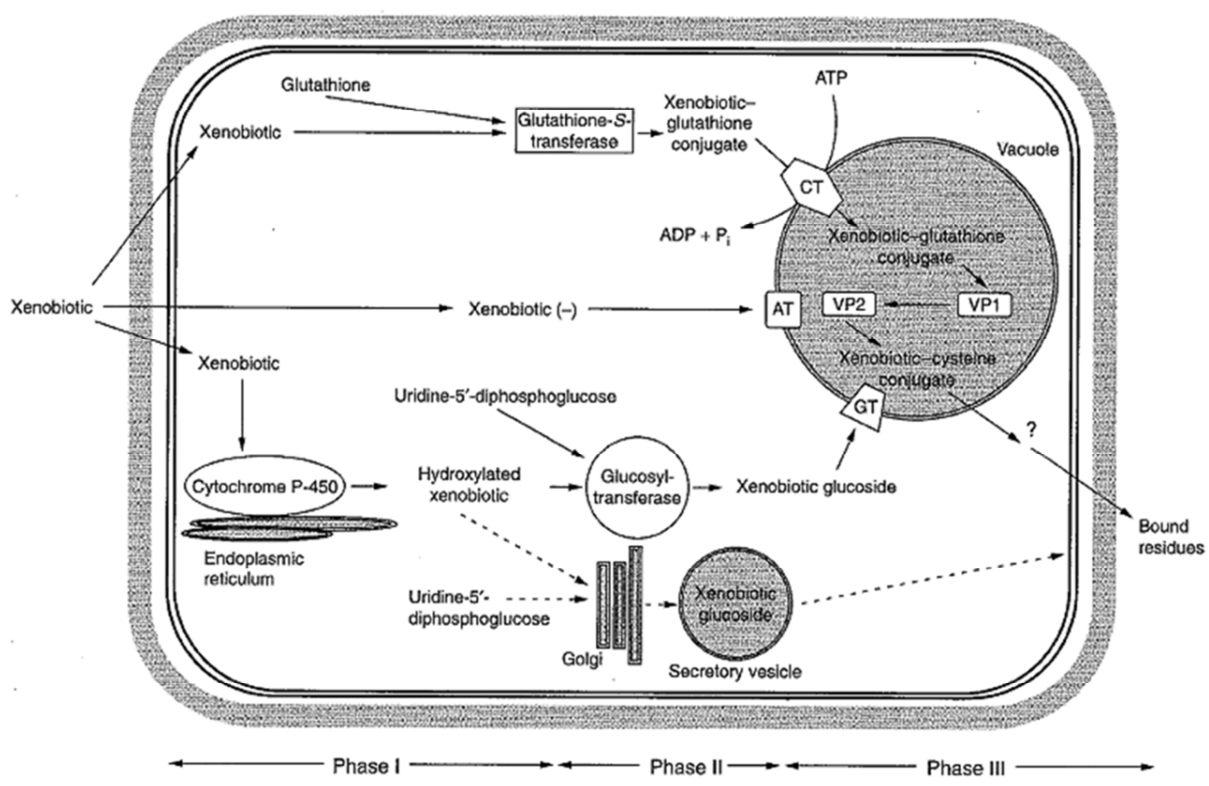

Figure 1.1 Detoxification of xenobiotics in plants (Coleman et al., 1997)

The enzyme-catalyzed reactions responsible for the detoxification of xenobiotics in plants are either localized in the cytosol or associated with the endomembrane system. The broken arrows represent a proposed pathway for glucosylation of xenobiotics in the Golgi compartment, followed by transport of metabolites into the vacuole or further release into the apoplast via exocytosis. Abbreviations: CT, glutathione conjugate transporter; AT, ATPdependent anion transporter; GT, ATP-dependent glucoside-conjugate transporter; VP, vacuolar peptidase.

TGA factors, belonging to the subfamily of basic domain/leucine zipper (bZIP) transcription factors (TFs), are required for the induction of several genes related to response against xenobiotic compounds [e.g. NITRILASE 4 (NIT4), ALDO KETO REDUCTASE FAMILY 4 MEMBER C9 (AKR4C9)] (Klinedinst et al., 2000; Mueller et al., 2008). Moreover, it was shown that safeners like isoxadifen-ethyl and mefenpyr- 
diethyl induce the xenobiotic detoxification response when applied to Arabidopsis; the majority of these safener-responsive genes depended on class II TGA TFs (TGA2, TGA5 and TGA6) and/or SA for induction (Behringer et al., 2011). TGA factors bind activation sequence-1 (as-1) elements which are overrepresented in promoters responsive to xenobiotic stress (Baerson et al., 2005; Mueller et al., 2008). The role of class II TGA TFs in detoxification was also emphasized when they were shown to interact with the Arabidopsis GRAS family protein SCARECROW-LIKE 14 (SCL 14). SCL14 is recruited to target promoters by the TGA factors and functions as a transcriptional co-activator (Fode et al., 2008). The TGA/SCL14 complex is important for the activation of several genes that are induced by xenobiotic stress. Application of toxic chemicals like 2,3,5-triiodobenzoic Acid (TIBA) or high concentrations of 2,4-dichlorophenoxyacetic acid (2,4-D) induce genes involved in the first (eg. cytochrome CYP81D11) or second phase (eg. GSTUT) of the detoxification process. This induction strictly requires the TGA factors and SCL14 with evidence being provided by corresponding knockout mutants (Fode et al., 2008). The activation mechanism of the TGA/SCL14 complex remains to be understood.

\subsection{Role of phytohormones in defense responses}

Phytohormones are small molecules within plants that are crucial for growth, development, reproduction and survival. The hormones salicylic acid (SA), jasmonic acid (JA) and ethylene (ET) are the well-studied classical players of defense response mounted against different pathogens. In addition to these, the role of other phytohormones in defense is also emerging. Reports indicate that abscisic acid (ABA) (Asselbergh et al., 2008; Mauch-Mani and Mauch, 2005; Xu et al., 2013a), gibberellic acid (GA) (Yang et al., 2012), brassinosteroids (BR) (Albrecht et al., 2012; Nakashita et al., 2003), auxin (Navarro et al., 2006; Spaepen and Vanderleyden, 2011; Wang et al., 2007) and cytokinins (CK) (Naseem and Dandekar, 2012; Siemens et al., 2006) modulate the immune response. 


\subsubsection{Salicylic acid pathway}

The phenolic signaling compound SA plays a major role in plant immune responses against biotrophic pathogens and is involved in pattern-triggered immunity (PTI) and effector-triggered immunity (ETI) (An and Mou, 2011; Glazebrook, 2005; Loake and Grant, 2007; Pieterse et al., 2009; Tsuda et al., 2009; Vlot et al., 2009). It is also essential for establishing long-term immunity in the form of systemic acquired resistance (SAR) (Durrant and Dong, 2004).
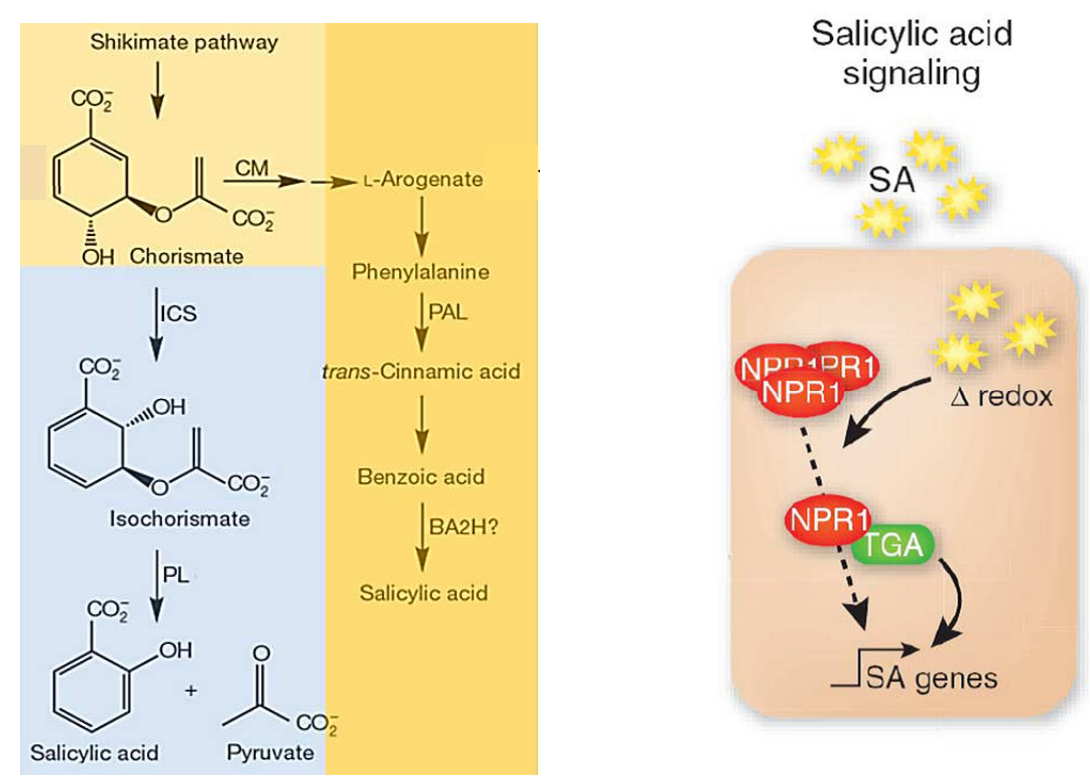

Figure 1.2 : Salicylic acid biosynthetic (adapted from Wildermuth et al., 2001) and signaling (Pieterse et al., 2009) pathways in plants

(Left) The isochorismate synthase (ICS) pathway (blue) is the primary route for SA production upon pathogen attack while the phenylalanine ammonia-lyase (PAL) pathway (yellow) has been implicated to play a minor role in Arabidopsis thaliana. Enzymes in the biosynthetic pathways are abbreviated as follows: isochorimate synthase (ICS), benzoic acid 2-hydoxylase $(\mathrm{BA2H})$, pyruvate lyase (PL, identified in bacteria), chorismate mutase (CM). (Right) Simplified model of SA signaling suggests that SA accumulation changes the redox potential within the cell, resulting in reduction of the NPR1 oligomer to its active monomer state. NPR1 then gets translocated into the nucleus where it functions as a transcriptional co-activator with TGA transcription factors to induce SA-responsive genes 
Biochemical and genetic approaches have revealed two pathways for the synthesis of SA in plants (Figure 1.2), the phenylalanine ammonia lyase (PAL)-pathway and the isochorismate synthase (ICS)-pathway (Chen et al., 2009; Wildermuth et al., 2001). Studies have indicated that the bulk of SA ( 95\%) that accumulates during plant-pathogen interaction is produced via the ICS pathway (Garcion et al., 2008). Once synthesized, SA can undergo modifications such as glucosylation, methylation or amino acid (AA) conjugation that make SA inactive and occur to fine-tune its accumulation or activity (Dempsey et al., 2011). SA signaling is mediated by both NPR1 (NON EXPRESSOR OF PR GENES 1) -dependent (Bowling et al., 1997; Cao et al., 1997; Dong, 2004; Shah et al., 1997) and NPR1-independent mechanisms (Bowling et al., 1997; Desveaux et al., 2004; Lorrain et al., 2004). In the un-induced state, NPR1 exists as an oligomer in the cell cytosol. Cellular redox changes result in its monomerization followed by its translocation to the nucleus where it is targeted for proteasomal degradation to dampen the basal expression of defense genes. SA perception stabilizes NPR1 in the nucleus which then acts as a co-activator for TFs like the TGA factors to regulate SA-responsive genes like the PATHOGENESIS RELATED-1 (PR-1) (Fu et al., 2012; Lu, 2009; Mou et al., 2003; Spoel et al., 2009; Tada et al., 2008). However studies indicate that $P R$ genes can be induced in an NPR1-independent manner indicating that there may be other proteins that also perceive SA (Blanco et al., 2005; Gou et al., 2009). Recently, it was found that the clade I TGA TFs (TGA1 and TGA4) positively regulate MAMP-triggered immunity through NPR1-independent mechanisms (Shearer et al., 2012; Wang and Fobert, 2013).

\subsubsection{Jasmonic acid pathway}

Jasmonates are lipid-derived molecules that regulate diverse processes like pollen maturation and response to wounding, herbivory and defense against necrotrophic pathogens (Browse, 2005; Wasternack, 2007). The biosynthesis of JA (Figure 1.3) begins with the octadecanoid pathway that initiates in the chloroplast when $\alpha$ linolenic acid is released from membrane lipids by phospholipases (Ellinger et al., 
2010; Hyun et al., 2008; Wasternack, 2007). Further enzymatic reactions involving 13-lipoxygenases (13-LOX) (Caldelari et al., 2011; Chauvin et al., 2013), ALLENE OXIDE SYNTHASE (AOS) (von Malek et al., 2002; Park et al., 2002a) and ALLENE OXIDE CYCLASE (AOC) (Stenzel et al., 2003a, 2003b, 2012) give rise to 12-oxophytodienoicacid (OPDA) which travels to the peroxisome where it may be actively taken up via transporters (Theodoulou et al., 2005). OPDA is then converted to (+)-7iso-JA through a series of reactions including three rounds of $\beta$-oxidation (Breithaupt et al., 2009; Kienow et al., 2008; Kombrink, 2012; Schilmiller et al., 2007; Stintzi and Browse, 2000). JA is subject to enzymatic conversions giving rise to numerous metabolites including amino acid conjugates [(+)-7-iso-Jasmonoyl-L-isoleucine (JAIle) being the natural bioactive jasmonate], methyl and glucose esters, hydroxylation products, the decarboxylation product cis-jasmone and reduced derivatives (Glauser et al., 2008, 2010; Kramell et al., 2005; Matthes et al., 2010; Seo et al., 2001; Staswick, 2009; Staswick and Tiryaki, 2004; Wasternack and Hause, 2013).

JA-perception and signaling is mediated via the F-box protein CORONATINE INSENSITIVE 1 (COI1) (Xie et al., 1998). The SCFCol1 complex targets the JASMONATE ZIM DOMAIN (JAZ) proteins for degradation allowing the release of positive activating TFs such as MYC2 that drives the expression of JA-responsive genes (Chini et al., 2007; Thines et al., 2007; Yan et al., 2007). It was recently shown that the JAZ proteins also recruit co-repressors TOPLESS (TPL), TPL-related proteins (TPRs) through adaptor protein Novel interactor of JAZ (NINJA) (Pauwels and Goossens, 2011; Pauwels et al., 2010). MYC2 activates its own expression as well as that of JA-responsive genes like VSP2 and LOX2 which are known to be induced in response to herbivorous insects and mechanical wounding (Lorenzo et al., 2004; Reymond et al., 2000; Rojo et al., 1999; Turner et al., 2002). 


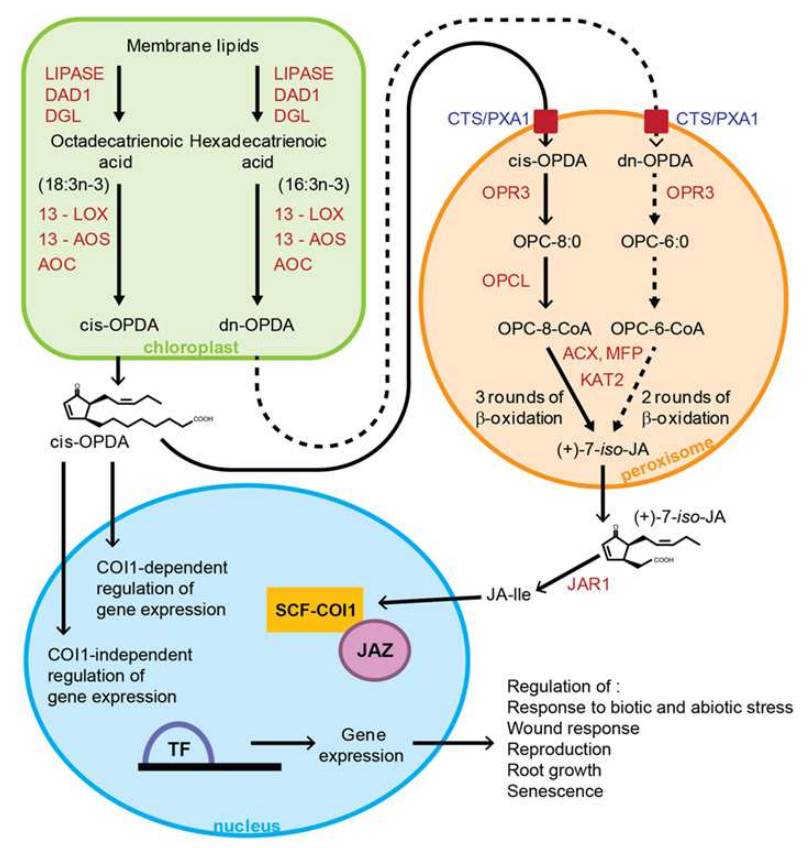

Figure 1.3: Jasmonic acid biosynthetic and signal transduction pathways in plants (Dave and Graham, 2012)

JA biosynthesis initiates in the plastid with intermediate cis-OPDA and dn-OPDA being transported into the peroxisome where sequential reactions lead to the formation of $(+)-7$-isoJA. JAR1 catalyzes the formation of JA-lle from JA in the cytosol which is perceived by the JA-receptor COI1 that then targets the JAZ repressors for degradation thus de-repressing the activation of JA-responsive genes. Enzyme names are shown in red. Dashed arrows indicate route to JA biosynthesis via dn-OPDA, where these steps are yet to be proven experimentally. DAD1, DEFECTIVE IN ANTHER DEHISCENCE1; DGL, DONGLE; 13-LOX, 13-lipoxygenase; 13-AOS, 13-allene oxide synthase; AOC, allene oxide cyclase; OPR3, 12oxophytodienoate reductase3; OPCL1, OPC-8:CoA ligase1; CTS, COMATOSE; ACX, acyl CoA oxidase; KAT, 3-I-ketoacyl-CoA-thiolase; MFP, multifunctional protein; JA, jasmonic acid; cis-OPDA, cis-(+)-12-oxo-phytodienoic acid; dn-OPDA, dinor-oxo-phytodienoic acid; JA-lle, jasmonoyl-L-isoleucine; COI1, CORONATINE-INSENSITIVE1; JAZ, jasmonate ZIM domain.

A second branch, leading to expression of JA-responsive genes like PLANT DEFENSIN1.2 (PDF1.2) and $b-C H /$ is regulated by a positive interaction between JA and ethylene $(\mathrm{ET})$ through transcription factor OCATDECANOID-RESPONSIVE 
ARABIDOPSIS 59 (ORA59 (Berrocal-Lobo et al., 2002; Lorenzo et al., 2004; Penninckx et al., 1998)). Thus, the JA pathway seems to be branched into two pathways that are regulated by MYC2 and ORA59, the latter requiring both JA and ET (Zander et al., 2010). Recently it was shown that ET-stabilized ETHYLENE INSENSITIVE 3 (EIN3) and EIN3-LIKE1 (EIL1) interact directly with JAZ proteins which along with co-repressors inhibit transcriptional activity of EIN3/EIL1 (Zhu et al., 2011). Introduction of JA in the system induces COI1-mediated degradation of JAZ proteins thus relieving the repressive effect of JAZ proteins on ET signaling.

\subsubsection{Antagonism between different phytohormones}

When plants perceive a pathogen or "attack" they respond by activating specific defense responses which affect the accumulation patterns of different phytohormones. The ensuing hormonal blend, known as "signal signature", varies in strength, composition and timing depending on the lifestyle, invasion and plantattacker combination (De Vos et al., 2005). Although there are exceptions, it is generally believed that pathogens with a biotrophic mode of lifestyle activate the SAdependent immune responses while the necrotrophic pathogens and herbivorous insects stimulate a JA-dependent response (Glazebrook, 2005; Howe and Jander, 2008; Pieterse et al., 2012). These two hormones are the major players in plant immunity and it is well established that antagonism between the two plays a central role in modulating the immune response (Figure 1.4). Recently, it was shown that SA-mediated suppression of JA-responsive genes is downstream of the SCFCOI1-JAZ machinery and works by targeting GCC-box motifs found in JA-responsive promoters via negative effect on the transcriptional activator ORA59 (Van der Does et al., 2013). Another player in the SA-JA cross-talk is the SA-induced NPR1 which is required for suppressing the JA response (Leon-Reyes et al., 2009). Other players in the SA-JA antagonism include WRKY factors (e.g. WRKY70), MITOGEN ACTIVATED PROTEIN KINASE 4 (MPK4) and glutaredoxins (e.g GRX480) (Li et al., 2004; Ndamukong et al., 2007; Petersen et al., 2000). It has been shown that GRX480 and several other CC-type GRXs can interact with class II TGA factors and 
suppress the JA/ET branch of JA-signaling by suppressing expression of ORA59 (Ndamukong et al., 2007; Zander et al., 2012). The two branches of JA-signaling MYC2 and ERF - themselves are antagonistic to each other (Figure 1.4). The JA-ET antagonism is modulated by an interaction between MYC2 and EIN3/EIL1 (Song et al., 2014). MYC2 can repress the EIN3/EIL1 to inhibit ET-regulated apical hook formation and response to necrotrophic pathogens. Conversely, EIN3/EIL can attenuate MYC2 to inhibit wound-responsive and herbivore-inducible gene expression.

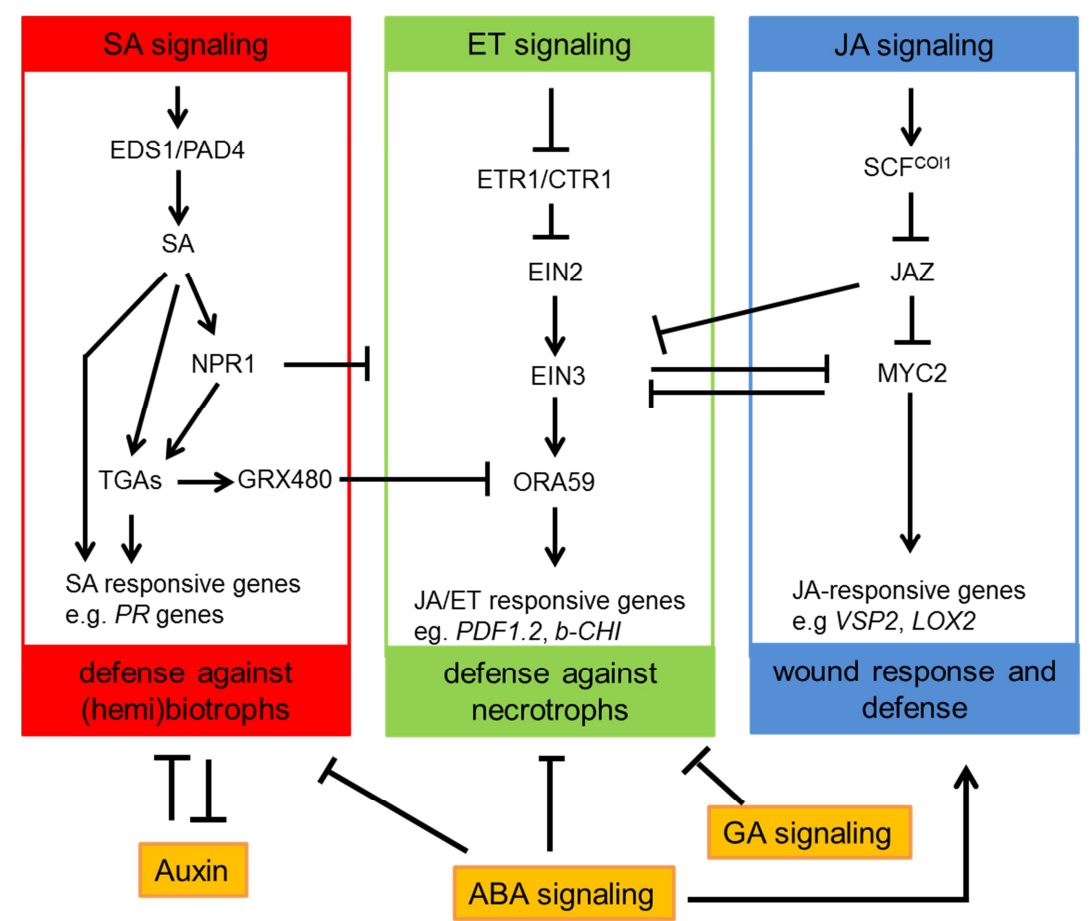

Figure 1.4: Cross-communication between phytohormones in immune response (adapted from Pieterse et al., 2009; Song et al., 2014; Zhu et al., 2011)

Cross-communication between hormone signaling pathways provides the plant with a large regulatory capacity that may tailor its defense response to different types of attackers. The SA, JA and ET signaling pathways represent the backbone of the defense signaling network, with other hormonal signaling pathways feeding into it. $\perp$ indicates negative effect; arrows indicate positive effect. 
As presented in Figure 1.4, abiotic stress and growth-related hormones like abscisic acid (ABA), gibberellic acid (GA), auxins and cytokinins usually feed into the defense network characterized by SA, JA and ET pathways to maintain the trade-off between defense and development (Gimenez-lbanez and Solano, 2013; Naseem and Dandekar, 2012; Robert-Seilaniantz et al., 2011). Studies with external application of $A B A$ suggest mainly a negative role of $A B A$ in plant immunity including suppression of SA-mediated PR-1 expression (Moeder et al., 2010). Similarly, Arabidopsis mutants impaired in ABA biosynthesis or sensitivity show more resistance to Pst DC3000 (de Torres-Zabala et al., 2007) as well as to necrotrophic fungal pathogen Fusarium oxysporium (Anderson et al., 2004). Making use of ABA and JA/ET signaling mutants it was shown that the two pathways act antagonistically to each other (Anderson et al., 2004). However ABA also plays a positive role in some instances where it was shown to contribute to JA accumulation and activation of JAdependent resistance (Adie et al., 2007). The observations that ABA can antagonistically interact with defense pathways suggest that plant abiotic stress can be prioritized over plant immunity and suggests a central role for ABA in this crosstalk between biotic and abiotic stress (Cao et al., 2011; Mauch-Mani and Mauch, 2005).

\subsection{Local and systemic wound response in plants}

Although JA has been accepted as the wound hormone in land plants, our understanding of how it exerts its local and systemic effects is still incomplete. In tomatoes, many components other than JA were identified as signals leading to activation of wound-responsive genes. These included oligosaccharides (Bishop et al., 1984; Doares et al., 1995), the peptide systemin (Pearce et al., 1991), phytohormones ABA and ET (O’Donnell et al., 1996; Peña-Cortés et al., 1995; Weiss and Bevan, 1991) and electrical (Wildon et al., 1992) signals. It was believed however that all of them contributed to a single pathway operating through JA. It is now well established that there exists, in Arabidopsis, JA-dependent as well as JAindependent wound signaling pathways, even though the latter ones are not well 
understood (León et al., 1998; McConn et al., 1997; Nishiuchi et al., 1997; Rojo et al., 1998, 1999; Titarenko et al., 1997). For example, it was shown that induction of CHOLINE KINASE (CK) and WOUND-RESPONSIVE 3 (WR3) is independent of JA synthesis and perception (León et al., 1998; Titarenko et al., 1997). These genes were induced by oligosaccharides that are released from plant cell walls upon wounding and were shown to be specifically involved in the activation of JAindependent wound-induction pathway (Rojo et al., 1999). The same study proposed a model where the oligosaccharide-induced pathway suppressed JA-dependent wound responses in the local tissue via induction of ET biosynthesis [known to be activated in wounded tissue; (O'Donnell et al., 1996)] while proposing that JA was involved mainly in the systemic response after wounding. However, another report showed that the JA-responsive AOS gene was strongly expressed in both local and systemic leaves after wounding (Kubigsteltig et al., 1999). More recently it was shown that JA levels increase within 2-5 min of wounding throughout the plant (Glauser et al., 2008). Electric signals may be involved in transmitting this rapid signal for accumulation of JA in distal unwounded leaves (Mousavi et al., 2013; Wildon et al., 1992) and among the 13-LOXs, LOX6 seems to contribute to this rapid JA synthesis (Chauvin et al., 2013). Furthermore, there is evidence of another gene, RNS1, which accumulates in both wounded and systemic leaves but independently of both JA and oligosaccharide-mediated responses (LeBrasseur et al., 2002). These studies indicate that the wound response is much more complex than was presumed and although JA seems to play a major role, other signaling pathways may interact functionally to optimize the wound response.

\subsection{NAC transcription factors}

Over 5\% of the Arabidopsis genome encodes for more than 2000 transcription factors and a sizeable percentage of these are specific to the plant kingdom. One such plant-specific group is the family of NAC transcription factors that are among the largest TF families in Arabidopsis consisting of more than a hundred members (Riechmann et al., 2000). The NAC (NAM/ATAF1/2/CUC2) domain was first 
identified from the NAM (NO APICAL MERISTEM) sequence from Petunia (Souer et al., 1996) and ATAF1, ATAF2 (ARABIDOPSIS THALIANA ACTIVATION FACTOR 1, 2) and CUC2 (CUP-SHAPED COTYLEDOM) sequences from Arabidopsis (Aida et al., 1997, 1999). Since then several members have been identified and characterized in Arabidopsis as well as in different plants like rice (Hu et al., 2006, 2008), soybean (Hao et al., 2011; Le et al., 2011; Tran et al., 2009), wheat (Kawaura et al., 2008; Xia et al., 2010), potato (Collinge and Boller, 2001) and even in tree species like poplar (Hu et al., 2010) and citrus (Liu et al., 2009; Oliveira et al., 2011). Few have also been reported in the moss Physcomitrella patens but none have been found in algae so far suggesting they are specific to land plants (Shen et al., 2009).

\subsubsection{Structure}

The NAC TFs are characterized by the presence of a consensus sequence, termed as NAC domain which is situated in the $\mathrm{N}$-terminal region of the protein and includes the DNA binding domain (DBD) (Duval et al., 2002; Kikuchi et al., 2000). This Nterminal region consisting of approximately 150 amino acids is highly conserved as opposed to the vastly variable C-terminal end (Ernst et al., 2004; Olsen et al., 2005). The NAC domain consists of five sub-domains A-E [Figure 1.5 (i)]. The sub-domains $A$ and $B$ show a net negative charge while all other sub-domains are positively charged which may help in DNA binding (Ernst et al., 2004; Xie et al., 1999). Studies suggest dimerization of NAC proteins is possible via conserved interactions including salt bridges and that the sub-domain A plays a major role in this. The DBD is suggested to be contained within the sub-domains $C$ and $D$ while $B$ and $E$ subdomains which are more diverse than others may contribute to functional diversity (Chen et al., 2011; Ernst et al., 2004; Jensen et al., 2010; Ooka et al., 2003). Structure of the NAC domain also reveals a unique transcription fold not yet seen in other TFs. It contains a twisted $\beta$-sheet surrounded by a few helical elements rather than the classical helix-turn-helix motif (Ernst et al., 2004). The transcriptional regulatory (TR) domain of the NAC proteins is usually present in the C-terminal end and can function to activate (He et al., 2005; Lu et al., 2007; Puranik et al., 2011; Tran et al., 2004) or to repress (Delessert et al., 2005; Kim et al., 2007; Yamaguchi et 
al., 2010) transcription. The TR region being highly variable may contribute to the functional diversity seen among the NAC proteins. Further, there are also some NAC proteins that show variations from the above described typical structure which is described in Figure 1.5 (ii) - (vi) (Hao et al., 2010; Jensen et al., 2010; Mitsuda et al., 2004; Seo et al., 2008; Yoshiyama et al., 2009).

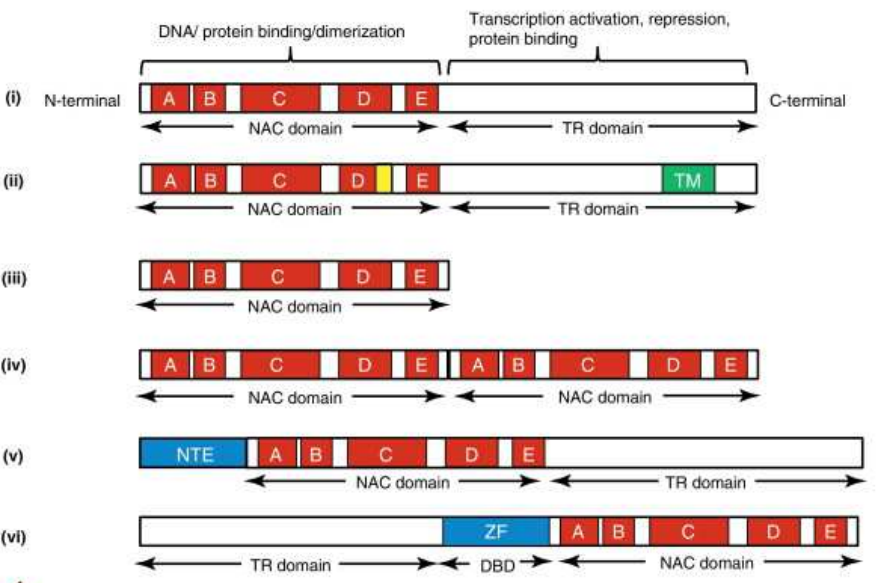

Figure 1.5: Structure of NAC proteins (Puranik et al., 2012)

Schematic representation showing (i) a typical NAC protein with a N-terminal NAC domain and a Cterminal transcriptional regulatory (TR) domain, (ii) NAC domain that may contain negative regulatory domain (shaded yellow) and/or a C-terminus having a transmembrane motif (shaded green), (iii) NAC proteins encoding only a NAC domain, (iv) proteins containing two tandemly repeated NAC domains, (v) proteins having a N-terminally extended (NTE) region preceding the conserved NAC domain and (vi) VOZ proteins that have a NAC domain at the C-terminal end while their TR domain lies at the N-terminal with a zinc-finger (ZF) motif functioning as a DBD (DNA-binding domain)

\subsubsection{Classification}

A decade ago, the first systematic analysis of NAC proteins was carried out with 75 and 105 predicted NAC proteins in rice and Arabidopsis respectively (Ooka et al., 2003). The proteins were classified into two supergroups (I and II) based on the predicted NAC sub-domain (A-E) amino acid sequences. The two groups were further divided into several sub groups on the basis of the NAC domain structure. With the identification of more than 100 putative NAC genes in rice, a new phylogenetic analysis (based on sub-domains A-D) was carried out which divided the 
family into five major groups (1-5) (Fang et al., 2008). A further classification of NAC genes (based on sub-domain A-C) from tobacco and compared with rice, Arabidopsis and poplar revealed a new NAC sub-family named as TNACS that appeared to be restricted to the Solanaceae family since it has been identified so far only in tomato, potato and pepper (Rensing et al., 2008). Thus classification of the NAC TFs has been a challenge since phylogeny changes with the inclusion of different sub-domain sequences.

More recently, Shen et al., 2009 included the highly diverse C-terminal sequences of the NAC proteins and attempted to classify this complex TF family. A total of 1,232 NAC genes from eleven different organisms were included in a sequence based phylogeny analysis (based on $\mathrm{N}$-terminal protein sub-domains $\mathrm{A}-\mathrm{E}$ ) which classified the proteins into eight subfamilies (NAC-a to NAC-h) (Figure 1.6). Each subfamily was further divided into subgroups based on tree topology and each subgroup members were divided into different clades based on their C-terminal motif patterns. The analysis showed that the C-terminus also show conserved motif patterns across sub-groups. Based on this the NAC genes with known different functions clearly fell into different subfamilies.

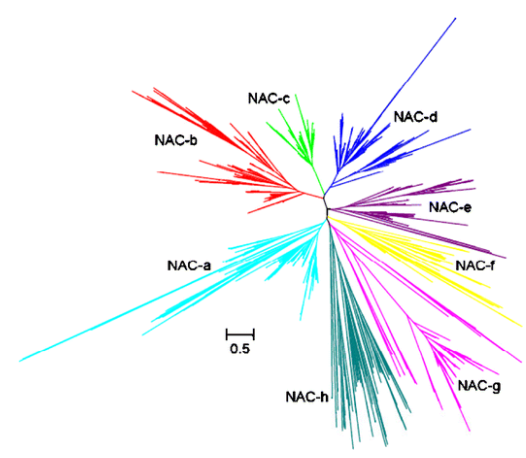

Fig 1.6 :Maximum likelihood (ML) phylogeny of 1,232 NAC proteins (Shen et al., 2009)

The NAC domain regions A-E were used in the analysis. The 1,232 proteins include 1,211 NAC proteins from 11 plant species (Physcomitrella patens spp patens (moss), Selaginella moellendorffii (spike moss), Populus trichocarpa, Vitis vinifera (grape), Medicago truncatula, Glycine max, Oryza sativa, Sorghum bicolor, Zea mays, Panicum virgatum and Arabidopsis thaliana) and an additional 21 NAC proteins collected from literature. Bar shows the distance scale for branch length (amino acid substitutions per site) 
Earlier classification placed wound-responsive ATAF1 and ATAF2 in the ATAF subfamily along with StNAC and OsNAC6 which are also stress-induced. This provided support to the idea that the members of the ATAF subgroup share a conserved role in response to stress stimuli (Ooka et al., 2003). In the new classification, biotic and abiotic stress related NAC proteins group into the NAC-a subfamily (Shen et al., 2009). The Arabidopsis ATAF sub-family members ATAF1, ATAF2, ANACO32 and ANAC102 contain the same motif clade and get grouped into NAC-a-sc2 clade which is part of the NAC-a-9 subgroup (Figure 1.7)

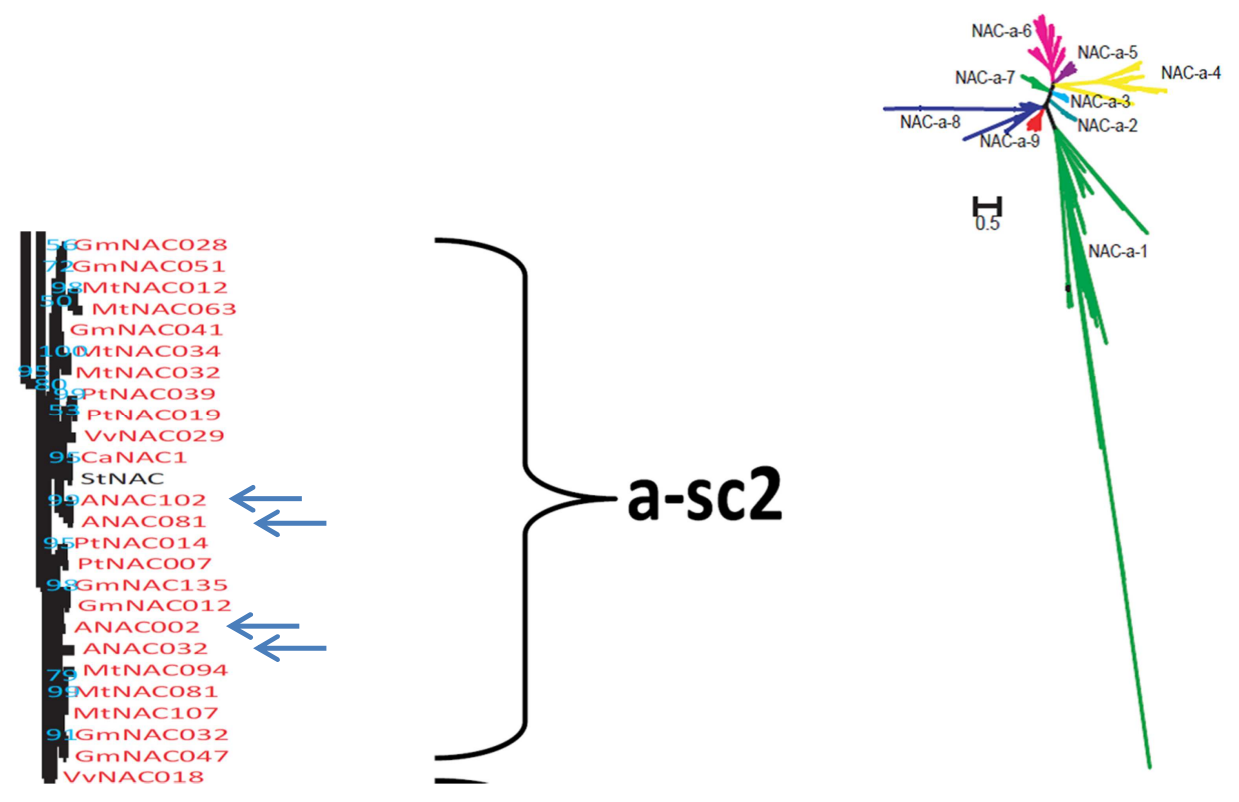

Figure 1.7: The motif clades and subgroups for the NAC-a subfamily.

Subgroups are a-1 to a-9 while motif clades are a-sc1 to a-sc20. The previously described ATAF subfamily members fall under a-sc2 clade (left) in sub-group NAC-a-9 (right) according to new classification. Blue arrows indicate the four Arabidopsis ATAF members (Shen et al., 2009, modified).

\subsubsection{Biological functions of NAC proteins}

Studies on $N A M$ and $C U C 2$, the first $N A C$ genes to be characterized, suggested that these are essential for proper development because mutations in these genes resulted in fused cotyledons and a lack of shoot apical meristems causing the 
mutants to die at a seedling stage (Aida et al., 1997; Souer et al., 1996). Since then a lot of studies in different plant species have provided information about the role of NAC proteins in plant growth and development (Aida et al., 1999; Hao et al., 2011; Hendelman et al., 2013; Hibara et al., 2006; Ishida et al., 2000; Kunieda et al., 2008; Ohtani et al., 2011; Pei et al., 2013; Ricachenevsky et al., 2013; Takeda et al., 2011). Many NAC proteins have also been identified by their induction in response to biotic stress. The potato $N A C$ gene $S t N A C$ is rapidly induced in response to infection by Phytophthora infestans and wounding (Collinge and Boller, 2001). The TaNAC8 and GRAB1 from wheat are induced in response to stripe rust pathogen and wheat dwarf geminivirus infections respectively (Xia et al., 2010; Xie et al., 1999). Studies indicated that membrane-bound NTL6 is proteolytically activated by cold further leading to expression of PATHOGENESIS-RELATED $(P R)$ genes which gave rise to the proposal of an adaptive strategy that protects plants against infection by hydrophilic pathogens known to occur in cold season (Seo et al., 2010a, 2010b). Recently, it was shown that infection with fungal Verticillium pathogen leads to induction of VND7 (a NAC-domain protein) that regulates de novo xylem formation thus enhancing water storage capacity of the host plant (Reusche et al., 2012). The previously known wound-responsive $A T A F 2$ was shown to interact with Tobacco Mosaic Virus replicase protein which led to suppression of basal host defenses and promotion of systemic virus accumulation (Wang et al., 2009a). Over-expression of the closely related member $A T A F 1$, also known to be induced after wounding, led to negative regulation of defense responses against necrotrophic pathogens in two independent studies, although its effect upon the expression of defense genes PR1 and PDF1.2 was contradictory in the two reports (Wang et al., 2009b; Wu et al., 2009). There is also controversial evidence regarding the role of ATAF1 in abiotic drought stress situation. One study found ataf1 mutant to be more drought tolerant and showed that ATAF1 negatively regulates expression of drought-responsive genes like COR47, ERD10 and RD29A (Jensen et al., 2008; Lu et al., 2007). Another study reported that over-expression of $A T A F 1$ conferred increased drought tolerance in Arabidopsis along with a higher expression of COR47 and RD29A genes at late stages of stress (Wu et al., 2009). One reason for these discrepancies may be 
environmental factors that modulate cross-talks between different signaling pathways. The ATAF1 and ATAF2 TFs have also roles in ABA and auxin synthesis respectively by directly regulating expression of key biosynthetic enzymes (Huh et al., 2012; Jensen et al., 2013). Several other NAC TFs have been described as being induced under a variety of abiotic stress situations like osmotic stress, salinity, drought, cold and oxidative stress (Fujita et al., 2004; Hu et al., 2008; Irsigler et al., 2007; Jin et al., 2013; Ramegowda et al., 2012; Wu et al., 2009; Xu et al., 2013b). Thus, more and more studies are emerging that indicate the diverse roles played by NAC TFs.

Most knowledge of potential downstream target genes of NAC TFs arise from transcriptome analyses in plants overexpressing the NAC protein. One study identified CGT(G/A) and CACG as core-DNA binding motif recognized by droughtresponsive NAC TFs ANAC019, ANAC055 and ANAC072 (Tran et al., 2004). Another study involving a calmodulin-binding NAC protein identified GCTT as the core NAC binding sequence flanked by other frequently repeating sequences (TTGCTTANNNNNNAAG) (Kim et al., 2007). More recently, the ATAF1 consensus binding sequences were identified as $T(A / C / G) C G T(A / G)$ and $T T(A / C / G) C G T$ (Jensen et al., 2013). Another analysis which made use of the recent ChIP-Seq and RNA-Seq techniques identified three potential NAC binding motifs $[G(A / T / C / G) G(A / G) G(A / G) G(A / G) ; C(A / C) C(G / A)(T / C / G)(G / A) C(C / G)$ and TGGGCC] for NAC proteins that are specifically induced during development of soybean seedlings (Shamimuzzaman and Vodkin, 2013). Future studies may reveal other novel NAC recognition sequences improving our understanding of functional diversity of NAC proteins.

\subsubsection{Regulation of NAC proteins}

In spite of extensive functional characterization of so many different NAC proteins, their regulation is poorly understood. Transcriptional regulation of stress responsive NAC TFs has been postulated by the presence of several stress-responsive cisacting elements in promoter regions. These include the ABA-responsive elements (ABREs), low-temperature responsive elements (LTREs), MYB and MYC binding 
sites, W-box, JA-responsive elements and SA-responsive elements (reviewed in Olsen et al., 2005; Puranik et al., 2012). A few NAC TFs have been shown to be regulated post-transcriptionally by microRNAs (miRNAs). For example, the NAC1 gene in maize was negatively regulated by miR164b ( $\mathrm{Li}$ et al., 2012) and the AsNAC60 in creeping bentgrass was shown to be regulated by miR319 (Zhou et al., 2013). A further mode of regulation of NAC TFs can be post-translational including ubiquitin-mediated protein degradation (Greve et al., 2003; Xie et al., 2002), dimerization (Ernst et al., 2004; Jeong et al., 2009; Puranik et al., 2012) and interactions with other proteins (Greve et al., 2003; Tran et al., 2007). The nuclear import of NTLs (membrane associated NAC TFs) is regulated by proteolytic cleavage of the anchor by transmembrane proteases, often in response to different stresses. An example is the NTL6 which is cleaved and imported to the nucleus under cold stress (Seo et al., 2010a). Another example of post-translational regulation is that of ATAF1 which was shown to interact with SnRK1 kinases in vitro. This interaction could modulate either the DNA binding activity of ATAF1 or target ATAF1 to proteasomal degradation by a second interaction of SnRK1 with E3-like ligases (Kleinow et al., 2009). 


\section{Aim of the Study}

This work is based on the findings of $\mathrm{Dr}$. Benjamin Fode ( $\mathrm{PhD}$ dissertation). It was shown that class II TGA factors (TGA2, TGA5 and TGA6) recruit the GRAS family protein SCL14 (SCARECROW-like 14) to promoters of downstream target genes. This TGA256/SCL14 complex triggers the detoxification response against toxic chemical substances like TIBA (2, 3, 4-triiodobenzoic acid). Microarray analysis revealed a number of genes that were up-regulated when SCL14 was overexpressed. The promoter sequences of these genes were then scanned for as1-like elements to which TGA factors can bind (Katagiri et al., 1989). Among the candidate target genes of the TGA/SCL14 complex that were thus identified, two of them belonged to the ATAF sub-family of NAC transcription factors (TFs) (Fode et al., 2008). These two members - ANACO32 and ATAF1 - are close homologs and along with other two members of the ATAF sub-family (ANAC102 and ATAF2) show similar expression profiles in response to a wide range of treatments (Kleinow et al., 2009). Although, ATAF1 was among the first NAC transcription factors to be identified (Souer et al., 1996), its function is not yet well understood. In this current thesis, we have tried to comprehend the possible functions of ATAF-type NAC TFs with more focus on ANACO32 as it has not been characterized before.

Since ANAC032 and ATAF1 were identified as targets of the TGA/SCL14 complex, the primary aim of the current study was to understand their contribution to the detoxification response and identify potential downstream target genes in the pathway. For this purpose, transgenic plants over-expressing the two NAC TFs as well as knockout mutants of the two were obtained and analyzed.

Further, the ATAF subfamily of TFs is predicted to be stress-responsive (Ooka et al., 2003). There has been contradicting evidence regarding the possible roles of ATAF1 in biotic as well as abiotic stress responses (Mauch-Mani and Flors, 2009). ATAF1 has been suggested to positively as well as negatively regulate gene expression of defense genes like PR1 (Wang et al., 2009b; Wu et al., 2009). In a previous study 
(Dr. Julia Köster, PhD dissertation) it was observed that over-expression of ANACO32 in Arabidopsis resulted in a suppression of methyl jasmonate (MeJA)induced CYP81D11 and PDF1.2 expression. These evidences suggest some role for the two NAC TFs in defense responses. It is known that phytohormones like SA and ABA can act antagonistically with JA/ET leading to suppression of PDF1.2 (see Introduction 1.2.3). Since the cross-talk depends on TGA factors and because these hormones can induce the NAC TFs, a role for the NAC proteins in mediating these cross-talks is also explored.

Transgenic over-expression lines of 35S:ANAC032 and 35S:ATAF1 that were generated showed developmental phenotypes as compared to the wild-type plants. Additionally, a look at the transcriptomic database, Arabidopsis eFP browser, indicated high levels of ANACO32 in the seed stage compared to any other plant tissue. Consequently, we have investigated their role in seed dormancy and also its contribution to development and growth of Arabidopsis.

To summarize, the key questions addressed in this current thesis were as follows:

1. Do $A N A C 032$ and $A T A F 1$ regulate a part of the TGA256/SCL14-induced response to xenobiotic compounds? If yes, what could be the down-stream target genes?

2. Which role do the NAC TFs play during the defense response involving the phytohormones? Do these TFs, as speculated from previous reports, regulate crosstalks seen frequently between different biotic and/or abiotic stress signaling pathways?

3. What is the probable role of ANACO32 in the development and growth of Arabidopsis? 


\section{Materials and Methods}

\subsection{Materials}

\subsubsection{Organisms}

\subsubsection{Bacteria}

\begin{tabular}{|c|c|c|}
\hline Strain & Description & Reference \\
\hline $\begin{array}{l}\text { Agrobacterium tumefaciens } \\
\text { GV3101::pMP90 }\end{array}$ & Rifr $^{r}$, Gent $^{r}$ & (Koncz and Schell, 1986) \\
\hline Escherichia coli DB3.1 & $\begin{array}{l}\mathrm{F}-\text { gyrA462 endA1 } \Delta(\mathrm{sr} 1- \\
\text { recA) mcrB mrr } \\
\text { hsdS20(rB-, mB-) supE44 } \\
\text { ara-14 ga/K2 lacY1 proA2 } \\
\text { rpsL20(SmR) xyl-5 } \lambda-\text { leu } \\
\text { mt/1 }\end{array}$ & $\begin{array}{l}\text { (Bernard and Couturier, } \\
\text { 1992) }\end{array}$ \\
\hline Escherichia coli DH5a & $\begin{array}{l}\text { F- Ф80lacZDM15 } \\
\Delta(\text { lacZYA-argF) U169 } \\
\text { recA1 endA1 hsdR17 (rK-, } \\
\text { mK+) phoA supE44 } \lambda-\text { thi- } \\
1 \text { gyrA96 relA1 }\end{array}$ & (Hanahan, 1985) \\
\hline
\end{tabular}

\subsubsection{Fungi}

\begin{tabular}{|c|c|c|}
\hline Strain & Description & Reference \\
\hline $\begin{array}{l}\text { Botrytis cinerea (named as } \\
\text { BMM strain) }\end{array}$ & Infects $A$. thaliana Col-0 & $\begin{array}{l}\text { Kindly provided by } \\
\text { Brigitte Mauch-Mani, } \\
\text { University of Neuchatel, } \\
\text { Switzerland }\end{array}$ \\
\hline $\begin{array}{l}\text { Saccharomyces cervisiae } \\
\text { (PJ69-4a strain) }\end{array}$ & $\begin{array}{l}\text { MATa, trp1-901, leu2- } \\
\text { 3,112, ura3-52, his3-200, } \\
\text { gal4 } \Delta \text {, gal80 } \Delta \text {, GAL2- } \\
\text { ADE2, LYS2 ::GAL1-HIS3, } \\
\text { met2::GAL7-lacZ }\end{array}$ & (James et al., 1996) \\
\hline
\end{tabular}

\subsubsection{Insect}

\begin{tabular}{|l|l|}
\hline \multicolumn{1}{|c|}{ Species } & \multicolumn{1}{c|}{ Reference } \\
\hline Plutella xylostella & Kindly provided by \\
(Diamondback moth) & Department of Agricultural \\
& Entomology, University of \\
& Göttingen, Germany \\
\hline
\end{tabular}

\subsubsection{Plant (Arabidopsis thaliana)}

\begin{tabular}{|c|l|l|}
\hline Genotype & \multicolumn{1}{|c|}{ Description } & \multicolumn{1}{c|}{ Reference } \\
\hline 35S:ANAC032 & $\begin{array}{l}\text { Transgenic line over- } \\
\text { expressing (N-terminal) } \\
\text { HA-tagged ANAC032 } \\
\text { gene under the control of } \\
\text { the CaMV 35S promoter }\end{array}$ & $\begin{array}{l}\text { Dr. Julia Köster; personal } \\
\text { communication }\end{array}$ \\
\hline
\end{tabular}




\begin{tabular}{|c|c|c|}
\hline 35S:ATAF1 & $\begin{array}{l}\text { Transgenic line over- } \\
\text { expressing (N-terminal) } \\
\text { HA-tagged ATAF1 gene } \\
\text { under the control of the } \\
\text { CaMV 35S promoter }\end{array}$ & $\begin{array}{l}\text { Dr. Julia Köster; personal } \\
\text { communication }\end{array}$ \\
\hline anac032 (SALK_012253) & $\begin{array}{l}\text { T-DNA insertion in the first } \\
\text { exon of } A N A C 032 \text { gene }\end{array}$ & NASC stock no. N512253 \\
\hline ataf1-1 (SALK_067648) & $\begin{array}{l}\text { T-DNA insertion in the } \\
\text { third exon of the } A T A F 1 \\
\text { gene }\end{array}$ & (Lu et al., 2007) \\
\hline ataf1anac032 & $\begin{array}{l}\text { Obtained by crossing } \\
\text { knockout mutants ataf1-1 } \\
\text { and anac032 }\end{array}$ & $\begin{array}{l}\text { Dr. Julia Köster; personal } \\
\text { communication }\end{array}$ \\
\hline coi1-t & $\begin{array}{l}\text { T-DNA insertion within the } \\
\text { cOl1 locus }\end{array}$ & (Mosblech et al., 2011) \\
\hline $\begin{array}{l}\text { Columbia accession-0 } \\
(\text { Col-0) }\end{array}$ & Wild type (WT) & NASC stock no. N1092 \\
\hline $\begin{array}{l}\text { delayed-dehiscence2-2 } \\
\text { (dde2-2) }\end{array}$ & $\begin{array}{l}\text { Knockout mutation in } \\
\text { ALLENE OXIDE } \\
\text { SYNTHASE (AOS) gene }\end{array}$ & (Park et al., 2002b) \\
\hline scl-14 scl-33 (sc/14/33) & $\begin{array}{l}\text { Double knockout of SCL14 } \\
\text { and SCL33 obtained by } \\
\text { crossing T-DNA insertion } \\
\text { mutants of each gene }\end{array}$ & $\begin{array}{l}\text { Alexander Meier; personal } \\
\text { communication }\end{array}$ \\
\hline $\begin{array}{l}\operatorname{tga} 2-1 \text { tga5-1 tga6 }-1 \\
(\operatorname{tga} 256)\end{array}$ & $\begin{array}{l}\text { Combined deletion } \\
\text { knockout mutants of } \\
T G A 2, T G A 5 \text { and TGA6 }\end{array}$ & (Zhang et al., 2003) \\
\hline JAZ10-GusPlus & $\begin{array}{l}\text { JA-responsive reporter } \\
\text { construct wherein JAZ10 } \\
\text { promoter and 5'UTR } \\
\text { region is cloned upstream } \\
\text { of the GUSPlus }{ }^{\mathrm{TM}} \text { gene }\end{array}$ & (Acosta et al., 2013) \\
\hline
\end{tabular}

\subsubsection{Media and Buffers}

\subsubsection{Media}

\begin{tabular}{|l|l|}
\hline \multicolumn{1}{|c|}{ Media } & \multicolumn{1}{|c|}{ Composition } \\
\hline dYT & $2 \%$ tryptone \\
& $1 \%$ yeast extract \\
& $1 \% \mathrm{NaCl}$ \\
\hline & $1 \%$ tryptone \\
Luria Bertani (LB) & $0.5 \%$ yeast extract \\
& $1 \% \mathrm{NaCl}$ \\
& $(1.5 \%$ agar in case of LB agar) \\
\hline Murashige and Skoog & $4.4 \mathrm{~g} / \mathrm{L} \mathrm{MS} \mathrm{(Duchefa} \mathrm{Chemie)}$ \\
(MS) & $\mathrm{pH} 5.7$ with KOH \\
\hline Potato Dextrose broth & $8 \mathrm{~g} / \mathrm{L}$ Select Agar (Invitrogen) \\
(PDB) & Sigma-Aldrich, Germany \\
\hline Selective amino acid & $0.67 \%$ yeast ammonia base without amino acids \\
dropout -Leu/ -Trp (SD-LT) & $2 \%$ glucose \\
& $0.062 \%$ SD -Leu, -Trp, -Ura \\
\hline
\end{tabular}




\begin{tabular}{|l|l|}
\hline & $20 \mathrm{mg} / \mathrm{L}$ Uracil \\
& $\mathrm{pH} 5.6$ with $1 \mathrm{M} \mathrm{NaOH}$ \\
& $(1.2 \%$ Select agar for SD-LT agar plates) \\
\hline & $1 \%$ yeast extract \\
& $2 \%$ peptone \\
Yeast extract-peptone- & $2 \%$ glucose \\
adenine-dextrose (YPAD) & $10 \mathrm{mg}$ Adeninehemisulfate \\
& $\mathrm{pH} 6.0$ with $\mathrm{HCl}$ \\
& $(1.2 \%$ Select agar in case of YPAD agar plates) \\
\hline & $10 \mathrm{~g}$ beef extract \\
& $2 \mathrm{~g}$ yeast extract \\
& $5 \mathrm{~g}$ peptone \\
& $5 \mathrm{~g}$ saccharose \\
& $\mathrm{pH} 7.0$ with $5 \mathrm{~N} \mathrm{NaOH}$ \\
& after autoclaving sterile $2 \mathrm{mM} \mathrm{MgSO}_{4}$ was added \\
\hline
\end{tabular}

\subsubsection{Buffers and Solutions}

\begin{tabular}{|c|c|}
\hline Media & Composition \\
\hline Buffer I for alkaline lysis & $\begin{array}{l}\text { 50mM Tris- } \mathrm{HCl}(\mathrm{pH} 8.0) \\
10 \mathrm{mM} \text { EDTA } \\
100 \mu \mathrm{g} / \mu \mathrm{l} \text { RNase A }\end{array}$ \\
\hline Buffer II for alkaline lysis & $\begin{array}{l}0.2 \mathrm{M} \mathrm{NaOH} \\
1 \%(\mathrm{w} / \mathrm{v}) \mathrm{SDS}\end{array}$ \\
\hline Buffer III for alkaline lysis & $\begin{array}{l}\text { 3M potassium acetate } \\
5 \% \text { formic acid }\end{array}$ \\
\hline DNA extraction buffer & $\begin{array}{l}\text { 200mM Tris- } \mathrm{HCl}(\mathrm{pH} 5.7) \\
250 \mathrm{mM} \mathrm{NaCl} \\
25 \mathrm{mM} \text { EDTA (pH 8.0) } \\
0.5 \% \text { SDS }\end{array}$ \\
\hline $\begin{array}{l}\text { Enzyme solution for } \\
\text { protoplast isolation }\end{array}$ & 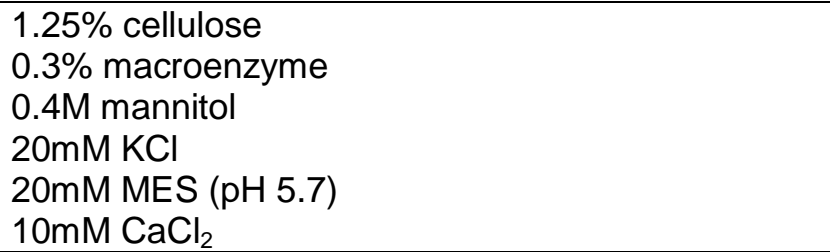 \\
\hline $\begin{array}{l}\text { Fixing solution (for GUS } \\
\text { staining protocol) }\end{array}$ & $\begin{array}{l}\text { 50mM sodium phosphate buffer }(\mathrm{pH} 7.0) \\
0.3 \mathrm{M} \text { mannitol } \\
0.3 \% \text { formaldehyde }\end{array}$ \\
\hline GUS extraction buffer & $\begin{array}{l}50 \mathrm{mM} \text { sodium phosphate buffer }(\mathrm{pH} 7.5) \\
10 \mathrm{mM} \text { EDTA } \\
0.1 \% \text { Triton } \mathrm{X}-100 \\
0.1 \% \text { Sarkosyl } \\
\text { Freshly add } 5 \mu \mathrm{l} \beta \text {-mercaptoethanol/10ml buffer just } \\
\text { before use }\end{array}$ \\
\hline GUS Stop solution & $0.2 \mathrm{M} \mathrm{Na}_{2} \mathrm{CO}_{3}$ \\
\hline $\begin{array}{l}\text { High Salt Precipitation } \\
\text { Buffer (HSPB) }\end{array}$ & $\begin{array}{l}1.2 \mathrm{M} \mathrm{NaCl} \\
0.8 \mathrm{M} \text { tri-sodium-citrate }\end{array}$ \\
\hline MEN (10X) & $\begin{array}{l}200 \mathrm{mM} \text { MOPS } \\
50 \mathrm{mM} \mathrm{NaOAc} \\
10 \mathrm{mM} \text { EDTA } \\
\text { pH adjusted to } 7.0 \text { with } 1 \mathrm{M} \mathrm{NaOH}\end{array}$ \\
\hline MMg solution & $\begin{array}{l}0.4 \mathrm{M} \text { mannitol } \\
15 \mathrm{mM} \mathrm{MgCl}_{2}\end{array}$ \\
\hline
\end{tabular}




\begin{tabular}{|c|c|}
\hline & $4 \mathrm{mM}$ MES (pH 5.7) \\
\hline MUG solution & $\begin{array}{l}\text { 4mM MUG (4-methyl-umbelliferyl-ß-D-glucuronide) } \\
\text { dissolved in GUS extraction buffer }\end{array}$ \\
\hline ONPG solution & $\begin{array}{l}\text { 4mg/ml o-nitrophenyl- } \beta \text {-D-galactopyranoside; dissolved } \\
\text { in Z-buffer }\end{array}$ \\
\hline ONPG Stop Solution & $1 \mathrm{M} \mathrm{Na}_{2} \mathrm{CO}_{3}$ \\
\hline $\begin{array}{l}\text { PEG solution for protoplast } \\
\text { transformation }\end{array}$ & $\begin{array}{l}\text { 20g PEG4000 } \\
13.3 \mathrm{ml} 0.75 \mathrm{M} \text { mannitol } \\
5 \mathrm{ml} 1 \mathrm{M} \mathrm{CaCl}_{2} \\
\text { Make volume up to } 50 \mathrm{ml} \text { using sterile de-ionized water }\end{array}$ \\
\hline RNA loading buffer (3X) & 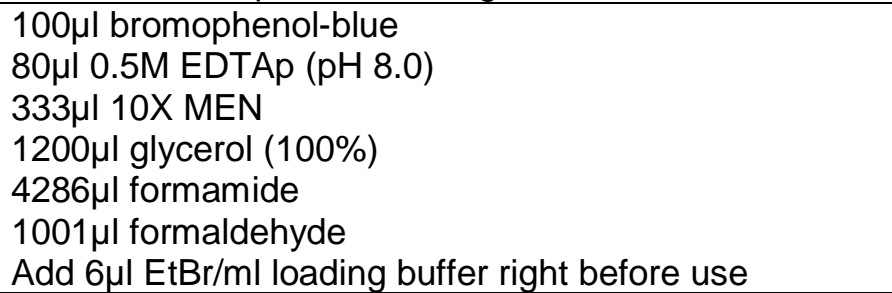 \\
\hline TAE (1X) & $\begin{array}{l}\text { 40mM Tris-acetate } \\
1 \mathrm{mM} \text { EDTA }(\mathrm{pH} 8.0)\end{array}$ \\
\hline Trizol buffer & $\begin{array}{l}380 \mathrm{ml} / \mathrm{L} \text { phenol with } 0.1 \mathrm{M} \text { Citrate buffer } \mathrm{pH} 4.3 \\
\text { saturated } \\
0.8 \mathrm{M} \text { guanidine thiocyanate } \\
0.4 \mathrm{M} \text { ammonium thiocyanate } \\
33.4 \mathrm{ml} / \mathrm{L} 3 \mathrm{M} \text { sodium acetate } \\
5 \% \text { glycerin }\end{array}$ \\
\hline W5 solution & $\begin{array}{l}154 \mathrm{mM} \mathrm{NaCl} \\
125 \mathrm{mM} \mathrm{CaCl}_{2} \\
5 \mathrm{mM} \mathrm{KCl} \\
2 \mathrm{mM} \mathrm{MES} \mathrm{(pH} \mathrm{5.7)}\end{array}$ \\
\hline WI solution & $\begin{array}{l}0.5 \mathrm{M} \text { mannitol } \\
4 \mathrm{mM} \mathrm{MES} \mathrm{(pH} \mathrm{5.7)} \\
20 \mathrm{mM} \mathrm{KCl}\end{array}$ \\
\hline X-Gluc Staining solution & $\begin{array}{l}50 \mathrm{mM} \text { sodium phosphate buffer }(\mathrm{pH} 7.0) \\
0.5 \mathrm{mM} \text { potassium ferricyanide } \\
0.5 \mathrm{mM} \text { potassium ferrocyanide } \\
2.5 \mathrm{mM} \text { bromo-4-chloro-3-indolyl- } \beta \text {-D-glucuronide }(\mathrm{X} \text { - } \\
\text { Gluc) } \\
10 \mathrm{mM} \text { EDTA } \\
2 \% \text { dimethyl formamide } \\
1 \% \text { Triton } X-100\end{array}$ \\
\hline $\begin{array}{l}\text { Yeast transformation mix } \\
\text { (prepared fresh before } \\
\text { use) }\end{array}$ & $\begin{array}{l}240 \mu \mathrm{l} 50 \%(\mathrm{w} / \mathrm{v}) \text { PEG3500 } \\
36 \mu \mathrm{l} 1 \mathrm{M} \text { lithium acetate } \\
50 \mu \mathrm{l} \text { Salmon Sperm DNA (previously boiled at } 95^{\circ} \mathrm{C} \text { for } \\
10 \mathrm{~min}) \\
29 \mu \mathrm{l} \text { sterile water }\end{array}$ \\
\hline Z-buffer & $\begin{array}{l}60 \mathrm{mM} \mathrm{Na}_{2} \mathrm{HPO}_{4}, 7 \mathrm{H}_{2} \mathrm{O} \\
40 \mathrm{mM} \mathrm{NaH}_{2} \mathrm{PO}_{4}, \mathrm{H}_{2} \mathrm{O} \\
10 \mathrm{mM} \mathrm{KCl}^{1 \mathrm{mM} \mathrm{MgSO}_{4}} \\
\mathrm{pH} 7.0\end{array}$ \\
\hline
\end{tabular}




\subsubsection{Antibiotics}

\begin{tabular}{|l|l|l|l|}
\hline \multicolumn{1}{|c|}{ Antibiotic } & \multicolumn{1}{c|}{ Stock solution } & \multicolumn{1}{c|}{$\begin{array}{c}\text { Working } \\
\text { concentration }\end{array}$} & \multicolumn{1}{c|}{ Source } \\
\hline Gentamycin & $25 \mathrm{mg} / \mathrm{ml}$ in water & $25 \mathrm{mg} / \mathrm{L}$ & Duchefa \\
\hline Kanamycin & $50 \mathrm{mg} / \mathrm{ml}$ in water & $50 \mathrm{mg} / \mathrm{L}$ & Sigma \\
\hline Rifampicin & $10 \mathrm{mg} / \mathrm{ml}$ in water & $50 \mathrm{mg} / \mathrm{L}$ & Duchefa \\
\hline Spectinomycin & $50 \mathrm{mg} / \mathrm{ml}$ in water & $100 \mathrm{mg} / \mathrm{L}$ & Sigma-Aldrich \\
\hline
\end{tabular}

All stock solutions were prepared and stored at $-20^{\circ} \mathrm{C}$

\subsubsection{Hormones and Chemicals}

\begin{tabular}{|l|l|l|}
\hline \multicolumn{1}{|c|}{ Hormone/Chemical } & \multicolumn{1}{c|}{ Concentration } & \multicolumn{1}{c|}{ Source } \\
\hline $\begin{array}{l}\text { 1-aminocyclopropane-1- } \\
\text { carboxylic acid (ACC) }\end{array}$ & $1 \mathrm{mM}$ in de-ionized $\mathrm{H}_{2} \mathrm{O}$ & Sigma \\
\hline $\begin{array}{l}2,3,4-t \text {-tiiodobenzoic acid } \\
\text { (TIBA) }\end{array}$ & $100 \mu \mathrm{M}$ in DMSO & Sigma-Aldrich \\
\hline Abscisic acid (ABA) & $100 \mu \mathrm{M}$ in $0.1 \% E t O H$ & \\
\hline Methyl jasmonate (MeJA) & $4.5 \mu \mathrm{M}$ & Sigma-Aldrich \\
\hline Salicylic acid (SA) & $1 \mathrm{mM}$ in de-ionized $\mathrm{H}_{2} \mathrm{O}$ & Merck \\
\hline
\end{tabular}

\subsubsection{Kits, Enzymes and Standards}

\begin{tabular}{|l|l|}
\hline \multicolumn{1}{|c|}{ Kit/Enzyme/Standard } & \multicolumn{1}{c|}{ Supplier } \\
\hline $\begin{array}{l}\text { Advantage 2 Polymerase } \\
\text { Mix }\end{array}$ & Clonetech \\
\hline BioTaq DNA Polymerase & Bioline \\
\hline $\begin{array}{l}\text { BP Clonase } \\
\text { Mix }\end{array}$ & II Enzyme \\
\hline DNAse I & MBI Fermentas \\
\hline $\begin{array}{l}\text { Dual Luciferase Reporter } \\
\text { Assay System }\end{array}$ & Promega \\
\hline GeneRuler 1kb DNA ladder & MBI Fermentas \\
\hline $\begin{array}{l}\text { iProof High-Fidelity DNA } \\
\text { Polymerase }\end{array}$ & Bio-Rad \\
\hline $\begin{array}{l}\text { LR Clonase } \\
\text { Mix II Enzyme }\end{array}$ & Invitrogen \\
\hline Nucleobond® PC 500 & Macherey-Nagel \\
\hline Nucleospin Extract II & Macherey-Nagel \\
\hline Nucleospin Plasmid & Macherey-Nagel \\
\hline Restriction Enzymes & MBI Fermentas \\
\hline Reverse Transcriptase & MBI Fermentas \\
\hline RNase A & Qiagen \\
\hline RNeasy Plant Mini Kit & Qiagen \\
\hline
\end{tabular}

\subsubsection{Plasmids}

\begin{tabular}{|l|l|l|}
\hline Plasmid & \multicolumn{1}{|c|}{ Description } & Reference/Source \\
\hline pB2GW7 & $\begin{array}{l}\text { GATEWAYTM vector for } \\
\text { plant transformation, } \\
\text { contains CaMV 35S } \\
\text { promoter and BASTA }\end{array}$ & (Karimi et al., 2002) \\
\hline
\end{tabular}




\begin{tabular}{|c|c|c|}
\hline & $\begin{array}{l}\text { resistance gene as } \\
\text { selection marker, Spec }\end{array}$ & \\
\hline pB2GW7-HA & $\begin{array}{l}\text { pB2GW7 vector with an } \\
\text { additional N-terminal 3X } \\
\text { HA-tag }\end{array}$ & $\begin{array}{l}\text { Dr. Corinna Thurow, } \\
\text { personal communication }\end{array}$ \\
\hline pB2GW7-HA-ANAC032 & $\begin{array}{l}\text { pB2GW7-HA derivative } \\
\text { containing the ANAC032 } \\
\text { coding sequence }\end{array}$ & $\begin{array}{l}\text { Dr. Julia Köster, personal } \\
\text { communication }\end{array}$ \\
\hline pB2GW7-HA-ATAF1 & $\begin{array}{l}\text { pB2GW7-HA derivative } \\
\text { containing the ATAF1 } \\
\text { coding sequence }\end{array}$ & $\begin{array}{l}\text { Dr. Julia Köster, personal } \\
\text { communication }\end{array}$ \\
\hline pBGWL7 & $\begin{array}{l}\text { Gateway }{ }^{\mathrm{TM}} \text { vector for } \\
\text { plant transformation, } \\
\text { contains the firefly (ff) } \\
\text { luciferase reporter gene, } \\
\text { and a BASTA resistance } \\
\text { gene as selection marker, } \\
\text { Spec }^{r}\end{array}$ & (Karimi et al., 2002) \\
\hline pBGWL7-3g04000prom & $\begin{array}{l}\text { pBGWL7 derivative } \\
\text { containing } 1267 \mathrm{bp} \\
\text { promoter fragment }(-1248 \\
\text { to }+19 \text { region) of } \\
\text { At3g04000 gene }\end{array}$ & This thesis \\
\hline pBGWL7-AKR4C9 prom & $\begin{array}{l}\text { pBGWL7 derivative } \\
\text { containing 939bp } \\
\text { promoter fragment (-913 } \\
\text { to }+26 \text { region) of } A K R 4 C 9 \\
\text { gene }\end{array}$ & This thesis \\
\hline pBGWL7-bHLH585prom & $\begin{array}{l}\text { pBGWL7 derivative } \\
\text { containing } 1250 \mathrm{bp} \\
\text { promoter fragment }(-1205 \\
\text { to }+45 \text { region) of } \\
\text { At1g10585 gene }\end{array}$ & This thesis \\
\hline pBGWL7-FLCprom & $\begin{array}{l}\text { pBGWL7 derivative } \\
\text { containing } 2709 b p \\
\text { promoter fragment }(-2537 \\
\text { to }+133 \text { region) of } F L C \\
\text { gene }\end{array}$ & $\begin{array}{l}\text { This thesis, Ulla Schneider } \\
\text { (Master student) }\end{array}$ \\
\hline pDONR201 & $\begin{array}{l}\text { GATEWAYTM -adapted } \\
\text { entry vector to generate } \\
\text { attL flanked entry clones } \\
\text { containing gene of } \\
\text { interest following } \\
\text { recombination with an } \\
\text { attB expression clone or } \\
\text { PCR product, } \mathrm{Km}^{\mathrm{r}}\end{array}$ & Invitrogen \\
\hline pDONR201-ANAC032 & $\begin{array}{l}\text { pDONR201 derivative } \\
\text { containing the coding } \\
\text { sequence of } A N A C 032 \\
\text { gene }\end{array}$ & $\begin{array}{l}\text { Dr. Julia Köster, personal } \\
\text { communication }\end{array}$ \\
\hline pDONR201-ATAF1 & $\begin{array}{l}\text { pDONR201 derivative } \\
\text { containing the coding } \\
\text { sequence of } A T A F 1 \text { gene }\end{array}$ & $\begin{array}{l}\text { Dr. Julia Köster, personal } \\
\text { communication }\end{array}$ \\
\hline pDONR207 & GATEWAYTM -adapted & Invitrogen \\
\hline
\end{tabular}




\begin{tabular}{|c|c|c|}
\hline & $\begin{array}{l}\text { entry vector to generate } \\
\text { attL flanked entry clones } \\
\text { containing gene of } \\
\text { interest following } \\
\text { recomibination with an } \\
\text { attB expression clone or } \\
\text { PCR product, Gm }{ }^{r}\end{array}$ & \\
\hline pDONR207-3g04000prom & $\begin{array}{l}\text { pDONR207 derivative } \\
\text { containing } 1267 \mathrm{bp} \\
\text { promoter fragment of } \\
\text { At3g04000 gene }\end{array}$ & This thesis \\
\hline pDONR207-AKR4C9prom & $\begin{array}{l}\text { pDONR207 derivative } \\
\text { containing 939bp } \\
\text { promoter fragment of } \\
\text { AKR4C9 gene }\end{array}$ & This thesis \\
\hline $\begin{array}{l}\text { pDONR207- } \\
\text { bHLH585prom }\end{array}$ & $\begin{array}{l}\text { pDONR207 derivative } \\
\text { containing } 1250 \mathrm{bp} \\
\text { promoter fragment of } \\
\text { At1g10585 gene }\end{array}$ & This thesis \\
\hline pDONR207-FLCprom & $\begin{array}{l}\text { pDONR207 derivative } \\
\text { containing 2709bp } \\
\text { promoter fragment of FLC } \\
\text { gene }\end{array}$ & $\begin{array}{l}\text { This thesis, Ulla Schneider } \\
\text { (Master student) }\end{array}$ \\
\hline pUBQ10GW7-HA & $\begin{array}{l}\text { GATEWAYTM vector for } \\
\text { plant transformation, } \\
\text { contains UBQ10 promoter } \\
\text { and BASTA resistance } \\
\text { gene as selection marker, } \\
\text { Spec }^{r}\end{array}$ & $\begin{array}{l}\text { Li-Jun Huang; personal } \\
\text { communication }\end{array}$ \\
\hline pUBQ10GW7-HA-VP16 & $\begin{array}{l}\text { VP16 fragment was cut } \\
\text { out of the vector } \\
\text { pALLIGATOR1 with Kpn2I } \\
\text { and ligated into } \\
\text { pUBQ10GW7-HA }\end{array}$ & $\begin{array}{l}\text { This thesis, Ulla Schneider } \\
\text { (Master student) }\end{array}$ \\
\hline pUBQ10-HA-ANAC032 & $\begin{array}{l}\text { pUBQ10-HA derivative } \\
\text { containing coding } \\
\text { sequence of } A N A C 032 \\
\text { gene }\end{array}$ & This thesis \\
\hline $\begin{array}{l}\text { pUBQ10-HA-ANAC032- } \\
\text { VP16 }\end{array}$ & $\begin{array}{l}\text { pUBQ10GW7-HA-VP16 } \\
\text { derivative; contains } \\
\text { coding sequence of } \\
\text { ANAC032 and VP16 } \\
\text { domain at its C-terminal } \\
\text { end }\end{array}$ & $\begin{array}{l}\text { This thesis, Ulla Schneider } \\
\text { (Master student) }\end{array}$ \\
\hline pUBQ10-HA-ATAF1 & $\begin{array}{l}\text { pUBQ10-HA derivative } \\
\text { containing coding } \\
\text { sequence of } A T A F 1 \text { gene }\end{array}$ & This thesis \\
\hline pUBQ10-HA-ATAF1-VP16 & $\begin{array}{l}\text { pUBQ10GW7-HA-VP16 } \\
\text { derivative; contains } \\
\text { coding sequence of } \\
\text { ATAF1 and VP16 domain } \\
\text { at its C-terminal end }\end{array}$ & $\begin{array}{l}\text { This thesis, Ulla Schneider } \\
\text { (Master student) }\end{array}$ \\
\hline
\end{tabular}




\subsubsection{Oligonucleotides}

QuantiTect Assay Primer (QPA) was ordered from Qiagen. All other primers were ordered from Invitrogen (Life Technologies)

\subsubsection{Oligonucleotides for qRT-PCR}

\begin{tabular}{|l|l|}
\hline \multicolumn{1}{|c|}{ Primer } & \multicolumn{1}{c|}{ Sequence (5'-3') } \\
\hline AKR4C9 & QPA (QT00718732*) \\
\hline ANAC032 & QPA (QT0074356*) \\
\hline ANAC102 & QPA (QT00848582*) \\
\hline At1g10585 (bHLH585) & QPA (QT01124690*) \\
\hline At3g04000 & QPA (QT00726054*) \\
\hline ATAF1 fwdRT & GAG TTC ACG AGC GAG GTT CA \\
\hline ATAF1 revRT & TCC ACG GTG GCA TCA ATG TA \\
\hline ATAF2 & QPA (QT00825769*) \\
\hline COR78 & QPA (QT00840406*) \\
\hline FLC & QPA (QT00826448*) \\
\hline PDF1.2 RT fwd & CTT GTT CTC TTT GCT GCT TTC \\
\hline PDF1.2 RT rev & CAT GTT TGG CTC CTT CAA G \\
\hline PR1 fwd & CTG ACT TTC TCC AAA CAA CTT G \\
\hline PR1 rev & GCG AGA AGG CTA ACT ACA ACT AC \\
\hline UBQ5 fwd & GAC GCT TCA TCT CGT CC \\
\hline UBQ5 rev & GTA AAC GTA GGT GAG TCC A \\
\hline VSP2 fwd RT & CAA ACT AAA CAA TAA ACC ATA CCA TAA \\
\hline VSP2 rev RT & GCC AAG AGC AAG AGA AGT GA \\
\hline
\end{tabular}

${ }^{*}$ Qiagen QuantiTect Primer catalog number

\subsubsection{Oligonucleotides for sequencing or genotyping}

\begin{tabular}{|l|l|}
\hline \multicolumn{1}{|c|}{ Primer } & \multicolumn{1}{c|}{ Sequence (5'-3') } \\
\hline ATAF1_RP & TAA AAC GGT CTC GTG TTG CCA TAA \\
\hline ATAF1_UP & CGC CAA GTT TCA GAG GTA GAG AGA G \\
\hline $\begin{array}{l}\text { LBb1 (for SALK line } \\
\text { genotyping) }\end{array}$ & GCG TGG ACC GCT TGC TGC AAC T \\
\hline SALK_012253_RP & CTT AAT ACC AAC CGG TTT AGG ACG \\
\hline SALK_012253_UP & TTT TTA ATT ACG GCG GAA AGA GAA TAG \\
\hline Seq-L1 & TCG CGT TAA CGC TAG CAT GGA TCT C \\
\hline Seq-L2 & GTA ACA TCA GAG ATT TTG AGA CAC \\
\hline
\end{tabular}

\subsubsection{Oligonucleotides for cloning}

\begin{tabular}{|l|l|}
\hline \multicolumn{1}{|c|}{ Primer } & \multicolumn{1}{c|}{ Sequence (5'-3') } \\
\hline $3 g 0400$ prom_fwd & $\begin{array}{l}\text { GGG GAC AAG TTT GTA CAA AAA AGC AGG CTG } \\
\text { GTT CAT GGA TTT GCT CCG C }\end{array}$ \\
\hline 3g0400prom_rev & $\begin{array}{l}\text { GGG GAC CAC TTT GTA CAA GAA AGC TGG GTC } \\
\text { TGA TGA CGC TGC AGC CAT }\end{array}$ \\
\hline AKR4C9prom_low & $\begin{array}{l}\text { GGG GAC CAC TTT GTA CAA GAA AGC TGG GTG } \\
\text { CCA TTA TCA GAT GTG GTG GT }\end{array}$ \\
\hline AKR4C9prom_up & $\begin{array}{l}\text { GGG GAC AAG TTT GTA CAA AAA AGC AGG CTC } \\
\text { CTA AGA CTA TTT CCT TAG TTC GCG }\end{array}$ \\
\hline
\end{tabular}




\begin{tabular}{|l|l|}
\hline bHLH585prom_low & $\begin{array}{l}\text { GGG GAC CAC TTT GTA CAA GAA AGC TGG GTC } \\
\text { CCA TTC TTT TTG TTT TCT TTT AAG CT }\end{array}$ \\
\hline bHLH585prom_up & $\begin{array}{l}\text { GGG GAC AAG TTT GTA CAA AAA AGC AGG CTC } \\
\text { TAG TCA CGG ATT TTC AAT GGC TA }\end{array}$ \\
\hline FLCprom_fwd & $\begin{array}{l}\text { GGG GAC AAG TTT GTA CAA AAA GCA GGC TTA } \\
\text { TTC GTG TTG CAA AAT CG }\end{array}$ \\
\hline FLCprom_rev & $\begin{array}{l}\text { GGG GAC CAC TTT GTA CAA GAA AGC TGG GTG } \\
\text { CCA TGG CTT CTC TCC GAG AGG }\end{array}$ \\
\hline
\end{tabular}

\subsubsection{Instruments}

\begin{tabular}{|l|l|}
\hline \multicolumn{1}{|c|}{ Instrument/Consumable } & \multicolumn{1}{c|}{ Supplier } \\
\hline $\begin{array}{l}\text { arium® pro DI Ultrapure } \\
\text { Water System }\end{array}$ & Sartorius Stedim Biotech \\
\hline $\begin{array}{l}\text { Centro XS }{ }^{3} \text { LB 960 } \\
\text { DLReady }{ }^{\text {M }} \text { Luminometer }\end{array}$ & Berthold Technologies \\
\hline Cooling microcentrifuge & Hettich Lab Technology \\
\hline $\begin{array}{l}\text { Gel electrophoresis unit } \\
\text { EV2xx }\end{array}$ & @ Consort bvba \\
\hline Gene Pulser® II & BioRad \\
\hline $\begin{array}{l}\text { Heraeus Pico17 micro } \\
\text { centrifuge }\end{array}$ & Thermo Scientific \\
\hline MyCycler ${ }^{\text {TM } \text { thermocycler }}$ & BioRad \\
\hline Nanodrop 2000 & PeqLab Biotechnologies \\
\hline pH meter HI 2212 & Hanna Instruments \\
\hline Photometer Libra S11 & Biochrom \\
\hline Real-time PCR iCycler & BioRad \\
\hline $\begin{array}{l}\text { ROTINA 38R } \\
\text { Ultracentrifuge }\end{array}$ & Hettich Lab Technology \\
\hline Synergy HT Plate reader & BioTek Instruments \\
\hline
\end{tabular}

\subsubsection{Software}

\begin{tabular}{|l|l|}
\hline \multicolumn{1}{|c|}{ Software } & \multicolumn{1}{c|}{ Supplier } \\
\hline AgriGO tool & (Du et al., 2010) \\
\hline Bio-Rad iQ5 & Bio-Rad \\
\hline Clone Manager ver 7 & Sci-Ed Software \\
\hline Geneious 5.3 & Biomatters Limited \\
\hline GraphPad Prism 5 & GraphPad Software \\
\hline Oligo 4.0 & $\begin{array}{l}\text { Molecular Biology Insights. } \\
\text { Inc }\end{array}$ \\
\hline
\end{tabular}




\subsection{Methods}

\subsubsection{Plant material, growth conditions and treatments}

Arabidopsis thaliana (accession Columbia [Col-0]) was used as wild type in this study. The overexpressing lines 35S:ANAC032 and 35S:ATAF1 were maintained as heterozygous seed batch and homozygous plants were selected for all the experiments based on the size of the plant (Homozygous 35S:ANAC032 and 35S:ATAF1 plants are extremely dwarf in comparison to Col-0 (see Results section 4.8 and Figure 4.18). Sterilized Arabidopsis seeds were grown either on sterile agar plates containing Murashige and Skoog (MS) medium or on soil under environmentally controlled conditions. Vapour-phase sterilization of the seeds was carried out using solution of $100 \mathrm{ml}$ sodium-hypochlorite and $5 \mathrm{ml}$ concentrated $\mathrm{HCl}$.

For germination assays, sterilized seeds were sown on sterile MS medium containing $100 \mu \mathrm{M}$ TIBA or $0.1 \%$ DMSO (as control). The plates were stratified at $4^{\circ} \mathrm{C}$ in the dark for two days before shifting them to long day conditions (LD; $22^{\circ} \mathrm{C}, 16-\mathrm{h}$ light/8-h dark cycle, $60 \%$ relative humidity and light intensity of $\left.100-150 \mu \mathrm{mol} / \mathrm{m}^{2} \mathrm{~s}\right)$.

For soil grown plants, sterilized seeds were sown on autoclaved soil and kept at $4^{\circ} \mathrm{C}$ for two days for stratification. They were then grown under LD or short day (SD; $22^{\circ} \mathrm{C}$, 8-h light/16-h dark cycle, $60 \%$ relative humidity and light intensity of 100 $150 \mu \mathrm{mol} / \mathrm{m}^{2} \mathrm{~s}$ ) conditions depending on the treatment as mentioned below. For all treatments (except for wounding and Botrytis infection) the complete rosette was harvested.

\subsubsection{TIBA treatment}

Six-week old plants, grown in controlled climate chambers under SD conditions, were sprayed with $100 \mu \mathrm{M}$ TIBA or $0.1 \%$ DMSO and material was harvested 8 hours later and immediately frozen in liquid nitrogen.

\subsubsection{MeJA treatment}

Plants were grown in controlled climate chambers under LD conditions. Four-week old plants were placed in a closed glass aquarium (sealed with wax) where $4.5 \mu \mathrm{M}$ MeJA was applied via the gaseous phase with help of Whatman filter paper. Plant material was harvested 8 hours later and immediately frozen in liquid nitrogen.

\subsubsection{ACC treatment}

Four-week old plants grown under LD conditions were sprayed with $1 \mathrm{mM} \mathrm{ACC} \mathrm{or}$ with de-ionized water as mock treatment. Material was harvested 24 hours later and immediately frozen in liquid nitrogen. (Treatment NOT done in glass aquarium) 


\subsubsection{SA treatment}

Four-week old plants grown under LD conditions were placed in a closed glass aquarium (sealed with wax) and sprayed with $1 \mathrm{mM}$ SA for 24 hours after which material was harvested and immediately frozen in liquid nitrogen.

\subsubsection{ABA treatment}

Plants were grown under LD conditions and four-week old plants were placed in a glass aquarium (sealed with wax) and sprayed with $100 \mu \mathrm{M}$ ABA. Material was harvested either 8 hours later or 24 hours later as required and immediately frozen in liquid nitrogen.

\subsubsection{Ozone treatment}

Four-week old LD grown plants were placed in the ozone cabinet where ozone levels were maintained at $0.3 p p m$ for 6 hours after which the plants were harvested and frozen in liquid nitrogen. As control, plants were placed in a similar cabinet for 6 hours but without ozone supply.

\subsubsection{Wounding}

Leaf surface of four-week old LD or 12-h light/12-h dark cycle grown plants were wounded with the help of a forcep. Wounded leaf material was harvested 90 minutes after wounding and immediately frozen in liquid nitrogen. To analyze systemic and local response, 2-3 leaves per rosette were wounded which were collected as local tissue sample and un-wounded leaves in the same rosette were collected as systemic tissue sample.

\subsubsection{Botrytis cinerea infection studies}

Six-week old plants grown under controlled environmental conditions with a 12-h light/12-h dark cycle were used for Botrytis cinerea infection assays. Botrytis cinerea (strain BMM) was grown on potato dextrose agar (PDA) plates kept in darkness at $20-22^{\circ} \mathrm{C}$ until full sporulation occurred. Harvesting of the spores was then done by adding quarter strength potato dextrose broth (PDB) onto the plates and then filtering through Mira cloth (Calbiochem $\AA$ ). Number of spores was counted under the microscope using a counting chamber and then was diluted in PDB to get a final concentration of $5 \times 10^{6} \mathrm{spores} / \mathrm{ml}$. For infection, plants were placed inside a glass aquarium filled with little water at the bottom to maintain humidity. Leaf surface of 5-6 leaves per plant was spot-inoculated with $6 \mu \mathrm{l}$ of $5 \times 10^{4}$ spores $/ \mathrm{ml}$ Botrytis culture. Quarter strength PDB was used to spot-inoculate surfaces of control plants. The diameters of lesions were measured three days post infection (dpi) and infected leaves were harvested by freezing in liquid nitrogen. 


\subsubsection{Insect feeding assay}

Four-week old plants grown under LD conditions were placed in a closed glass aquarium (NOT sealed with wax) and one larva ( $1^{\text {st }}$ instar of Plutella xylostella) was placed on top of each plant. The insect were allowed to feed on the plants until it had eaten approximately half of the plant leaf tissue.

\subsubsection{Molecular biology methods}

\subsubsection{Genomic DNA isolation from Arabidopsis (Edwards et al., 1991)}

Sample was collected using the lid of a $1.5 \mathrm{ml}$ centrifuge tube to pinch out a disc of material (from 2-3 week old plant) and immediately frozen in liquid nitrogen. The frozen material was crushed inside the centrifuge tube itself using a pestle after which $400 \mu \mathrm{l}$ of DNA extraction buffer [200mM Tris- $\mathrm{HCl}(\mathrm{pH} 7.5), 250 \mathrm{mM} \mathrm{NaCl}, 25 \mathrm{mM}$ EDTA ( $\mathrm{pH} 8.0$ ) and $0.5 \% \mathrm{SDS}$ ] was immediately added to it. The sample was then centrifuged for $5 \mathrm{~min}(13000 \mathrm{rpm}, \mathrm{RT})$ and $300 \mu \mathrm{l}$ of the supernatant was taken into a new centrifuge tube containing $300 \mu \mathrm{l}$ of isopropanol. Additional centrifugation step was carried out for 5 min (13000rpm, RT) and the resulting pellet was washed with $70 \% \mathrm{EtOH}$ by a final centrifugation step of 5 minutes (13000pm, RT). The pellet was then dried at $37^{\circ} \mathrm{C}$ for $10 \mathrm{~min}$ and dissolved in $100 \mu$ de-ionized water. The concentration of isolated DNA was determined using the Nanodrop 2000 spectrophotometer.

\subsubsection{Plasmid DNA isolation from $E$. coli}

Plasmid DNA isolation from E. coli was prepared either using commercially available kits or by alkaline lysis method, depending on purpose. The concentration of isolated plasmid DNA was determined using Nanodrop 2000 spectrophotometer.

For sequencing and cloning purpose, high purity plasmid DNA was isolated using the Nucleospin Mini kit (Macherey and Nagel). A $5 \mathrm{ml} \mathrm{O} / \mathrm{N}$ culture was always used and plasmid was eluted in $50 \mu \mathrm{l}$ de-ionized water. Larger amounts of plasmid DNA was prepared using the NucleoBond ${ }^{\mathrm{TM}}$ PC 500 Kit (Macherey and Nagel). Final volume was decided based on the size of the DNA pellet to be re-suspended in de-ionized water.

Small amounts of plasmid DNA for analytical purposes were isolated using a modified alkaline lysis method (Le Gouill et al., 1994). $2 \mathrm{ml}$ of an overnight $E$. coli culture was centrifuged for $1 \mathrm{~min}$ (13000rpm, RT) and the supernatant was discarded. The cells were re-suspended in $100 \mu$ l of Buffer I $(50 \mathrm{mM}$ Tris- $\mathrm{HCl}(\mathrm{pH} 8.0)$, $10 \mathrm{mM}$ EDTA, $100 \mu \mathrm{g} / \mu \mathrm{l}$ RNase A) by vortexing. To this $200 \mu \mathrm{l}$ of Buffer II $(0.2 \mathrm{M}$ $\mathrm{NaOH}, 1 \%(\mathrm{w} / \mathrm{v})$ SDS) was added and the suspension was incubated on ice for 5 min. Buffer II was neutralized by addition of $150 \mu \mathrm{I}$ of Buffer III (3M CH3COOK, $5 \%$ formic acid) and inverting the tubes 6-8 times. The suspension was then centrifuged for $10 \mathrm{~min}$ (13000rpm, RT) after which the aqueous supernatant was transferred to a new tube containing $1 \mathrm{ml} 96 \%(\mathrm{v} / \mathrm{v}) \mathrm{EtOH}$. The DNA was left to precipitate at $-20^{\circ} \mathrm{C}$ for $20 \mathrm{~min}$. The precipitated DNA was collected by centrifugation for $10 \mathrm{~min}$ (13000rpm, 
$4^{\circ} \mathrm{C}$ ). The pellet obtained was washed with $70 \% \mathrm{EtOH}$ and dried at $37^{\circ} \mathrm{C}$ for $10 \mathrm{~min}$. The DNA pellet was then dissolved in $20 \mu \mathrm{l}$ de-ionized water.

\subsubsection{Restriction digestion of DNA}

The digestion reactions were incubated in a buffer system optimized for the used enzyme. The amount of enzyme (Enzyme Unit, U) necessary for each digestion reaction was determined according to following formula,

$\mathrm{U}=$ [Lambda phage $(\lambda)$ DNA length in bp] $\mathrm{X}$ [no. of RE sites in target sequence]

[No. of $R E$ sites in $\lambda$ sequence] $X$ [size of target sequence in bp]

\subsubsection{Agarose Gel Electrophoresis}

Analysis and separation of DNA molecules was done by electrophoresis using an agarose gel matrix. The gel was run horizontally with $1 \mathrm{X}$ TAE $(40 \mathrm{mM}$ Tris-acetate and $1 \mathrm{mM}$ EDTA, $\mathrm{pH} 8.0$ ) as the running buffer. For DNA fragments between 500 $14000 \mathrm{bp}$, samples were run on $1 \%$ agarose whereas for lower size DNA fragments a $2 \%$ agarose gel was used. The DNA samples were mixed with $1 / 10^{\text {th }}$ volume of $10 \mathrm{X}$ DNA Loading Buffer and then loaded into separate lanes in the cast gel. Electrophoresis was then carried out at $120 \mathrm{~V}$ for $\sim 45 \mathrm{~min}$. After the run, the gel was stained using $0.1 \%(\mathrm{w} / \mathrm{v})$ ethidium bromide and then visualized under a UV transilluminator (Gel Doc system). The size and amount of DNA fragments were determined using a DNA standard (DNA ladder mix, MBI Fermentas, Germany).

The elution of DNA fragments from agarose gel for cloning purpose was carried out using the Nucleospin Extract II Gel Extraction kit (Macherey-Naggel, Germany)

\subsubsection{PCR}

Polymerase chain reaction (PCR) was performed to amplify oligonucleotide of interest for cloning purposes or a 3-primer PCR was performed for genotyping TDNA insertion lines. PCR reactions were carried out in a MyCycler ${ }^{\mathrm{TM}}$ Bio-Rad thermocycler. For cloning purposes, the iProof ${ }^{\mathrm{TM}}$ High Fidelity DNA polymerase (BioRad) was used with denaturation and extension steps carried out at $98^{\circ} \mathrm{C}$ and $72^{\circ} \mathrm{C}$ respectively. The annealing temperature depended on the primers used. For PCRbased genotyping, the Advantage Taq DNA Polymerase was used along with genomic DNA as the template. The wild type allele was identified with the combination of RP and LP primers while the corresponding T-DNA insertion alleles was identified with the combination of the RP and LB primers. Homozygous mutant plants gave a single band corresponding to the use of RP and LB primers while heterozygous mutant plants gave two PCR fragments corresponding to both sets of primers. 


\subsubsection{Gateway® cloning}

The GATEWAY® Technology with Clonase ${ }^{\mathrm{TM}}$ II system from Invitrogen was used for cloning binary vectors for transient and stable plant transformations. The technology makes use of the site-specific recombination properties of lambda phage and provides a rapid and efficient way to clone DNA sequences (flanked by modified att sites) into multiple vectors (Hartley et al., 2000).

\subsection{BP reaction}

For generating entry clones, PCR reaction (using iProof high-fidelity DNA polymerase) was carried out such that the gene of interest was flanked with modified attB sites (attB1: 5'-GGGG ACA AGT TTG TAC AAA AAA GCA GGC T-3' ; attB2: 5'GGGG ACC ACT TTG TAC AAG AAA GCT GGG T-3'). Purified attB-PCR products were then used in a BP recombination reaction where equimolar amounts ( 150ng) of the PCR product and of either pDONR201 $\left(\mathrm{Km}^{r}\right)$ or pDONR207 $\left(\mathrm{Gm}^{r}\right)$, along with $2 \mu \mathrm{l}$ of BP Clonase ${ }^{\mathrm{TM}}$ II enzyme mix was kept at RT for 1 hour. The reaction was then transformed into E. coli DH5a cells as described in 3.2.2.7

\subsection{LR reaction}

For creating expression clones, an LR reaction was carried out between an attL containing entry vector and an attR containing destination vector ( $\mathrm{pUBQ10HA}$ or pBGWL7). Purified plasmid of the entry clone (50-150ng) was added to 150ng of the destination vector along with $2 \mu \mathrm{l}$ of LR Clonase ${ }^{\mathrm{TM}}$ II enzyme mix and kept at RT for 1 hour. The reaction was then transformed into $E$. coli DH5a cells as described in 3.2.2.7

\subsubsection{Transformation of E. coli (Hanahan, 1985)}

Heat shock was used to transform chemically competent $E$. coli DH5a cells that were prepared using the $\mathrm{CaCl}_{2}$ method and stored at $-80^{\circ} \mathrm{C}$ until use. $200 \mu \mathrm{l}$ of the competent cells were thawed on ice for 20-30 min before adding 50-70ng of plasmid DNA. The contents were mixed gently and then incubated on ice for $30 \mathrm{~min}$. Heat shock was then applied by keeping the mixture at $42^{\circ} \mathrm{C}$ for $90 \mathrm{~s}$ after which the cells were immediately placed on ice for $5-10 \mathrm{~min}$. $700 \mu \mathrm{l}$ of LB medium was added to the cells and the suspension was mixed on a horizontal roller for $60 \mathrm{~min}$ at $37^{\circ} \mathrm{C}$. The culture was then spread on LB agar plates supplemented with antibiotic (as required for selection). The plates were incubated overnight at $37^{\circ} \mathrm{C}$.

\subsubsection{Transformation of $A$. tumefaciens (Mattanovich et al., 1989)}

Cells of $A$. tumefaciens GV3101 strain (stored at $-80^{\circ} \mathrm{C}$ prior to use) were transformed using the electroporation method. Cells were thawed on ice before adding 100-200ng plasmid DNA to it. The mixture was then transferred to an electroporation cuvette with an electrode distance of $0.2 \mathrm{~cm}$. A single electric pulse of $2.5 \mathrm{kV}$ initial voltage $(25 \mu \mathrm{F}, 400 \mathrm{~W})$ was applied using GenePulser II. The cells were immediately suspended in $1 \mathrm{ml}$ YEB ( $1 \%$ beef extract, $0.2 \%$ yeast extract, $0.5 \%$ 
peptone, $0.5 \%$ saccharose, $\mathrm{pH} 7.0$, after autoclaving, sterile $2 \mathrm{mM} \mathrm{MgSO}_{4}$ ) medium and incubated for $2 \mathrm{~h}$ at $29^{\circ} \mathrm{C}$. The culture was then spread on YEB agar plates supplemented with antibiotics (as required for selection). Plates were incubated for 2 3 days at $29^{\circ} \mathrm{C}$.

\subsubsection{Transformation of Arabidopsis (Clough and Bent, 1998)}

Arabidopsis plants were transformed via Agrobacterium-mediated gene transfer using the floral dip method. Agrobacterium cells, transformed with gene of interest, were grown over-night in $20 \mathrm{ml}$ YEB medium supplemented with antibiotics (as required for selection) at $29^{\circ} \mathrm{C}$ on a shaker. This pre-inoculum was then used to inoculate $380 \mathrm{ml}$ of YEB medium (with antibiotics) and the culture was incubated overnight at $29^{\circ} \mathrm{C}$ with constant shaking. Cells were then harvested by centrifugation for $20 \mathrm{~min}$ (4000rpm, RT) and re-suspended in $200 \mathrm{ml}$ of $5 \%(\mathrm{w} / \mathrm{v})$ saccharose solution. $100 \mu \mathrm{l}$ of Silwet surfactant was added and Arabidopsis inflorescence was dipped into the solution. Plants were then shifted back to the climate chambers and kept under humid conditions over-night. Positive T1 transformed plants were selected by BASTA selection.

\subsubsection{Transformation of Saccharomyces cervisiae (Gietz and Woods, 2002)}

A high efficiency transformation protocol was used to transfer PJ69-4a yeast strain in yeast-two-hybrid assays. The yeast cells were grown overnight in $20 \mathrm{ml}$ YPAD medium at $29^{\circ} \mathrm{C}$ on a shaker (200rpm). The optical density (OD) at $600 \mathrm{~nm}$ was measured the following day using the Photometer Libra S11, Biochrom and enough cells were transferred to $80 \mathrm{ml}$ of YPAD medium such that the new OD would be $\sim 0.4$. The culture was then again incubated for 4-5 hours (for approx. two cell divisions to occur) at $29^{\circ} \mathrm{C}$ on a shaker. Cells were harvested by centrifugation for 5 min (4000rpm, RT) and resulting pellet was washed once with sterile water by centrifugation for $5 \mathrm{~min}$ (4000rpm, RT). The pellet was then re-suspended in $1 \mathrm{ml}$ of sterile water and distributed as $100 \mu \mathrm{l}$ aliquots into $1.5 \mathrm{ml}$ centrifuge tube (number of aliquots depend on number of transformation reactions). $355 \mu$ of transformation mix

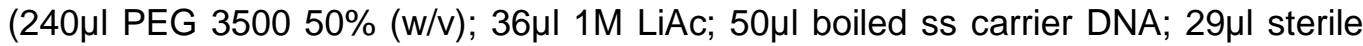
de-ionized $\mathrm{H} 2 \mathrm{O}$ ) and plasmid DNA (bait + prey plasmid for yeast two hybrid, 500ng each). The mixture was incubated at $29^{\circ} \mathrm{C}$ for $30 \mathrm{~min}$ after which it was kept at $42^{\circ} \mathrm{C}$ for $40 \mathrm{~min}$. The reaction mixture was then centrifuged for $30 \mathrm{~s}$ (13000rpm, RT) and the cell pellet obtained was re-suspended into $1 \mathrm{ml}$ sterile water and different dilutions were spread on selective SD-LT agar plates and incubated at $29^{\circ} \mathrm{C}$ for $2-3$ days.

\subsubsection{Sequencing}

Samples were sent for sequencing to SeqLab-Microsynth AG, Göttingen. Samples were prepared as per the company's requirements.

\subsubsection{RNA extraction ( Chomczynski, 1993)}

The TRIZOL extraction method was used to isolate RNA from plant material. $1.3 \mathrm{ml}$ of Trizol buffer $(380 \mathrm{ml} / \mathrm{l}$ phenol saturated with $0.1 \mathrm{M}$ citrate buffer $\mathrm{pH} 4.3,0.8 \mathrm{M}$ 
guanidine thiocyanate, $0.4 \mathrm{M}$ ammonium thiocyanate, $33.4 \mathrm{ml} 3 \mathrm{M} \mathrm{Na}$-acetate $\mathrm{pH} 5.2$, $5 \%$ glycerol) was added to frozen grinded plant material $(100-200 \mathrm{mg})$. After continuous vortexing for $15 \mathrm{~min}, 260 \mu \mathrm{l}$ chloroform was added to each sample and the tubes were vortexed for another $15 \mathrm{~min}$. The samples were then centrifuged for 60 $\min \left(13000 \mathrm{rpm}, 4^{\circ} \mathrm{C}\right) .900 \mu \mathrm{l}$ of the supernatant was taken into a new microcentrifuge tube that contained $325 \mu$ precipitation buffer (HSPB, $1.2 \mathrm{M} \mathrm{NaCl}, 0.8 \mathrm{M} \mathrm{Na}$-citrate) and $325 \mu \mathrm{l}$ 2-propanol. The contents were mixed by inverting the tubes several times and then incubated for $10 \mathrm{~min}$ at RT. After a second centrifugation step for $30 \mathrm{~min}$ $\left(13000 \mathrm{rpm}, 4^{\circ} \mathrm{C}\right)$, pellets were washed with $70 \% \mathrm{EtOH}$. After complete removal of $\mathrm{EtOH}$, pellets were dried at $37^{\circ} \mathrm{C}$ for $5 \mathrm{~min}$. The RNA pellet was then dissolved in $40-$ $60 \mu \mathrm{l}$ of de-ionized water. The concentration of extracted RNA was determined using Nanodrop 2000 spectrophotometer.

\subsubsection{3 cDNA preparation}

cDNA was synthesized from $1 \mu \mathrm{g}$ of RNA. The RNA samples were initially incubated with $1 \mu \mathrm{l}$ DNase I (along with $1 \mu \mathrm{l} 10 \mathrm{X}$ DNase I buffer, Fermentas) for $30 \mathrm{~min}$ at $37^{\circ} \mathrm{C}$. DNase I was then denatured by adding $1 \mu \mathrm{l} 25 \mathrm{mM}$ EDTA and incubating the samples for $10 \mathrm{~min}$ at $60^{\circ} \mathrm{C}$. $20 \mathrm{pmol}$ of oligo dT primer and $200 \mathrm{pmol}$ of random nonamer oligonucleotides were added to the samples and the mixture was incubated for 10 $\min$ at $70^{\circ} \mathrm{C}$. Finally, $20 \mathrm{nmol}$ dNTPs, $4 \mu \mathrm{l}$ RT 5X-Reaction Buffer and $60 \mathrm{U}$ Reverse Transcriptase $\mathrm{H}$ - (Fermentas) were added and the reaction mixture was incubated at $42^{\circ} \mathrm{C}$ for $30 \mathrm{~min}$ followed by incubation at $70^{\circ} \mathrm{C}$ for $10 \mathrm{~min}$. The cDNA thus prepared was stored at $-20^{\circ} \mathrm{C}$.

\subsubsection{Quantitative real-time PCR}

Gene expression was analyzed using quantitative real-time PCR (qRT-PCR). Amplification and quantification was carried out in the iCycler System (Bio-Rad, USA). The reaction mixture consisted of $1 \mathrm{X}$ NH4-reaction buffer (Bioline, Germany); $2 \mathrm{mM} \mathrm{MgCl} 2 ; 100 \mu \mathrm{M}$ of dNTPs; $0.4 \mu \mathrm{M}$ of primers (self-made or QuantiTect $\AA$, Qiagen), 0.25U BIOTaq DNA polymerase (Bioline, Germany); 10nM Fluorescein (Bio-Rad, USA); 100,000 times diluted SYBR Green I solution (Cambrex, USA); $1 \mu \mathrm{l}$ of $1: 10$ diluted cDNA as template. The obtained $\mathrm{Ct}$ values were normalized to housekeeping gene $U B Q 5$ and relative quantification was done using the $2^{-\triangle \triangle C T}$ method (Livak and Schmittgen, 2001).

\subsubsection{Microarray}

For performing a microarray analysis, whole rosettes from 4-week old Col-O and 35S:ANAC032 plants (five individual plants as replicates) were harvested. The RNA extracted by Trizol method was purified using the RNeasy Plant Mini Kit (Qiagen) and samples was sent to Westfälische-Universität Münster, Integrierte Funktionelle Genomik (Germany) where the array was performed with Arabidopsis ATH1 genome arrays.

Functional enrichment of differentially regulated genes was analyzed by singular enrichment analysis (SEA) with the agriGO tool (Du et al., 2010). The statistical 
method used was Fisher Test while the Yekutieli method was used for multiple comparison correction.

\subsubsection{Protoplast isolation and transformation (Sheen, 2001)}

Leaves from 3-4 week old plants (grown in 12h-light/12h-dark photoperiod) were used for isolation of protoplasts. The protocol followed for isolation and transformation was as described by Sheen, 2001. The isolated protoplasts were transformed with $5 \mu \mathrm{g}$ of promoter constructs (promoter of interest gene:firefly luciferase gene; pBGWL7 derivatives), $7.5 \mu \mathrm{g}$ of effector constructs (pUBQ10-HA derivatives) and $1 \mu \mathrm{g}$ of 35S:Renilla luciferase plasmid. The firefly and renilla luciferase activities were measured the following day as described in 3.2.4

\subsubsection{Luciferase assay}

After over-night incubation, the transformed protoplasts settle at the bottom. The incubation buffer (WI solution, $33.3 \mathrm{ml} 0.75 \mathrm{M}$ mannitol, $2 \mathrm{ml} 0,5 \mathrm{M} \mathrm{KCl}, 0.4 \mathrm{ml} 0.5 \mathrm{M}$ MES, volume made upto $50 \mathrm{ml}$ using de-ionized water) was then removed using a syringe and the sample was immediately frozen in liquid nitrogen. The luciferase assay was then performed using the Dual Luciferase Reporter Assay System from Promega. The measurements were recorded using the DLR Ready luminometer.

\subsubsection{ONPG assay}

Yeast PJ69-4a strain was transformed using bait and prey vectors (as described in 3.2.2.10). The yeast transformants were inoculated into $5 \mathrm{ml}$ of SD-LT medium and incubated overnight at $29^{\circ} \mathrm{C}$ on a shaker. On the following day, culture was centrifuged for $1 \mathrm{~min}$ (13000rpm, RT) and supernatant was discarded. After washing the cell pellet once using $1 \mathrm{ml} Z$-buffer $\left(60 \mathrm{mM} \mathrm{Na}_{2} \mathrm{HPO}_{4}, 40 \mathrm{mM} \mathrm{NaH}_{2} \mathrm{PO}_{4}, 10 \mathrm{mM} \mathrm{KCl}\right.$, $1 \mathrm{mM} \mathrm{MgSO}_{4}$ ), they were re-suspended in $300 \mu \mathrm{l}$ of Z-buffer out of which $100 \mu \mathrm{l}$ was transferred to a new $1.5 \mathrm{ml}$ centrifuge safe-lock tube (rest of the solution was kept on ice for measuring OD of yeast cells). The cells were then lysed by repeated freezing and thawing using liquid nitrogen. After this $700 \mu$ of Z-buffer with $0.27 \%$ freshly added $\beta$-mercaptoethanol was added to the cell lysates and also to a tube containing $100 \mu \mathrm{l}$ of Z-buffer which served as a blank control. The contents were mixed by inverting the tubes and then $160 \mu \mathrm{l}$ of ONPG solution $(4 \mathrm{mg} / \mathrm{ml}$ o-nitrophenyl- $\beta$-Dgalactopyranoside in Z-buffer) was added, mixed and reactions were incubated at $37^{\circ} \mathrm{C}$ until development of yellow colour. After colour development, time was recorded and reaction stopped using ONPG stop solution $\left(1 \mathrm{M} \mathrm{Na}_{2} \mathrm{CO}_{3}\right)$. Samples were then centrifuged for $10 \mathrm{~min}$ (13000rpm, RT) and 200 $\mathrm{\mu l}$ of the supernatant was added to wells of a microtitre plate. Amount of o-nitrophenyl was determined by measuring OD at $420 \mathrm{~nm}$ using the BioTek plate reader. Dilutions of the cell suspension (previously stored on ice) were added to another microtitre plate and OD was measured at $595 \mathrm{~nm}$. The $\beta$-galactosidase activity were measured in units as,

$\beta$-Gal units $=\frac{1000 \times \mathrm{OD}_{420}}{\mathrm{~T} \times \mathrm{OD}_{600} \times \mathrm{F}} \quad \begin{array}{r}\text { where }, T=\text { reaction time in minutes } \\ \mathrm{F}=\text { dilution factor for cell suspension }\end{array}$ 


\subsubsection{Metabolite measurements}

Determination of various metabolite concentrations were performed using HPLCMS/MS by the Department of Plant Biochemistry (Prof. Dr. Ivo Feußner, Dr. Tim Iven), University of Göttingen, Germany.

\subsubsection{Quantitative GUS assay (Jefferson et al., 1987)}

\subsubsection{Protein extraction for MUG assay}

Crude protein extracts were prepared by addition of $150 \mu$ GUS extraction buffer (50mM sodium phosphate buffer pH 7.5, 10mM EDTA, $0.1 \%$ Triton X-100, $0.1 \%$ Sarkosyl; freshly added $10 \mathrm{mM} \beta$-mercaptoethanol) to frozen ground plant material. Samples were kept on ice till they thawed after which contents were mixed by inverting the tubes. The samples were then centrifuged for 10 min (10000rpm, RT). Clear supernatant was transferred to new $1.5 \mathrm{ml}$ centrifuge tubes and placed on ice.

\subsubsection{Protein estimation}

Protein concentrations were determined using a commercial Bradford assay solution (CARL ROTH, Germany). Equal volumes of protein extract $(0.5-2 \mu \mathrm{l})$ were added to wells of a microtitre plate containing $200 \mu \mathrm{l}$ of 5 -fold diluted Bradford assay solution. After mixing the contents with pipette tips, the reaction was incubated at RT for 5$10 \mathrm{~min}$ after which OD was measured at $595 \mathrm{~nm}$ using the BioTek plate reader. Protein concentrations were determined with the help of standard curve derived from different known BSA concentrations (1, 3 and $6 \mu \mathrm{g}$ ).

\subsubsection{Measurement of relative GUS activity}

Volume of protein extract, corresponding to approximately $25 \mu \mathrm{g}$ of protein, was added to well of flat-bottomed microtitre plate and filled up to $100 \mu \mathrm{l}$ using GUS extraction buffer. To this, $100 \mu$ l of MUG solution (4mM MUG in GUS extraction buffer) was added and contents were mixed using pipette tips. The reaction was incubated at $37^{\circ} \mathrm{C}$ for $10 \mathrm{~min}$ in dark. $100 \mu \mathrm{l}$ of the sample was then transferred to a new well containing $100 \mu$ l of GUS stop solution (0.2M Na2CO3); this served as t0 (zero time-point) value. The plate was further incubated at $37^{\circ} \mathrm{C}$ for $60 \mathrm{~min}$ in dark after which $100 \mu \mathrm{l}$ of GUS stop solution was added to the remaining reaction providing t60 values. Fluorescence was then measured at $365 \mathrm{~nm}$ using the BioTek plate reader. Relative GUS activities were calculated from the t0 and t60 values.

\subsubsection{GUS staining}

Tissue to be analyzed (siliques or leaves) were taken in $2 \mathrm{ml}$ centrifuge tubes and submerged in the fixing solution $(50 \mathrm{mM}$ sodium phosphate buffer $(\mathrm{pH} 7.0), 0.3 \mathrm{M}$ mannitol and $0.3 \%$ formaldehyde) for $30 \mathrm{~min}$. After washing twice with $50 \mathrm{mM}$ sodium phosphate buffer ( $\mathrm{pH} 7.0$ ), $2 \mathrm{ml}$ of X-Gluc staining solution (50mM sodium phosphate buffer $(\mathrm{pH} 7.0), 0.5 \mathrm{mM}$ potassium ferricyanide, $0.5 \mathrm{mM}$ potassium ferrocyanide, $2.5 \mathrm{mM} \quad 5$-Bromo-4-chloro-3-indolyl- $\beta$-D-glucuronide, $\quad 10 \mathrm{mM} \quad$ EDTA, $2 \%$ 
dimethylyformamide and $0.1 \%$ Triton X-100) was added. Samples were subjected to vacuum infiltration for $3 \mathrm{~min}$ and then incubated $\mathrm{O} / \mathrm{N}$ at $37^{\circ} \mathrm{C}$. Chlorophyll was then cleared by washing with $100 \%$ ethanol after which the GUS-stained samples were visualized under the microscope.

\subsubsection{Juvenility assessment}

The phenotypic analyses to distinguish juvenile and mature adult leaves was done as described by Willmann and Poethig, 2011. Juvenile leaves were defined as rosette leaves without abaxial (on the lower surface) trichomes, transition leaves as rosette leaves with abaxial trichomes that did not fully span the proximodistal axis, and adult leaves as rosette leaves with abaxial trichomes covering the whole surface up to the distal tip.

\subsubsection{Germination test for seed dormancy analysis}

Freshly harvested seeds from siliques that had turned slightly brown (but not yet dried) were collected for analysis of dormancy. Completely dried seeds fully released from dormancy (dried since more than 10-weeks) were used as controls. About 50 seeds (freshly harvested or completely dried out) were plated onto a filter paper moistened with demineralized water in Petri dishes and incubated under long day conditions. Scoring of radicle emergence was done 3 days later. 


\section{Results}

\subsection{ANACO32 and ATAF1 are downstream target genes of the TGA/SCL14 complex in the detoxification response}

Fode et al., 2008 showed that SCL14 (SCARECROW-LIKE 14) acts as a transcriptional co-activator of class-II TGA transcription factors (TFs). The TGA/SCL14 complex regulates the expression of genes involved in the detoxification of toxic chemical compounds. Whole-genome microarray analysis identified two NAC TFs - ANACO32 and ATAF1 - which showed more than a four-fold up-regulation in the HA3-SCL 14 overexpressing transgenic line as compared to the $s c / 14$ knockout mutant. It was shown by chromatin immunoprecipitation assays that SCL14 is recruited to direct target genes by TGA factors (2, 5 and 6$)$ which are known to bind to as-1 (activation sequence-1)-like elements in promoter regions (Katagiri et al., 1989). Since the promoters of the two NAC factors contain putative as-1-like elements, they are likely to be direct targets of the TGA/SCL14 complex (Figure 4.1 A). To confirm that the NAC gene expression actually depends on the TGA/SCL14 complex under inducing conditions, wild-type, tga256 [combined deletion knockout mutants of TGA2, TGA5 and TGA6, (Zhang et al., 2003)] and sc/14/33 [combined TDNA insertion mutants of SCL14 and its close homologue SCL33] plants were treated with the xenobiotic toxic chemical TIBA (2,3,5-triiodobenzoic acid) and expression was analyzed. Quantitative real time-PCR (qRT-PCR) indicated that both, ANACO32 and ATAF1 are induced by application of TIBA and that this induction requires the presence of class-II TGA factors and SCL14/SCL33 (Figure $4.1 \mathrm{~B}$ ). Moreover, the basal expression seemed to be slightly reduced in the tga256 and sc/14/33 knockout plants. The two other closely related NAC proteins - ATAF2 and ANAC102 - belonging to the same motif clade as ANAC032 and ATAF1 (Supplementary Figure S1) - also contain as-1-like elements in their respective promoters (Figure $4.1 \mathrm{~A}$ ). Consistently, these two TFs are induced by TIBA in a TGA/SCL14-dependent manner (Figure 4.2 B). 
A

\begin{tabular}{|l|c|c|}
\hline \multicolumn{1}{|c|}{ Gene } & AGI code & \multicolumn{1}{c|}{$\begin{array}{c}\text { as-1-like element } \\
(-1000 \text { bp promoter region })\end{array}$} \\
\hline ANAC032 $^{\prime}$ & At1g77450 & -206 TGACGTAAgcaaTGACAAAA $_{-187}$ \\
\hline ATAF1/ANAC002 & At1g01720 & -179 AGACGTAAgcaaTGACAACA $_{-160}$ \\
\hline ATAF2/ANAC081 & At5g08790 & ${ }_{-231}$ TGACGCAAgcaaTGACAACA $_{-212}$ \\
\hline ANAC102 & At5g63790 & -187 TGACGGAAgcaaTGACATCA $_{-168}$ \\
\hline consensus & & TGACGTCAnnnnTGACGTCA $^{2}$ \\
\hline
\end{tabular}

B
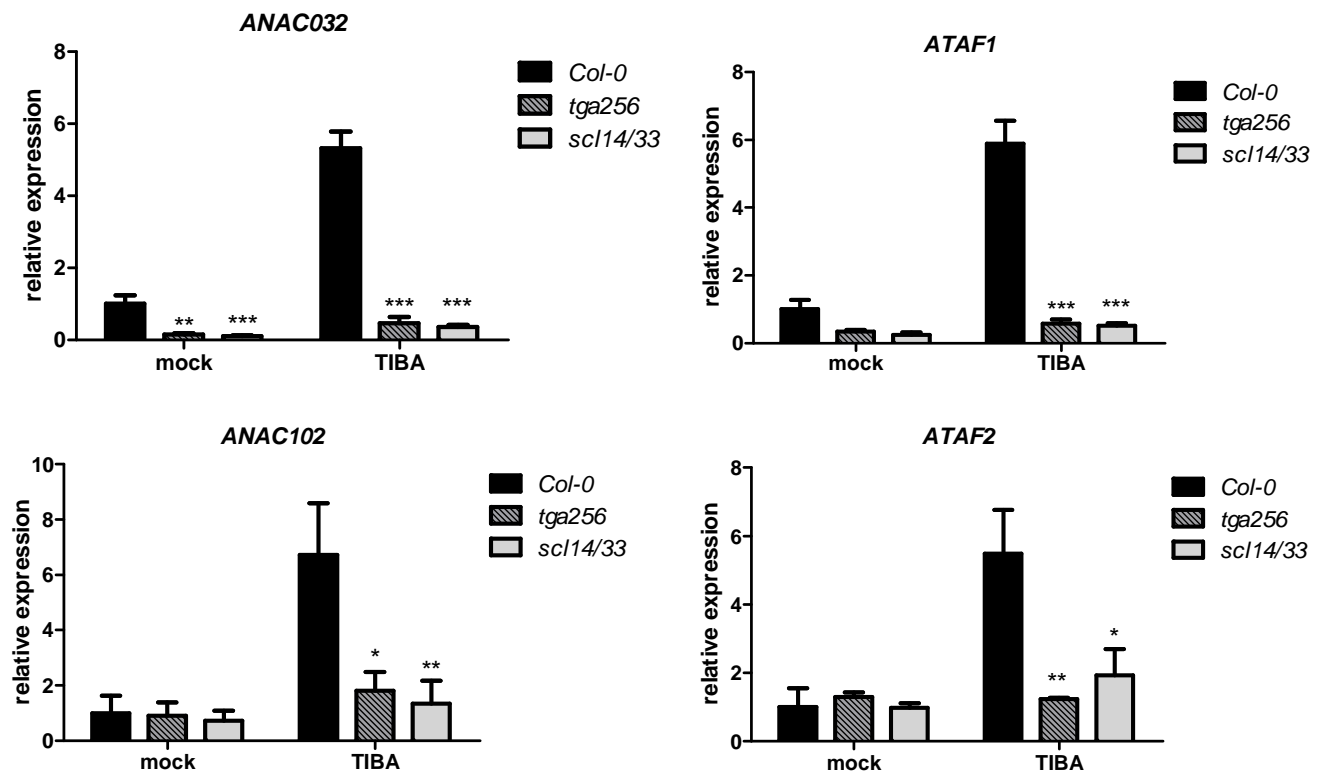

Figure 4.1: Expression of TIBA-induced ATAF TFs require the TGASSC14 complex

A: Table showing the sequences of putative as-1-like elements present in the promoter regions of the four ATAF-type TFs. The numbers indicate their positions relative to the transcriptional start sites $(+1)$. Conserved nucleotides within the 8-bp palindromes (capital letters) are highlighted in red. The consensus sequence described for the as-1 element (Katagiri et al., 1989) is shown in the last row.

B: Six-week old soil-grown (short day) Col-0, tga256 and sc/14/33 plants were treated with $0.1 \mathrm{mM}$ TIBA for 8 hours. Treatment with $0.1 \%$ DMSO served as control (mock). The relative transcript levels (normalized to house-keeping gene UBQ5) of ANAC032, ATAF1, ANAC102 and $A T A F 2$ were determined by qRT-PCR. The average relative expression in mock treated Col-O plants was set to 1 . The mean values $( \pm S E)$ from two experiments - each with 4-5 individual plants - are shown. Asterisks indicate significant differences compared with wildtype (Two-way ANOVA; ${ }^{* * *} \mathrm{P}<0.001,{ }^{* *} \mathrm{P}<0.01,{ }^{*} \mathrm{P}<0.05$ ) 
It was shown earlier that tga256 and sc/14 display increased sensitivity towards TIBA (Fode et al., 2008). In a similar experiment, the NAC single knockouts ataf1 and anac032 (T-DNA insertion lines) and double knockout ataf1anac032 were grown on MS plates containing TIBA to evaluate their sensitivity towards the toxic chemical. However, the single and double knockout plants behaved like the wild-type in their ability to germinate and grow on TIBA-containing media (Figure 4.2). This suggests that these two NAC TFs are not essential for the response towards TIBA and instead may be regulating just a sub-branch of the TGA/SCL14-triggered response. Alternatively, functional redundancy between the four NAC TFs in response to TIBA (Figure 4.1 B and Figure 4.6 A) may account for the absence of increased sensitivity in single and double knockouts.

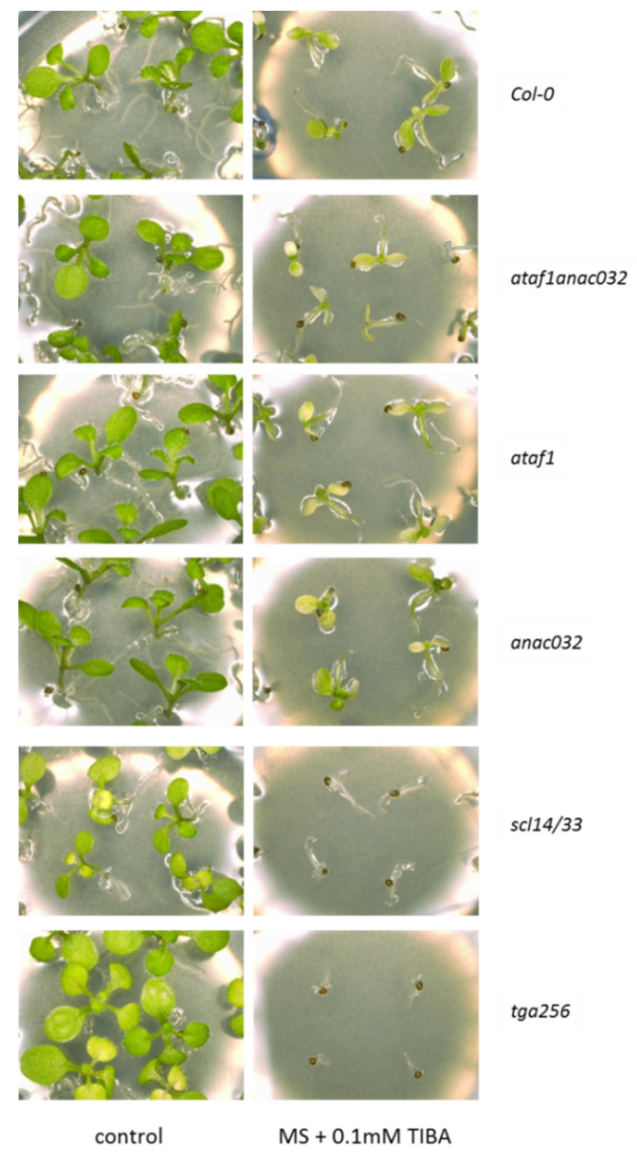

Figure 4.2: ANACO32 and $A T A F 1$ is not essential for the observed sensitivity of tga256 and $s c / 14 / 33$ mutant plants towards the toxic chemical TIBA

Col-0, ataf1anac032, ataf1, anac032, sc/14/33 and tga256 mutant plants were sown on MS plates containing $0.1 \mathrm{mM}$ TIBA and grown under long-day conditions. Photographs were taken two weeks after germination. 


\subsection{AKR4C9, bHLH585 and At3g04000 may be direct downstream targets of ANAC032 in the detoxification response towards xenobiotic compounds}

To further elucidate the role of the two NAC proteins in the detoxification response after TIBA treatment, transgenic plants ectopically expressing HA-ANAC032 or HAATAF1 under the control of the Cauliflower mosaic virus (CaMV) $35 S$ promoter were generated. As mentioned above, SCL14-dependent genes containing as-1-like elements that were identified in the microarray analysis were assumed to be direct targets of the TGA/SCL14 complex (Fode et al., 2008). However there were a number of SCL14-dependent genes that contain no as-1-like element in their promoters. Therefore we speculated that these may be downstream genes of other TFs, like e.g. NAC proteins. To explore this and other possible target genes of the NAC TFs, microarray analysis, using RNA from untreated samples of $\mathrm{Col}-\mathrm{O}$ and 35S:ANAC032 plants, was carried out. Of the 22,000 Arabidopsis genes on the Affymetrix ATH1 gene chip, 347 genes were more than 2-fold $(p<0.05)$ up-regulated while 147 were more than 2 -fold $(p<0.05)$ down-regulated in the 35S:ANAC032 plants when compared with wild-type. The fold-induction of the top twenty upregulated genes is shown in Table 4.1 (The complete list of significantly up- and down-regulated genes is listed in supplementary Table S1 and S2, respectively). 
Table 4.1: List of twenty most up-regulated genes in 35S:ANAC032

\begin{tabular}{|c|c|c|c|c|c|}
\hline No. & Gene code & Symbol & Description & $\begin{array}{c}\text { 35S:ANACO32 } \\
\text { ICol-0 }\end{array}$ & $\mathrm{p}$-value \\
\hline 1 & AT1G77450 & ANAC032 & $\begin{array}{l}\text { NAC domain containing } \\
\text { protein }\end{array}$ & 115.4942215 & 4.61E-09 \\
\hline 2 & AT2G37770 & AKR4C9 & $\begin{array}{l}\text { aldo/keto reductase } \\
\text { family protein }\end{array}$ & 56.89304997 & 7.81E-07 \\
\hline 3 & AT1G10585 & & bHLH transcription factor & 43.08498055 & $1.48 \mathrm{E}-06$ \\
\hline 4 & AT3G26690 & ATNUDX13 & $\begin{array}{l}\text { bis (5'-adenosyl)- } \\
\text { pentaphosphatase/ } \\
\text { hydrolase }\end{array}$ & 29.7490688 & 3.83E-08 \\
\hline 5 & AT1G69880 & ATH8 & thioredoxin H-type 8 & 25.14220013 & 0.000349 \\
\hline 6 & AT1G66570 & ATSUC7 & sucrose-proton symporter & 24.81858879 & 0.000148 \\
\hline 7 & AT4G23680 & & $\begin{array}{l}\text { major latex protein- } \\
\text { related / MLP-related }\end{array}$ & 23.64446669 & 9.69E-05 \\
\hline 8 & AT1G62570 & $\begin{array}{l}\text { FMO GS- } \\
\text { OX4 }\end{array}$ & $\begin{array}{l}\text { Flavin-Monooxygenase } \\
\text { Glucosinolate S- } \\
\text { Oxygenase } 4\end{array}$ & 19.91268303 & 1.43E-06 \\
\hline 9 & AT1G02850 & BGLU11 & Hydrolase & 19.66124129 & $2.18 \mathrm{E}-06$ \\
\hline 10 & AT2G43820 & SAGT1 & $\begin{array}{l}\text { Salicylic acid } \\
\text { glucosyltransferase }\end{array}$ & 18.93009073 & 7.38E-05 \\
\hline 11 & AT3G50970 & LTI30 & $\begin{array}{l}\text { Low Temperature- } \\
\text { Induced } 30\end{array}$ & 15.20645997 & 0.000104 \\
\hline 12 & AT3G09260 & PYK10 & beta-glucosidase & 14.52883705 & 0.005794 \\
\hline 13 & AT3G04000 & & $\begin{array}{l}\text { short-chain } \\
\text { dehydrogenase/ } \\
\text { reductase protein }\end{array}$ & 13.73017707 & 0.000384 \\
\hline 14 & AT1G34040 & & alliinase & 13.44781841 & 1.23E-05 \\
\hline 15 & AT2G38380 & PER22 & peroxidase & 13.32886285 & 0.001039 \\
\hline 16 & AT2G37760 & AKR4C8 & $\begin{array}{l}\text { aldo/keto reductase } \\
\text { family protein }\end{array}$ & 12.63507277 & 2.64E-05 \\
\hline 17 & AT4G15490 & UGT84A3 & UDP-glycosyltransferase & 12.35113466 & $8.21 \mathrm{E}-06$ \\
\hline 18 & AT2G45210 & & $\begin{array}{l}\text { auxin-responsive protein- } \\
\text { related }\end{array}$ & 11.79463674 & 1.19E-05 \\
\hline 19 & AT2G04040 & ATDTX1 & multidrug efflux pump & 11.73727594 & 0.000732 \\
\hline 20 & AT5G10140 & FLC & $\begin{array}{l}\text { FLOWERING LOCUS C; } \\
\text { transcriptional repressor }\end{array}$ & 11.57218365 & 0.000308 \\
\hline
\end{tabular}


The set of 494 differentially regulated $(>2$-fold, $p<0.05)$ genes was further analyzed for specific enrichment of different gene ontology (GO) terms as specified by the TAIR database. As shown in Figure 4.3, several GO terms were significantly enriched when compared to the background (i.e. set of genes present in the ATH1 Affymetrix chip). Within the up-regulated genes (Figure $4.3 \mathrm{~A}$ ), $30 \%$ were associated with response to different stimuli (abiotic, chemical, and biotic stress). Approximately $13 \%$ of up-regulated genes showed oxidoreductase activity and $8 \%$ were transmembrane transporters of which most belonged to the group of multidrug efflux transporters. Other significantly up-regulated GO terms included cell-wall, vacuole and peroxisome - associated, secondary metabolic process, amino acid metabolic process, organic acid catabolic process, glucosyl transferases and co-factor binding. Among the down-regulated genes only few GO terms were enriched (Figure 4.3 B). These were catalytic activity (45\%; includes kinase, hydrolase and monooxygenase activity), response to stimulus (30\%), endomembrane associated $(28 \%)$, cell-wall associated ( $8 \%)$, oxygen and tetrapyrrole binding (5\% each). 
A

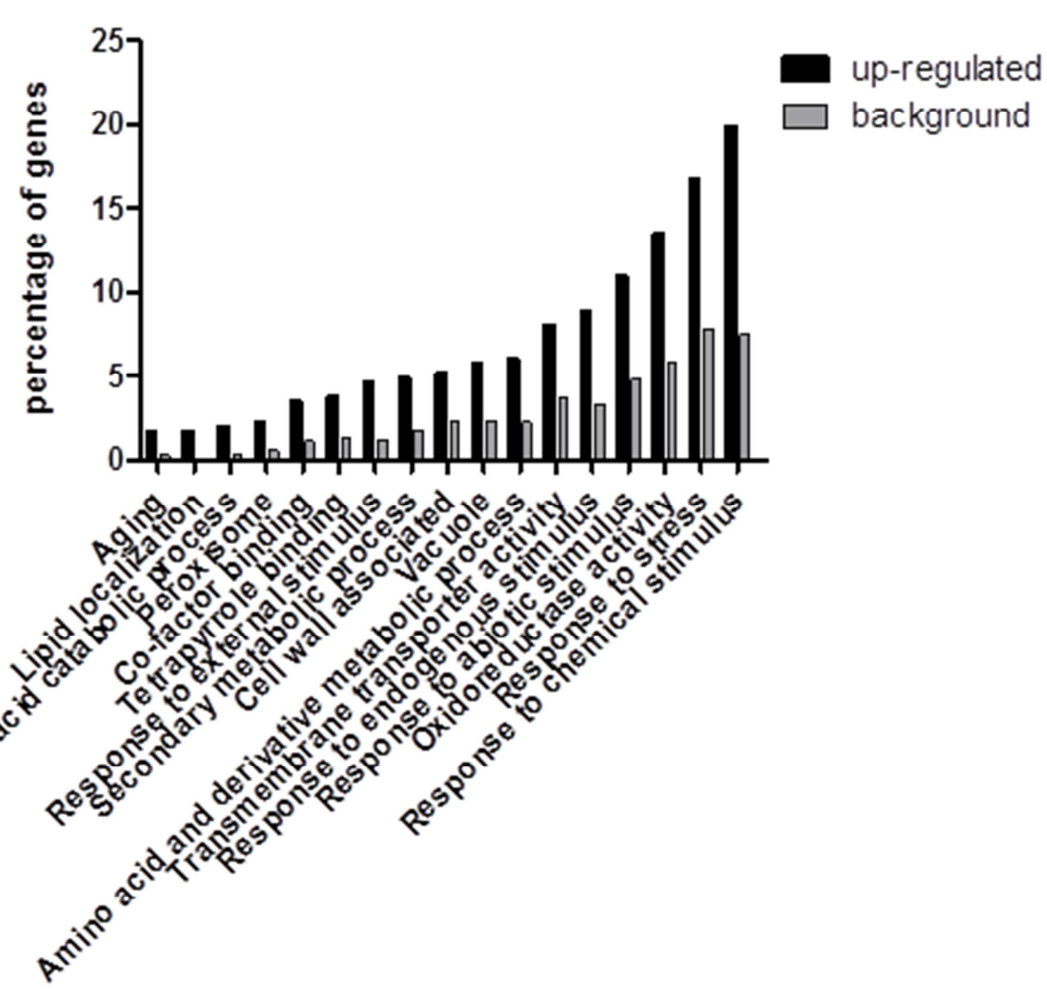

B

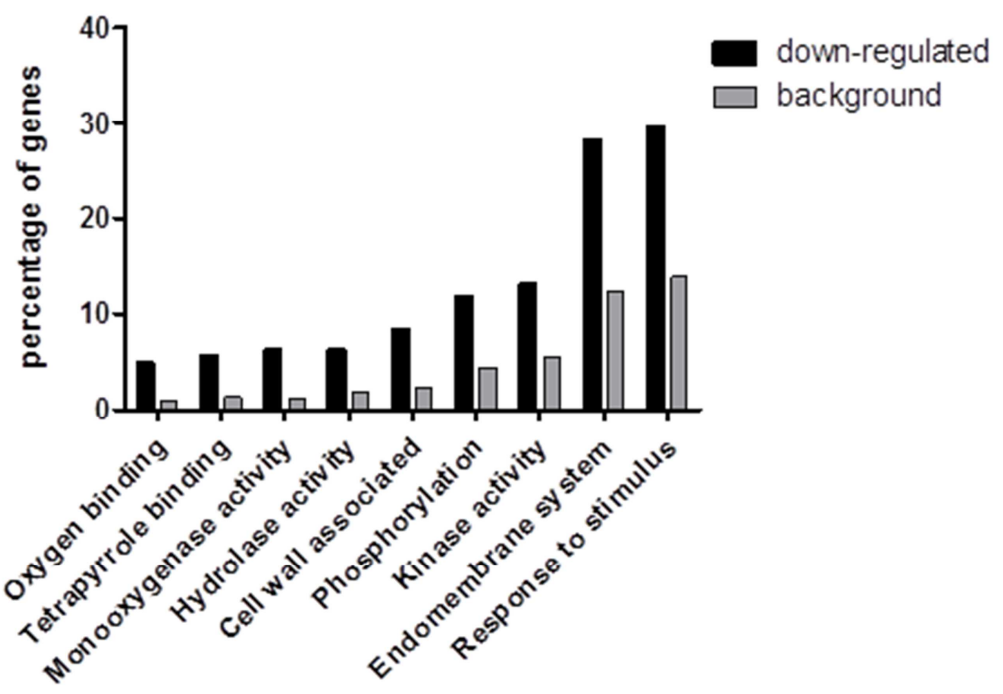

Figure 4.3: GO terms significantly enriched among up-regulated and down-regulated genes in 35S:ANAC032 plants

The GO term enrichment analysis was performed using the AgriGO tool and the 347 up-regulated (A) and 147 down-regulated (B) genes as input respectively. The background shown is the percentage of genes, belonging to different categories, present on the ATH1 Affymetrix array chip. 
The up-regulated genes were also compared to genes identified in a previous array performed with RNA from mock and TIBA-induced wild-type Col-O plants (Ph.D. Thesis by Dr. Julia Köster). A total of seventy-eight genes were induced (>2-fold) in both arrays (Figure 4.4; list of the genes is mentioned in Supplementary Table S3). These genes could be potential downstream targets of ANAC032 in the detoxification response triggered by TIBA. Interestingly, some of these common genes were also the genes that depended on the TGA/SCL14 complex but did not contain an as-1-like element in their promoters (based on the SCL14 array mentioned above, (Fode et al., 2008)). Three of the common genes - the two highest up-regulated At2g37770 (AKR4C9) and At1g10585 (bHLH585) as well as At3g04000 [which is speculated to detoxify reactive carbonyl compounds; (Yamauchi et al., 2011)] were selected for further analysis. A fourth gene, FLC (FLOWERING LOCUS C (At5g10140)), a wellknown transcriptional repressor/transcription factor regulating the initiation of flowering, was also selected for analysis.

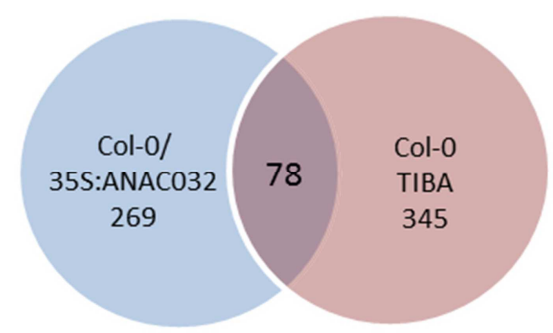

Figure 4.4: Venn diagram illustrating number of genes commonly up-regulated by TIBA and ectopic expression of ANAC032

The microarray results were first confirmed by qRT-PCR for the four selected genes which showed several fold up-regulations in plants overexpressing ANAC032. Additionally, it was observed that these genes are also induced when the other NAC TF ATAF1 was over-expressed (Figure 4.5) suggesting redundancy between the two TFs in regulating induction of these genes. 

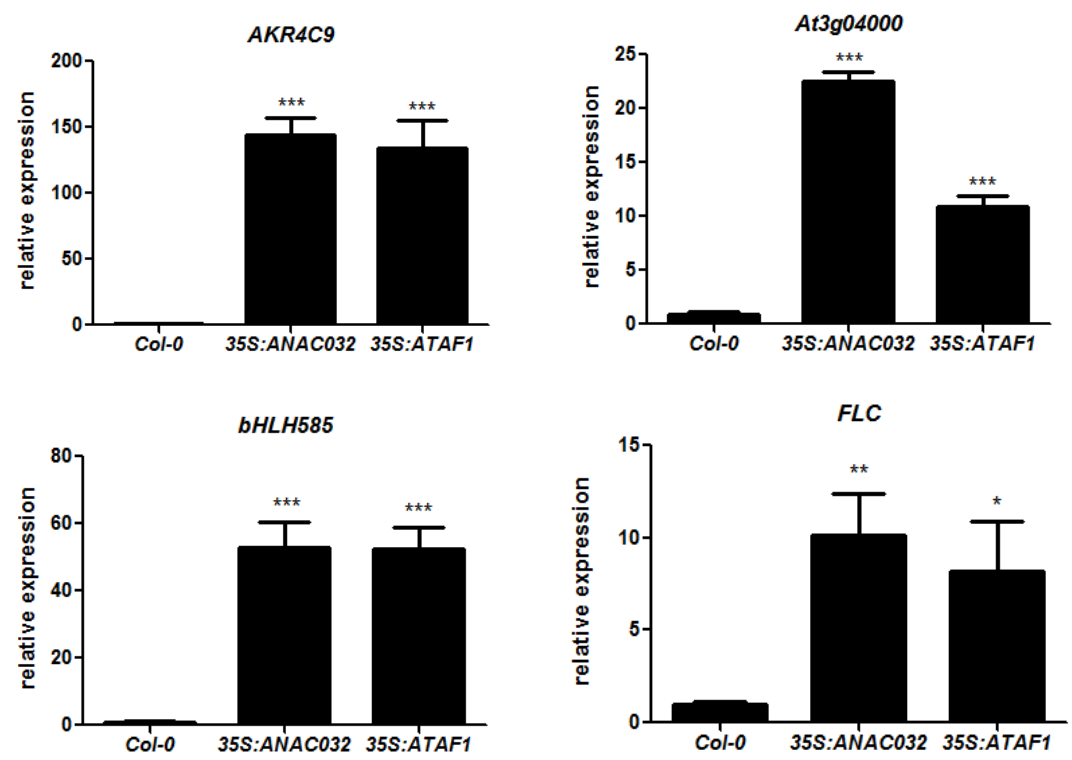

Figure 4.5: $A K R 4 C 9, \quad b H L H 585, A t 3 g 04000$ and $F L C$ are up-regulated upon ectopic expression of $A N A C 032$ or $A T A F 1$

Four-week old soil-grown (long day) Col-0, 35S:ANAC032 and 35S:ATAF1 plants were analyzed. The relative transcript levels (normalized to house-keeping gene UBQ5) of AKR4C9, bHLH585, At3g04000 and FLC (indicated above each graph) were determined by qRT-PCR. The average relative expression value in Col-O was set to 1 . The mean values $( \pm$ SE) from five individual plants are shown. Asterisks indicate significant differences compared with wild-type (Two-way ANOVA; ${ }^{* *} \mathrm{P}<0.001,{ }^{* *} \mathrm{P}<0.01,{ }^{*} \mathrm{P}<0.05$ )

Next, single knockouts ataf1 and anac032 and the double knockout ataf1anac032 were tested for compromised induction of AKR4C9, bHLH585, At3g04000 and FLC after application of TIBA. Three of the selected genes namely, AKR4C9, bHLH585 and $A t 3 g 04000$ were induced in Col-O upon TIBA application. This induction seemed to be compromised in the single knockouts as well as in the double knockout albeit in varying degrees for the three different genes. The induction of AKR4C9 in the ataf1 knockout was only slightly less as compared to wild-type whereas anac032 and the double knockout ataf1anac032 showed a strong suppression suggesting that ANAC032 contributes more to the expression of AKR4C9 than ATAF1. In the case of bHLH585 and At3g04000, both single knockouts and the double knockout showed similar levels of compromised induction (Figure 4.6 A). Furthermore, the induction of 
the three selected candidate genes was suppressed in the tga256 and sc/14/33 knockout mutants suggesting that these are indeed indirect target genes in the detoxification pathway (Supplementary Figure S2).

The role of $A K R 4 C 9, b H L H 585$ and $A t 3 g 04000$ as direct targets of the NAC proteins is also supported by transient expression assays that were carried out in ataf1anac032 leaf protoplasts. To this aim, the promoters of the target genes were fused to a luciferase reporter gene, while ANACO32 and ATAF1 were fused to the ubiquitin $(U B / 10)$ promoter. All three promoter constructs were activated by the NAC proteins when fused to the strong activating domain VP16 (Figure 4.6 B). Since the unfused NAC proteins were unable to activate the promoter constructs (Supplementary Figure S4), we suggest that the NAC proteins can bind to the target promoters but require additional factor(s) for transcriptional activation. All these data taken together suggest that $A K R 4 C 9, b H L H 585$ and $A t 3 g 04000$ are direct targets of ANAC032 and ATAF1 in the detoxification pathway triggered by the TGA/SCL14 complex. Nevertheless, in the case of all three candidate target genes, their induction by TIBA was not completely abolished in ataf1anac032, suggesting that perhaps other redundant NAC proteins (possibly ATAF2 and ANAC102) are at play.

The fourth gene selected for analysis - FLC - was not induced by TIBA and its promoter could not be significantly induced in transient protoplast expression assays suggesting that this gene may not be a direct target of the NAC TFs and may not play a role in the detoxification pathway (Figure 4.6). However, NAC-activated FLC expression might play a role in seed dormancy (see below). 

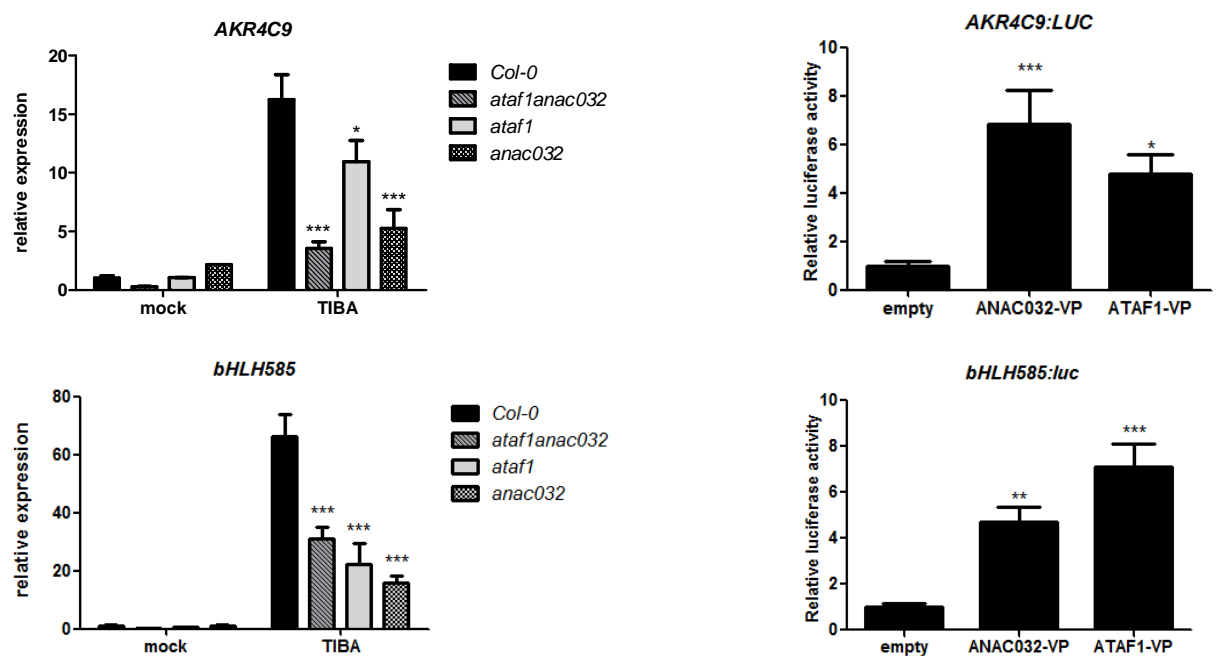

- Col-O

ataf1anac032

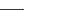

anac032

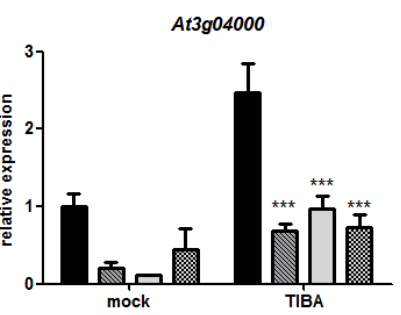

- Col-O

ataf1anac032

$\square$ ataf1

anac032

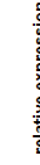

FLC
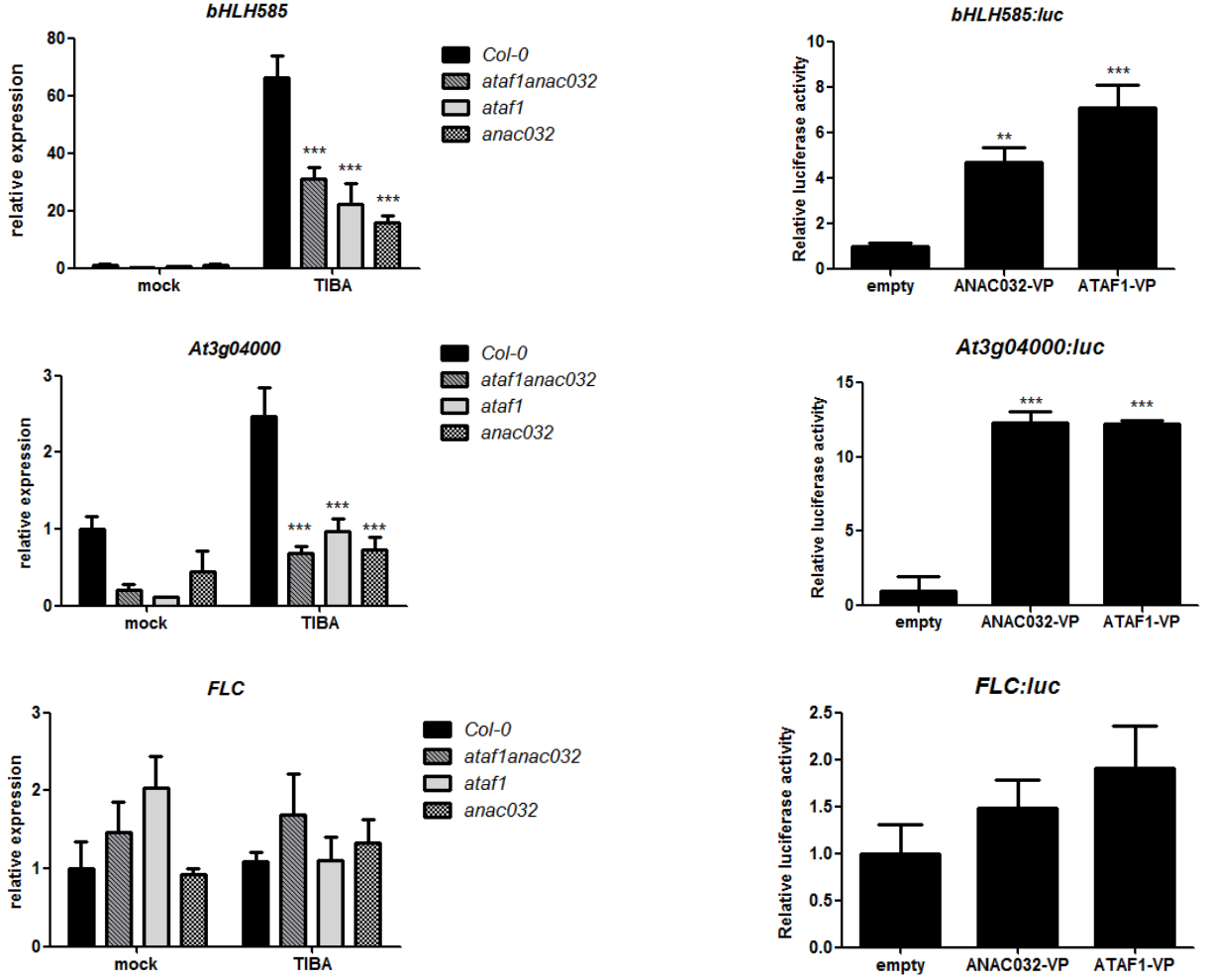

Figure 4.6: $A K R 4 C 9, b H L H 585$ and At3g04000 are possible direct targets of the ANAC032 and ATAF1 TFs in the detoxification response

(A) Six-week old soil-grown (short day) plants were treated with $0.1 \mathrm{mM}$ TIBA or with $0.1 \%$ DMSO (control) for 8 hours. The relative transcript levels (normalized to house-keeping gene UBQ5) of AKR4C9, bHLH585, At3g04000 and FLC were determined by qRT-PCR. Average relative expression value in mock treated Col-O plants was set to 1 . The mean values $( \pm \mathrm{SE})$ from three individual experiments, each conducted with 5-6 individual plants/genotype are shown. Asterisks indicate significant differences compared with mock Col-O plants (One-way ANOVA; ${ }^{* * *} \mathrm{P}<0.001,{ }^{*} \mathrm{P}<0.05$ )

(B) Leaves from four-week old soil-grown ataf1anac032 plants grown under 12-h light/12-h dark photoperiod were used for protoplast isolation and transformation with different effector and reporter constructs as indicated in the graphs. The values shown are means of two independent experiments, each with 5-6 reactions per effector construct. Asterisks indicate significant differences compared with transformation with empty vector (One-way ANOVA; ${ }^{* * *} \mathrm{P}<0.001$, ${ }^{* *} \mathrm{P}<0.01,{ }^{*} \mathrm{P}<0.05$ ) 


\subsection{ANACO32 and ATAF1 and their downstream targets are involved in diverse stress responses}

The ATAF subfamily members are predicted to be stress-responsive (Ooka et al., 2003). Genevestigator data show that they can be induced under variety of abiotic stress conditions, by application of most major hormones and also by pathogen infection (Figure 4.7 A). To better understand the induction pattern of ANACO32 upon different stimuli and to find conditions where expression of the gene can reach levels found in the 35S:ANAC032 transgenic lines, wild-type plants grown together under same conditions were treated in different ways as indicated in Figure 4.7 B and C. Application with ABA (abscisic acid), MeJA (methyl jasmonate) and TIBA was analyzed 8 hours after treatment while ACC (1-aminocyclopropane-1-carboxylic acid; precursor of ethylene) and SA (salicylic acid) treatments were done for 24 hours. These time-points were selected because high induction of marker genes of the respective pathways can be observed for the different treatments. Under our conditions, ANACO32 was not highly induced after application of the hormones MeJA, ACC or SA. It was rather significantly induced after treatments with ABA (abscisic acid), TIBA and after infection with Botrytis cinerea (roughly a 15-fold induction as compared to untreated plants). The highest induction was observed after wounding (60-80-fold) and also to some extent after ozone application (20-30-fold). ANAC032 induction after wounding was on an average $60 \%$ of that found in the overexpressing plants (Figure 4.7 B). The ATAF1 expression pattern was quite similar to ANACO32 in that it showed no or very low induction after MeJA, ACC or SA at the time-points checked. There was a $\sim 10$-fold induction detected after ABA, TIBA or ozone treatments and $\sim 20$-fold induction after wounding and Botrytis infection. Even though wounding elicited the highest expression in this case, it was a mere $20 \%$ of that found in 35S:ATAF1 plants (Figure $4.7 \mathrm{C}$ ). Therefore, the effects observed in plants over-expressing ATAF1 may be much stronger than ever achieved under natural conditions. 
A

2,4,6 T/ mock treated seedlings

2,4-dichlorophenoxyacetic acid/ mock treated plant samples 4-thiazolidinone/acetic acid / solvent treated seedlings

AgNO3 / mack treated seedlings

CMP (24h) / solvent treated root culture samples (24h)

CMP ( $4 \mathrm{~h})$ / solvent treated root culture samples ( $4 \mathrm{~h})$

cycloheximide / mock treated seedlings

DFPM (Col-0) / solvent treated seedling samples ( $\mathrm{Col}-0)$

dicamba (10h) / H2O treated seedling samples (10h)

fenclorim $(24 \mathrm{~h}) /$ solvent treated root culture samples ( $24 \mathrm{~h})$

fenclorim ( $4 \mathrm{~h})$ / solvent treated root culture samples ( $4 \mathrm{~h}$ )

furvl acrvlate ester/s olvent treated seedlinas

hydrogen peroxide (Col-0)/ untreated seedlings ( $\mathrm{Col}-0)$

ozone / air treated seedlings

phytoprostane A1 (cell culture) / solvent treated cell culture samples

phytoprostane $\mathrm{A} 1(\mathrm{COl}-0)$ / solvent tre ated $(\mathrm{Col}-0)$ seedlings

TIBA / mock treated seedlings

B. cinerea / nan-infected rosette leaf samples

B. graminis (Col-0)/ non-infected rosette leaf samples

P. syringae pv. maculicola (Col-0)/ mock tre ated le af samples (Col-0)

P. syringae pv. tomato study 12 ( $\mathrm{Col}-0)$ / untreated leaf tissue samples ( $\mathrm{Col}-0)$ $A B A(1 \mathrm{~h}) /$ mock treated see dlings ( $1 \mathrm{~h})$

ABA (30min) / mock treated seedlings (30 min)

$A B A(3 \mathrm{~h}) /$ mock treated see dlings ( $3 \mathrm{~h}$ )

ABA study $4(\mathrm{Col}-0) /$ mock treated leaf samples ( $\mathrm{Col}-0)$

$\mathrm{ABA}$ study $5(\mathrm{Col}-0)$ / untreated plant samples ( $\mathrm{COl}-0)$

ABA study $6(\mathrm{Col}-0) /$ untreated plant samples ( $\mathrm{Col}-0)$

MeJa study 2 (3h) / mock tre ated seedlings ( $3 \mathrm{~h}$ )

MeJa study $3(0.5 \mathrm{~h}) /$ solvent treated cell culture samples $(0.5 \mathrm{~h})$

Me Ja study $3(2 h) /$ solvent treated cell culture samples ( $2 h$ )

MeJa study $3(6 \mathrm{~h}) /$ solvent treated cell culture samples $(6 \mathrm{~h})$

MeJa study 4 (Col-0) / mock treated plant samples (Col-0)

salicylic acid/ mock treated seedlings

salicylic acid study 10 (4d) / mock treated Col-0 rosette leaf samples (4d)

high light $(\mathrm{C} 0 \mathrm{l}-0)$ / low light grawn seedlings $(\mathrm{CO}-0)$

iron deficiency/protoplasting / iron deficiency study $8(24 \mathrm{~h})$

shift to $\mathrm{pH} 4.6$ / protoplasting/ shift to $\mathrm{pH} 4.6$ (24h)

drought study 16 (Col) / mock tre ated Col whole plant samples

drought study $6(\mathrm{Col}-0) /$ untreated plant samples (Col-0)

hypoxia study 14 (COl-0) / mock treated rosette samples (Col-0)

osmotic study 4 (root) / mock treated Col-0 root samples

osmotic study 4 (shoot) / mock treated Col-a shoot samples

salt study $3(\mathrm{Col}-0) / \mathrm{H} 20$ treated rosette leaf samples (Col-0)

wounding (early) / untreated green tissue samples (early)

wounding (late) / untreated green tissue samples (late)

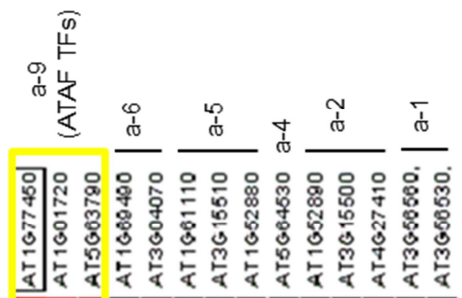


B

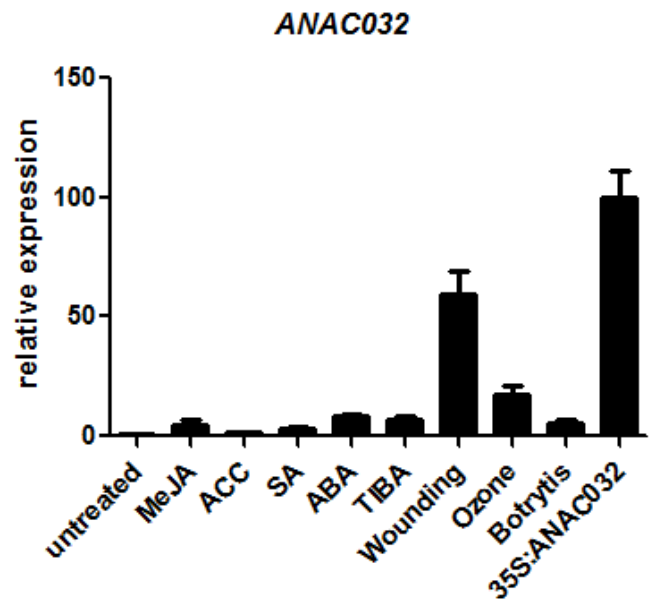

C

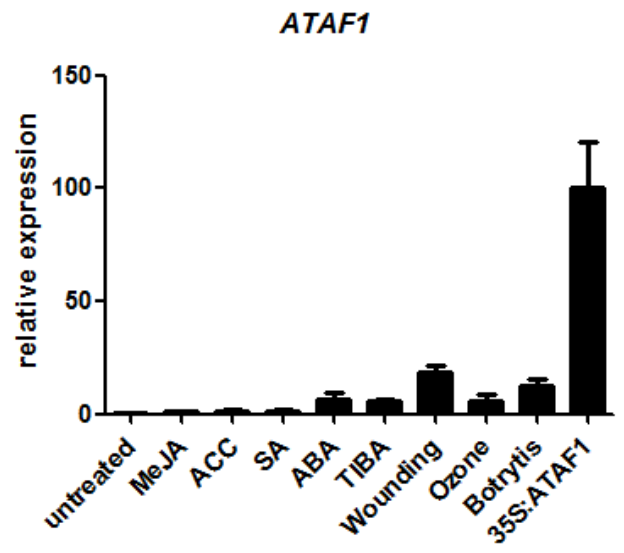

D

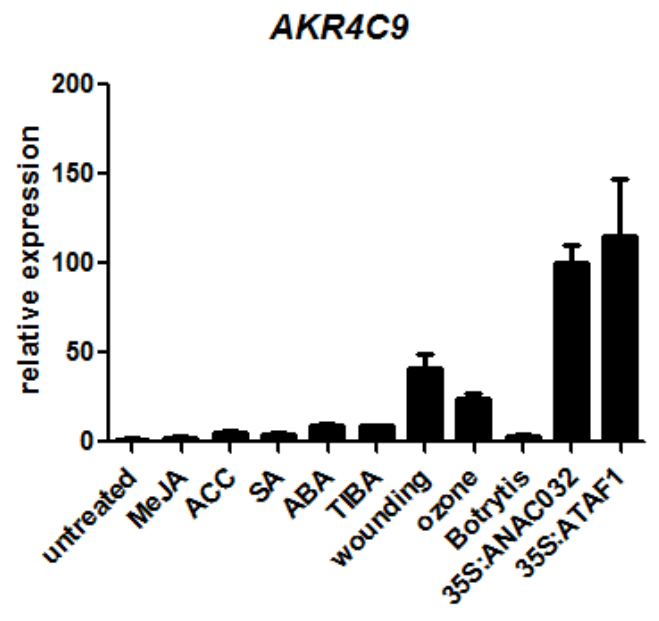




\section{bHLH585}
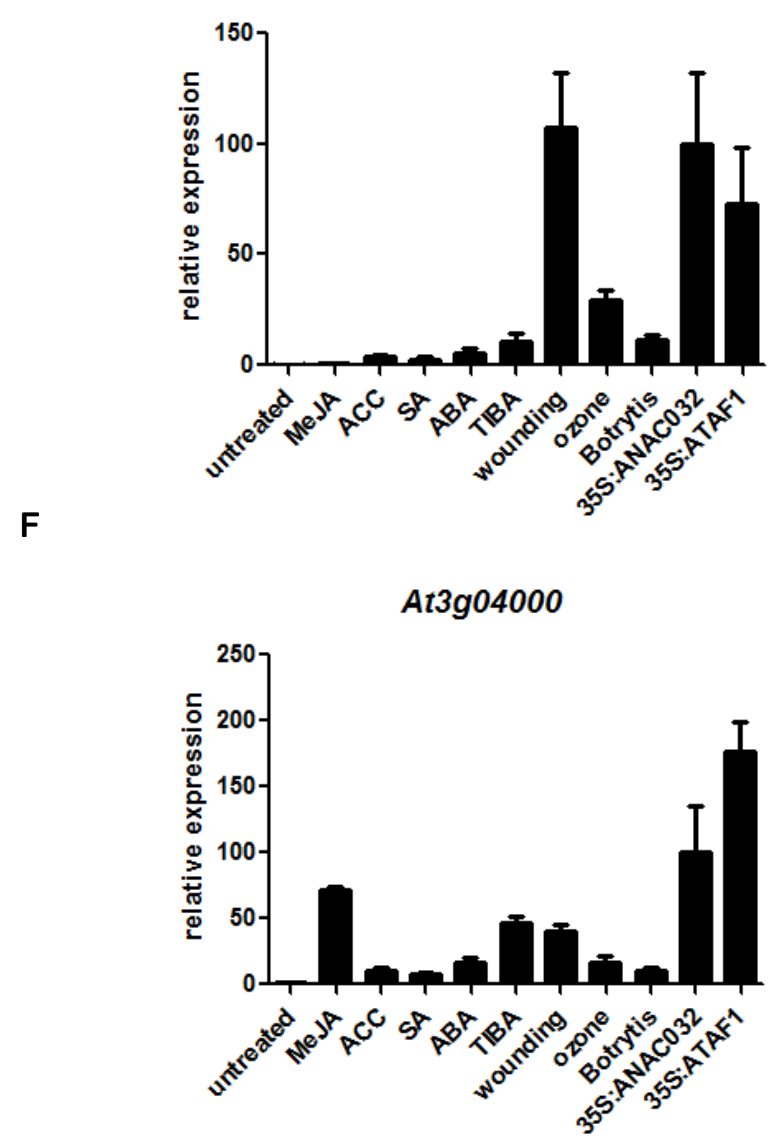

Figure 4.7: $A N A C O 32$ and $A T A F 1$ and their target genes can be significantly induced under various stress conditions

A: Comparison of the transcript profiles of $A$.thaliana NAC TFs belonging to NAC-a-9 motif clade (ATAF proteins; within the yellow box) and other closely-related members of NAC-a sub-family (motif clades indicated above) in response to various stimuli. Data were extracted from Genevestigator microarray database (Hruz et al., 2008).

B-F: Four-week old soil-grown Col-O plants were used for different treatments. MeJA application was achieved via gaseous phase treatment of plants for 8hours. Plants were treated with $1 \mathrm{mM}$ ACC or $1 \mathrm{mM} \mathrm{SA}$ for 24 hours and with $0.1 \mathrm{mM}$ ABA or $0.1 \mathrm{mM}$ TIBA for 8 hours by spraying the chemicals on the leaf surface. Plants were treated with $0.3 p p m$ ozone for 6 hours. Wounding was achieved by use of forceps and samples were harvested 90 min later. Infection by Botrytis cinerea was performed by spot inoculating $6 \mu \mathrm{l}$ of 50,000 spores $/ \mathrm{ml}$ culture onto the leaf surface and infected leaves were harvested 3dpi. Untreated plants served as control. The relative transcript levels (normalized to house-keeping gene UBQ5) of ANAC032 (B), ATAF1 (C), AKR4C9 (D), bHLH585 (E) or At3g04000 (F) in untreated and treated wild-type plants is compared to untreated 35S:ANACO32 (B, D, E and F) or untreated 35S:ATAF1 (C) plants which is set to 100. 
The target genes identified after TIBA application were also analyzed for their expression under these different conditions. As shown in Figure 4.7 C and D, $A K R 4 C 9$ and $b H L H 585$ followed a pattern very similar to $A N A C 032$. Both genes were induced slightly after ABA and TIBA application ( 10-fold induction), moderately high after ozone treatment ( 25 -fold induction) and showed maximum induction after wounding ( $\sim 50$-fold for $A K R 4 C 9$ and $\sim 100$-fold for $b H L H 585$ ). Unlike $A K R 4 C 9$, the $b H L H 585$ was also significantly induced after Botrytis infection ( 12-fold). The third gene, At3g04000, showed a slightly different pattern (Figure $4.7 \mathrm{E}$ ) in that it was induced after all treatments and showed maximum induction after MeJA ( 60-fold induction) while its induction after wounding was little bit lower ( 40-fold) in the same range as after induction with TIBA. It was also induced after ABA and ozone treatment ( $\sim 15$ fold) and also slightly after ACC, SA and Botrytis infection ( 8-fold). These expression profiles suggest that these genes are not specific to the detoxification triggered by a xenobiotic compound like TIBA. Instead they may be general stress-responsive enzymes (AKR4C9 and At3g04000) or transcription factors ( $b H L H 585)$ that are triggered under different conditions by the NAC proteins for detoxification of stress-induced toxic compounds/metabolites.

The induction of ANACO32 after TIBA requires class-II TGA factors and SCL14 (Figure $4.1 \mathrm{~B}$ ). Similarly, its induction and also the induction of the three target genes, requires the TGA and SCL14 factors after wounding (Figure 4.8 A and B). However, not all three genes showed compromised induction in wounded ataf1anac032 plants (Figure $4.8 \mathrm{C}$ ) The AKR4C9 had significantly lower expression in wounded knockout plants. Expression of At3g04000 after wounding was less significantly affected while $b H L H 585$ expression was unaffected in the double knockout. This could again be an indication that TGA/SCL14 triggers expression of other ATAF TFs which contribute to the expression of these target genes. Indeed as shown in Figure $4.8 \mathrm{D}$, ANAC102 and ATAF2 are both significantly induced upon wounding. 
A
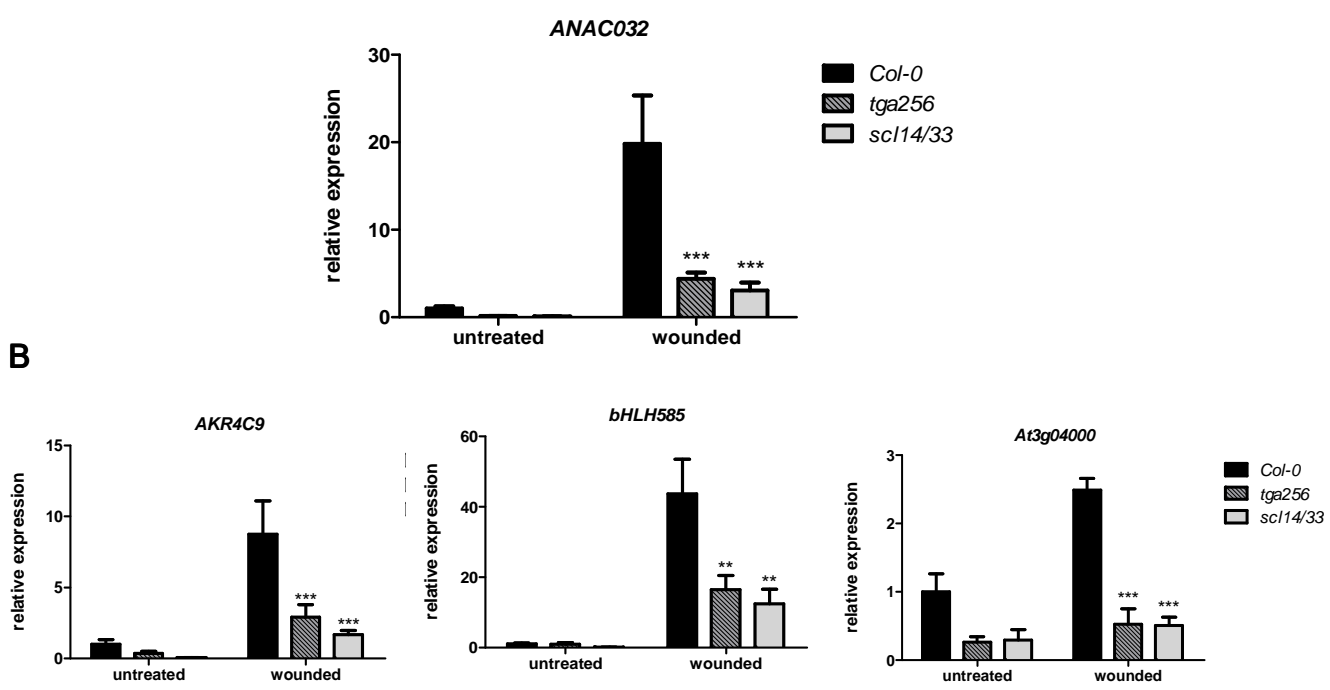

C
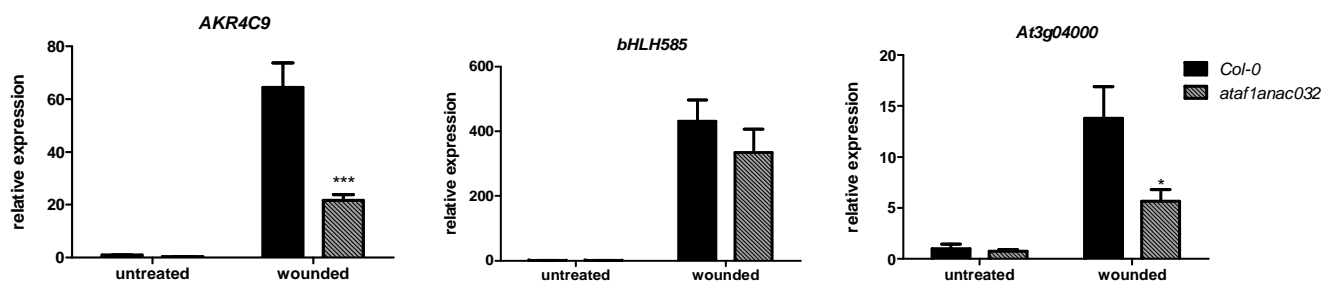

D
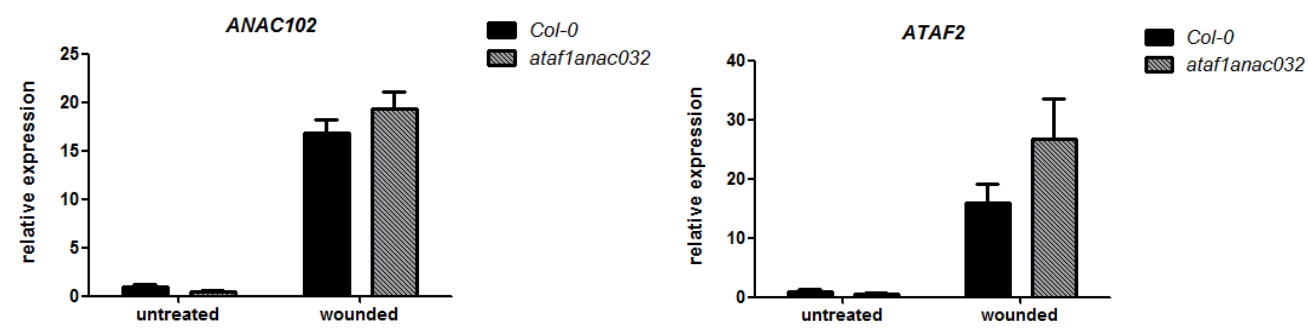

Figure 4.8: Wound-induced $A N A C O 32$ and its target genes also require TGA and SCL14 factors

Four-week old soil-grown (long day) plants were wounded using a forceps and material was harvested 90 minutes later. Untreated plants served as control. The relative transcript levels (normalized to house-keeping gene UBQ5) of (A) ANAC032 or (B and C) AKR4C9, bHLH585 and $A t 3 g 04000$ or (D) $A N A C 102$ and ATAF2 was determined by qRT-PCR. The average relative expression value in untreated Col-O plants was set to 1 . The mean values ( $\pm \mathrm{SE}$ ) from 5-6 individual plants are shown. Asterisks indicate significant differences compared with wildtype (Two-way ANOVA; $\left.{ }^{* * *} \mathrm{P}<0.001 ;{ }^{* *} \mathrm{P}<0.01\right)$ 


\subsection{ANAC032 plays a JA-independent role in wound response}

To understand further the probable role of $A N A C 032$ in the wound response, plants over-expressing ANACO32 and knockout mutant plants were wounded and gene expression of the well-known wound-responsive gene $V S P 2$ was analyzed (Figure 4.9). Both 35S:ANACO32 and 35S:ATAF1 showed compromised induction of VSP2 after mechanical wounding indicating a negative role of these NAC TFs. No difference was observed between Col-O and ataf1anac032 (Figure 4.9).

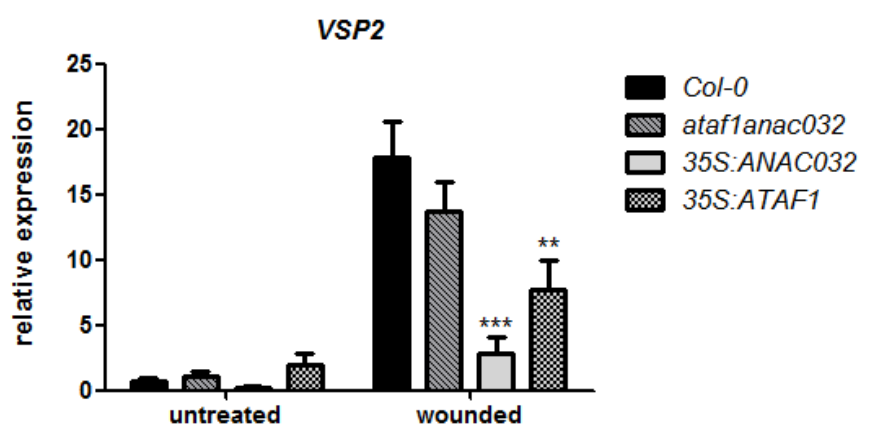

Figure 4.9: $A N A C 032$ and $A T A F 1-o v e r e x p r e s s i o n$ suppresses $V S P 2$ induction after wounding

Four-week old soil-grown (long day) plants were wounded using a forceps and material was harvested 90 minutes later. Untreated plants served as control. The relative transcript levels (normalized to house-keeping gene UBQ5) of VSP2 was determined by qRT-PCR. The average relative expression value in untreated Col-O plants was set to 1 . The mean values $( \pm$ SE) from three individual experiments, each conducted with 5-6 individual plants are shown. Asterisks indicate significant differences compared with wild-type (Two-way ANOVA; ${ }^{* * *} \mathrm{P}<$ $\left.0.001 ;{ }^{* *} \mathrm{P}<0.01\right)$

VSP2 expression in Arabidopsis is a jasmonic acid (JA)-mediated response (Berger et al., 1996; Staswick et al., 1992). In order to elucidate whether the induction of ANAC032 after wounding was also JA-mediated, wounding experiments were carried out with the JA-biosynthesis mutant dde2-2 (knockout mutation in ALLENE OXIDE 
SYNTHASE (AOS), (Park et al., 2002a)) and JA-receptor mutant coi1-t (T-DNA insertion within CO/1 locus, (Mosblech et al., 2011)). As shown in Figure 4.10, wounding highly induced $A N A C O 32$ in wild-type, but it was also induced in both knockout mutants suggesting that JA is not involved in wound-induced ANACO32 expression.

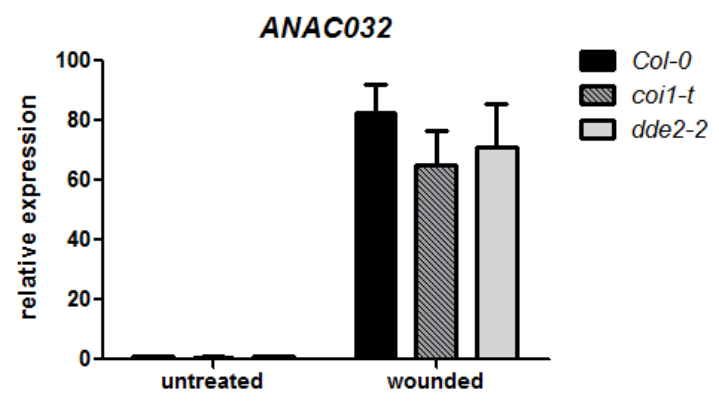

Figure 4.10: Wound-induced ANACO32 expression is JA-independent

Four-week old soil-grown (12h light/12h dark photoperiod) plants were wounded using a forceps and material was harvested 90 minutes later. Untreated plants served as control. The relative transcript levels (normalized to house-keeping gene UBQ5) of ANAC032 was determined by qRT-PCR. The average relative expression value in untreated $\mathrm{Col}-O$ plants was set to 1 . The mean values $( \pm S E)$ from two experiments each with six individual plants are shown. Analysis by Two-way ANOVA suggests no significant differences between the genotypes.

In contrast to the JA-dependent wound response, which leads to systemic induction of gene expression, the JA-independent response which can be induced by oligogalacturonides, was shown to be restricted to the local wound site ((Rojo et al., 1999); See section 1.3). Therefore, local wounded leaves and systemic unwounded leaves were harvested separately and analyzed for ANAC032 gene expression. Indeed, as shown in Figure 4.11 A, ANACO32 was induced only in local tissues after wounding. Furthermore, the induction seemed to be transient, the expression peaked within 90 min and then gradually decreased with induction reducing to less than half within 6 hours (Figure $4.11 \mathrm{~B}$ ). Other than mechanical wounding, a common source 
of injury is herbivory. Although there are common genes induced by both challenges, there are also genes induced specifically for either of the stresses (Reymond et al., 2000). Moreover, herbivory provides a situation where continuous wounding occurs due to feeding by larvae and this might lead to a prolonged expression of $A N A C 032$, thus closely resembling the state in 35S:ANAC032 plants. To assess the behavior of ANAC032 under such a situation, wild-type and ataf1anac032 mutant plants were challenged with the specialist herbivore Plutella xylostella and the feeding pattern was observed for two days until when the larvae had fed on approximately half the plant tissue. The remaining tissue was harvested and analyzed for gene expression. Firstly, as shown in Figure $4.11 \mathrm{C}$, the specialist performed equally well on both genotypes as indicated by their body weight. Secondly, ANACO32 was also induced upon insect challenge (Figure 4.11 D) although to a low degree ( 10 fold) as compared to its induction after mechanical wounding (which can reach up to 60-80 folds). 
A

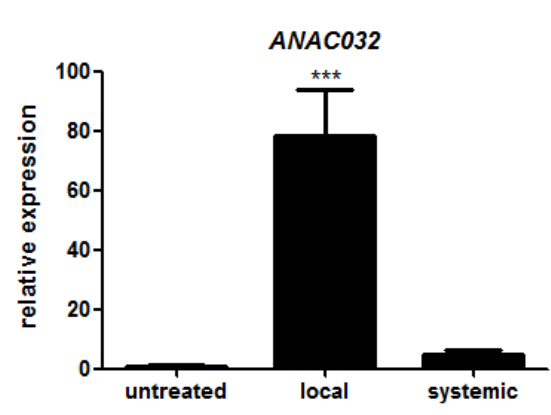

C

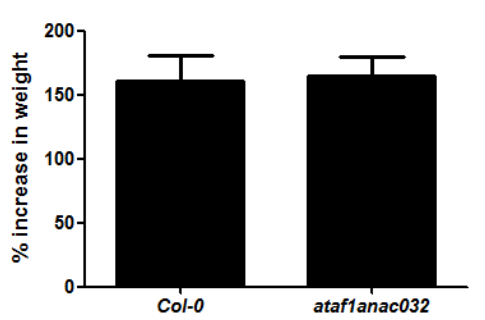

B

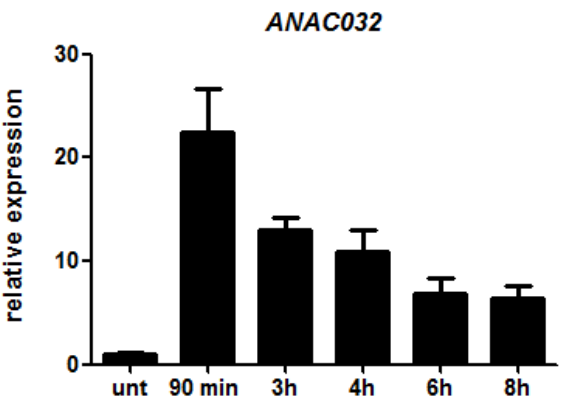

D

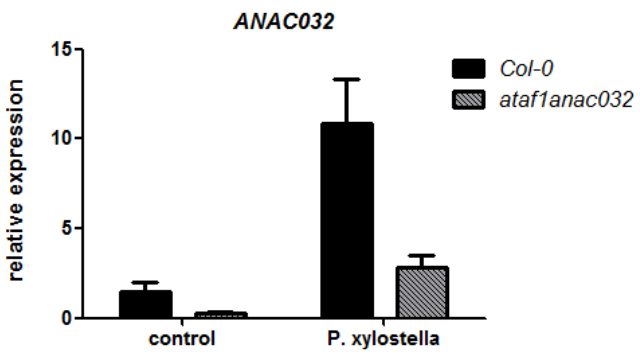

Figure 4.11: $A N A C 032$ is locally and transiently induced upon wounding of tissue

A and B: Three week old soil-grown (long day) Col-O plants were wounded using a forceps such that almost the entire leaf area was injured. Local wounded leaves and systemic unwounded leaves from wounded plants were harvested separately after $90 \mathrm{~min}(\mathrm{~A})$ or local wounded leaves after time points $90 \mathrm{~min}, 3 \mathrm{~h}, 4 \mathrm{~h}, 6 \mathrm{~h}$ and $8 \mathrm{~h}$ were collected (B). Untreated plants served as control. The relative transcript levels (normalized to house-keeping gene UBQ5) of $A N A C 032$ was determined by qRT-PCR. The average relative expression value in untreated $\mathrm{Col}-\mathrm{O}$ plants was set to 1 . The mean values $( \pm \mathrm{SE})$ from two experiments each with 5 or more individual plants are shown. Asterisks indicate significant differences compared with wild-type (Two-way ANOVA; ${ }^{* *} \mathrm{P}<0.001 ;{ }^{* *} \mathrm{P}<0.01$ ).

C and D: First instar of specialist herbivore Plutella xylostella were placed on three week old (long-day) $\mathrm{Col}-\mathrm{O}$ and ataf1anac032 plants and half-eaten leaves were harvested 2 days later. Untreated plants served as control. The larvae weight gain (shown in percentage) was measured two days after feeding (C). The relative transcript levels (normalized to housekeeping gene UBQ5) of ANACO32 was determined by qRT-PCR. The average relative expression value in untreated Col-O plants was set to 1 (D). The mean values $( \pm S E)$ are from ten individual plants or insects. 


\subsection{Over-expression of ANACO32 suppresses JA-, ET- and SA- induced gene expression}

Wound-induced VSP2 expression was reduced in plants ectopically expressing the NAC TFs. To find out, whether this is due to interference with the JA signaling pathway, the effect of the TFs on VSP2 expression was studied after external application of MeJA. As observed after wounding, the induction was suppressed in the 35S:ANAC032 plants (Figure 4.12 A). Since JA in the presence of ET leads to induction of defense genes like PDF1.2, the effect of the NAC TFs on this branch of the JA signaling network was examined by treating plants with $\mathrm{ACC}$, the precursor of ET. PDF1.2 induction was also suppressed in the 35S:ANAC032 plants while no difference could be observed between wild-type and ataf1anac032 knockout plants (Figure $4.12 \mathrm{C}$ ). In both kinds of treatment the 35S:ATAF1 plants behaved like the 35S:ANAC032 plants. Further, it was observed that the suppression took place at the level of transcription of $M Y C 2$ and ORA59, which are upstream regulatory factors in JA and JA/ET pathways respectively (Figure 4.12 B and D). 
A

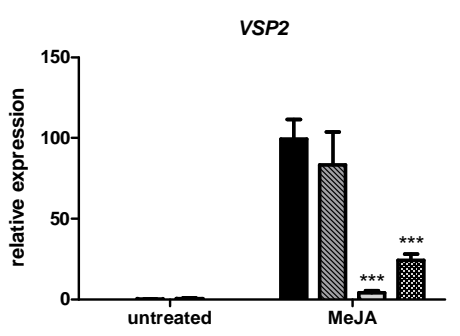

C

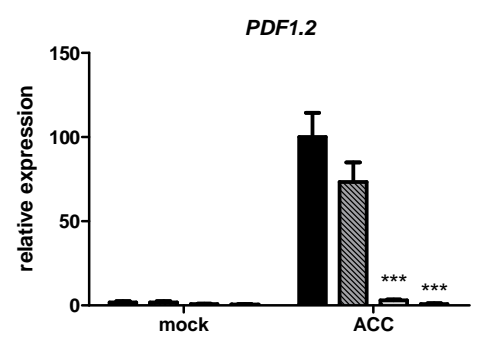

B

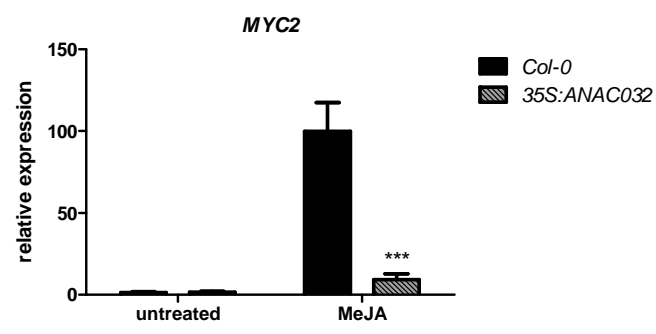

D

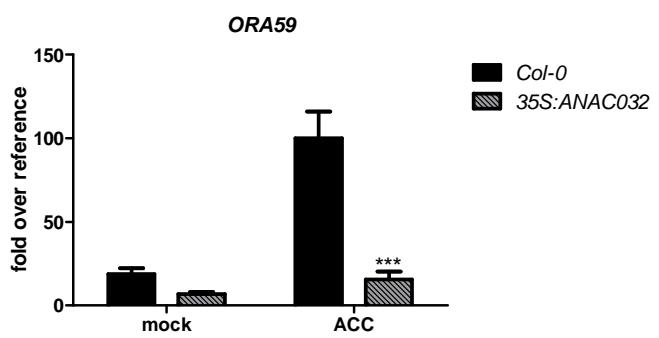

Figure 4.12: Over-expression of $A N A C O 32$ suppresses induction of JA and JA/ET-responsive genes

Four week old soil-grown (long day) plants were treated with $4.5 \mu \mathrm{M}$ MeJA via the gaseous phase for 8 hours (A) or with $1 \mathrm{mM} \mathrm{ACC}$ for 24 hours (B). Untreated (A) or water treated (B) plants served as controls. The relative transcript levels (normalized to house-keeping gene UBQ5) of VSP2 (A), MYC2 (B), PDF1.2(C) or ORA59 (D) was determined by qRT-PCR. The average relative expression value in treated Col-O plants was set to 100 . The mean values $( \pm$ $\mathrm{SE})$ from three experiments each with 5 or more individual plants are shown. Asterisks indicate significant differences compared with wild-type (Two-way ANOVA; ${ }^{* * *} \mathrm{P}<0.001$ ).

Salicylic acid (SA) is known to suppress the JA/ET pathway and this cross-talk depends on class-II TGA TFs (Ndamukong et al., 2007; Zander et al., 2012). Since SA can induce the NAC TFs in a class-II TGA-dependent manner ( 2 -fold, after $24 \mathrm{~h}$ treatment), we speculated that part of this cross-talk is mediated by $A N A C 032$, To address this, cross-talk experiments were carried out where Col-0, ataf1anac032 and 35S:ANAC032 plants were treated either with ACC alone or with both ACC and SA 
simultaneously. Twenty-four hours after treatment with ACC, both $\mathrm{Col}-\mathrm{O}$ and ataf1anac032 showed similar levels of induction of PDF1.2 and as observed before the 35S:ANAC032 plants strongly suppressed this induction. After additional SA treatment the Col-O plants showed reduced PDF1.2 induction due to antagonistic effect of the SA pathway. This suppression was however also observed in the ataf1anac032 plants suggesting that NAC proteins might not play a role in the crosstalk (Figure 4.13 A). Still, the potential redundancy with the other two NACs and with maybe NAC-independent mechanisms has to be considered.

Interestingly, when $P R 1$ induction was analyzed to control for the efficiency of the SA treatment, PR1 was also found to be suppressed in the 35S:ANAC032 plants treated with SA and ACC. This was then confirmed by a second experiment where plants were treated with SA alone and PR1 expression was compromised in 35S:ANAC032 as well as in 35S:ATAF1 plants (Figure $4.13 \mathrm{~B}$ ). The ABA hormone pathway is also known to have antagonistic effects on the defense pathways leading to PR1 (SApathway) and PDF1.2 (JA/ET pathway) suppression. Thus, a cross-talk experiment was also carried out where the plants were simultaneously treated with the hormones $\mathrm{ABA}$ and $\mathrm{ACC}$ (Fig $4.13 \mathrm{C}$ ). Here again ataf1anac032 knockout mutant behaved like the wild-type and showed suppression of the PDF1.2 gene when both hormones were applied together suggesting that $A N A C 032$ is not required for the ABAmediated cross-talk. Additionally, the ABA-responsive gene COR78 was suppressed by over-expression of $A N A C 032$ (Figure 4.13 D). 
A

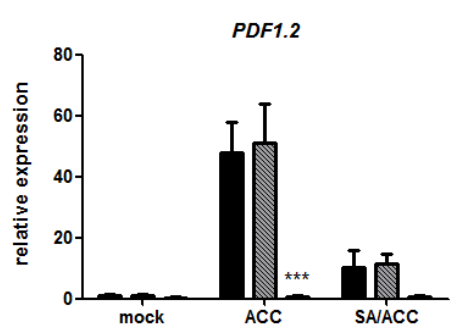

C

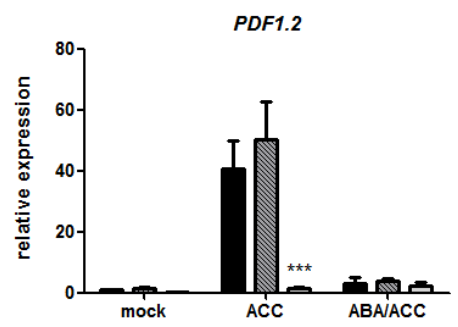

B
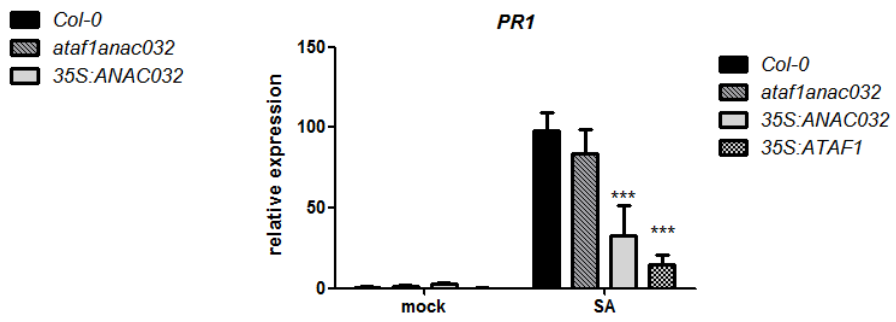

D

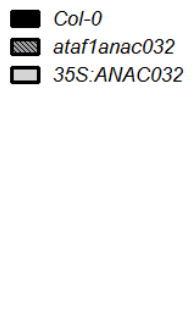

Figure 4.13: ANACO32 may not play a role in different hormonal cross-talks

A and B: Four week old soil-grown (long day) plants were treated either with $1 \mathrm{mM} \mathrm{ACC}, 1 \mathrm{mM}$ SA or simultaneously with both hormones for 24 hours. Water treated plants served as controls. The relative transcript levels (normalized to house-keeping gene UBQ5) of PDF1.2 (A) or PR1 (B) was determined by qRT-PCR. The average relative expression value in control Col-O plants was set to 1 . The mean values $( \pm S E)$ from 5 or more individual plants are shown. Asterisks indicate significant differences compared with wild-type (Two-way ANOVA; ${ }^{* * *} \mathrm{P}<$ $0.001)$.

C and D: Four week old soil-grown (long day) plants were treated either with $1 \mathrm{mM} \mathrm{ACC}$, $100 \mu \mathrm{M}$ ABA or simultaneously with both hormones for 24 hours. Water treated plants served as controls. The relative transcript levels (normalized to house-keeping gene UBQ5) of PDF1.2 (A) or COR78 (B) was determined by QRT-PCR. The average relative expression value in control Col-O plants was set to 1 . The mean values $( \pm \mathrm{SE})$ from 5 or more individual plants are shown. Asterisks indicate significant differences compared with wild-type (Two-way ANOVA; $\left.{ }^{* * *} \mathrm{P}<0.001\right)$. 
It was observed previously that in protoplasts, the expression of $P D F 1.2$ and $V S P 2$ is strongly suppressed (Thesis by Julia Köster). Genevestigator data suggested that ANACO32 and ATAF1 gene expression is highly induced in response to protoplasting which could indeed be reproduced (Figure 4.14 A). Therefore it was speculated that this high induction of the NAC proteins during protoplast isolation might be mirroring the state in the over-expressing plants leading to the suppressed expression of the defense genes in protoplasts. However as shown in Figure $4.14 \mathrm{~B}$, protoplasts prepared from wild-type and ataf1anac032 plants showed similar levels of suppression of both genes.

A

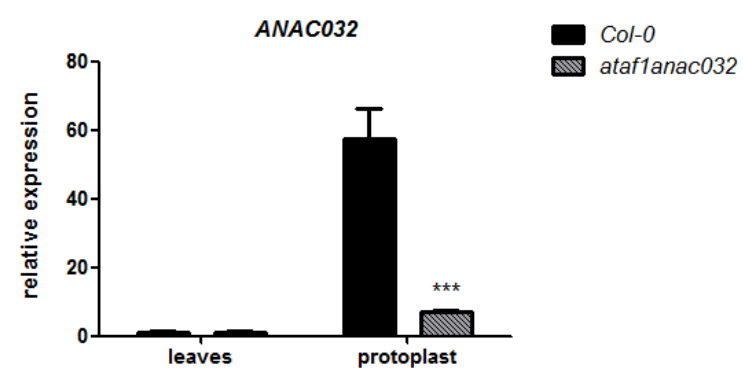

B
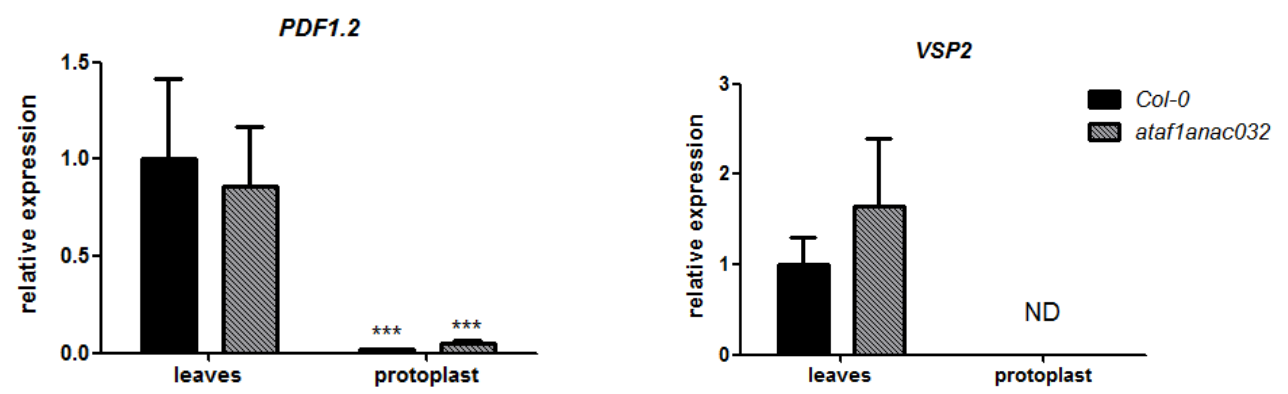

Figure 4.14: $A N A C O 32$ does not contribute to suppression of PDF1.2 and VSP2 in protoplasts

Four week old plants were used to isolate protoplasts and as control leaves were also harvested. The relative transcript levels (normalized to house-keeping gene UBQ5) of ANAC032 (A) or PDF1.2 and VSP2 (B) was determined by qRT-PCR. The average relative expression value in leaves of $\mathrm{Col}-\mathrm{O}$ plants was set to 1 . The mean values $( \pm \mathrm{SE})$ from five individual plants are shown. Asterisks indicate significant differences compared with wild-type (Two-way ANOVA; $\left.{ }^{* * *} \mathrm{P}<0.001\right)$. ND = not determined 
As a first step towards understanding the mode of suppression of various signal cascades by NAC TFs, yeast two-hybrid studies were carried out. We tested whether ATAF subfamily proteins could interact with some known key players of the different pathways like EIN3 and TGA factors 2 and 5, which are important for the induction of PDF1.2 upon ET treatment. Moreover, the potential interaction between NACs and GRX480, a negative regulator of the JA/ET pathway, was tested. However the NAC proteins did not interact with any of them (data not shown). All these results propose that overexpression of ANAC032 suppresses JA-, JA/ET- , SA- and ABAinduced gene expression via a yet-unknown mechanism.

\subsection{Over-expression of $A N A C 032$ most likely affects signaling and not biosynthesis of phytohormones}

The suppression of hormone-responsive genes could be either due to defective hormone accumulation or altered signaling. Given that the NACs induce the detoxification program, it might be assumed that the applied hormones are inactivated. Therefore, basal and induced levels of different hormones and their related metabolites were measured in plants with elevated or reduced expression levels of ANAC032 and ATAF1. For this purpose we chose to treat the plants with ozone since this treatment can at the same time trigger the accumulation of all three defense phytohormones ET, JA and SA (Kangasjärvi et al., 1994; Rao et al., 2000, 2002). The outcome of two independent experiments is documented in Figure 4.15 and 4.16. First, SA levels were increased after ozone treatment to the same degree in Col-O and the ataf1anac032 mutant. Basal SA levels were slightly elevated in 35S:ANAC032 and 35S:ATAF1 plants. In contrast, ozone-induced SA levels were lower than in the wild-type in the first experiment but not in the second (Figure 4.15 A and B respectively). Similar to tobacco, SA in Arabidopsis is thought to be stored in the vacuole as SAG (Dean et al., 2005; Dempsey et al., 2011). There was slight or no increase in the SAG levels upon ozone treatment in Col-O and ataf1anac032 plants. In contrast, SAG levels were high in 35S:ANAC032 plants from beginning on in both experiments and in 35S:ATAF1 plants in one of the experiments (Figure 4.15 
C and D). This correlates well with increased expression of UGT74F2/SAGT1 in 35S:ANAC032 plants as indicated by the microarray ( 19-fold induction).

A

SA

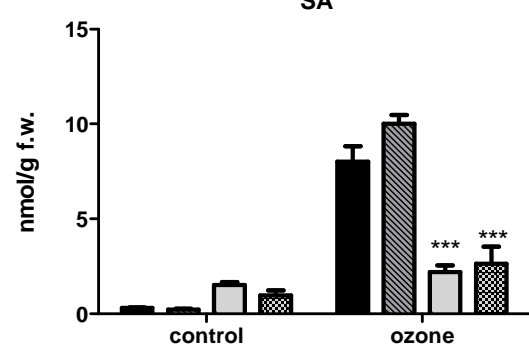

C

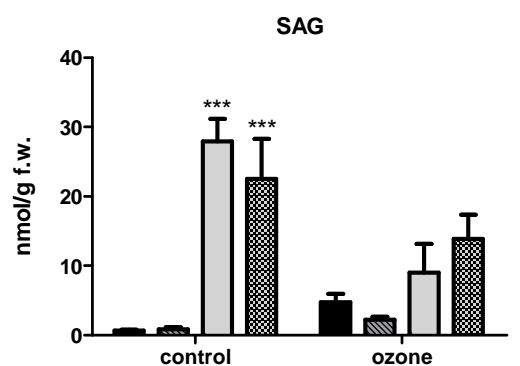

B

D
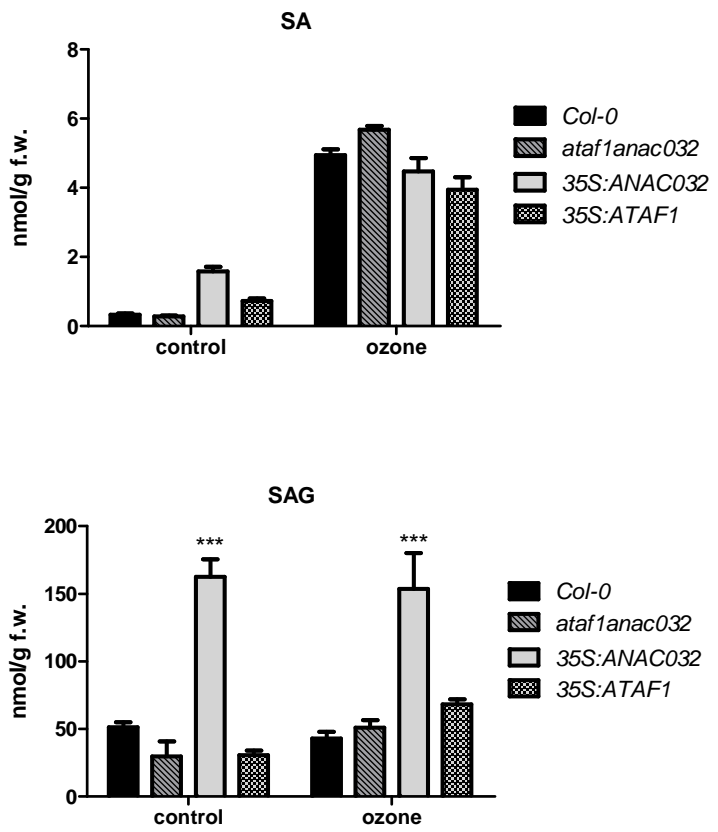

Figure 4.15: Accumulation of SA is not suppressed in 35S:ANACO32

Four week old (long day) plants were treated with $0.3 p p m$ ozone for 6 hours. Untreated plants served as control. The total SA ( $A$ and $B$ ) and SAG (C and D) contents were measured by HPLC MS/MS technique. The graphs $A$ and $C$ belong to the first experiment while $B$ and $D$ belong to the second experiment. The first experiment consisted of four individual plants for Col-O and ataf1anac032 and four pools, each of four individual plants, for the over-expressing plants as biological replicates. The second experiment consisted of four pools of four individual plants for all genotypes as biological replicates. The mean values $( \pm S E$ ) of the replicates are shown. Asterisks indicate significant differences compared with wild-type (Twoway ANOVA; $\left.{ }^{* *} \mathrm{P}<0.001\right)$.

JA levels were increased in all genotypes after ozone treatment and levels were again comparable between wild-type and ataf1anac032 mutant plants. However, 35S:ANAC032 (but not 35S:ATAF1) accumulated more JA after ozone treatment and in one of the experiments the basal levels were also much higher (Figure 4.16 $\mathrm{A}$ and B). The amount of the JA-precursor 12-Oxo-Phytodienoic Acid (OPDA) did not 
significantly differ between genotypes and showed no increase after treatment in both experiments (figure 4.16 C and D). Thus, increased JA levels should be due to the increased activity of enzymes that convert OPDA to JA to JA-lle. The microarray data indicates that $A C X 1$ (ACYL-COA OXIDASE 1 ) is induced ( 2.5-fold) in the 35S:ANAC032 plants. This enzyme catalyzes the first $\beta$-oxidation step in the synthesis of JA from OPDA (Schilmiller et al., 2007) and thus may account for the observed increased levels of JA. The amino acid derivative JA-isoleucine (JA-lleu) and degradation product hydroxyjasmonate $(11,12-\mathrm{OH}-\mathrm{JA})$ show a similar behavior like JA with increased amounts observed in 35S:ANAC032 plants (Figure 4.16 E, F and $\mathrm{G}, \mathrm{H}$ respectively). Therefore, it seems unlikely that the decreased transcript levels of VSP2 and PDF1.2 are due to the degradation of active JA. 
A

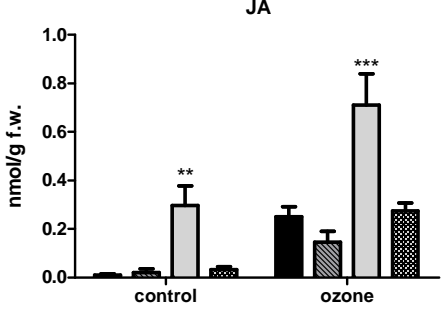

C

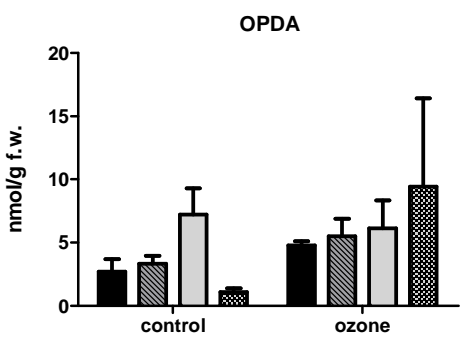

E

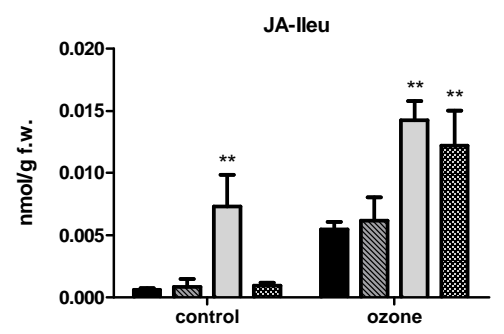

G

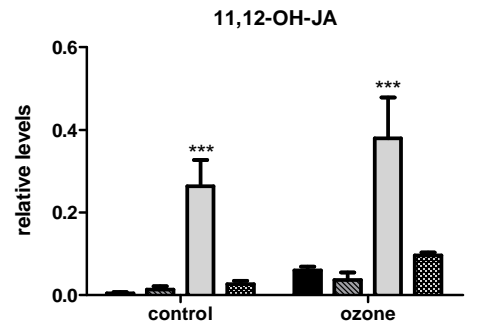

B

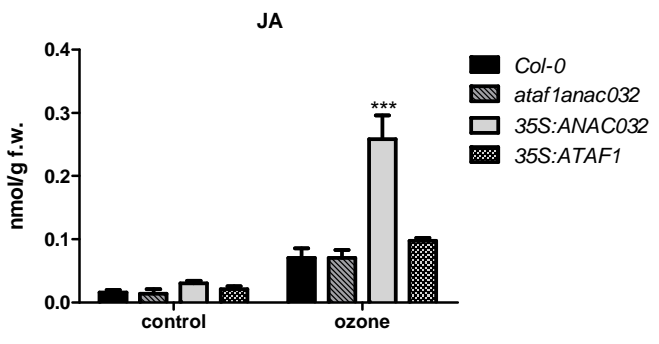

D

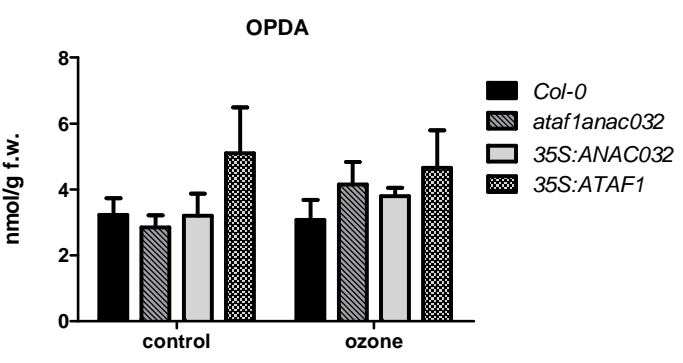

F

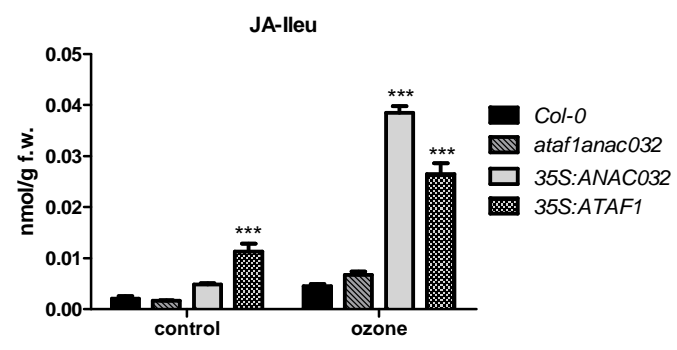

H

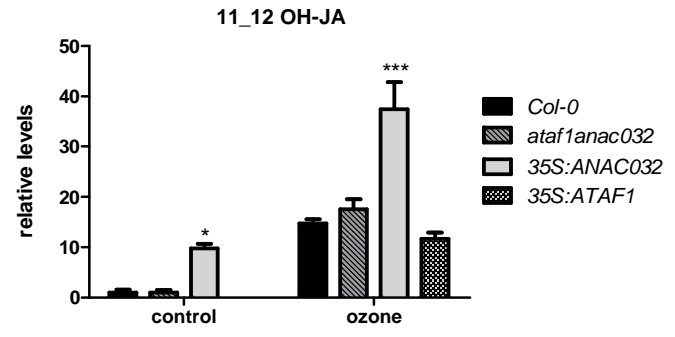

Figure 4.16: Accumulation of JA and JA-lleu is not suppressed in 35S:ANACO32

4-week old soil-grown (long day) plants were treated with $0.3 p p m$ ozone for 6 hours. Untreated plants served as control. The total JA (A, B), OPDA (C, D), JA-lleu (E, F) and 11, 12-OH-JA (G, H) contents were measured by HPLC MS/MS technique. The graphs $A, C, E$ and $G$ belong to the first experiment while $\mathrm{B}, \mathrm{D}, \mathrm{F}$ and $\mathrm{H}$ belong to the second experiment. The first experiment consisted of four individual plants for $\mathrm{Col}-\mathrm{O}$ and ataf1anac032 and four pools, each of four individual plants, for the over-expressing plants as biological replicates. The second experiment consisted of four pools of four individual plants for all genotypes as biological replicates. The mean values $( \pm S E)$ of the replicates are shown. Asterisks indicate significant differences compared with wild-type (Two-way ANOVA; ${ }^{* \star *} \mathrm{P}<0.001,{ }^{* *} \mathrm{P}<0.01$ and $\left.{ }^{*} \mathrm{P}<0.05\right)$ 


\subsection{Over-expression of $A T A F 1$ leads to increased basal levels of abscisic acid (ABA)}

As shown above, over-expression of ANAC032 led to reduced induction of the ABAresponsive COR78 gene (Figure 4.15 D). However over-expression of ANAC032 did not affect basal ABA levels. On the other hand, over-expression of ATAF1 led to increased basal levels of ABA (Figure 4.17). Moreover, although ABA levels did not drastically change after ozone treatment in wild-type and ataf1anac032, both overexpressors showed more accumulation of the hormone ( $\sim$-fold and $\sim 1.5$-fold more in 35:ATAF1 and 35S:ANAC032 plants respectively). Conversely, the single knockouts, especially ataf1, did not accumulate any ABA after ozone treatment.

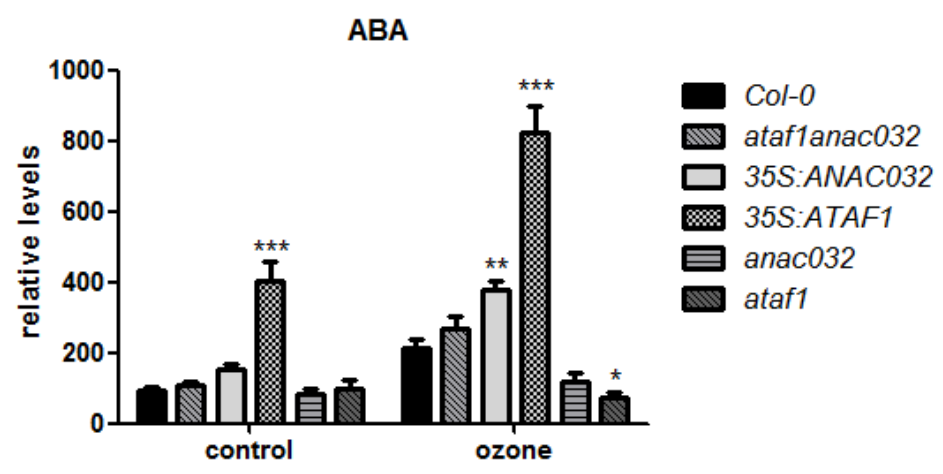

Figure 4.17: Over-expression of $A T A F 1$ leads to increased accumulation of ABA

Four week old long day grown plants were treated with $0.3 p p m$ ozone for 6 hours. Untreated plants served as control. The ABA content was measured by HPLC MS/MS technique. Values $( \pm S E)$ obtained from two independent ozone experiments are shown. The first experiment consisted of four individual plants for $\mathrm{CO}-\mathrm{O}$ and ataf1anac032 and four pools, each of four individual plants, for the over-expressing plants as replicates. The second experiment consisted of four pools of four individual plants for all genotypes as replicates. Asterisks indicate significant differences compared with wild-type (Two-way ANOVA; *** $\mathrm{P}<0.001$, ${ }^{* *} \mathrm{P}<0.01$ and ${ }^{*} \mathrm{P}<0.05$ ) (NOTE: Unlike, $\mathrm{SA}$ and JA levels shown above, the ABA levels were comparable between experiments and therefore single graph is plotted from all values obtained) 


\subsection{ANAC032 has a potential role in plant developmental processes}

The 35S:ANACO32 and 35S:ATAF1 transgenic lines presented phenotypic differences compared to wild-type (Figure 4.18). The plants were dwarf in size, with crinkled and upward curled leaves that showed early yellowing along the veins and leaf edges (Figure 4.18 A). The size of the plant seemed to correlate with the amount of transgenic gene present. Homozygous plants of 35S:ANACO32 exhibited strong dwarfism, had an extended lifetime and were sterile producing only very short inflorescences. The heterozygous plants, on the other hand, displayed a less severe phenotype and were comparable to the wild-type in terms of size but still showed the early yellowing of the leaves. These plants were fertile and produced seeds so that the seed stock was maintained as a heterozygous pool with homozygous plants being selected for various experiments based on their small size. 35S:ANAC032 showed delayed flowering as shown in Figure 4.18 B. This might be due to the high expression of the floral repressor gene FLC in 35S:ANAC032 plants as indicated by the microarray analysis and qRT-PCR (Figure 4.5). Recently it was shown that FLC also plays a role in delaying the juvenile-to-adult vegetative transition and that it affects different leaf traits associated with vegetative phase change (Willmann and Poethig, 2011). Plants over-expressing FLC were shown to contain more number of juvenile or transition leaves which are characterized by more rounder leaves (lower length:width ratio) and by less number of abaxial trichomes compared to adult leaves. Consistent to this, the 35S:ANAC032 transgenic plants also have a higher number of juvenile leaves as judged by the number of abaxial trichomes present (Figure $4.17 \mathrm{C}$ and D). Since 35S:ANAC032 plants are more juvenile it was checked whether in general juvenile leaves show reduced induction of defense genes. For this purpose, JAZ10-GusPlus reporter lines were treated with MeJA and GUS activity was quantified in juvenile and mature leaves separately. However both type of leaves showed no difference in their ability to respond to the hormone treatment (Figure 4.18 E). 
A

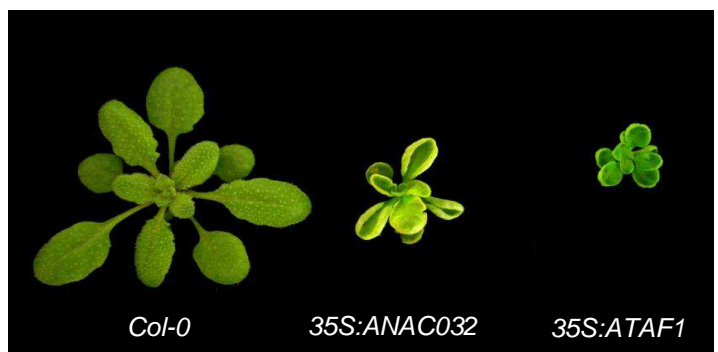

B

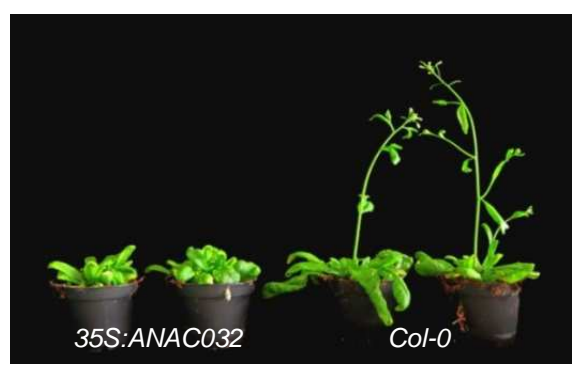

C

D
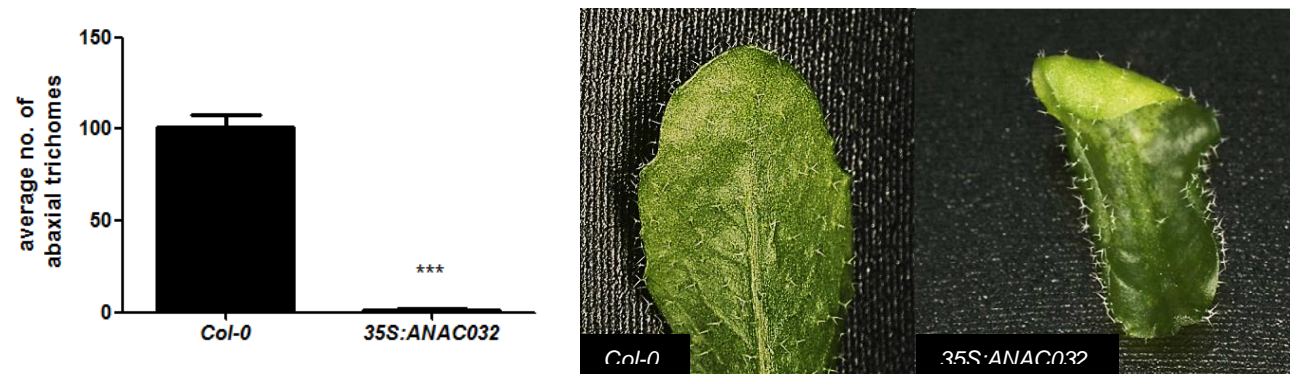

E

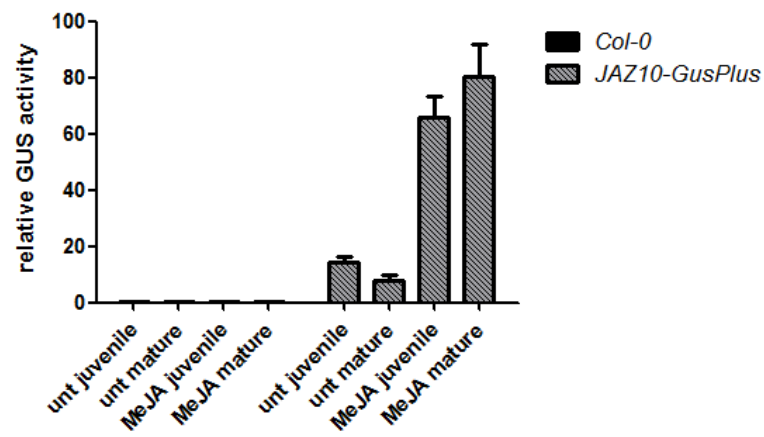

Figure 4.18: 35S:ANACO32 show altered phenotypic characteristics including increased juvenility

A. Plants were grown under long-day conditions and photographs taken 3-4 weeks later. B. 6week old plants grown under long day conditions showing Col-O (right) plants already flowering while heterozygous 35S:ANAC032 (left) plants have not yet bolted. C. Average number of abaxial trichomes counted on the $8^{\text {th }}$ to $10^{\text {th }}$ leaf positions from ten plants. $\mathbf{D}$. Representative photograph showing number of abaxial trichomes. E. Four week old long day grown plants were treated with $4.5 \mu \mathrm{M}$ MeJA via the gaseous phase for 8 hours. GUS activity was measured by MUG assay. Col-O plants and JAZ10-GusPlus untreated plants served as controls. The average relative GUS activities ( \pm SE) from four individual plants are shown. 
The transcriptomic database, Arabidopsis eFP browser [http://bar.utoronto.ca/efp/cgibin/efpWeb.cgi; (Winter et al., 2007)] indicates that ANACO32 and ATAF1 transcript levels are very high in the seed stage (Figure 4.19). Moreover, the other members of the clade $A N A C 102$ and $A T A F 2$ do not show this high expression in seed and hence may not be functionally redundant in this context, providing a good chance to observe a phenotype for the ataf1anac032 double knockout. Considering that ANACO32 is a negative regulator of hormone signaling, we speculated that ANACO32 might negatively regulate ABA-induced dormancy. Therefore, freshly harvested seeds of $\mathrm{Col}-\mathrm{O}$ and ataf1anac032 knockout mutants were placed on wet filter paper and observed for germination. Seeds that had been dried for over ten weeks (and hence fully released from dormancy) were used as controls. All seeds were first exposed to two days in the cold to partially break dormancy and then radicle emergence was scored three days later. As shown in Figure 4.20 A, C and E, there was no difference in the germination rate between completely dried $\mathrm{Col}-\mathrm{O}$ and ataf1anac032 seeds and 100\% germination was observed for both within 3 days of incubation. Contrastingly, the freshly harvested seeds germinated more slowly where Col-O showed $80 \%$ germination and ataf1anac032 showed only $18-20 \%$ germination (Figure $4.20 \mathrm{~B}, \mathrm{D}$ and $\mathrm{E}$ ). This supports our assumption that the NAC TFs are negative regulators of seed dormancy. 


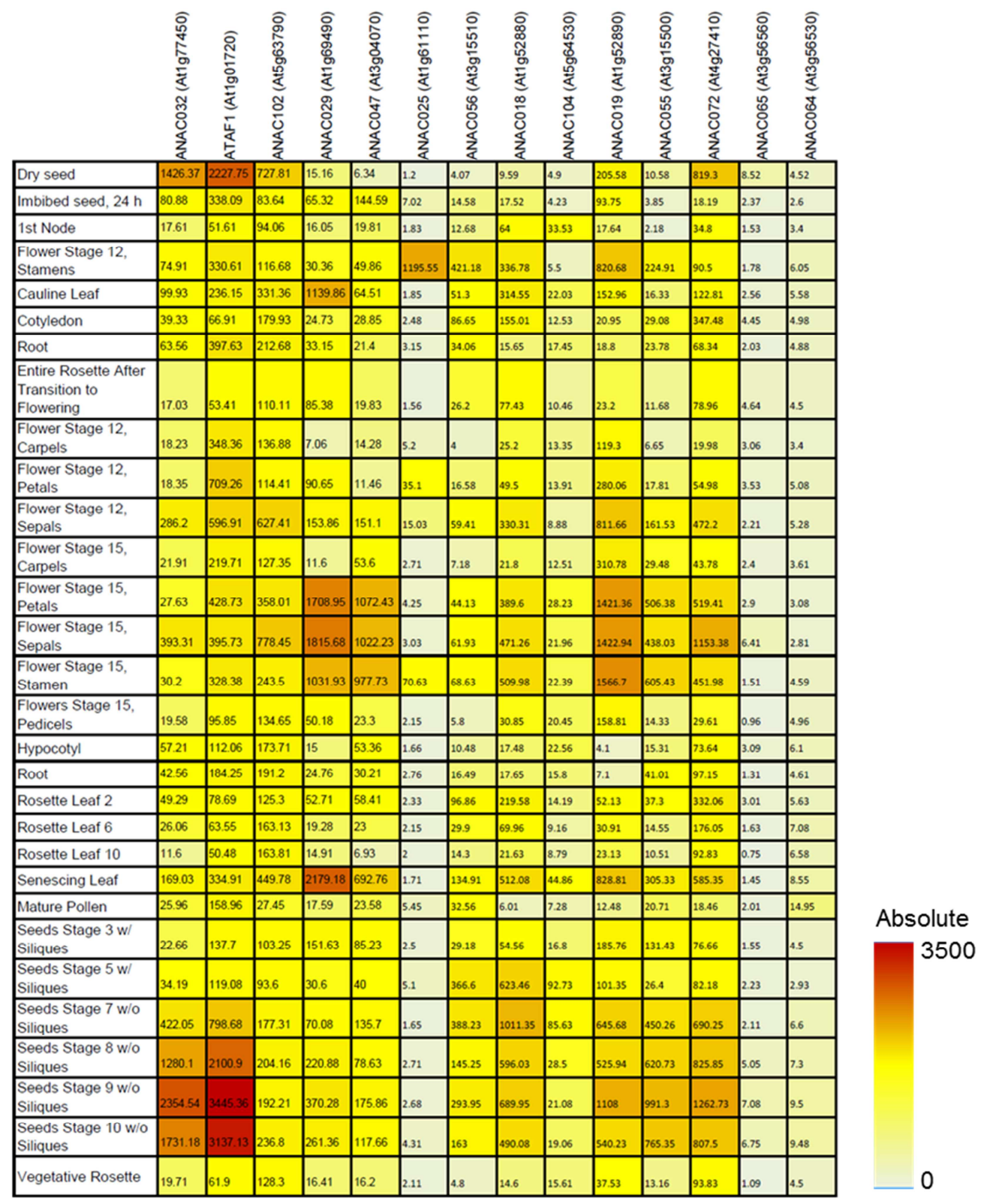

Figure 4.19: $A N A C 032$ and $A T A F 1$ show highest expression in mature seed stages

Developmental expression of the ATAF members (first three lanes) and other NAC TFs from the NAC-a sub-family are shown. The data is reported as absolute expression values (as reported by eFP Browser) such that higher values are shaded red as indicated by the gradient scale. 
A

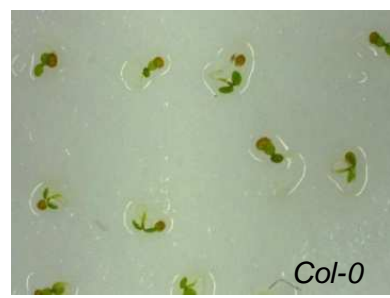

B

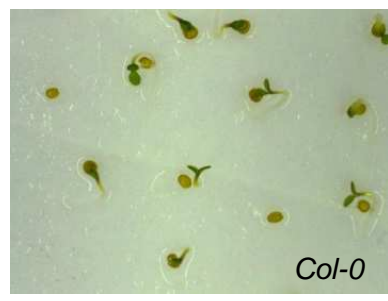

C
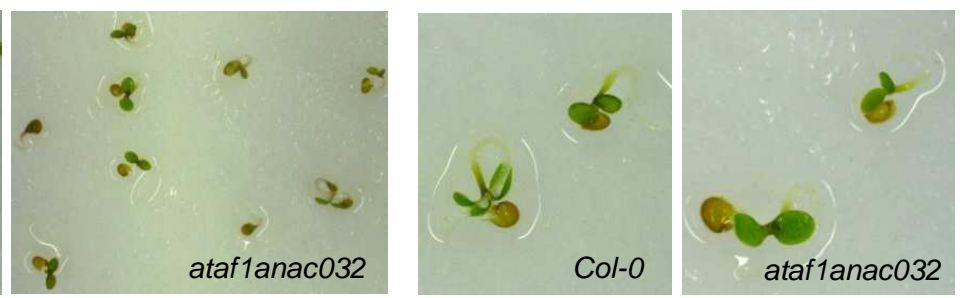

D
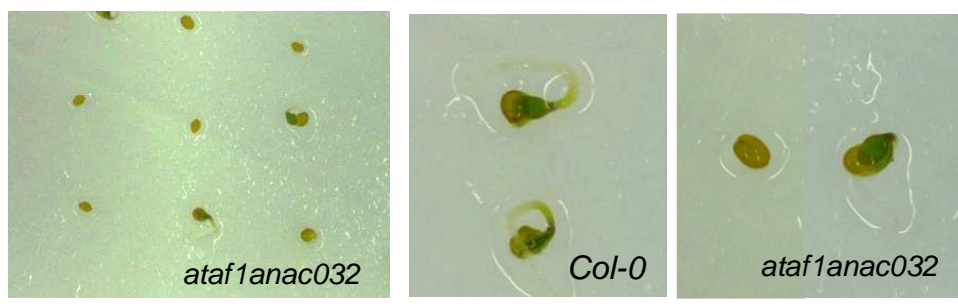

E

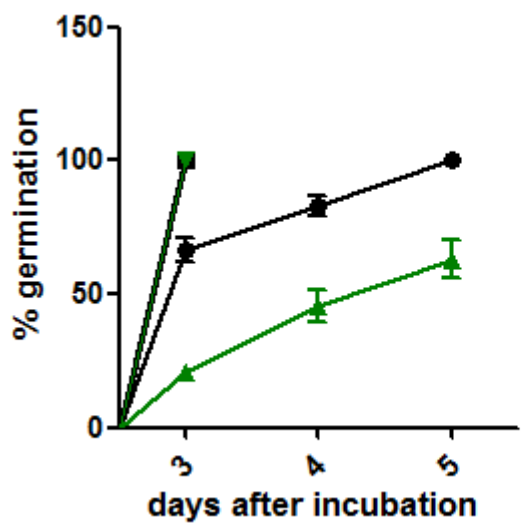

$*$ Col-0 fresh
$\rightarrow$ Col-0 dried
* ataf1anac032 fresh
$\rightarrow$ ataf1anac032 dried

days after incubation

Figure 4.20: $A N A C 032$ and $A T A F 1$ are negative regulators of dormancy

About 50 completely dried (hence fully released from dormancy) (A) and freshly harvested seeds (B) were plated onto a filter paper moistened with demineralized water in Petri dishes and incubated under long day conditions. Photographs and scoring of radicle emergence was done 3 days later. $\mathbf{C}$ and $\mathbf{D}$ are representative close-up pictures of $A$ and $B$ respectively $(E)$ Germination profiles of $\mathrm{CO}-\mathrm{O}$ and ataf1anac032 dried and freshly harvested seeds. Percentages are means $( \pm S E)$ of two experiments each with two biological repeats.

Further, it was speculated that if seeds have high ANACO32 expression they may not show induction of defense-related genes (since over-expression of ANACO32 led to suppression of defense-related genes of SA, JA and JA/ET pathways, shown above). As a first indication to see if this might be true, plants containing the JAZ10-GusPlus 
reporter construct (in the Col-O background) were grown until 10-15 days after siliques started appearing. The plants were then treated with MeJA and the siliques were subjected to the GUS staining procedure. As shown in Figure 4.21 fresh green siliques responded to MeJA by inducing expression of JAZ10-GusPlus reporter as indicated by the blue colouring. The seeds within these siliques however do not stain suggesting no induction of $J A Z 10$ occurs in the seeds. Yet, this is no direct evidence of the high levels of NAC TFs suppressing JA response in the seeds and more experiments need to be conducted to provide support to the hypothesis.
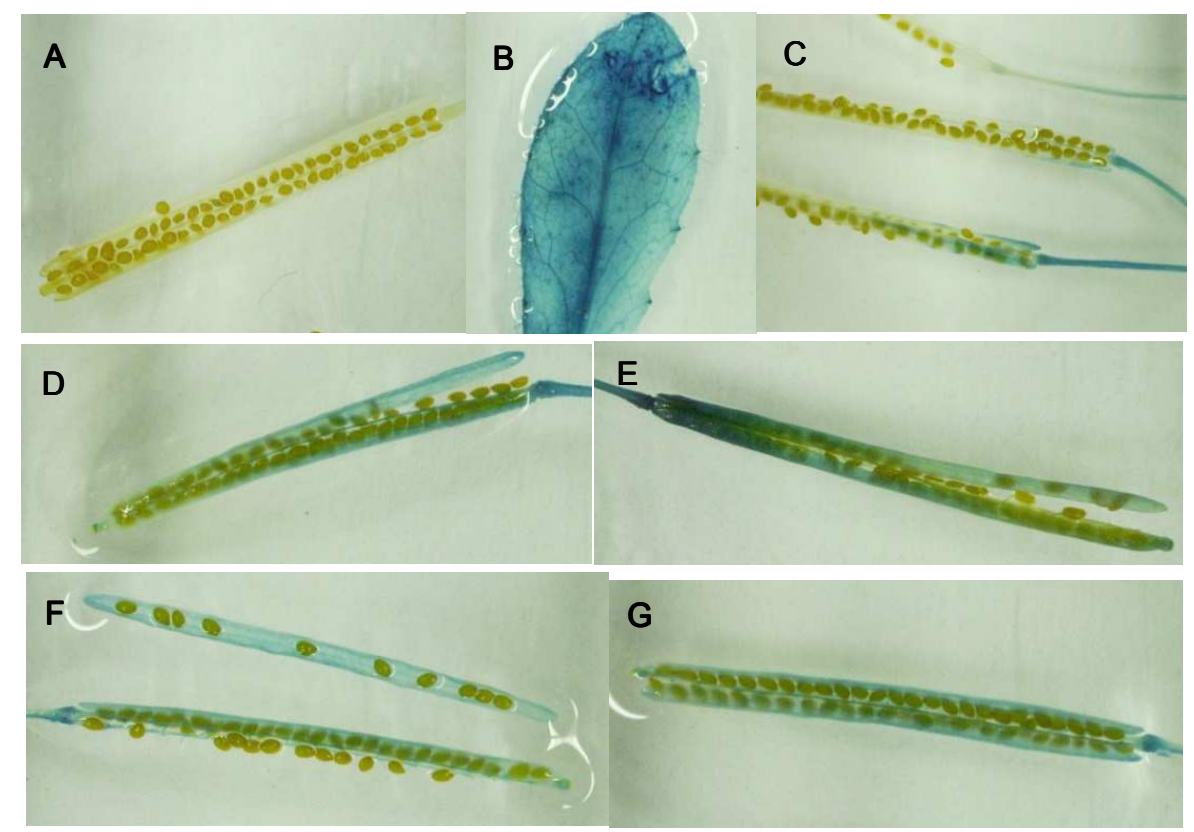

Figure 4.21: Seeds do not show JA-induced expression of JAZ10

JA-responsive JAZ10-GusPlus reporter lines were grown (long day) until 10-12 days after the first siliques were formed. The plants were then treated with $4.5 \mu \mathrm{M}$ MeJA via the gaseous phase for 6 hours, untreated plants served as controls. Siliques and leaves (control) were cut and subjected to GUS staining protocol. A untreated B JA-treated rosette leaf C siliques that had already started turning brown D, E, F and $\mathbf{G}$ green siliques cut open after staining to show unstained seeds within. Col-O plants were also included as controls and these did not show any staining (photographs not shown) 


\section{Discussion}

The NAC superfamily of proteins, consisting of more than a hundred members, is a group of plant-specific transcription factors (TFs) that are involved in many different plant processes. Some NAC TFs have been identified as being necessary for proper development while others seem to play roles in response to various stresses or in plant defense (Olsen et al., 2005; Ooka et al., 2003). The ATAF subfamily, which consists of four members - ANACO32 (At1g77450), ATAF1 (At1g01720), ATAF2 (At5g08790) and ANAC102 (At5g63790) - is induced by many abiotic stress situations as well as after pathogen infection. ATAF1 and ATAF2 were first identified due to their ability to activate the Cauliflower mosaic virus CaMV 355 promoter in yeast (Xie et al., 1999). ATAF2 is reported to be induced in response to wounding, SA, MeJA, pathogens like Tobacco mosaic virus and abiotic stress (Delessert et al., 2005; Wang et al., 2009a). It was recently reported that the ATAF2 promoter can be induced upon treatment with indole-3-acetonitrile which is converted within the plant to auxin via nitrilases. ATAF2 was further found to directly regulate the expression of NITRILASE2 (NIT2) gene involved in auxin biosynthesis (Huh et al., 2012). In case of ATAF1, however, there have been contradicting studies suggesting both positive and negative roles in biotic and abiotic stress responses (reviewed by Mauch-Mani and Flors, 2009). The remaining two members of the ATAF sub-family have not been characterized until now. Previously, we reported ATAF1 and its closest homologue ANAC032 as being target genes of the TGA/SCL14 complex in the detoxification pathway triggered by toxic chemicals like TIBA (Fode et al., 2008). This thesis focuses on unravelling the role played by these two NAC TFs in the detoxification pathway as well as their possible roles in defense and development.

\subsection{Role of $A N A C 032$ and $A T A F 1$ in the xenobiotic-induced detoxification response}

It has been shown that $A N A C O 32$ and $A T A F 1$ transcript levels are four-fold more abundant in the HA3-SCL 14 overexpressing transgenic line as compared to the $s c / 14$ 
knockout mutant. Because of this and since the two NAC proteins contain putative as-1-like elements in their promoters (Figure $4.1 \mathrm{~A}$ ) they are likely direct targets of the TGA/SCL14 complex. This complex recognizes as-1-like sequences and promotes gene expression in response to xenobiotic stress (Fode et al., 2008; Katagiri et al., 1989). Consistently, TIBA-induced and to some extent the basal expression of $A N A C 032$ and $A T A F 1$ was severely suppressed in the tga256 triple and sc/14/33 double mutants (Figure $4.1 \mathrm{~B}$ ). Since ANACO32 and ATAF1 are significantly induced after TIBA application they might be playing a role in the TGA/SCL14-triggered detoxification response (Figure 4.1). However, the NAC TFs do not seem to be essential for the complete response because unlike tga256 and sc/14/33 which are unable to grow on TIBA-containing media, the single knockouts anac032 and ataf1 as well as the double knockout ataf1anac032 germinate and grow like wild-type Col-O seedlings (Figure 4.2). This may be due to functional redundancy with the two other ATAF-type proteins - ATAF2 and ANAC102 - both of which contain as-1-like promoter elements and are induced after TIBA in a TGA/SCL14 dependent manner (Figure 4.1). Alternatively, it might be that these transcription factors regulate only a sub-branch of the TGA/SCL14-dependent detoxification program.

Contrary to $A T A F 1$, functional studies on $A N A C 032$ have not been carried out previously and hence this present study was focused more on the characterization of ANAC032. Thus, microarray analysis was carried out comparing untreated wild-type plants with transgenic plants that over-expressed 35S:ANAC032. GO term enrichment analysis indicated that of the 347 genes that were up-regulated ( $>2$-fold, $\mathrm{p}<0.05)$ in the $35 S: A N A C 032$ plants, $30 \%$ were associated with response to various stimuli of which chemical stimulus was the most prominent (69 genes) (Figure 4.3 A). Further, these sixty-nine genes noticeably revealed the up-regulation of many transmembrane transporters that are involved in multidrug transport. There were seven members that belonged to the MATE (multidrug and toxic compound extrusion) efflux family which are known to localize to vacuoles or to the plasma membrane and play a role in the detoxification of secondary metabolites generated in plants and xenobiotics (Hvorup et al., 2003; Omote et al., 2006). The MATE 
transporter ATDTX1 (Arabidopsis thaliana detoxification 1; At2g04040) which was strongly up-regulated ( 12 -fold) was previously reported to localize to the plasma membrane where it mediates the export of plant derived alkaloids, antibiotics and other toxic compounds such as tetraethylammonium and berberine (Li et al., 2002). The ATMRP4 (Arabidopsis thaliana multidrug resistance-associated protein 4; At2g47800), which was moderately induced ( $\sim$-fold), belongs to the ABC group of transporters of which many are known to be involved in detoxification of cells (Kang et al., 2011). These observations suggest that $A N A C 032$, in response to a chemical stimulus, induces drug transporters so as to sequester secondary metabolites or xenobiotic compounds in vacuoles or to excrete them out of cells.

Comparison of the array to a previous array that identified TIBA-induced genes in Col-O plants (Thesis by Dr. Julia Köster) showed around 78 genes that were commonly up-regulated according to the two arrays and 8 genes that were downregulated in both experiments (Supplementary Tables S3 and S4). All of these genes could be potential direct or indirect targets of the NAC TFs after activation of the detoxification pathway. Among these, two genes that were strongly induced in 35S:ANAC032 plants are aldo-keto reductases - AKR4C9 ( 57-fold; At2g37770) and AKR4C8 ( 13-fold; At2g37760) - which were recently shown to be induced by various forms of stresses and proposed to play a role in detoxification of sugarderived reactive carbonyls (Saito et al., 2013; Simpson et al., 2009). The two proteins were shown to have an inclination to reduce a wide range of substrates including 4hydroxy-2-trans-nonenal, hexenal, glyoxal and methylglyoxal that are known to arise as a result of lipid peroxidation, sugar fermentation especially under stress conditions (Farmer and Davoine, 2007; Saito et al., 2013; Yadav et al., 2008). Another strongly induced oxidoreductase, At3g04000 ( 14-fold), in a study along with AKR4C9 was implicated in the reduction of saturated and unsaturated aldehydes in chloroplasts (Yamauchi et al., 2011). In vitro studies suggested that the primary role of these oxidoreductases maybe to detoxify a range of toxic aldehydes and ketones produced during stress. 
The AKR4C9 and At3g04000 genes along with a third gene, At1g10585 which is a bHLH-type TF [second-most highly induced gene ( 43-fold)] were selected for further analysis. All of the three genes were induced by application of TIBA in the wild-type, with induction being compromised in the single and double knockouts of the NAC TFs (Figure 4.6 A). Moreover, promoters of these three genes could be induced by ANAC032 and ATAF1, in transiently transformed protoplasts, although only when fused to the strong activating domain VP16. Additionally, all three target genes show in their promoter regions the presence of two or more putative NAC binding sites as described by Jensen et al., 2013 for ATAF1 TF (Supplementary Figure S3). This suggests that the three candidate genes are direct targets of the NAC proteins which perhaps require additional factor(s) for transcriptional activation. (Figure 4.6 B). The fact that induction of the three genes after TIBA application was suppressed in the tga256 and sc/14/33 mutants further supports the hypothesis that these are downstream targets of the NAC TFs in the TGA/SCL14-triggered detoxification signaling cascade (Supplementary Figure S2).

Available microarray databases (Genevestigator) and previous studies suggest that ANACO32 and ATAF1 can be induced under a variety of stress conditions (Hruz et al., 2008; Kleinow et al., 2009). As shown in Figure 4.7, ANAC032 and ATAF1 can indeed be induced by application of various hormones and chemicals like MeJA, ABA, TIBA and ozone. They can also be induced via wounding and infection with the necrotrophic pathogen Botrytis cinerea. The level of induction differed depending on treatment as well as perhaps the time for which treatment was applied. The three target genes AKR4C9, bHLH585 and At3g04000 were also induced by these different treatments with a pattern quite consistent with that observed for the NAC TFs (Figure 4.7 D-F). Similar to TIBA application, the induction of ANAC032 seemed to require the TGA/SCL14 complex after wounding (Figure 4.8 A). Consistently, the three target genes which were all strongly induced after wounding showed compromised induction in the ataf1anac032 and the tga256 and sc/14/33 mutant plants (Figure 4.8 B and C). 
The compromised induction of the target genes seen in the ataf1anac032 mutant plants be it after TIBA treatment or wounding, was never completely abolished. This was especially observed in case of $b H L H 585$ which showed similar levels of induction after wounding in the double knockout and wild-type plants which would suggest that its expression is not fully dependent on the NAC TFs. Nonetheless, it is possible that the two other closely related ATAF-type NAC factors (ATAF2 and ANAC102) may function redundantly and knockout of all four may be required to perceive differences with the wild-type (since ATAF2 and ANAC102 are also induced under these situations; Figure 4.1 B, Figure 4.7 A, and Figure 4.8 D).

All of the above observations suggest that ANACO32 and ATAF1 may directly target many genes and activate a downstream response involving transcription factors like bHLH585 and enzymes (like AKR4C9 and At3g04000) and maybe other proteins like drug transporters etc. However, this response is not specifically activated after stimulus from a xenobiotic compound like TIBA. Instead we propose that the NAC TFs are more likely to be activators of a general stress response triggered under different stress situations and part of their function is to induce genes that will then help in detoxification of toxic compounds generated under stress conditions.

\subsection{Role of $A N A C 032$ in phytohormone-mediated defense responses}

Previously in our lab, it was observed that over-expression of ANACO32 led to the suppression of MeJA-induced PDF1.2 and VSP2 expression (Dr. Julia Köster, PhD thesis). This suppression of VSP2 by 35S:ANAC032 was confirmed in this study and it was further observed that over-expression of 35S:ATAF1 had the same effect whereas ataf1anac032 knockout mutant induced the genes to similar levels like wildtype (Figure $4.12 \mathrm{~A}$ ). Moreover, the ACC-induced expression of PDF1.2 was compromised by over-expressing the two NAC TFs with no obvious effects observed in ataf1anac032 plants (Figure $4.12 \mathrm{C}$ ). Further, these suppressive effects could be seen at the level of MYC2 and ORA59 genes which act up-stream of VSP2 and PDF1.2 respectively (Figure $4.12 \mathrm{~B}$ and $\mathrm{D}$ ). The antagonism between SA-JA or SA- 
ET signaling pathways is a well-established phenomenon with reports of several different proteins playing a role in the cross-talk, including the TGA factors, leading to suppression of downstream defense genes (see Introduction section 1.2.3; Van der Does et al., 2013; Pieterse et al., 2009; Zander et al., 2010, 2012). To check if this antagonism could explain the suppression observed in the 35S:ANAC032 plants, cross-talk experiments were carried out with the ataf1anac032 mutant plants. However, the suppressive effects of the cross-talk observed in ataf1anac032 were as prominent as in wild-type (Figure $4.13 \mathrm{~A}$ ). This perhaps suggests that the NAC proteins do not play a role in the SA-ET cross-talk; alternatively, their role may be minor and other proteins carrying out the cross-talk leave no discernible effects to be detected in the knockout plants. For instance, glutaredoxins like GRX480 was found to interact with TGA factors and suppress the expression of ORA59 (Ndamukong et al., 2007; Zander et al., 2012). Thus two redundant mechanisms, one involving the GRX proteins and another involving the NAC TFs, may exist for the SA-ET antagonism due to which knockout of either one shows no phenotype.

Surprisingly, the NAC over-expressing plants also showed a compromised induction of the SA-inducible PR1 gene after SA treatment (Figure $4.13 \mathrm{~B}$ ). There have been previous contradictory reports about effects of ATAF1-overexpression on the induction of defense genes. One report described a down-regulation of both $P R 1$ and PDF1.2 (Wang et al., 2009b) while another claimed that PR1 expression was induced by ATAF1 with no effects on PDF1.2 (Wu et al., 2009). Another study has also shown down-regulation of $P R$ genes by $A T A F 2$, one of the four ATAF proteins (Delessert et al., 2005). In this current study, over-expression of ANAC032 and ATAF1 seemed to suppress JA-, ACC-, as well as SA-responsive genes.

To see if suppression is due to altered signaling or defective accumulation, hormone levels were measured in plants treated with ozone. Measurement of hormone levels in 35S:ANACO32 and 35S:ATAF1 were not stringently reproducible between three independent experiments (Figure 4.15 and 4.16) leading to inconclusive data. However, the basal total SA content was consistently higher in both the NAC-over expressing plants as compared to wild-type (Figure 4.15 A and B) suggesting that 
these plants are capable of synthesizing SA. The glucosylated form of SA, SA-2-O- $\beta$ D-glucoside (SAG) is also greatly elevated in 35S:ANAC032 plants (Figure 4.16 C and D) which may be due to the high expression of UGT74F2 gene (as indicated by the microarray, $\sim 19-$ fold) that is responsible for the conversion of SA to SAG (Lim et al., 2002). However the reasons for high SAG needs to be confirmed especially because a previous report indicates that contrary to expectation, over-expression of UGT74F2 leads to reduced levels of both free SA and SAG and instead shows enhanced levels of MeSA and MeSAG leading to compromised immune response (Song et al., 2008). Nonetheless, the high UGT74F2 expression could in principle lead to increased accumulation of inactive forms of SA and thus explain the reduced PR1 expression observed after SA treatment.

The measured levels of JA and its related metabolites were even more difficult to comprehend. In one experiment 35S:ANAC032 showed increased amounts of JA in basal and induced conditions while in the second experiment only induced levels were significantly higher than wild-type (Figure 4.17 A and B). In the case of amino acid conjugate JA-lle, one experiment showed higher basal levels only in 35S:ANAC032 while the second experiment showed high basal levels only in 35S:ATAF1. On the other hand, in both experiments, the induced levels of JA-lle were significantly higher in both over-expressing plants compared to wild-type (Figure $4.17 \mathrm{E}$ and $\mathrm{F}$ ). The hydroxylation product 11_12-OH-JA showed similar pattern to measured JA levels with 35S:ANACO32 containing significantly abundant basal and induced levels of the metabolite (Figure $4.17 \mathrm{G}$ and $\mathrm{H}$ ). A third ozoneexperiment conducted showed differences again leading to no concrete conclusions. In all experiments however the knockout ataf1anac032 consistently behaved like wild-type unlike the over-expressers that showed different results between experiments. This is almost similar to the above mentioned controversial reports about the suppression of gene expression and perhaps these discrepancies are due to environmental factors influencing the regulation by NAC proteins. Nevertheless, the ability to synthesize or accumulate the hormones (SA, JA and related metabolites) after induction was not compromised in 35S:ANAC032 or 35S:ATAF1 plants, suggesting that the suppressive effects are probably targeted at signaling 
rather than inactivation of the hormones. Instead, in some experiments overexpression of the NAC TFs seemed to positively regulate the biosynthesis of SA and JA.

Over the years, JA has been established as the wound hormone although it is now clear that other signaling pathways contribute to the wound response (see Introduction section 1.3). The ANACO32 induction observed after wounding does not seem to depend on JA since both JA-biosynthesis mutant dde2-2 as well as JAsignaling mutant coi1-t accumulates ANACO32 to similar levels as wild-type (Figure 4.10). Moreover this induction seems to be transient (peaking within 90 minutes) and restricted to the locally wounded tissue with minor or no induction detected in unwounded systemic leaves (Figure 4.11 A and B). Although JA rapidly accumulates in local as well as systemic leaves after wounding, its role in local leaves is poorly understood with most effects being evident in the systemic tissue where it establishes defense response against further attack by herbivores or pathogens. In contrast, locally-induced genes are speculated to be involved in wound healing and repair in addition to protection against water loss and invasion by pathogens (Delessert et al., 2004; Glauser et al., 2008). Since wound-induced VSP2 is suppressed in the 35S:ANAC032 and 35S:ATAF1 plants with no difference between ataf1anac032 and wild-type, the two ATAF members do not seem to contribute to establish JA-induced systemic defense response (Figure 4.9). Further, because ANAC032 strongly induces similar genes after activation of detoxification pathway and wounding (e.g. AKR4C9, bHLH585, Figure 4.6 and Figure 4.8), it is reasonable to speculate that here too at least part of its function is as an activator of a more general stress response helping perhaps in the local wound healing process.

The ABA pathway which is central to the abiotic stress response is also known to have antagonistic effects on the defense pathways (see Introduction 1.2.3; Cao et al., 2011; Mauch-Mani and Mauch, 2005; Moeder et al., 2010). ATAF1 was previously reported to negatively regulate $A B A$-inducible genes (that normally play a role in abiotic stress response) and act as an attenuator of ABA signaling upon infection by Blumeria graminis f.sp. hordei (Jensen et al., 2008). However basal levels of ABA 
were found to be low in ataf1 mutants suggesting a positive role for ATAF1 in ABA biosynthesis. This pointed to an antagonistic function of ATAF1 and it was postulated to act as a switch between abiotic stress tolerance and defense responses (MauchMani and Flors, 2009). To see if the suppression of PDF1.2 in plants ectopically expressing the NAC TFs can be explained by antagonistic interaction with ABA, cross-talk experiments were carried out by treating plants with ABA and ET. However, like wild-type the ataf1anac032 plants also displayed suppression of PDF1.2 due to antagonistic action of ABA indicating that the NAC TFs do not contribute to the ABA-ET cross-talk (Figure $4.13 \mathrm{C}$ ). However, as postulated in case of SA-ET cross-talk, the ABA-ET antagonism may also be mediated in more ways than one, making it difficult to observe a phenotype in the ataf1anac032 plants. Moreover, ectopic expression of ANACO32 also led to suppressed induction of ABAinducible COR78 gene (Figure $4.16 \mathrm{D}$ ). Further, it was observed that 35S:ATAF1 plants contain significantly higher levels of ABA (Figure 4.17) and its inactive form ABA-GE (data not shown) under basal as well as induced conditions after ozone treatment. Consistent to this, the single knockout ataf1 showed compromised accumulation of ABA after ozone treatment although the double knockout ataf1anac032 displayed wild-type-like levels (Figure 4.17). This finding that overaccumulation of $A T A F 1$ leads to increased accumulation of $A B A$ is consistent with a recent report that ATAF1 positively regulates $A B A$ biosynthesis through the transcriptional activation of the biosynthesis gene NCED3 (Jensen et al., 2013). ANAC032, however, does not seem to function redundantly in this case although after ozone treatment it may be contributing slightly to increased ABA accumulation (Figure 4.17). 


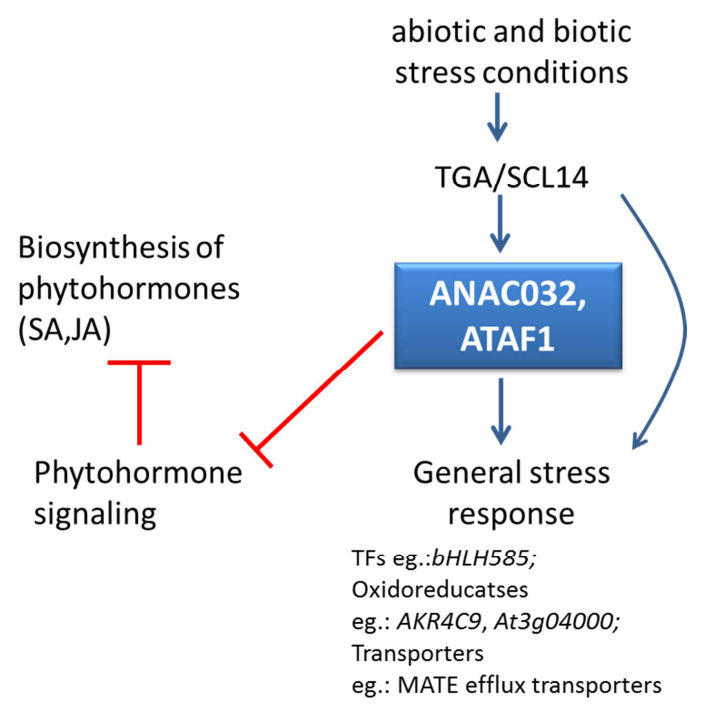

Figure 5.1: Schematic representation of role of ANAC032 and ATAF1 in stress response

ANAC032 and ATAF1 are induced within the plant under diverse stress conditions and in turn it induces a number of genes which may be part of a general stress response. The induction of the NAC TFs seems to depend upon the activation of the TGA/SCL14 complex depending on the stress cue. The NAC TFs may also suppress phytohormone-induced defense responses and directly/indirectly promote hormone biosynthesis via yet unknown mechanism.

Based on the current and reported studies a model may be proposed for ANAC032 and $A T A F 1$ in response to abiotic and biotic stress (Figure 5.1). The ATAF TFs are induced under diverse abiotic as well as biotic stress conditions and in some cases the induction may be rapid (within 3 hours) and transient. Moreover the induction of ANAC032 requires the TGA/SCL14 complex not only under chemical stress but also under stress situations like wounding. Induced ANACO32 most likely triggers a general stress response rather than stress-specific response, directly inducing several genes like oxidoreductases and other TFs. It also may induce directly or indirectly a number of transmembrane transporters including multidrug efflux transporters which play a role in the sequestration/excretion of toxic compounds.

The NAC TFs also seem to modulate phytohormone-mediated defense responses (Figure 5.1). The study indicates that all defense (SA, JA and ET) and abiotic stress 
(ABA) signaling is suppressed to some degree by the over-expression of both NAC TFs. On the other hand, the biosynthesis of hormones seems to be positively regulated by the NAC TFs. However, this could be an indirect effect stemming from a suppressed signaling cascade leading to a lack of feed-back control on biosynthesis by components of the signal transduction. The mechanism by which suppression of hormone-induced gene expression is brought about remains unclear. One possibility is that the NAC TFs induce a regulator which is then able to suppress all hormoneinduced defense mechanisms within the plant. However, microarray analysis of differentially regulated genes in 35S:ANAC032 plants did not provide any clue for the identity of such a repressor. On the other hand, such a repressor may accumulate at the protein level leading to suppression. This has been observed in the case of gibberrellic acid (GA) pathway, where DELLA repressors accumulate thereby suppressing GA signaling and thus plant growth (Achard and Genschik, 2009). As mentioned above, only the fused NAC TFs were able to activate the promoters of the target genes, which suggests requirement of co-activators in the system. Thus a second likelihood is that, the NAC TFs may act similarly by recruiting co-repressors to promoters of key regulators of the phytohormone pathways thus suppressing them. A further possibility is that the NAC TFs themselves directly interact and functionally block players of phytohormone-mediated responses. Moreover elements such as environmental factors may influence the positive or negative regulatory functions of the NAC TFs which may be the cause of inconsistencies observed in this and reported studies. Alternatively, the suppressive effects on defense pathways could be artifacts of constitutive over-expression of the NAC TFs. The expression levels found in the transgenic plants may never be achieved for long durations under natural circumstances since studies suggest that ATAF members are rapidly and transiently induced by some hormones and treatments (Wu et al., 2009, wounding experiments in this study). 


\subsection{Role of $A N A C 032$ in plant developmental processes}

Transgenic Arabidopsis plants carrying overexpression constructs for either ANACO32 or ATAF1 showed severe developmental defects (Figure 4.18). This included dwarfism crinkled and upward curled leaves showing early yellowing, sterility and delayed or absent flower initiation. The severity of these irregularities seemed to depend on the expression levels of the transgene with stronger expression leading to more severe effects. Similar phenotypic defects have been characterized earlier for transgenic plants over-expressing ATAF1 (Jensen et al., 2013; Kleinow et al., 2009; Wu et al., 2009) or ATAF2 (Huh et al., 2012). Microarray analysis and qRT-PCR revealed that 35S:ANAC032 plants showed an increased expression of FLOWERING LOCUS C (FLC) (Figure 4.5, Table 4.1), a MADS box transcriptional regulator which may explain the delayed flowering phenotype (Figure $4.18 \mathrm{~B})$. High FLC activity in plants leads to late flowering because FLC directly suppresses expression of floral inducers FLOWERING LOCUS $T(F T)$ and SUPPRESSOR OF OVEREXPRESSION OF CO 1 (SOC1) (Hepworth et al., 2002; Searle et al., 2006). Recently, a study showed that FLC delays the juvenile-to-adult vegetative transition and affects traits associated with vegetative phase change. It was shown that plants over-expressing FLC contain a higher number of juvenile leaves which are characterized by rounder leaves and by decreased number of abaxial trichomes compared to adult leaves (Willmann and Poethig, 2011). Consistent to this, the 35S:ANAC032 plants also show more juvenile leaves that are rounder and have less abaxial trichomes (Figure $4.18 \mathrm{C}$ and $\mathrm{D}$ ). In summary, the delayed juvenile to adult transition and the delayed flowering of 35S:ANAC032 plants might be due to the elevated $F L C$ expression. However, the slow growth must be due to other mechanisms since 35S:FLC plants grow normally (Michaels and Amasino, 2001). Even though FLC does not seem to be a direct target of ANAC032 or ATAF1 (Figure 4.6 B), it seems to be indirectly induced by these NAC proteins, a process that might be of physiological relevance in seeds, where high levels of ANAC032 and ATAF1 are expressed (see below). 
Since ANAC032 and ATAF1 are highly expressed in mature seeds (Figure 4.19), we tested whether they affect the establishment of seed dormancy. Seed dormancy is the mechanism to prevent germination under unsuitable ecological conditions when the probability of survival is low. The transition between dormancy and germination is very critical and is regulated by hormones whose degradation and synthesis respond to external environmental factors. Abscisic acid and gibberellic acid (GA) play a dynamic role in maintaining the equilibrium between dormancy and germination (del Carmen Rodriguez-Gacio et al., 2009). ABA usually promotes dormancy induction and maintenance while GA promotes germination. The two hormones act antagonistically to each other. The master regulators of this process are the DELLA proteins RGL1, RGL2 and RGL3, which stimulate ABA synthesis. ABA acts in a feedforward mechanism to maintain RGL transcription. The ABA-induced signal cascade negatively regulates GA synthesis. Signals that break dormancy lead to the degradation of $A B A$ through ABA-deactivating enzymes like CYP707A2 and to reduced transcription of $R G L 1,2,3$. This leads to the release of suppression on GA biosynthesis and increased GA content, which in turn favours degradation of RGL1,2,3, so that ABA biosynthesis is strongly impaired (Ariizumi et al., 2011; Footitt et al., 2011; Lee et al., 2010; Seo et al., 2006) (see further Figure 5.2). Since ABA can significantly induce $A N A C 032$, we speculated whether ABA-induced ANACO32 plays a role in regulation of seed dormancy.

In Arabidopsis, freshly harvested seeds are dormant and environmental cues like light, low temperature and after-ripening break dormancy (Koornneef et al., 2002). In order to monitor different levels of dormancy, freshly harvested seeds were exposed to two days in the cold to partially relieve the dormant state. Indeed, freshly harvested and stratified seeds of ataf1anac032 showed less germination ( 20\%) as compared to wild-type (80\%) three days after placing them on wet filter paper (Figure 4.20). This shows that $A N A C O 32$ and $A T A F 1$ are negative regulators of seed dormancy. In contrast, germination rates were similar when seeds were exposed to after ripening and stratification, indicating that germination per se is not affected. A previous study had stated that ataf1 knockout plants showed a very low germination rate while over-expression of $A T A F 1$ led to increased germination rate compared to 
wild-type (Wu et al., 2009). However, the paper does not describe whether dormant or non-dormant seeds were used for the analysis. Our microarray analysis has revealed candidate genes which might confer dormancy when being expressed in seeds. Known negative-regulator of ABA-induced seed dormancy, CBLINTERACTING PROTEIN KINASE 3 (CIPK3) (Kim et al., 2003; Pandey et al., 2008) is induced ( 2-fold) in 35S:ANAC032 plants. Other candidates include INOSITOL(1,4,5)P3 5-PHOSPHATASE // (AT5PTASE2, 4-fold induction) which when overexpressed is reported to be insensitive to $A B A$ in germination assays (Gunesekera et al., 2007) and ARABIDOPSIS THALIANA ENT-KAURENE OXIDASE 1 (ATKO1; 3.5-fold induction) which is a GA-biosynthesis gene up-regulated during seed germination (Ogawa et al., 2003). Further, it was recently shown that protein levels of $A B I 3$ and $A B I 5$, which are positive regulators of $A B A$-induced seed dormancy, are higher in the sc/14 mutant (Bassel et al., 2011). Hence it is conceivable that ANACO32 expression in mature seeds is dependent on the TGA/SCL14 complex which would explain the lower germination rate of freshly harvested sc/14 mutants and the ataf1anac032 double mutant. Moreover, FLC has also been reported to play a role in the developmental transition towards germination. The FLC regulation of germination involves FT and SOC1 which directly or indirectly promotes the ABA catabolic pathway (via CYP707A2) and the gibberellin biosynthetic pathway (via GA20ox 1) in seeds (Chiang et al., 2009). Even though FLC does not seem to be a direct target of ANAC032 (Figure 4.6 B), it may be indirectly induced by the NAC protein to high degree during seed maturation. Lastly, since ANAC032 expression is very high in seeds we speculated that, if ANAC032 can indeed suppress phytohormone signaling then seeds should not show up-regulation of defense-related genes, for example MeJA-induced JAZ10 expression. Indeed, as seen in Figure 4.21, when JAZ10-GusPlus reporter lines were treated with MeJA, green siliques stained blue indicating activation of the $J A Z 10$ promoter while the seeds within them remained unstained. However, it remains to be analyzed whether this observation is undeniably due to high expression of $A N A C 032$. 


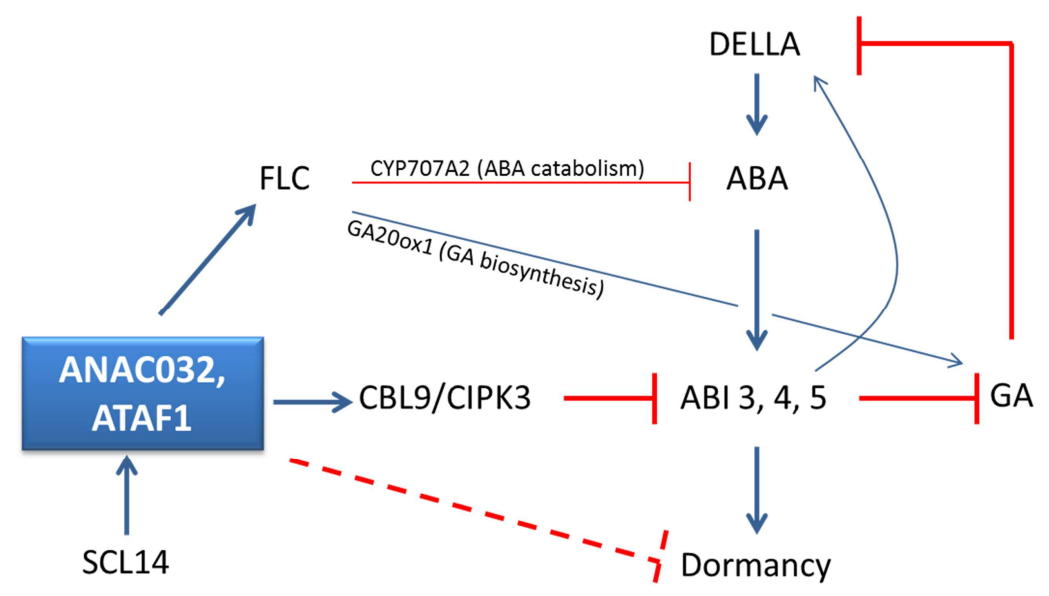

Figure 5.2: Schematic representation role of ANAC032 and ATAF1 in seed dormancy

ANAC032 and ATAF1 show high expression within mature seeds where it negatively influences seed dormancy (observed phenotype is indicated by dotted line). This may be via induction of CIPK3 which is known to negatively influence dormancy, or possibly via FLC also known to influence the ABA-GA balance in favour of germination. The TGA/SCL14 is likely to play a role in the induction of $A N A C O 32$ within seeds. The dotted line represents the actual observation.

Thus, apart from its role in stress response, a second important function of the NAC TFs can be imagined in the mature seed (Figure 5.2) where they are highly expressed. Here, ANACO32 seems to negatively regulate seed dormancy and promote germination. This may be achieved via induction of CIPK3 which has been shown to negatively regulate dormancy. Further, studies indicate SCL14 promotes germination, probably by an indirect influence on protein accumulation of positive regulators of dormancy such as $\mathrm{ABI} 3$ and $\mathrm{ABI}$. Therefore, we propose that SCL14induced $A N A C 032$ may further induce genes like CIPK3 which through its kinase activity may deactivate or alter the stability of $A B I 3$ and $A B I 5$. Promotion of seed germination by $A N A C 032$ may be partly achieved via $F L C$ which promotes transition to seed germination by promoting both $A B A$ catabolism and GA biosynthesis. Additionally, induction of GA biosynthesis genes in the 35S:ANACO32 plant indicates that there may be more direct ways in which ANAC032 influences seed dormancy. 
As mentioned earlier, the ATAF sub-family members are proposed to function redundantly as it is co-expressed under varied conditions (Kleinow et al., 2009). Indeed in the current study knockout of ATAF1 and ANACO32 alone did not lead to a complete suppression of expression of target genes. Moreover, ataf1anac032 behaved like the wild-type in most cases when looking at phytohormone-mediated gene expression. This could be due to the functional redundancy between the ATAF TFs and a future knockout of all four members may be required to observe a stronger and clearer phenotype. However in some respects all four proteins do not seem to be redundant. For example, over-expression of $A T A F 1$ positively regulates $A B A$ synthesis while ANACO32 overexpression shows only minor and/or insignificant increase in $A B A$ accumulation (Figure 4.16). On the other hand, JA synthesis seems to be positively regulated only by ANACO32 and not by ATAF1 which behaves like the wild-type (Figure 4. $15 \mathrm{~A}$ and B). The function of ANACO32 and ATAF1 may be redundant in the mature seed as indicated by ataf1anac032 mutant, however this function may not be true of $A N A C 102$ since it does not show high expression in seeds and instead shows highest expression in senescent leaves (from eFP browser). Thus more careful and stringent studies need to be carried out in future to dissect out the various redundant and non-redundant functions of the ATAF-type transcription factors. 


\section{Summary}

In higher plants, xenobiotic chemicals induce transcriptional activation of genes involved in their detoxification. A generally accepted concept explaining gene regulatory networks is that, activation of pre-existing primary transcription factors regulates transcription of secondary transcription factors that in turn induce genes that execute the appropriate response. In the detoxification program, TGA transcription factors and their transcriptional co-activator SCL14 bind to promoters containing activation sequence-1 (as-1)-like cis-elements. Microarray analysis of plants containing either lower or higher amounts of SCL14 had identified two NAC transcription factors - ANACO32 and ATAF1 - whose expression was affected by SCL14 (Fode et al., 2008). Thus, these are candidate secondary transcription factors that lead to the expression of downstream genes. In the current study, a microarray of transgenic 35S:ANAC032 plants was compared to a previous array that had identified genes that were activated by the xenobiotic TIBA. Seventy-eight genes were up-regulated upon TIBA treatment or ectopic expression of ANACO32 and were thus potential direct or indirect target genes of the NAC TFs in the detoxification response. Three such potential target genes - AKR4C9, bHLH585 and At3g04000were found to be induced by TIBA in a TGA/SCL14-dependent manner with induction being compromised in varying degrees in the ataf1 and anac032 single knockout and ataf1anac032 double knockout plants. Additionally, transient expression assays indicated that the promoters of the three genes could be induced by ANAC032 and ATAF1, although only when fused to the strong activating domain VP16. High SCL14/TGA-dependent induction of NAC TFs and the three target genes, AKR4C9, $b H L H 585$ and $A t 3 g 04000$ was also observed upon wounding. This wound response was not dependent on the plant hormone jasmonic acid.

Ectopic expression of the two NAC TFs was also found to suppress SA-, JA/ET-, JAand $\mathrm{ABA}$ - responsive genes. Since their expression is also triggered by these hormones, they are candidates to mediate the antagonism between the corresponding pathways. This could not be confirmed using the ataf1anac032 double knock out, which might be due to the redundancy with the two related transcription factors ANAC102 and ATAF2 or NAC-independent mechanisms. 
Lastly, ectopically expressed ANAC032 and ATAF1 led to developmental defects including dwarfism, curled leaves showing early yellowing and delayed or absent flower initiation. The latter may be due to increased expression of $F L C$ observed in the 35S:ANAC032 and 35S:ATAF1 plants. Consistently, these plants show increased juvenility which is characteristic of plants over-expressing the $F L C$ gene. As revealed by increased dormancy of ataf1anac032 seeds, ANAC032 and ATAF1 seem to negatively regulate seed dormancy. The molecular basis of this regulation needs to be carefully studied in the future. However, clues may be provided by the microarray which indicated that 35S:ANAC032 plants show an up-regulation of genes related to negative regulation of seed dormancy. To sum up, the ATAF-type NAC TFs seem to have two major roles, one in modulating responses under stress conditions and the other in regulating seed dormancy. 


\section{References}

1. Achard, P., and Genschik, P. (2009). Releasing the brakes of plant growth: how GAs shutdown DELLA proteins. J. Exp. Bot. 60, 1085-1092.

2. Acosta, I.F., Gasperini, D., Chételat, A., Stolz, S., Santuari, L., and Farmer, E.E. (2013). Role of NINJA in root jasmonate signaling. Proc. Natl. Acad. Sci. 110, 15473-15478.

3. Adie, B.A.T., Pérez-Pérez, J., Pérez-Pérez, M.M., Godoy, M., Sánchez-Serrano, J.-J., Schmelz, E.A., and Solano, R. (2007). ABA is an essential signal for plant resistance to pathogens affecting JA biosynthesis and the activation of defenses in Arabidopsis. Plant Cell 19, 1665-1681.

4. Aida, M., Ishida, T., Fukaki, H., Fujisawa, H., and Tasaka, M. (1997). Genes involved in organ separation in Arabidopsis: an analysis of the cup-shaped cotyledon mutant. Plant Cell 9, 841-857.

5. Aida, M., Ishida, T., and Tasaka, M. (1999). Shoot apical meristem and cotyledon formation during Arabidopsis embryogenesis: interaction among the CUP-SHAPED COTYLEDON and SHOOT MERISTEMLESS genes. Development 126, 1563-1570.

6. Albrecht, C., Boutrot, F., Segonzac, C., Schwessinger, B., Gimenez-Ibanez, S., Chinchilla, D., Rathjen, J.P., de Vries, S.C., and Zipfel, C. (2012). Brassinosteroids inhibit pathogenassociated molecular pattern-triggered immune signaling independent of the receptor kinase BAK1. Proc. Natl. Acad. Sci. U. S. A. 109, 303-308.

7. An, C., and Mou, Z. (2011). Salicylic Acid and its Function in Plant ImmunityF. J. Integr. Plant Biol. 53, 412-428.

8. Anderson, J.P., Badruzsaufari, E., Schenk, P.M., Manners, J.M., Desmond, O.J., Ehlert, C., Maclean, D.J., Ebert, P.R., and Kazan, K. (2004). Antagonistic interaction between abscisic acid and jasmonate-ethylene signaling pathways modulates defense gene expression and disease resistance in Arabidopsis. Plant Cell 16, 3460-3479.

9. Ariizumi, T., Lawrence, P.K., and Steber, C.M. (2011). The role of two f-box proteins, SLEEPY1 and SNEEZY, in Arabidopsis gibberellin signaling. Plant Physiol. 155, 765-775.

10. Asselbergh, B., Achuo, A.E., Höfte, M., and Van Gijsegem, F. (2008). Abscisic acid deficiency leads to rapid activation of tomato defence responses upon infection with Erwinia chrysanthemi. Mol. Plant Pathol. 9, 11-24.

11. Baerson, S.R., Sánchez-Moreiras, A., Pedrol-Bonjoch, N., Schulz, M., Kagan, I.A., Agarwal, A.K., Reigosa, M.J., and Duke, S.O. (2005). Detoxification and Transcriptome Response in Arabidopsis Seedlings Exposed to the Allelochemical Benzoxazolin-2(3H)one. J. Biol. Chem. 280, 21867-21881.

12. Bassel, G.W., Lan, H., Glaab, E., Gibbs, D.J., Gerjets, T., Krasnogor, N., Bonner, A.J., Holdsworth, M.J., and Provart, N.J. (2011). Genome-wide network model capturing seed germination reveals coordinated regulation of plant cellular phase transitions. Proc. Natl. Acad. Sci. 108, 9709-9714. 
13. Behringer, C., Bartsch, K., and Schaller, A. (2011). Safeners recruit multiple signalling pathways for the orchestrated induction of the cellular xenobiotic detoxification machinery in Arabidopsis. Plant Cell Environ. 34, 1970-1985.

14. Berger, S., Bell, E., and Mullet, J.E. (1996). Two Methyl Jasmonate-Insensitive Mutants Show Altered Expression of AtVsp in Response to Methyl Jasmonate and Wounding. Plant Physiol. 111, 525-531.

15. Bernard, P., and Couturier, M. (1992). Cell killing by the F plasmid CcdB protein involves poisoning of DNA-topoisomerase II complexes. J. Mol. Biol. 226, 735-745.

16. Berrocal-Lobo, M., Molina, A., and Solano, R. (2002). Constitutive expression of ETHYLENE-RESPONSE-FACTOR1 in Arabidopsis confers resistance to several necrotrophic fungi. Plant J. Cell Mol. Biol. 29, 23-32.

17. Bishop, P.D., Pearce, G., Bryant, J.E., and Ryan, C.A. (1984). Isolation and characterization of the proteinase inhibitor-inducing factor from tomato leaves. Identity and activity of poly- and oligogalacturonide fragments. J. Biol. Chem. 259, 13172-13177.

18. Blanco, F., Garretón, V., Frey, N., Dominguez, C., Pérez-Acle, T., Straeten, D.V. der, Jordana, X., and Holuigue, L. (2005). Identification of NPR1-Dependent and Independent Genes Early Induced by Salicylic Acid Treatment in Arabidopsis. Plant Mol. Biol. 59, 927-944.

19. Bowling, S.A., Clarke, J.D., Liu, Y., Klessig, D.F., and Dong, X. (1997). The cpr5 mutant of Arabidopsis expresses both NPR1-dependent and NPR1-independent resistance. Plant Cell 9, 1573-1584.

20. Breithaupt, C., Kurzbauer, R., Schaller, F., Stintzi, A., Schaller, A., Huber, R., Macheroux, P., and Clausen, T. (2009). Structural basis of substrate specificity of plant 12oxophytodienoate reductases. J. Mol. Biol. 392, 1266-1277.

21. Browse, J. (2005). Jasmonate: an oxylipin signal with many roles in plants. Vitam. Horm. $72,431-456$.

22. Caldelari, D., Wang, G., Farmer, E.E., and Dong, X. (2011). Arabidopsis lox3 lox4 double mutants are male sterile and defective in global proliferative arrest. Plant Mol. Biol. 75, 25-33.

23. Cao, F.Y., Yoshioka, K., and Desveaux, D. (2011). The roles of ABA in plant-pathogen interactions. J. Plant Res. 124, 489-499.

24. Cao, H., Glazebrook, J., Clarke, J.D., Volko, S., and Dong, X. (1997). The Arabidopsis NPR1 gene that controls systemic acquired resistance encodes a novel protein containing ankyrin repeats. Cell 88, 57-63.

25. Del Carmen Rodriguez-Gacio, M., Matilla-Vazquez, M.A., and Matilla, A.J. (2009). Seed dormancy and ABA signaling. Plant Signal. Behav. 4, 1035-1048.

26. Chauvin, A., Caldelari, D., Wolfender, J.-L., and Farmer, E.E. (2013). Four 13lipoxygenases contribute to rapid jasmonate synthesis in wounded Arabidopsis thaliana 
leaves: a role for lipoxygenase 6 in responses to long-distance wound signals. New Phytol. 197, 566-575.

27. Chen, Q., Wang, Q., Xiong, L., and Lou, Z. (2011). A structural view of the conserved domain of rice stress-responsive NAC1. Protein Cell 2, 55-63.

28. Chen, Z., Zheng, Z., Huang, J., Lai, Z., and Fan, B. (2009). Biosynthesis of salicylic acid in plants. Plant Signal. Behav. 4, 493-496.

29. Chiang, G.C.K., Barua, D., Kramer, E.M., Amasino, R.M., and Donohue, K. (2009). Major flowering time gene, FLOWERING LOCUS C, regulates seed germination in Arabidopsis thaliana. Proc. Natl. Acad. Sci. 106, 11661-11666.

30. Chini, A., Fonseca, S., Fernández, G., Adie, B., Chico, J.M., Lorenzo, O., García-Casado, G., López-Vidriero, I., Lozano, F.M., Ponce, M.R., et al. (2007). The JAZ family of repressors is the missing link in jasmonate signalling. Nature 448, 666-671.

31. Chomczynski, P. (1993). A reagent for the single-step simultaneous isolation of RNA, DNA and proteins from cell and tissue samples. BioTechniques 15, 532-534, 536-537.

32. Clough, S.J., and Bent, A.F. (1998). Floral dip: a simplified method for Agrobacteriummediated transformation of Arabidopsis thaliana. Plant J. Cell Mol. Biol. 16, 735-743.

33. Coleman, J., Blake-Kalff, M., and Davies, E. (1997). Detoxification of xenobiotics by plants: chemical modification and vacuolar compartmentation. Trends Plant Sci. 2, 144151.

34. Collinge, M., and Boller, T. (2001). Differential induction of two potato genes, Stprx2 and StNAC, in response to infection by Phytophthora infestans and to wounding. Plant Mol. Biol. 46, 521-529.

35. Dave, A., and Graham, I.A. (2012). Oxylipin Signaling: A Distinct Role for the Jasmonic Acid Precursor cis-(+)-12-Oxo-Phytodienoic Acid (cis-OPDA). Front. Plant Sci. 3.

36. Dean, J.V., Mohammed, L.A., and Fitzpatrick, T. (2005). The formation, vacuolar localization, and tonoplast transport of salicylic acid glucose conjugates in tobacco cell suspension cultures. Planta 221, 287-296.

37. Delessert, C., Wilson, I., Straeten, D.V.D., Dennis, E., and Dolferus, R. (2004). Spatial and temporal analysis of the local response to wounding. Plant Mol. Biol. 55, 165-181.

38. Delessert, C., Kazan, K., Wilson, I.W., Straeten, D.V.D., Manners, J., Dennis, E.S., and Dolferus, R. (2005). The transcription factor ATAF2 represses the expression of pathogenesis-related genes in Arabidopsis. Plant J. 43, 745-757.

39. Dempsey, D.A., Vlot, A.C., Wildermuth, M.C., and Klessig, D.F. (2011). Salicylic Acid Biosynthesis and Metabolism. Arab. Book Am. Soc. Plant Biol. 9.

40. Desveaux, D., Subramaniam, R., Després, C., Mess, J.-N., Lévesque, C., Fobert, P.R., Dangl, J.L., and Brisson, N. (2004). A "Whirly" transcription factor is required for salicylic acid-dependent disease resistance in Arabidopsis. Dev. Cell 6, 229-240. 
41. Dixon, D.P., Cummins, I., Cole, D.J., and Edwards, R. (1998). Glutathione-mediated detoxification systems in plants. Curr. Opin. Plant Biol. 1, 258-266.

42. Doares, S.H., Syrovets, T., Weiler, E.W., and Ryan, C.A. (1995). Oligogalacturonides and chitosan activate plant defensive genes through the octadecanoid pathway. Proc. Natl. Acad. Sci. U. S. A. 92, 4095-4098.

43. Van der Does, D., Leon-Reyes, A., Koornneef, A., Van Verk, M.C., Rodenburg, N., Pauwels, L., Goossens, A., Korbes, A.P., Memelink, J., Ritsema, T., et al. (2013). Salicylic Acid Suppresses Jasmonic Acid Signaling Downstream of SCFCOI1-JAZ by Targeting GCC Promoter Motifs via Transcription Factor ORA59[C][W][OA]. Plant Cell 25, 744-761.

44. Dong, X. (2004). NPR1, all things considered. Curr. Opin. Plant Biol. 7, 547-552.

45. Du, Z., Zhou, X., Ling, Y., Zhang, Z., and Su, Z. (2010). agriGO: a GO analysis toolkit for the agricultural community. Nucleic Acids Res. 38, W64-W70.

46. Durrant, W.E., and Dong, X. (2004). Systemic Acquired Resistance. Annu. Rev. Phytopathol. 42, 185-209.

47. Duval, M., Hsieh, T.-F., Kim, S.Y., and Thomas, T.L. (2002). Molecular characterization of AtNAM: a member of the Arabidopsis NAC domain superfamily. Plant Mol. Biol. 50, 237-248.

48. Edwards, K., Johnstone, C., and Thompson, C. (1991). A simple and rapid method for the preparation of plant genomic DNA for PCR analysis. Nucleic Acids Res. 19, 1349.

49. Ellinger, D., Stingl, N., Kubigsteltig, I.I., Bals, T., Juenger, M., Pollmann, S., Berger, S., Schuenemann, D., and Mueller, M.J. (2010). DONGLE and DEFECTIVE IN ANTHER DEHISCENCE1 Lipases Are Not Essential for Wound- and Pathogen-Induced Jasmonate Biosynthesis: Redundant Lipases Contribute to Jasmonate Formation. Plant Physiol. 153, 114-127.

50. Ernst, H.A., Nina Olsen, A., Skriver, K., Larsen, S., and Lo Leggio, L. (2004). Structure of the conserved domain of ANAC, a member of the NAC family of transcription factors. EMBO Rep. 5, 297-303.

51. Fang, Y., You, J., Xie, K., Xie, W., and Xiong, L. (2008). Systematic sequence analysis and identification of tissue-specific or stress-responsive genes of NAC transcription factor family in rice. Mol. Genet. Genomics MGG 280, 547-563.

52. Farmer, E.E., and Davoine, C. (2007). Reactive electrophile species. Curr. Opin. Plant Biol. 10, 380-386.

53. Fode, B., Siemsen, T., Thurow, C., Weigel, R., and Gatz, C. (2008). The Arabidopsis GRAS Protein SCL14 Interacts with Class II TGA Transcription Factors and Is Essential for the Activation of Stress-Inducible Promoters. Plant Cell 20, 3122-3135.

54. Footitt, S., Douterelo-Soler, I., Clay, H., and Finch-Savage, W.E. (2011). Dormancy cycling in Arabidopsis seeds is controlled by seasonally distinct hormone-signaling pathways. Proc. Natl. Acad. Sci. U. S. A. 108, 20236-20241. 
55. Fu, Z.Q., Yan, S., Saleh, A., Wang, W., Ruble, J., Oka, N., Mohan, R., Spoel, S.H., Tada, Y., Zheng, N., et al. (2012). NPR3 and NPR4 are receptors for the immune signal salicylic acid in plants. Nature $486,228-232$.

56. Fujita, M., Fujita, Y., Maruyama, K., Seki, M., Hiratsu, K., Ohme-Takagi, M., Tran, L.-S.P., Yamaguchi-Shinozaki, K., and Shinozaki, K. (2004). A dehydration-induced NAC protein, RD26, is involved in a novel ABA-dependent stress-signaling pathway. Plant J. 39, 863876.

57. Garcion, C., Lohmann, A., Lamodière, E., Catinot, J., Buchala, A., Doermann, P., and Métraux, J.-P. (2008). Characterization and biological function of the ISOCHORISMATE SYNTHASE2 gene of Arabidopsis. Plant Physiol. 147, 1279-1287.

58. Gietz, R.D., and Woods, R.A. (2002). Transformation of yeast by lithium acetate/singlestranded carrier DNA/polyethylene glycol method. Methods Enzymol. 350, 87-96.

59. Gimenez-Ibanez, S., and Solano, R. (2013). Nuclear jasmonate and salicylate signaling and crosstalk in defense against pathogens. Front. Plant Sci. 4.

60. Glauser, G., Grata, E., Dubugnon, L., Rudaz, S., Farmer, E.E., and Wolfender, J.-L. (2008). Spatial and temporal dynamics of jasmonate synthesis and accumulation in Arabidopsis in response to wounding. J. Biol. Chem. 283, 16400-16407.

61. Glauser, G., Boccard, J., Rudaz, S., and Wolfender, J.-L. (2010). Mass spectrometrybased metabolomics oriented by correlation analysis for wound-induced molecule discovery: identification of a novel jasmonate glucoside. Phytochem. Anal. PCA 21, 95101.

62. Glazebrook, J. (2005). Contrasting Mechanisms of Defense Against Biotrophic and Necrotrophic Pathogens. Annu. Rev. Phytopathol. 43, 205-227.

63. Gou, M., Su, N., Zheng, J., Huai, J., Wu, G., Zhao, J., He, J., Tang, D., Yang, S., and Wang, G. (2009). An F-box gene, CPR30, functions as a negative regulator of the defense response in Arabidopsis. Plant J. Cell Mol. Biol. 60, 757-770.

64. Le Gouill, C., Parent, J.-L., Rola-Pleszczynski, M., and Stankova, J. (1994). Analysis of recombinant plasmids by a modified alkaline lysis method. Anal. Biochem. 219, 164.

65. Greve, K., La Cour, T., Jensen, M.K., Poulsen, F.M., and Skriver, K. (2003). Interactions between plant RING-H2 and plant-specific NAC (NAM/ATAF1/2/CUC2) proteins: RINGH2 molecular specificity and cellular localization. Biochem. J. 371, 97-108.

66. Grzam, A., Martin, M.N., Hell, R., and Meyer, A.J. (2007). gamma-Glutamyl transpeptidase GGT4 initiates vacuolar degradation of glutathione S-conjugates in Arabidopsis. FEBS Lett. 581, 3131-3138.

67. Gunesekera, B., Torabinejad, J., Robinson, J., and Gillaspy, G.E. (2007). Inositol Polyphosphate 5-Phosphatases 1 and 2 Are Required for Regulating Seedling Growth. Plant Physiol. 143, 1408-1417.

68. Hanahan, D. (1985). DNA Cloning: A Practical Approach. In DNA Cloning: A Practical Approach (Glover, D.M., Ed.), (McLean,Virginia: IRL Press), p. 109. 
69. Hao, Y.-J., Song, Q.-X., Chen, H.-W., Zou, H.-F., Wei, W., Kang, X.-S., Ma, B., Zhang, W.K., Zhang, J.-S., and Chen, S.-Y. (2010). Plant NAC-type transcription factor proteins contain a NARD domain for repression of transcriptional activation. Planta 232, 10331043.

70. Hao, Y.-J., Wei, W., Song, Q.-X., Chen, H.-W., Zhang, Y.-Q., Wang, F., Zou, H.-F., Lei, G., Tian, A.-G., Zhang, W.-K., et al. (2011). Soybean NAC transcription factors promote abiotic stress tolerance and lateral root formation in transgenic plants. Plant J. Cell Mol. Biol. 68, 302-313.

71. Hartley, J.L., Temple, G.F., and Brasch, M.A. (2000). DNA cloning using in vitro sitespecific recombination. Genome Res. 10, 1788-1795.

72. He, X.-J., Mu, R.-L., Cao, W.-H., Zhang, Z.-G., Zhang, J.-S., and Chen, S.-Y. (2005). AtNAC2, a transcription factor downstream of ethylene and auxin signaling pathways, is involved in salt stress response and lateral root development. Plant J. 44, 903-916.

73. Hendelman, A., Stav, R., Zemach, H., and Arazi, T. (2013). The tomato NAC transcription factor SINAM2 is involved in flower-boundary morphogenesis. J. Exp. Bot. 64, 54975507.

74. Hepworth, S.R., Valverde, F., Ravenscroft, D., Mouradov, A., and Coupland, G. (2002). Antagonistic regulation of flowering-time gene SOC1 by CONSTANS and FLC via separate promoter motifs. EMBO J. 21, 4327-4337.

75. Hibara, K., Karim, M.R., Takada, S., Taoka, K., Furutani, M., Aida, M., and Tasaka, M. (2006). Arabidopsis CUP-SHAPED COTYLEDON3 regulates postembryonic shoot meristem and organ boundary formation. Plant Cell 18, 2946-2957.

76. Howe, G.A., and Jander, G. (2008). Plant immunity to insect herbivores. Annu. Rev. Plant Biol. 59, 41-66.

77. Hruz, T., Laule, O., Szabo, G., Wessendorp, F., Bleuler, S., Oertle, L., Widmayer, P., Gruissem, W., and Zimmermann, P. (2008). Genevestigator V3: A Reference Expression Database for the Meta-Analysis of Transcriptomes. Adv. Bioinforma. 2008.

78. Hu, H., Dai, M., Yao, J., Xiao, B., Li, X., Zhang, Q., and Xiong, L. (2006). Overexpressing a NAM, ATAF, and CUC (NAC) transcription factor enhances drought resistance and salt tolerance in rice. Proc. Natl. Acad. Sci. U. S. A. 103, 12987-12992.

79. Hu, H., You, J., Fang, Y., Zhu, X., Qi, Z., and Xiong, L. (2008). Characterization of transcription factor gene SNAC2 conferring cold and salt tolerance in rice. Plant Mol. Biol. 67, 169-181.

80. Hu, R., Qi, G., Kong, Y., Kong, D., Gao, Q., and Zhou, G. (2010). Comprehensive Analysis of NAC Domain Transcription Factor Gene Family in Populus trichocarpa. BMC Plant Biol. 10, 145.

81. Huh, S.U., Lee, S.-B., Kim, H.H., and Paek, K.-H. (2012). ATAF2, a NAC transcription factor, binds to the promoter and regulates NIT2 gene expression involved in auxin biosynthesis. Mol. Cells 34, 305-313. 
82. Hvorup, R.N., Winnen, B., Chang, A.B., Jiang, Y., Zhou, X.-F., and Saier, M.H., Jr (2003). The multidrug/oligosaccharidyl-lipid/polysaccharide (MOP) exporter superfamily. Eur. J. Biochem. FEBS 270, 799-813.

83. Hyun, Y., Choi, S., Hwang, H.-J., Yu, J., Nam, S.-J., Ko, J., Park, J.-Y., Seo, Y.S., Kim, E.Y., Ryu, S.B., et al. (2008). Cooperation and Functional Diversification of Two Closely Related Galactolipase Genes for Jasmonate Biosynthesis. Dev. Cell 14, 183-192.

84. Irsigler, A.S., Costa, M.D., Zhang, P., Reis, P.A., Dewey, R.E., Boston, R.S., and Fontes, E.P. (2007). Expression profiling on soybean leaves reveals integration of ER- and osmotic-stress pathways. BMC Genomics 8, 431.

85. Ishida, T., Aida, M., Takada, S., and Tasaka, M. (2000). Involvement of CUP-SHAPED COTYLEDON genes in gynoecium and ovule development in Arabidopsis thaliana. Plant Cell Physiol. 41, 60-67.

86. Izawa, T., Foster, R., and Chua, N.H. (1993). Plant bZIP protein DNA binding specificity. J. Mol. Biol. 230, 1131-1144.

87. James, P., Halladay, J., and Craig, E.A. (1996). Genomic libraries and a host strain designed for highly efficient two-hybrid selection in yeast. Genetics 144, 1425-1436.

88. Jefferson, R.A., Kavanagh, T.A., and Bevan, M.W. (1987). GUS fusions: betaglucuronidase as a sensitive and versatile gene fusion marker in higher plants. EMBO J. 6, 3901-3907.

89. Jensen, M.K., Hagedorn, P.H., De Torres-Zabala, M., Grant, M.R., Rung, J.H., Collinge, D.B., and Lyngkjaer, M.F. (2008). Transcriptional regulation by an NAC (NAM-ATAF1,2CUC2) transcription factor attenuates ABA signalling for efficient basal defence towards Blumeria graminis f. sp. hordei in Arabidopsis. Plant J. 56, 867-880.

90. Jensen, M.K., Kjaersgaard, T., Nielsen, M.M., Galberg, P., Petersen, K., O'Shea, C., and Skriver, K. (2010). The Arabidopsis thaliana NAC transcription factor family: structurefunction relationships and determinants of ANAC019 stress signalling. Biochem. J. 426, 183-196.

91. Jensen, M.K., Lindemose, S., Masi, F. de, Reimer, J.J., Nielsen, M., Perera, V., Workman, C.T., Turck, F., Grant, M.R., Mundy, J., et al. (2013). ATAF1 transcription factor directly regulates abscisic acid biosynthetic gene NCED3 in Arabidopsis thaliana. FEBS Open Bio 3, 321-327.

92. Jeong, J.S., Park, Y.T., Jung, H., Park, S.-H., and Kim, J.-K. (2009). Rice NAC proteins act as homodimers and heterodimers. Plant Biotechnol. Rep. 3, 127-134.

93. Jin, H., Xu, G., Meng, Q., Huang, F., and Yu, D. (2013). GmNAC5, a NAC Transcription Factor, Is a Transient Response Regulator Induced by Abiotic Stress in Soybean. Sci. World J. 2013.

94. Kang, J., Park, J., Choi, H., Burla, B., Kretzschmar, T., Lee, Y., and Martinoia, E. (2011). Plant ABC Transporters. Arab. Book Am. Soc. Plant Biol. 9.

95. Kangasjärvi, J., Talvinen, J., Utriainen, M., and Karjalainen, R. (1994). Plant defence systems induced by ozone. Plant Cell Environ. 17, 783-794. 
96. Karimi, M., Inzé, D., and Depicker, A. (2002). GATEWAY ${ }^{\top M}$ vectors for Agrobacteriummediated plant transformation. Trends Plant Sci. 7, 193-195.

97. Katagiri, F., Lam, E., and Chua, N.-H. (1989). Two tobacco DNA-binding proteins with homology to the nuclear factor CREB. Nature 340, 727-730.

98. Kawaura, K., Mochida, K., and Ogihara, Y. (2008). Genome-wide analysis for identification of salt-responsive genes in common wheat. Funct. Integr. Genomics 8 , 277-286.

99. Kienow, L., Schneider, K., Bartsch, M., Stuible, H.-P., Weng, H., Miersch, O., Wasternack, C., and Kombrink, E. (2008). Jasmonates meet fatty acids: functional analysis of a new acyl-coenzyme A synthetase family from Arabidopsis thaliana. J. Exp. Bot. 59, 403-419.

100. Kikuchi, K., Ueguchi-Tanaka, M., Yoshida, K.T., Nagato, Y., Matsusoka, M., and Hirano, H.-Y. (2000). Molecular analysis of the NAC gene family in rice. Mol. Gen. Genet. MGG $262,1047-1051$.

101. Kim, H.S., Park, B.O., Yoo, J.H., Jung, M.S., Lee, S.M., Han, H.J., Kim, K.E., Kim, S.H., Lim, C.O., Yun, D.-J., et al. (2007). Identification of a Calmodulin-binding NAC Protein as a Transcriptional Repressor in Arabidopsis. J. Biol. Chem. 282, 36292-36302.

102. Kim, K.-N., Cheong, Y.H., Grant, J.J., Pandey, G.K., and Luan, S. (2003). CIPK3, a Calcium Sensor-Associated Protein Kinase That Regulates Abscisic Acid and Cold Signal Transduction in Arabidopsis. Plant Cell 15, 411-423.

103. Kleinow, T., Himbert, S., Krenz, B., Jeske, H., and Koncz, C. (2009). NAC domain transcription factor ATAF1 interacts with SNF1-related kinases and silencing of its subfamily causes severe developmental defects in Arabidopsis. Plant Sci. 177, 360-370.

104. Klinedinst, S., Pascuzzi, P., Redman, J., Desai, M., and Arias, J. (2000). A xenobioticstress-activated transcription factor and its cognate target genes are preferentially expressed in root tip meristems. Plant Mol. Biol. 42, 679-688.

105. Kombrink, E. (2012). Chemical and genetic exploration of jasmonate biosynthesis and signaling paths. Planta 236, 1351-1366.

106. Koncz, C., and Schell, J. (1986). The promoter of TL-DNA gene 5 controls the tissuespecific expression of chimaeric genes carried by a novel type of Agrobacterium binary vector. Mol. Gen. Genet. MGG 204, 383-396.

107. Koornneef, M., Bentsink, L., and Hilhorst, H. (2002). Seed dormancy and germination. Curr. Opin. Plant Biol. 5, 33-36.

108. Kramell, R., Schmidt, J., Herrmann, G., and Schliemann, W. (2005). N(jasmonoyl)tyrosine-derived compounds from flowers of broad beans (Vicia faba). J. Nat. Prod. 68, 1345-1349.

109. Kubigsteltig, I., Laudert, D., and Weiler, E.W. (1999). Structure and regulation of the Arabidopsis thaliana allene oxide synthase gene. Planta 208, 463-471.

110. Kunieda, T., Mitsuda, N., Ohme-Takagi, M., Takeda, S., Aida, M., Tasaka, M., Kondo, M., Nishimura, M., and Hara-Nishimura, I. (2008). NAC family proteins NARS1/NAC2 and 
NARS2/NAM in the outer integument regulate embryogenesis in Arabidopsis. Plant Cell 20, 2631-2642.

111. Le, D.T., Nishiyama, R., Watanabe, Y., Mochida, K., Yamaguchi-Shinozaki, K., Shinozaki, K., and Tran, L.-S.P. (2011). Genome-Wide Survey and Expression Analysis of the PlantSpecific NAC Transcription Factor Family in Soybean During Development and Dehydration Stress. DNA Res. Int. J. Rapid Publ. Rep. Genes Genomes 18, 263-276.

112. LeBrasseur, N.D., Maclntosh, G.C., Pérez-Amador, M.A., Saitoh, M., and Green, P.J. (2002). Local and systemic wound-induction of RNase and nuclease activities in Arabidopsis: RNS1 as a marker for a JA-independent systemic signaling pathway. Plant J. 29, 393-403.

113. Lee, K.P., Piskurewicz, U., Turecková, V., Strnad, M., and Lopez-Molina, L. (2010). A seed coat bedding assay shows that RGL2-dependent release of abscisic acid by the endosperm controls embryo growth in Arabidopsis dormant seeds. Proc. Natl. Acad. Sci. U. S. A. 107, 19108-19113.

114. León, J., Rojo, E., Titarenko, E., and Sánchez-Serrano, J.J. (1998). Jasmonic aciddependent and -independent wound signal transduction pathways are differentially regulated by $\mathrm{Ca} 2+/$ calmodulin in Arabidopsis thaliana. Mol. Gen. Genet. MGG 258, 412-419.

115. Leon-Reyes, A., Spoel, S.H., De Lange, E.S., Abe, H., Kobayashi, M., Tsuda, S., Millenaar, F.F., Welschen, R.A.M., Ritsema, T., and Pieterse, C.M.J. (2009). Ethylene modulates the role of NONEXPRESSOR OF PATHOGENESIS-RELATED GENES1 in cross talk between salicylate and jasmonate signaling. Plant Physiol. 149, 1797-1809.

116. Li, J., Brader, G., and Palva, E.T. (2004). The WRKY70 transcription factor: a node of convergence for jasmonate-mediated and salicylate-mediated signals in plant defense. Plant Cell 16, 319-331.

117. Li, J., Guo, G., Guo, W., Guo, G., Tong, D., Ni, Z., Sun, Q., and Yao, Y. (2012). miRNA164directed cleavage of ZmNAC1 confers lateral root development in maize (Zea mays L.). BMC Plant Biol. 12, 220.

118. Li, L., He, Z., Pandey, G.K., Tsuchiya, T., and Luan, S. (2002). Functional cloning and characterization of a plant efflux carrier for multidrug and heavy metal detoxification. J. Biol. Chem. 277, 5360-5368.

119. Lim, E.-K., Doucet, C.J., Li, Y., Elias, L., Worrall, D., Spencer, S.P., Ross, J., and Bowles, D.J. (2002). The activity of Arabidopsis glycosyltransferases toward salicylic acid, 4hydroxybenzoic acid, and other benzoates. J. Biol. Chem. 277, 586-592.

120. Liu, Y.-Z., Baig, M.N.R., Fan, R., Ye, J.-L., Cao, Y.-C., and Deng, X.-X. (2009). Identification and Expression Pattern of a Novel NAM, ATAF, and CUC-Like Gene from Citrus sinensis Osbeck. Plant Mol. Biol. Report. 27, 292-297.

121. Livak, K.J., and Schmittgen, T.D. (2001). Analysis of relative gene expression data using real-time quantitative PCR and the 2(-Delta Delta C(T)) Method. Methods San Diego Calif 25, 402-408. 
122. Loake, G., and Grant, M. (2007). Salicylic acid in plant defence-the players and protagonists. Curr. Opin. Plant Biol. 10, 466-472.

123. Lorenzo, O., Chico, J.M., Sanchez-Serrano, J.J., and Solano, R. (2004). JASMONATEINSENSITIVE1 Encodes a MYC Transcription Factor Essential to Discriminate between Different Jasmonate-Regulated Defense Responses in Arabidopsis. Plant Cell 16, 19381950.

124. Lorrain, S., Lin, B., Auriac, M.C., Kroj, T., Saindrenan, P., Nicole, M., Balagué, C., and Roby, D. (2004). Vascular associated death1, a novel GRAM domain-containing protein, is a regulator of cell death and defense responses in vascular tissues. Plant Cell 16, 2217-2232.

125. Lu, H. (2009). Dissection of salicylic acid-mediated defense signaling networks. Plant Signal. Behav. 4, 713-717.

126. Lu, P.-L., Chen, N.-Z., An, R., Su, Z., Qi, B.-S., Ren, F., Chen, J., and Wang, X.-C. (2007). A novel drought-inducible gene, ATAF1, encodes a NAC family protein that negatively regulates the expression of stress-responsive genes in Arabidopsis. Plant Mol. Biol. 63, 289-305.

127. Von Malek, B., van der Graaff, E., Schneitz, K., and Keller, B. (2002). The Arabidopsis male-sterile mutant dde2-2 is defective in the ALLENE OXIDE SYNTHASE gene encoding one of the key enzymes of the jasmonic acid biosynthesis pathway. Planta 216, 187192.

128. Mattanovich, D., Ruker, F., Machado, A.C., Laimer, M., Regner, F., Steinkellner, H., Himmler, G., and Katinger, H. (1989). Efficient transformation of Agrobacterium spp. by electroporation. Nucleic Acids Res. 17, 6747.

129. Matthes, M.C., Bruce, T.J.A., Ton, J., Verrier, P.J., Pickett, J.A., and Napier, J.A. (2010). The transcriptome of cis-jasmone-induced resistance in Arabidopsis thaliana and its role in indirect defence. Planta 232, 1163-1180.

130. Mauch-Mani, B., and Flors, V. (2009). The ATAF1 transcription factor: At the convergence point of ABA-dependent plant defense against biotic and abiotic stresses. Cell Res. 19, 1322-1323.

131. Mauch-Mani, B., and Mauch, F. (2005). The role of abscisic acid in plant-pathogen interactions. Curr. Opin. Plant Biol. 8, 409-414.

132. McConn, M., Creelman, R.A., Bell, E., Mullet, J.E., and Browse, J. (1997). Jasmonate is essential for insect defense in Arabidopsis. Proc. Natl. Acad. Sci. U. S. A. 94, 5473-5477.

133. Michaels, S.D., and Amasino, R.M. (2001). Loss of FLOWERING LOCUS C activity eliminates the late-flowering phenotype of FRIGIDA and autonomous pathway mutations but not responsiveness to vernalization. Plant Cell 13, 935-941.

134. Mitsuda, N., Hisabori, T., Takeyasu, K., and Sato, M.H. (2004). VOZ; Isolation and Characterization of Novel Vascular Plant Transcription Factors with a One-Zinc Finger from Arabidopsis thaliana. Plant Cell Physiol. 45, 845-854. 
135. Moeder, W., Ung, H., Mosher, S., and Yoshioka, K. (2010). SA-ABA antagonism in defense responses. Plant Signal. Behav. 5, 1231-1233.

136. Mosblech, A., Thurow, C., Gatz, C., Feussner, I., and Heilmann, I. (2011). Jasmonic acid perception by COI1 involves inositol polyphosphates in Arabidopsis thaliana. Plant J. 65, 949-957.

137. Mou, Z., Fan, W., and Dong, X. (2003). Inducers of plant systemic acquired resistance regulate NPR1 function through redox changes. Cell 113, 935-944.

138. Mousavi, S.A.R., Chauvin, A., Pascaud, F., Kellenberger, S., and Farmer, E.E. (2013). GLUTAMATE RECEPTOR-LIKE genes mediate leaf-to-leaf wound signalling. Nature 500, 422-426.

139. Mueller, S., Hilbert, B., Dueckershoff, K., Roitsch, T., Krischke, M., Mueller, M.J., and Berger, S. (2008). General Detoxification and Stress Responses Are Mediated by Oxidized Lipids through TGA Transcription Factors in Arabidopsis. Plant Cell 20, 768785.

140. Nakashita, H., Yasuda, M., Nitta, T., Asami, T., Fujioka, S., Arai, Y., Sekimata, K., Takatsuto, S., Yamaguchi, I., and Yoshida, S. (2003). Brassinosteroid functions in a broad range of disease resistance in tobacco and rice. Plant J. Cell Mol. Biol. 33, 887-898.

141. Naseem, M., and Dandekar, T. (2012). The Role of Auxin-Cytokinin Antagonism in PlantPathogen Interactions. PLoS Pathog. 8.

142. Navarro, L., Dunoyer, P., Jay, F., Arnold, B., Dharmasiri, N., Estelle, M., Voinnet, O., and Jones, J.D.G. (2006). A plant miRNA contributes to antibacterial resistance by repressing auxin signaling. Science 312, 436-439.

143. Ndamukong, I., Abdallat, A.A., Thurow, C., Fode, B., Zander, M., Weigel, R., and Gatz, C. (2007). SA-inducible Arabidopsis glutaredoxin interacts with TGA factors and suppresses JA-responsive PDF1.2 transcription. Plant J. Cell Mol. Biol. 50, 128-139.

144. Nishiuchi, T., Hamada, T., Kodama, H., and Iba, K. (1997). Wounding changes the spatial expression pattern of the arabidopsis plastid omega-3 fatty acid desaturase gene (FAD7) through different signal transduction pathways. Plant Cell 9, 1701-1712.

145. O'Donnell, Calvert, Atzorn, Wasternack, Leyser, and Bowles (1996). Ethylene as a Signal Mediating the Wound Response of Tomato Plants. Science 274, 1914-1917.

146. Ogawa, M., Hanada, A., Yamauchi, Y., Kuwahara, A., Kamiya, Y., and Yamaguchi, S. (2003). Gibberellin Biosynthesis and Response during Arabidopsis Seed Germination. Plant Cell Online 15, 1591-1604.

147. Ohtani, M., Nishikubo, N., Xu, B., Yamaguchi, M., Mitsuda, N., Goué, N., Shi, F., OhmeTakagi, M., and Demura, T. (2011). A NAC domain protein family contributing to the regulation of wood formation in poplar. Plant J. Cell Mol. Biol. 67, 499-512.

148. Oliveira, T.M. de, Cidade, L.C., Gesteira, A.S., Filho, M.A.C., Filho, W.S.S., and Costa, M.G.C. (2011). Analysis of the NAC transcription factor gene family in citrus reveals a novel member involved in multiple abiotic stress responses. Tree Genet. Genomes 7, 1123-1134. 
149. Olsen, A.N., Ernst, H.A., Leggio, L.L., and Skriver, K. (2005). NAC transcription factors: structurally distinct, functionally diverse. Trends Plant Sci. 10, 79-87.

150. Omote, H., Hiasa, M., Matsumoto, T., Otsuka, M., and Moriyama, Y. (2006). The MATE proteins as fundamental transporters of metabolic and xenobiotic organic cations. Trends Pharmacol. Sci. 27, 587-593.

151. Ooka, H., Satoh, K., Doi, K., Nagata, T., Otomo, Y., Murakami, K., Matsubara, K., Osato, N., Kawai, J., Carninci, P., et al. (2003). Comprehensive Analysis of NAC Family Genes in Oryza sativa and Arabidopsis thaliana. DNA Res. 10, 239-247.

152. Pandey, G.K., Grant, J.J., Cheong, Y.H., Kim, B.-G., Li, L.G., and Luan, S. (2008). Calcineurin-B-Like Protein CBL9 Interacts with Target Kinase CIPK3 in the Regulation of ABA Response in Seed Germination. Mol. Plant 1, 238-248.

153. Papadopoulos, J.S., and Agarwala, R. (2007). COBALT: constraint-based alignment tool for multiple protein sequences. Bioinforma. Oxf. Engl. 23, 1073-1079.

154. Park, J.-H., Halitschke, R., Kim, H.B., Baldwin, I.T., Feldmann, K.A., and Feyereisen, R. (2002a). A knock-out mutation in allene oxide synthase results in male sterility and defective wound signal transduction in Arabidopsis due to a block in jasmonic acid biosynthesis. Plant J. 31, 1-12.

155. Park, J.-H., Halitschke, R., Kim, H.B., Baldwin, I.T., Feldmann, K.A., and Feyereisen, R. (2002b). A knock-out mutation in allene oxide synthase results in male sterility and defective wound signal transduction in Arabidopsis due to a block in jasmonic acid biosynthesis. Plant J. Cell Mol. Biol. 31, 1-12.

156. Pauwels, L., and Goossens, A. (2011). The JAZ proteins: a crucial interface in the jasmonate signaling cascade. Plant Cell 23, 3089-3100.

157. Pauwels, L., Barbero, G.F., Geerinck, J., Tilleman, S., Grunewald, W., Pérez, A.C., Chico, J.M., Bossche, R.V., Sewell, J., Gil, E., et al. (2010). NINJA connects the co-repressor TOPLESS to jasmonate signalling. Nature $464,788-791$.

158. Pearce, G., Strydom, D., Johnson, S., and Ryan, C.A. (1991). A polypeptide from tomato leaves induces wound-inducible proteinase inhibitor proteins. Science 253, 895-897.

159. Pei, H., Ma, N., Tian, J., Luo, J., Chen, J., Li, J., Zheng, Y., Chen, X., Fei, Z., and Gao, J. (2013). An NAC transcription factor controls ethylene-regulated cell expansion in flower petals. Plant Physiol. 163, 775-791.

160. Peña-Cortés, H., Fisahn, J., and Willmitzer, L. (1995). Signals involved in wound-induced proteinase inhibitor II gene expression in tomato and potato plants. Proc. Natl. Acad. Sci. U. S. A. 92, 4106-4113.

161. Penninckx, I.A., Thomma, B.P., Buchala, A., Metraux, J.P., and Broekaert, W.F. (1998). Concomitant activation of jasmonate and ethylene response pathways is required for induction of a plant defensin gene in Arabidopsis. Plant Cell 10, 2103-2113.

162. Petersen, M., Brodersen, P., Naested, H., Andreasson, E., Lindhart, U., Johansen, B., Nielsen, H.B., Lacy, M., Austin, M.J., Parker, J.E., et al. (2000). Arabidopsis map kinase 4 negatively regulates systemic acquired resistance. Cell 103, 1111-1120. 
163. Pieterse, C.M.J., Leon-Reyes, A., Van der Ent, S., and Van Wees, S.C.M. (2009). Networking by small-molecule hormones in plant immunity. Nat. Chem. Biol. 5, 308316.

164. Pieterse, C.M.J., Van der Does, D., Zamioudis, C., Leon-Reyes, A., and Van Wees, S.C.M. (2012). Hormonal Modulation of Plant Immunity. Annu. Rev. Cell Dev. Biol. 28, 489521.

165. Puranik, S., Bahadur, R.P., Srivastava, P.S., and Prasad, M. (2011). Molecular Cloning and Characterization of a Membrane Associated NAC Family Gene, SiNAC from Foxtail Millet [Setaria italica (L.) P. Beauv.]. Mol. Biotechnol. 49, 138-150.

166. Puranik, S., Sahu, P.P., Srivastava, P.S., and Prasad, M. (2012). NAC proteins: regulation and role in stress tolerance. Trends Plant Sci. 17, 369-381.

167. Ramegowda, V., Senthil-Kumar, M., Nataraja, K.N., Reddy, M.K., Mysore, K.S., and Udayakumar, M. (2012). Expression of a Finger Millet Transcription Factor, EcNAC1, in Tobacco Confers Abiotic Stress-Tolerance. PLoS ONE 7.

168. Rao, M.V., Lee, H., Creelman, R.A., Mullet, J.E., and Davis, K.R. (2000). Jasmonic Acid Signaling Modulates Ozone-Induced Hypersensitive Cell Death. Plant Cell Online 12, 1633-1646.

169. Rao, M.V., Lee, H., and Davis, K.R. (2002). Ozone-induced ethylene production is dependent on salicylic acid, and both salicylic acid and ethylene act in concert to regulate ozone-induced cell death. Plant J. 32, 447-456.

170. Rensing, S.A., Lang, D., Zimmer, A.D., Terry, A., Salamov, A., Shapiro, H., Nishiyama, T., Perroud, P.-F., Lindquist, E.A., Kamisugi, Y., et al. (2008). The Physcomitrella genome reveals evolutionary insights into the conquest of land by plants. Science 319, 64-69.

171. Reusche, M., Thole, K., Janz, D., Truskina, J., Rindfleisch, S., Drubert, C., Polle, A., Lipka, V., and Teichmann, T. (2012). Verticillium Infection Triggers VASCULAR-RELATED NAC DOMAIN7-Dependent de Novo Xylem Formation and Enhances Drought Tolerance in Arabidopsis[W]. Plant Cell 24, 3823-3837.

172. Reymond, P., Weber, H., Damond, M., and Farmer, E.E. (2000). Differential Gene Expression in Response to Mechanical Wounding and Insect Feeding in Arabidopsis. Plant Cell Online 12, 707-719.

173. Ricachenevsky, F.K., Menguer, P.K., and Sperotto, R.A. (2013). kNACking on heaven's door: how important are NAC transcription factors for leaf senescence and $\mathrm{Fe} / \mathrm{Zn}$ remobilization to seeds? Front. Plant Sci. 4.

174. Riechmann, J.L., Heard, J., Martin, G., Reuber, L., -Z, C., Jiang, Keddie, J., Adam, L., Pineda, O., Ratcliffe, O.J., et al. (2000). Arabidopsis Transcription Factors: GenomeWide Comparative Analysis Among Eukaryotes. Science 290, 2105-2110.

175. Robert-Seilaniantz, A., Grant, M., and Jones, J.D.G. (2011). Hormone Crosstalk in Plant Disease and Defense: More Than Just JASMONATE-SALICYLATE Antagonism. Annu. Rev. Phytopathol. 49, 317-343. 
176. Rojo, E., Titarenko, E., León, J., Berger, S., Vancanneyt, G., and Sánchez-Serrano, J.J. (1998). Reversible protein phosphorylation regulates jasmonic acid-dependent and independent wound signal transduction pathways in Arabidopsis thaliana. Plant J. 13, 153-165.

177. Rojo, E., León, J., and Sánchez-Serrano, J.J. (1999). Cross-talk between wound signalling pathways determines local versus systemic gene expression in Arabidopsis thaliana. Plant J. 20, 135-142.

178. Saito, R., Shimakawa, G., Nishi, A., Iwamoto, T., Sakamoto, K., Yamamoto, H., Amako, K., Makino, A., and Miyake, C. (2013). Functional Analysis of the AKR4C Subfamily of Arabidopsis thaliana: Model Structures, Substrate Specificity, Acrolein Toxicity, and Responses to Light and [CO2]. Biosci. Biotechnol. Biochem.

179. Sandermann Jr., H. (1992). Plant metabolism of xenobiotics. Trends Biochem. Sci. 17, $82-84$.

180. Schilmiller, A.L., Koo, A.J.K., and Howe, G.A. (2007). Functional diversification of acylcoenzyme A oxidases in jasmonic acid biosynthesis and action. Plant Physiol. 143, 812824.

181. Searle, I., He, Y., Turck, F., Vincent, C., Fornara, F., Krober, S., Amasino, R.A., and Coupland, G. (2006). The transcription factor FLC confers a flowering response to vernalization by repressing meristem competence and systemic signaling in Arabidopsis. Genes Dev. 20, 898-912.

182. Seo, H.S., Song, J.T., Cheong, J.J., Lee, Y.H., Lee, Y.W., Hwang, I., Lee, J.S., and Choi, Y.D. (2001). Jasmonic acid carboxyl methyltransferase: a key enzyme for jasmonateregulated plant responses. Proc. Natl. Acad. Sci. U. S. A. 98, 4788-4793.

183. Seo, M., Hanada, A., Kuwahara, A., Endo, A., Okamoto, M., Yamauchi, Y., North, H., Marion-Poll, A., Sun, T.-P., Koshiba, T., et al. (2006). Regulation of hormone metabolism in Arabidopsis seeds: phytochrome regulation of abscisic acid metabolism and abscisic acid regulation of gibberellin metabolism. Plant J. Cell Mol. Biol. 48, 354-366.

184. Seo, P.J., Kim, S.-G., and Park, C.-M. (2008). Membrane-bound transcription factors in plants. Trends Plant Sci. 13, 550-556.

185. Seo, P.J., Kim, M.J., Song, J.-S., Kim, Y.-S., Kim, H.-J., and Park, C.-M. (2010a). Proteolytic processing of an Arabidopsis membrane-bound NAC transcription factor is triggered by cold-induced changes in membrane fluidity. Biochem. J. 427, 359-367.

186. Seo, P.J., Kim, M.J., Park, J.-Y., Kim, S.-Y., Jeon, J., Lee, Y.-H., Kim, J., and Park, C.-M. (2010b). Cold activation of a plasma membrane-tethered NAC transcription factor induces a pathogen resistance response in Arabidopsis. Plant J. 61, 661-671.

187. Shah, J., Tsui, F., and Klessig, D.F. (1997). Characterization of a salicylic acid-insensitive mutant (sai1) of Arabidopsis thaliana, identified in a selective screen utilizing the SAinducible expression of the tms2 gene. Mol. Plant-Microbe Interact. MPMI 10, 69-78.

188. Shamimuzzaman, M., and Vodkin, L. (2013). Genome-wide identification of binding sites for NAC and YABBY transcription factors and co-regulated genes during soybean seedling development by ChIP-Seq and RNA-Seq. BMC Genomics 14, 477. 
189. Shearer, H.L., Cheng, Y.T., Wang, L., Liu, J., Boyle, P., Després, C., Zhang, Y., Li, X., and Fobert, P.R. (2012). Arabidopsis Clade I TGA Transcription Factors Regulate Plant Defenses in an NPR1-Independent Fashion. Mol. Plant. Microbe Interact. 25, 14591468.

190. Sheen, J. (2001). Signal Transduction in Maize and Arabidopsis Mesophyll Protoplasts. Plant Physiol. 127, 1466-1475.

191. Shen, H., Yin, Y., Chen, F., Xu, Y., and Dixon, R.A. (2009). A Bioinformatic Analysis of NAC Genes for Plant Cell Wall Development in Relation to Lignocellulosic Bioenergy Production. BioEnergy Res. 2, 217-232.

192. Siemens, J., Keller, I., Sarx, J., Kunz, S., Schuller, A., Nagel, W., Schmülling, T., Parniske, M., and Ludwig-Müller, J. (2006). Transcriptome analysis of Arabidopsis clubroots indicate a key role for cytokinins in disease development. Mol. Plant-Microbe Interact. MPMI 19, 480-494.

193. Simpson, P.J., Tantitadapitak, C., Reed, A.M., Mather, O.C., Bunce, C.M., White, S.A., and Ride, J.P. (2009). Characterization of two novel aldo-keto reductases from Arabidopsis: expression patterns, broad substrate specificity, and an open active-site structure suggest a role in toxicant metabolism following stress. J. Mol. Biol. 392, 465480.

194. Song, J.T., Koo, Y.J., Seo, H.S., Kim, M.C., Choi, Y.D., and Kim, J.H. (2008). Overexpression of AtSGT1, an Arabidopsis salicylic acid glucosyltransferase, leads to increased susceptibility to Pseudomonas syringae. Phytochemistry 69, 1128-1134.

195. Song, S., Huang, H., Gao, H., Wang, J., Wu, D., Liu, X., Yang, S., Zhai, Q., Li, C., Qi, T., et al. (2014). Interaction between MYC2 and ETHYLENE INSENSITIVE3 Modulates Antagonism between Jasmonate and Ethylene Signaling in Arabidopsis. Plant Cell Online tpc.113.120394.

196. Souer, E., van Houwelingen, A., Kloos, D., Mol, J., and Koes, R. (1996). The No Apical Meristem Gene of Petunia Is Required for Pattern Formation in Embryos and Flowers and Is Expressed at Meristem and Primordia Boundaries. Cell 85, 159-170.

197. Spaepen, S., and Vanderleyden, J. (2011). Auxin and Plant-Microbe Interactions. Cold Spring Harb. Perspect. Biol. 3.

198. Spoel, S.H., Mou, Z., Tada, Y., Spivey, N.W., Genschik, P., and Dong, X. (2009). Proteasome-Mediated Turnover of the Transcription Co-Activator NPR1 Plays Dual Roles in Regulating Plant Immunity. Cell 137, 860-872.

199. Staswick, P.E. (2009). The tryptophan conjugates of jasmonic and indole-3-acetic acids are endogenous auxin inhibitors. Plant Physiol. 150, 1310-1321.

200. Staswick, P.E., and Tiryaki, I. (2004). The oxylipin signal jasmonic acid is activated by an enzyme that conjugates it to isoleucine in Arabidopsis. Plant Cell 16, 2117-2127.

201. Staswick, P.E., Su, W., and Howell, S.H. (1992). Methyl jasmonate inhibition of root growth and induction of a leaf protein are decreased in an Arabidopsis thaliana mutant. Proc. Natl. Acad. Sci. 89, 6837-6840. 
202. Stenzel, I., Hause, B., Maucher, H., Pitzschke, A., Miersch, O., Ziegler, J., Ryan, C.A., and Wasternack, C. (2003a). Allene oxide cyclase dependence of the wound response and vascular bundle-specific generation of jasmonates in tomato - amplification in wound signalling. Plant J. Cell Mol. Biol. 33, 577-589.

203. Stenzel, I., Hause, B., Miersch, O., Kurz, T., Maucher, H., Weichert, H., Ziegler, J., Feussner, I., and Wasternack, C. (2003b). Jasmonate biosynthesis and the allene oxide cyclase family of Arabidopsis thaliana. Plant Mol. Biol. 51, 895-911.

204. Stenzel, I., Otto, M., Delker, C., Kirmse, N., Schmidt, D., Miersch, O., Hause, B., and Wasternack, C. (2012). ALLENE OXIDE CYCLASE (AOC) gene family members of Arabidopsis thaliana: tissue- and organ-specific promoter activities and in vivo heteromerization. J. Exp. Bot. 63, 6125-6138.

205. Stintzi, A., and Browse, J. (2000). The Arabidopsis male-sterile mutant, opr3, lacks the 12-oxophytodienoic acid reductase required for jasmonate synthesis. Proc. Natl. Acad. Sci. U. S. A. 97, 10625-10630.

206. Tada, Y., Spoel, S.H., Pajerowska-Mukhtar, K., Mou, Z., Song, J., Wang, C., Zuo, J., and Dong, X. (2008). Plant immunity requires conformational changes of NPR1 via Snitrosylation and thioredoxins. Science 321, 952-956.

207. Takeda, S., Hanano, K., Kariya, A., Shimizu, S., Zhao, L., Matsui, M., Tasaka, M., and Aida, M. (2011). CUP-SHAPED COTYLEDON1 transcription factor activates the expression of LSH4 and LSH3, two members of the ALOG gene family, in shoot organ boundary cells. Plant J. Cell Mol. Biol. 66, 1066-1077.

208. Theodoulou, F.L., Job, K., Slocombe, S.P., Footitt, S., Holdsworth, M., Baker, A., Larson, T.R., and Graham, I.A. (2005). Jasmonic acid levels are reduced in COMATOSE ATPbinding cassette transporter mutants. Implications for transport of jasmonate precursors into peroxisomes. Plant Physiol. 137, 835-840.

209. Thines, B., Katsir, L., Melotto, M., Niu, Y., Mandaokar, A., Liu, G., Nomura, K., He, S.Y., Howe, G.A., and Browse, J. (2007). JAZ repressor proteins are targets of the SCF(COI1) complex during jasmonate signalling. Nature 448, 661-665.

210. Titarenko, E., Rojo, E., Leon, J., and Sanchez-Serrano, J.J. (1997). Jasmonic AcidDependent and -Independent Signaling Pathways Control Wound-Induced Gene Activation in Arabidopsis thaliana. Plant Physiol. 115, 817-826.

211. De Torres-Zabala, M., Truman, W., Bennett, M.H., Lafforgue, G., Mansfield, J.W., Rodriguez Egea, P., Bögre, L., and Grant, M. (2007). Pseudomonas syringae pv. tomato hijacks the Arabidopsis abscisic acid signalling pathway to cause disease. EMBO J. 26, 1434-1443.

212. Tran, L.-S.P., Nakashima, K., Sakuma, Y., Simpson, S.D., Fujita, Y., Maruyama, K., Fujita, M., Seki, M., Shinozaki, K., and Yamaguchi-Shinozaki, K. (2004). Isolation and Functional Analysis of Arabidopsis Stress-Inducible NAC Transcription Factors That Bind to a Drought-Responsive cis-Element in the early responsive to dehydration stress 1 Promoter. Plant Cell 16, 2481-2498.

213. Tran, L.-S.P., Nakashima, K., Sakuma, Y., Osakabe, Y., Qin, F., Simpson, S.D., Maruyama, K., Fujita, Y., Shinozaki, K., and Yamaguchi-Shinozaki, K. (2007). Co-expression of the 
stress-inducible zinc finger homeodomain ZFHD1 and NAC transcription factors enhances expression of the ERD1 gene in Arabidopsis. Plant J. 49, 46-63.

214. Tran, L.-S.P., Quach, T.N., Guttikonda, S.K., Aldrich, D.L., Kumar, R., Neelakandan, A., Valliyodan, B., and Nguyen, H.T. (2009). Molecular characterization of stress-inducible GmNAC genes in soybean. Mol. Genet. Genomics MGG 281, 647-664.

215. Tsuda, K., Sato, M., Stoddard, T., Glazebrook, J., and Katagiri, F. (2009). Network Properties of Robust Immunity in Plants. PLoS Genet 5, e1000772.

216. Turner, J.G., Ellis, C., and Devoto, A. (2002). The Jasmonate Signal Pathway. Plant Cell 14, s153-s164.

217. Vlot, A.C., Dempsey, D.A., and Klessig, D.F. (2009). Salicylic Acid, a Multifaceted Hormone to Combat Disease. Annu. Rev. Phytopathol. 47, 177-206.

218. De Vos, M., Van Oosten, V.R., Van Poecke, R.M.P., Van Pelt, J.A., Pozo, M.J., Mueller, M.J., Buchala, A.J., Métraux, J.-P., Van Loon, L.C., Dicke, M., et al. (2005). Signal signature and transcriptome changes of Arabidopsis during pathogen and insect attack. Mol. Plant-Microbe Interact. MPMI 18, 923-937.

219. Wang, L., and Fobert, P.R. (2013). Arabidopsis clade I TGA factors regulate apoplastic defences against the bacterial pathogen Pseudomonas syringae through endoplasmic reticulum-based processes. PloS One 8, e77378.

220. Wang, D., Pajerowska-Mukhtar, K., Culler, A.H., and Dong, X. (2007). Salicylic acid inhibits pathogen growth in plants through repression of the auxin signaling pathway. Curr. Biol. CB 17, 1784-1790.

221. Wang, X., Goregaoker, S.P., and Culver, J.N. (2009a). Interaction of the Tobacco Mosaic Virus Replicase Protein with a NAC Domain Transcription Factor Is Associated with the Suppression of Systemic Host Defenses. J. Virol. 83, 9720-9730.

222. Wang, X., Basnayake, B.M.V.S., Zhang, H., Li, G., Li, W., Virk, N., Mengiste, T., and Song, F. (2009b). The Arabidopsis ATAF1, a NAC transcription factor, is a negative regulator of defense responses against necrotrophic fungal and bacterial pathogens. Mol. PlantMicrobe Interact. MPMI 22, 1227-1238.

223. Wasternack, C. (2007). Jasmonates: an update on biosynthesis, signal transduction and action in plant stress response, growth and development. Ann. Bot. 100, 681-697.

224. Wasternack, C., and Hause, B. (2013). Jasmonates: biosynthesis, perception, signal transduction and action in plant stress response, growth and development. An update to the 2007 review in. Ann. Bot. 111, 1021-1058.

225. Weiss, C., and Bevan, M. (1991). Ethylene and a Wound Signal Modulate Local and Systemic Transcription of win2 Genes in Transgenic Potato Plants. Plant Physiol. 96, 943-951.

226. Wildermuth, M.C., Dewdney, J., Wu, G., and Ausubel, F.M. (2001). Isochorismate synthase is required to synthesize salicylic acid for plant defence. Nature 414, 562-565. 
227. Wildon, D.C., Thain, J.F., Minchin, P.E.H., Gubb, I.R., Reilly, A.J., Skipper, Y.D., Doherty, H.M., O'Donnell, P.J., and Bowles, D.J. (1992). Electrical signalling and systemic proteinase inhibitor induction in the wounded plant. Nature 360, 62-65.

228. Willmann, M.R., and Poethig, R.S. (2011a). The effect of the floral repressor FLC on the timing and progression of vegetative phase change in Arabidopsis. Dev. Camb. Engl. $138,677-685$.

229. Willmann, M.R., and Poethig, R.S. (2011b). The effect of the floral repressor FLC on the timing and progression of vegetative phase change in Arabidopsis. Dev. Camb. Engl. $138,677-685$.

230. Winter, D., Vinegar, B., Nahal, H., Ammar, R., Wilson, G.V., and Provart, N.J. (2007). An "Electronic Fluorescent Pictograph" Browser for Exploring and Analyzing Large-Scale Biological Data Sets. PLoS ONE 2, e718.

231. Wu, Y., Deng, Z., Lai, J., Zhang, Y., Yang, C., Yin, B., Zhao, Q., Zhang, L., Li, Y., Yang, C., et al. (2009). Dual function of Arabidopsis ATAF1 in abiotic and biotic stress responses. Cell Res. 19, 1279-1290.

232. Xia, N., Zhang, G., Liu, X.-Y., Deng, L., Cai, G.-L., Zhang, Y., Wang, X.-J., Zhao, J., Huang, L.-L., and Kang, Z.-S. (2010). Characterization of a novel wheat NAC transcription factor gene involved in defense response against stripe rust pathogen infection and abiotic stresses. Mol. Biol. Rep. 37, 3703-3712.

233. Xie, D.X., Feys, B.F., James, S., Nieto-Rostro, M., and Turner, J.G. (1998). COI1: an Arabidopsis gene required for jasmonate-regulated defense and fertility. Science 280 , 1091-1094.

234. Xie, Q., Sanz-Burgos, A.P., Guo, H., García, J.A., and Gutiérrez, C. (1999). GRAB proteins, novel members of the NAC domain family, isolated by their interaction with a geminivirus protein. Plant Mol. Biol. 39, 647-656.

235. Xie, Q., Guo, H.-S., Dallman, G., Fang, S., Weissman, A.M., and Chua, N.-H. (2002). SINAT5 promotes ubiquitin-related degradation of NAC1 to attenuate auxin signals. Nature 419, 167-170.

236. Xu, J., Audenaert, K., Hofte, M., and De Vleesschauwer, D. (2013a). Abscisic Acid Promotes Susceptibility to the Rice Leaf Blight Pathogen Xanthomonas oryzae pv oryzae by Suppressing Salicylic Acid-Mediated Defenses. PLoS ONE 8.

237. Xu, Z.-Y., Kim, S.Y., Hyeon, D.Y., Kim, D.H., Dong, T., Park, Y., Jin, J.B., Joo, S.-H., Kim, S.K., Hong, J.C., et al. (2013b). The Arabidopsis NAC Transcription Factor ANAC096 Cooperates with bZIP-Type Transcription Factors in Dehydration and Osmotic Stress Responses. Plant Cell Online 25, 4708-4724.

238. Yadav, S.K., Singla-Pareek, S.L., and Sopory, S.K. (2008). An overview on the role of methylglyoxal and glyoxalases in plants. Drug Metabol. Drug Interact. 23, 51-68.

239. Yamaguchi, M., Ohtani, M., Mitsuda, N., Kubo, M., Ohme-Takagi, M., Fukuda, H., and Demura, T. (2010). VND-INTERACTING2, a NAC Domain Transcription Factor, Negatively Regulates Xylem Vessel Formation in Arabidopsis[W][OA]. Plant Cell 22, 1249-1263. 
240. Yamauchi, Y., Hasegawa, A., Taninaka, A., Mizutani, M., and Sugimoto, Y. (2011). $\mathrm{NADPH}$-dependent reductases involved in the detoxification of reactive carbonyls in plants. J. Biol. Chem. 286, 6999-7009.

241. Yan, Y., Stolz, S., Chételat, A., Reymond, P., Pagni, M., Dubugnon, L., and Farmer, E.E. (2007). A downstream mediator in the growth repression limb of the jasmonate pathway. Plant Cell 19, 2470-2483.

242. Yang, D.-L., Yao, J., Mei, C.-S., Tong, X.-H., Zeng, L.-J., Li, Q., Xiao, L.-T., Sun, T., Li, J., Deng, X.-W., et al. (2012). Plant hormone jasmonate prioritizes defense over growth by interfering with gibberellin signaling cascade. Proc. Natl. Acad. Sci. U. S. A. 109, E1192E1200.

243. Yoshiyama, K., Conklin, P.A., Huefner, N.D., and Britt, A.B. (2009). Suppressor of gamma response 1 (SOG1) encodes a putative transcription factor governing multiple responses to DNA damage. Proc. Natl. Acad. Sci. U. S. A. 106, 12843-12848.

244. Zander, M., La Camera, S., Lamotte, O., Métraux, J.-P., and Gatz, C. (2010). Arabidopsis thaliana class-II TGA transcription factors are essential activators of jasmonic acid/ethylene-induced defense responses. Plant J. 61, 200-210.

245. Zander, M., Chen, S., Imkampe, J., Thurow, C., and Gatz, C. (2012). Repression of the Arabidopsis thaliana jasmonic acid/ethylene-induced defense pathway by TGAinteracting glutaredoxins depends on their C-terminal ALWL motif. Mol. Plant 5, 831840 .

246. Zhang, Y., Tessaro, M.J., Lassner, M., and Li, X. (2003). Knockout analysis of Arabidopsis transcription factors TGA2, TGA5, and TGA6 reveals their redundant and essential roles in systemic acquired resistance. Plant Cell 15, 2647-2653.

247. Zhou, M., Li, D., Li, Z., Hu, Q., Yang, C., Zhu, L., and Luo, H. (2013). Constitutive Expression of a miR319 Gene Alters Plant Development and Enhances Salt and Drought Tolerance in Transgenic Creeping Bentgrass1[W][OA]. Plant Physiol. 161, 1375-1391.

248. Zhu, Z., An, F., Feng, Y., Li, P., Xue, L., A, M., Jiang, Z., Kim, J.-M., To, T.K., Li, W., et al. (2011). Derepression of ethylene-stabilized transcription factors (EIN3/EIL1) mediates jasmonate and ethylene signaling synergy in Arabidopsis. Proc. Natl. Acad. Sci. U. S. A. $108,12539-12544$. 


\section{Acknowledgement}

Completion of this doctoral thesis was possible only due to the help and support from several people to whom I shall forever be very grateful.

First and foremost I would like to offer my sincere gratitude to my supervisor Prof. Dr. Christiane Gatz for giving me the opportunity to work in her lab and on this topic. She has been a wonderful guide, encouraging at all times while patiently and critically guiding me in taking this project forward.

I wish to express my heartfelt thanks to my thesis committee and examiners Prof. Dr. Volker Lipka, Prof. Dr. Ivo Feussner, PD Dr. Thomas Teichmann, Jr. Prof. Cynthia Gleason and Prof. Dr. Andrea Polle for their constructive discussions towards the progress of this work. I sincerely appreciate the insightful suggestions and discussions of Dr. Corinna Thurow throughout this project.

I would also like to thank Prof. Ivo Feussner and Dr. Tim Iven for doing the metabolite measurements.

I would like to convey my warm and most sincere gratitude to the technical support provided by Ronny, Anna and Larissa. They all have been immensely helpful and I have always felt that they do such a wonderful job that working in the laboratory becomes considerably easy! I would like to say special thanks to Guido who is always ready to help with whatever problems or requests that you take to him. And of course, I owe a very big thanks to all my present and past colleagues - Mark, Martin, Anjali, Alex, Johanna, Li-Jun, Ning, Armin, Joachim, Sonja, Fred and Natthanon. It has been an honour and pleasure to know and work with you all. I could not have asked for a better (or more fun) working environment!

I would also like to acknowledge all my lovely friends, here and from back home, for being the wonderful, understanding and caring friends that they are.

My parents have been my inspiration throughout life and I am greatly indebted to them and my whole family who have unconditionally loved, supported and believed in me. I thank my dear husband, Nishit, for encouraging me to pursue my interests even though it meant that we would be miles apart! 


\section{Supplementary Material}

Table S1: List of genes up-regulated in 35S:ANAC032 plants ( $>2$-fold; $\mathrm{P}<0.05$ )

\begin{tabular}{|c|c|c|c|c|c|}
\hline No. & Gene code & Symbol & Description & $\begin{array}{c}\text { 35S:ANAC032/ } \\
\text { Col-0 } \\
\text { (fold induction) }\end{array}$ & $p$-value \\
\hline \multicolumn{6}{|c|}{ Cell wall related } \\
\hline 1 & AT1G26770 & $\begin{array}{l}\text { ATEXPA10, } \\
\text { ATHEXP, } \\
\text { ALPHA } 1.1 \\
\end{array}$ & $\begin{array}{l}\text { ARABIDOPSIS THALIANA } \\
\text { EXPANSIN A 10; structural } \\
\text { constituent of cell wall }\end{array}$ & 7.724935 & 0.000106 \\
\hline 2 & AT4G30290 & XTH19 & $\begin{array}{l}\text { XYLOGLUCAN } \\
\text { ENDOTRANSGLUCOSYLA } \\
\text { SE/HYDROLASE 19; } \\
\text { hydrolase }\end{array}$ & 4.89963 & 0.001922 \\
\hline 3 & AT5G34940 & AtGUS3 & $\begin{array}{l}\text { Arabidopsis thaliana } \\
\text { glucuronidase } 3 \text {; beta- } \\
\text { glucuronidase }\end{array}$ & 4.183797 & 0.00031 \\
\hline 4 & AT5G06860 & PGIP1 & $\begin{array}{l}\text { POLYGALACTURONASE } \\
\text { INHIBITING PROTEIN 1; } \\
\text { protein binding }\end{array}$ & 3.653244 & 0.001729 \\
\hline 5 & AT3G43270 & & pectinesterase family protein & 3.565157 & 3.57E-06 \\
\hline 6 & AT4G14130 & XTR7 & $\begin{array}{l}\text { XYLOGLUCAN } \\
\text { ENDOTRANSGLYCOSYLA } \\
\text { SE 7; hydrolase }\end{array}$ & 3.401027 & 0.001132 \\
\hline 7 & AT1G28600 & & lipase, putative & 3.353894 & 0.003991 \\
\hline 8 & AT1G32960 & SBT3.3 & $\begin{array}{l}\text { identical protein binding / } \\
\text { serine-type endopeptidase }\end{array}$ & 3.331092 & 0.014816 \\
\hline 9 & AT4G19410 & & $\begin{array}{l}\text { pectinacetylesterase, } \\
\text { putative }\end{array}$ & 2.724269 & 0.000827 \\
\hline 10 & AT5G06870 & PGIP2 & $\begin{array}{l}\text { POLYGALACTURONASE } \\
\text { INHIBITING PROTEIN 2; } \\
\text { protein binding }\end{array}$ & 2.528479 & 0.003115 \\
\hline 11 & AT3G45970 & $\begin{array}{l}\text { ATEXLA1, } \\
\text { ATHEXP } \\
\text { BETA } 2.1 \\
\end{array}$ & $\begin{array}{l}\text { ARABIDOPSIS THALIANA } \\
\text { EXPANSIN-LIKE A1 }\end{array}$ & 2.312124 & $3.38 \mathrm{E}-05$ \\
\hline 12 & AT1G32170 & $\begin{array}{l}\text { XTR4, } \\
\text { XTH30 }\end{array}$ & $\begin{array}{l}\text { XYLOGLUCAN } \\
\text { ENDOTRANSGLYCOSYLA } \\
\text { SE 4; hydrolase }\end{array}$ & 2.250298 & 0.003565 \\
\hline 13 & AT3G55430 & & $\begin{array}{l}\text { glycosyl hydrolase family } 17 \\
\text { protein }\end{array}$ & 2.219432 & 0.002884 \\
\hline 14 & AT2G01850 & $\begin{array}{l}\text { EXGT-A3, } \\
\text { XTH27 }\end{array}$ & $\begin{array}{l}\text { hydrolase, acting on glycosyl } \\
\text { bonds }\end{array}$ & 2.186094 & 0.00019 \\
\hline 15 & AT3G14060 & & Unknown function & 2.008632 & 0.000479 \\
\hline 16 & $\begin{array}{l}\text { AT4G11320; } \\
\text { AT4G11310 }\end{array}$ & & cysteine proteinase, putative & 3.660721 & 0.026587 \\
\hline \multicolumn{6}{|c|}{ Glucosyltransferase } \\
\hline 17 & AT2G43820 & $\begin{array}{l}\text { UGT74F2, } \\
\text { SAGT1 }\end{array}$ & $\begin{array}{l}\text { UDP-glucose:4- } \\
\text { aminobenzoate } \\
\text { acylglucosyltransferase }\end{array}$ & 18.93009 & 7.38E-05 \\
\hline 18 & AT4G15490 & UGT84A3 & $\begin{array}{l}\text { UDP-glycosyltransferase/ } \\
\text { sinapate 1- } \\
\text { glucosyltransferase }\end{array}$ & 12.35113 & 8.21E-06 \\
\hline 19 & AT1G05680 & UGT74E2 & $\begin{array}{l}\text { UDP-glucosyl transferase } \\
\text { family protein }\end{array}$ & 9.512387 & 7.81E-05 \\
\hline 20 & AT3G11340 & UGT76B1 & $\begin{array}{l}\text { UDP-glucosyl transferase } \\
\text { family protein }\end{array}$ & 8.511282 & 0.005196 \\
\hline 21 & AT3G46660 & UGT76E12 & $\begin{array}{l}\text { quercetin 3-O- } \\
\text { glucosyltransferase/ } \\
\text { quercetin 7-O- }\end{array}$ & 7.649356 & 0.002896 \\
\hline
\end{tabular}


Supplementary Material

\begin{tabular}{|c|c|c|c|c|c|}
\hline & & & glucosyltransferase & & \\
\hline 22 & AT3G46670 & UGT76E11 & $\begin{array}{l}\text { quercetin 3-O- } \\
\text { glucosyltransferase }\end{array}$ & 4.685537 & 0.002451 \\
\hline 23 & AT2G30140 & UGT87A2 & $\begin{array}{l}\text { UDP-glucosyl transferase } \\
\text { family protein }\end{array}$ & 3.745069 & 0.000208 \\
\hline 24 & AT2G36750 & UGT73C1 & $\begin{array}{l}\text { cis-zeatin O-beta-D- } \\
\text { glucosyltransferase/ trans- } \\
\text { zeatin O-beta-D- } \\
\text { glucosyltransferase }\end{array}$ & 3.558715 & 0.015248 \\
\hline 25 & AT2G36970 & & $\begin{array}{l}\text { UDP-glucosyl transferase } \\
\text { family protein }\end{array}$ & 2.825846 & 0.000183 \\
\hline 26 & AT1G70090 & $\begin{array}{l}\text { GATL9, } \\
\text { LGT8 }\end{array}$ & $\begin{array}{l}\text { GLUCOSYL } \\
\text { TRANSFERASE FAMILY 8; } \\
\text { polygalacturonate 4-alpha- } \\
\text { galacturonosyltransferase }\end{array}$ & 2.343912 & 0.002902 \\
\hline 27 & AT1G05560 & UGT75B1 & $\begin{array}{l}\text { UDP-glycosyltransferase/ } \\
\text { abscisic acid } \\
\text { glucosyltransferase }\end{array}$ & 2.219308 & 0.038063 \\
\hline 28 & $\begin{array}{l}\text { AT2G36780; } \\
\text { AT2G36770 }\end{array}$ & & $\begin{array}{l}\text { UDP-glucosyl transferase } \\
\text { family protein }\end{array}$ & 4.159371 & 0.001763 \\
\hline \multicolumn{6}{|c|}{ Kinase activity } \\
\hline 29 & AT5G51830 & & $\begin{array}{l}\text { pfkB-type carbohydrate } \\
\text { kinase family protein }\end{array}$ & 3.66412 & 0.00038 \\
\hline 30 & AT5G11020 & & ATP binding / protein kinase & 3.443754 & 0.000584 \\
\hline 31 & AT5G26570 & $\begin{array}{l}\text { PWD, OK1, } \\
\text { ATGWD3 }\end{array}$ & $\begin{array}{l}\text { carbohydrate kinase/ } \\
\text { phosphoglucan, water } \\
\text { dikinase }\end{array}$ & 2.926173 & 0.009493 \\
\hline 32 & AT3G04810 & ATNEK2 & $\begin{array}{l}\text { NIMA-RELATED KINASE 2; } \\
\text { ATP binding / protein kinase }\end{array}$ & 2.924224 & 7.36E-05 \\
\hline 33 & AT2G26980 & CIPK3 & $\begin{array}{l}\text { CBL-INTERACTING } \\
\text { PROTEIN KINASE 3; }\end{array}$ & 2.343199 & 0.001401 \\
\hline 34 & AT2G16790 & & $\begin{array}{l}\text { shikimate kinase family } \\
\text { protein }\end{array}$ & 2.239525 & 0.008115 \\
\hline 35 & AT4G37250 & & $\begin{array}{l}\text { leucine-rich repeat family } \\
\text { protein / protein kinase }\end{array}$ & 2.085429 & 0.000253 \\
\hline 36 & AT3G25560 & NIK2 & $\begin{array}{l}\text { NSP-INTERACTING } \\
\text { KINASE } 2\end{array}$ & 2.034801 & 0.000999 \\
\hline 37 & AT4G36450 & MPK14 & $\begin{array}{l}\text { Mitogen-activated protein } \\
\text { kinase 14; MAP kinase }\end{array}$ & 2.031579 & 0.000177 \\
\hline \multicolumn{6}{|c|}{ Lipid metabolism } \\
\hline 38 & AT1G76470 & & $\begin{array}{l}\text { 3-beta-hydroxy-delta5- } \\
\text { steroid dehydrogenase/ } \\
\text { cinnamoyl-CoA reductase }\end{array}$ & 6.669548 & 0.001012 \\
\hline 39 & AT5G14180 & MPL1 & $\begin{array}{l}\text { MYZUS PERSICAE- } \\
\text { INDUCED LIPASE } 1\end{array}$ & 5.611732 & 0.014726 \\
\hline 40 & $\begin{array}{l}\text { AT1G54000; } \\
\text { AT1G54010 }\end{array}$ & & $\begin{array}{l}\text { myrosinase-associated } \\
\text { protein, }\end{array}$ & 3.016294 & 0.003784 \\
\hline 41 & AT5G01870 & & $\begin{array}{l}\text { lipid transfer protein, } \\
\text { putative }\end{array}$ & 2.630331 & 0.001856 \\
\hline 42 & AT4G16760 & $\mathrm{ACX} 1$ & ACYL-COA OXIDASE 1 & 2.619378 & 0.000233 \\
\hline 43 & AT5G07010 & ST2A & $\begin{array}{l}\text { SULFOTRANSFERASE 2A; } \\
\text { hydroxyjasmonate } \\
\text { sulfotransferase }\end{array}$ & 2.545133 & 0.038603 \\
\hline 44 & AT4G30140 & CDEF1 & $\begin{array}{l}\text { CUTICLE DESTRUCTING } \\
\text { FACTOR 1, GDSL-motif } \\
\text { lipase/hydrolase family } \\
\text { protein }\end{array}$ & 2.534671 & 0.006042 \\
\hline 45 & AT5G45950 & & $\begin{array}{l}\text { GDSL-motif lipase/hydrolase } \\
\text { family protein }\end{array}$ & 2.48638 & 0.008911 \\
\hline 46 & AT5G45670 & & $\begin{array}{l}\text { GDSL-motif lipase/hydrolase } \\
\text { family protein }\end{array}$ & 2.369604 & 0.034023 \\
\hline
\end{tabular}


Supplementary Material

\begin{tabular}{|c|c|c|c|c|c|}
\hline 47 & AT1G76090 & SMT3 & $\begin{array}{l}\text { STEROL } \\
\text { METHYLTRANSFERASE 3; } \\
\text { S-adenosylmethionine- } \\
\text { dependent } \\
\text { methyltransferase }\end{array}$ & 2.140516 & 0.000637 \\
\hline 48 & AT2G38180 & & $\begin{array}{l}\text { GDSL-motif lipase/hydrolase } \\
\text { family protein }\end{array}$ & 2.102785 & 0.009514 \\
\hline 49 & AT4G34250 & KCS16 & $\begin{array}{l}\text { 3-KETOACYL-COA } \\
\text { SYNTHASE 16; } \\
\text { acyltransferase }\end{array}$ & 2.010724 & 0.043582 \\
\hline \multicolumn{6}{|c|}{ Organic acid catabolism } \\
\hline 50 & AT3G45300 & IVD & $\begin{array}{l}\text { ISOVALERYL-COA- } \\
\text { DEHYDROGENASE }\end{array}$ & 5.084359 & 0.000157 \\
\hline 51 & AT4G33150 & & $\begin{array}{l}\text { lysine-ketoglutarate } \\
\text { reductase/saccharopine } \\
\text { dehydrogenase bifunctional } \\
\text { enzyme }\end{array}$ & 4.641545 & 0.000616 \\
\hline 52 & AT3G04520 & THA2 & Threonine Aldolase 2 & 2.717481 & 0.000128 \\
\hline 53 & AT3G22200 & $\begin{array}{l}\text { POP2, } \\
\text { GABA-T, } \\
\text { HER1 }\end{array}$ & $\begin{array}{l}\text { POLLEN-PISTIL } \\
\text { INCOMPATIBILITY 2; 4- } \\
\text { aminobutyrate transaminase }\end{array}$ & 2.643913 & 0.00629 \\
\hline 54 & $\begin{array}{l}\text { AT2G02000; } \\
\text { AT2G02010 }\end{array}$ & $\begin{array}{l}\text { at2g02000: } \\
\text { GAD3 } \\
\text { at2g02010: } \\
\text { GAD4 } \\
\end{array}$ & $\begin{array}{l}\text { glutamate decarboxylase; } \\
\text { calmodulin }\end{array}$ & 2.370822 & 0.003104 \\
\hline 55 & AT3G58750 & CSY2 & citrate synthase 2 & 2.034736 & 0.030029 \\
\hline \multicolumn{6}{|c|}{ Oxidoreductase activity } \\
\hline 56 & AT2G37770 & AKR4C9 & $\begin{array}{l}\text { aldo/keto reductase family } \\
\text { protein }\end{array}$ & 56.89305 & 7.81E-07 \\
\hline 57 & AT1G62570 & $\begin{array}{l}\text { FMO GS- } \\
\text { OX4 }\end{array}$ & $\begin{array}{l}\text { FLAVIN- } \\
\text { MONOOXYGENASE } \\
\text { GLUCOSINOLATE S- } \\
\text { OXYGENASE } 4 \\
\end{array}$ & 19.91268 & $1.43 E-06$ \\
\hline 58 & AT3G04000 & & $\begin{array}{l}\text { short-chain dehydrogenase/ } \\
\text { reductase (SDR) family } \\
\text { protein }\end{array}$ & 13.73018 & 0.000384 \\
\hline 59 & $\begin{array}{l}\text { AT2G38380; } \\
\text { AT2G38390 }\end{array}$ & $\begin{array}{l}\text { at2g38380: } \\
\text { (PER22) }\end{array}$ & $\begin{array}{l}\text { at2g38380: peroxidase } \\
\text { at2g38390: peroxidase, } \\
\text { putative }\end{array}$ & 13.32886 & 0.001039 \\
\hline 60 & AT2G37760 & AKR4C8 & $\begin{array}{l}\text { aldo/keto reductase family } \\
\text { protein }\end{array}$ & 12.63507 & 2.64E-05 \\
\hline 61 & AT2G29370 & & $\begin{array}{l}\text { tropinone reductase, } \\
\text { putative }\end{array}$ & 10.33212 & $6.23 E-06$ \\
\hline 62 & AT1G77120 & $\mathrm{ADH} 1$ & $\begin{array}{l}\text { ALCOHOL } \\
\text { DEHYDROGENASE } 1\end{array}$ & 7.962909 & 0.000243 \\
\hline 63 & AT1G17020 & SRG1 & $\begin{array}{l}\text { SENESCENCE-RELATED } \\
\text { GENE 1; oxidoreductase, } \\
\text { acting on diphenols and } \\
\text { related substances as } \\
\text { donors }\end{array}$ & 7.01945 & 0.00285 \\
\hline 64 & AT5G24910 & CYP714A1 & $\begin{array}{l}\text { electron carrier/ heme } \\
\text { binding / monooxygenase/ } \\
\text { oxygen binding }\end{array}$ & 6.44529 & $1.64 \mathrm{E}-05$ \\
\hline 65 & AT1G17745 & PGDH & $\begin{array}{l}\text { 3-PHOSPHOGLYCERATE } \\
\text { DEHYDROGENASE }\end{array}$ & 6.444687 & $9.94 \mathrm{E}-05$ \\
\hline 66 & $\begin{array}{l}\text { AT1G63340; } \\
\text { AT1G62580 }\end{array}$ & & $\begin{array}{l}\text { flavin-containing } \\
\text { monooxygenase family } \\
\text { protein }\end{array}$ & 6.124668 & 0.000401 \\
\hline 67 & AT2G34810 & & $\begin{array}{l}\text { FAD-binding domain- } \\
\text { containing protein }\end{array}$ & 5.385956 & 0.000127 \\
\hline 68 & AT1G54100 & ALDH7B4 & $\begin{array}{l}\text { Aldehyde Dehydrogenase } \\
\text { 7B4 }\end{array}$ & 4.519785 & 0.000288 \\
\hline
\end{tabular}


Supplementary Material

\begin{tabular}{|c|c|c|c|c|c|}
\hline 69 & AT3G03470 & CYP89A9 & $\begin{array}{l}\text { electron carrier/ heme } \\
\text { binding / monooxygenase/ } \\
\text { oxygen binding }\end{array}$ & 4.403794 & 0.004824 \\
\hline 70 & AT1G09420 & G6PD4 & $\begin{array}{l}\text { GLUCOSE-6-PHOSPHATE } \\
\text { DEHYDROGENASE } 4\end{array}$ & 4.039865 & 0.001239 \\
\hline 71 & AT1G60730 & & $\begin{array}{l}\text { aldo/keto reductase family } \\
\text { protein }\end{array}$ & 3.834442 & 0.00119 \\
\hline 72 & AT5G19440 & & $\begin{array}{l}\text { cinnamyl-alcohol } \\
\text { dehydrogenase, putative }\end{array}$ & 3.728064 & 0.002512 \\
\hline 73 & $\begin{array}{l}\text { AT1G21400; } \\
\text { AT5G34780 }\end{array}$ & & $\begin{array}{l}\text { at5g34780: dehydrogenase } \\
\text { E1 component family protein } \\
\text { at1g21400: 2-oxoisovalerate } \\
\text { dehydrogenase, putative }\end{array}$ & 3.656392 & 0.0007 \\
\hline 74 & AT4G33420 & & peroxidase, putative & 3.034868 & 0.00632 \\
\hline 75 & AT3G14610 & CYP72A7 & $\begin{array}{l}\text { electron carrier/ heme } \\
\text { binding / monooxygenase/ } \\
\text { oxygen binding }\end{array}$ & 2.947295 & 0.000171 \\
\hline 76 & AT5G14780 & $\mathrm{FDH}$ & $\begin{array}{l}\text { FORMATE } \\
\text { DEHYDROGENASE; NAD } \\
\text { or NADH binding / binding / } \\
\text { catalytic/ cofactor binding / } \\
\text { oxidoreductase }\end{array}$ & 2.785644 & 0.012996 \\
\hline 77 & AT3G14620 & CYP72A8 & $\begin{array}{l}\text { electron carrier/ heme } \\
\text { binding / monooxygenase/ } \\
\text { oxygen binding }\end{array}$ & 2.677795 & 0.00037 \\
\hline 78 & AT5G43450 & & $\begin{array}{l}\text { 2-oxoglutarate-dependent } \\
\text { dioxygenase, putative }\end{array}$ & 2.623955 & 0.000481 \\
\hline 79 & AT3G13450 & DIN4 & $\begin{array}{l}\text { DARK INDUCIBLE 4; 3- } \\
\text { methyl-2-oxobutanoate } \\
\text { dehydrogenase }\end{array}$ & 2.562279 & 0.007083 \\
\hline 80 & AT4G37410 & CYP81F4 & $\begin{array}{l}\text { electron carrier/ heme } \\
\text { binding / monooxygenase/ } \\
\text { oxygen binding }\end{array}$ & 2.516202 & 0.000108 \\
\hline 81 & $\begin{array}{l}\text { AT4G12290; } \\
\text { AT4G12280 }\end{array}$ & & $\begin{array}{l}\text { copper amine oxidase family } \\
\text { protein }\end{array}$ & 2.404675 & 0.049043 \\
\hline 82 & AT5G50130 & & $\begin{array}{l}\text { short-chain } \\
\text { dehydrogenase/reductase } \\
\text { (SDR) family protein }\end{array}$ & 2.205913 & 9.07E-05 \\
\hline 83 & AT3G20110 & CYP705A20 & $\begin{array}{l}\text { electron carrier/ heme } \\
\text { binding / monooxygenase/ } \\
\text { oxygen binding }\end{array}$ & 2.159889 & 0.019475 \\
\hline 84 & AT2G45570 & CYP76C2 & $\begin{array}{l}\text { electron carrier/ heme } \\
\text { binding / monooxygenase/ } \\
\text { oxygen binding }\end{array}$ & 2.151626 & 0.01489 \\
\hline 85 & AT3G26290 & CYP71B26 & $\begin{array}{l}\text { electron carrier/ heme } \\
\text { binding / monooxygenase/ } \\
\text { oxygen binding }\end{array}$ & 2.102462 & 0.001483 \\
\hline 86 & AT1G23800 & ALDH2B7 & $\begin{array}{l}\text { 3-chloroallyl aldehyde } \\
\text { dehydrogenase }\end{array}$ & 2.08388 & 0.015458 \\
\hline 87 & AT4G37980 & $\begin{array}{l}\text { ELI3-1, } \\
\text { CAD7 }\end{array}$ & $\begin{array}{l}\text { ELICITOR-ACTIVATED } \\
\text { GENE 3-1; oxidoreductase/ } \\
\text { zinc ion binding }\end{array}$ & 2.076803 & 0.002029 \\
\hline 88 & AT5G64110 & & peroxidase, putative & 2.035728 & 0.000999 \\
\hline 89 & AT1G31710 & & $\begin{array}{l}\text { copper amine oxidase, } \\
\text { putative }\end{array}$ & 2.006096 & 0.03852 \\
\hline \multicolumn{6}{|c|}{ Peroxisome } \\
\hline 90 & AT3G09260 & $\begin{array}{l}\text { PYK10, } \\
\text { PSR3.1, } \\
\text { BGLU23 }\end{array}$ & $\begin{array}{l}\text { beta-glucosidase / } \\
\text { fucosidase/ hydrolase }\end{array}$ & 14.52884 & 0.005794 \\
\hline 91 & AT1G26930 & & $\begin{array}{l}\text { kelch repeat-containing F- } \\
\text { box family protein }\end{array}$ & 5.139911 & 0.000564 \\
\hline 92 & AT3G15950 & NAI2 & $\begin{array}{l}\text { ER body organization, } \\
\text { response to salt stress }\end{array}$ & 3.99937 & 0.004366 \\
\hline
\end{tabular}


Supplementary Material

\begin{tabular}{|c|c|c|c|c|c|}
\hline 93 & AT4G18360 & GOX3 & $\begin{array}{l}\text { GLYCOLATE OXIDASE 3, } \\
\text { peroxisomal }\end{array}$ & 3.507086 & 2.26E-06 \\
\hline 94 & AT1G52410 & TSA1 & $\begin{array}{l}\text { TSK-ASSOCIATING } \\
\text { PROTEIN 1; calcium ion } \\
\text { binding }\end{array}$ & 2.584917 & 0.004693 \\
\hline 95 & AT5G27600 & LACS7 & $\begin{array}{l}\text { LONG-CHAIN ACYL-COA } \\
\text { SYNTHETASE } 7\end{array}$ & 2.35029 & 0.000182 \\
\hline \multicolumn{6}{|c|}{ Response to chemical stimulus } \\
\hline 96 & AT2G45210 & & $\begin{array}{l}\text { auxin-responsive protein- } \\
\text { related }\end{array}$ & 11.79464 & 1.19E-05 \\
\hline 97 & AT4G33540 & & $\begin{array}{l}\text { metallo-beta-lactamase } \\
\text { family protein }\end{array}$ & 7.213347 & 0.000347 \\
\hline 98 & AT4G18010 & $\begin{array}{c}\text { IP5PII, } \\
\text { AT5PTASE2 }\end{array}$ & $\begin{array}{l}\text { MYO-INOSITOL } \\
\text { POLYPHOSPHATE 5- } \\
\text { PHOSPHATASE } 2\end{array}$ & 4.391116 & $5.69 \mathrm{E}-05$ \\
\hline 99 & AT2G41380 & & $\begin{array}{l}\text { embryo-abundant protein- } \\
\text { related }\end{array}$ & 4.137567 & 0.000309 \\
\hline 100 & AT3G63210 & MARD1 & $\begin{array}{l}\text { MEDIATOR OF ABA- } \\
\text { REGULATED DORMANCY } \\
1\end{array}$ & 4.117897 & 0.000665 \\
\hline 101 & AT4G23060 & IQD22 & $\begin{array}{l}\text { IQ-domain 22; calmodulin } \\
\text { binding }\end{array}$ & 3.355644 & 0.000124 \\
\hline 102 & AT1G28290 & AGP31 & $\begin{array}{l}\text { ARABINOGALACTAN- } \\
\text { PROTEIN } 31\end{array}$ & 2.895593 & 0.047104 \\
\hline 103 & AT1G07610 & MT1C & copper ion binding & 2.527668 & 0.012588 \\
\hline 104 & AT3G48990 & AAE3 & $\begin{array}{l}\text { ACYL-ACTIVATING } \\
\text { ENZYME 3, oxalate } \\
\text { degradation }\end{array}$ & 2.246423 & 0.006626 \\
\hline 105 & AT1G09570 & $\begin{array}{c}\text { PHYA, } \\
\text { FHY2, } \\
\text { FRE1, HY8 }\end{array}$ & $\begin{array}{l}\text { PHYTOCHROME A; G- } \\
\text { protein coupled } \\
\text { photoreceptor }\end{array}$ & 2.064945 & 0.023521 \\
\hline \multicolumn{6}{|c|}{ Response to stress } \\
\hline 106 & AT4G23680 & & major latex protein-related & 23.64447 & $9.69 \mathrm{E}-05$ \\
\hline 107 & AT3G50970 & $\begin{array}{l}\text { LTI30, } \\
\text { XERO2 } \\
\end{array}$ & $\begin{array}{l}\text { LOW TEMPERATURE- } \\
\text { INDUCED } 30\end{array}$ & 15.20646 & 0.000104 \\
\hline 108 & AT4G23600 & CORI3 & $\begin{array}{l}\text { CORONATINE INDUCED 1; } \\
\text { cystathionine beta-lyase/ } \\
\text { transaminase }\end{array}$ & 7.4803 & 8.93E-07 \\
\hline 109 & AT5G59320 & LTP3 & $\begin{array}{l}\text { LIPID TRANSFER } \\
\text { PROTEIN } 3 \\
\end{array}$ & 7.354773 & 0.022232 \\
\hline 110 & AT4G35770 & SEN1, DIN1 & SENESCENCE 1 & 6.780057 & 0.057303 \\
\hline 111 & AT3G62550 & & $\begin{array}{l}\text { universal stress protein } \\
\text { (USP) family protein }\end{array}$ & 6.312355 & 0.029628 \\
\hline 112 & AT5G59310 & LTP4 & $\begin{array}{l}\text { LIPID TRANSFER } \\
\text { PROTEIN } 4\end{array}$ & 5.709177 & 0.002963 \\
\hline 113 & AT2G03760 & $\begin{array}{l}\text { RAR047, } \\
\text { ST1 }\end{array}$ & $\begin{array}{l}\text { brassinosteroid } \\
\text { sulfotransferase }\end{array}$ & 5.253201 & 0.000687 \\
\hline 114 & AT1G72900 & & $\begin{array}{l}\text { disease resistance protein } \\
\text { (TIR-NBS class), putative }\end{array}$ & 5.037367 & 0.005756 \\
\hline 115 & AT3G16450 & & jacalin lectin family protein & 4.886648 & 0.002338 \\
\hline 116 & AT4G37990 & $\begin{array}{l}\text { ELI3-2, } \\
\text { ATCAD8, } \\
\text { CAD-B2 }\end{array}$ & $\begin{array}{l}\text { ELICITOR-ACTIVATED } \\
\text { GENE 3-2; aryl-alcohol } \\
\text { dehydrogenase/ mannitol } \\
\text { dehydrogenase }\end{array}$ & 4.832402 & 0.012029 \\
\hline 117 & AT2G18050 & HIS1-3 & $\begin{array}{l}\text { HISTONE H1-3; DNA } \\
\text { binding }\end{array}$ & 4.374517 & 0.042773 \\
\hline 118 & AT3G02480 & & $\begin{array}{l}\text { ABA-responsive protein- } \\
\text { related }\end{array}$ & 4.333186 & 0.008918 \\
\hline 119 & AT5G22300 & NIT4 & $\begin{array}{l}\text { NITRILASE } 4 ; 3- \\
\text { cyanoalanine hydratase/ } \\
\text { indole-3-acetonitrile nitrilase }\end{array}$ & 4.251954 & 0.009543 \\
\hline
\end{tabular}


Supplementary Material

\begin{tabular}{|c|c|c|c|c|c|}
\hline 120 & AT1G29395 & $\begin{array}{l}\text { COR414- } \\
\text { TM1 }\end{array}$ & $\begin{array}{l}\text { COLD REGULATED } 414 \\
\text { THYLAKOID MEMBRANE } \\
\text { 1, cellular response to water } \\
\text { deprivation }\end{array}$ & 4.043442 & 0.002945 \\
\hline 121 & AT2G33380 & RD20 & $\begin{array}{l}\text { RESPONSIVE TO } \\
\text { DESSICATION 20; calcium } \\
\text { ion binding }\end{array}$ & 3.752382 & 0.01044 \\
\hline 122 & AT2G21620 & RD2 & $\begin{array}{l}\text { response to desiccation, } \\
\text { galactolipid biosynthetic } \\
\text { process }\end{array}$ & 3.674696 & 0.000442 \\
\hline 123 & $\begin{array}{l}\text { AT1G18020; } \\
\text { AT1G17990 }\end{array}$ & & $\begin{array}{l}\text { 12-oxophytodienoate } \\
\text { reductase, putative }\end{array}$ & 3.262797 & 0.026082 \\
\hline 124 & AT1G20440 & $\begin{array}{l}\text { COR47, } \\
\text { RD17 }\end{array}$ & COLD-REGULATED 47 & 3.201476 & 0.000524 \\
\hline 125 & AT5G28010 & & $\begin{array}{l}\text { Bet } v \text { I allergen family } \\
\text { protein }\end{array}$ & 3.078546 & 0.000808 \\
\hline 126 & AT3G16460 & & jacalin lectin family protein & 3.006419 & 0.023107 \\
\hline 127 & $\begin{array}{l}\text { AT4G37530; } \\
\text { AT4G37520 }\end{array}$ & $\begin{array}{c}\text { at4g37520:P } \\
\text { ER50, } \\
\text { PRXR2 } \\
\end{array}$ & $\begin{array}{l}\text { at4g37530: peroxidase, } \\
\text { putative } \\
\text { at4g37520: peroxidase } 50\end{array}$ & 2.956057 & 0.010932 \\
\hline 128 & AT2G18170 & ATMPK7 & $\begin{array}{l}\text { ARABIDOPSIS THALIANA } \\
\text { MAP KINASE } 7\end{array}$ & 2.92323 & 0.016671 \\
\hline 129 & AT1G12780 & UGE1 & $\begin{array}{l}\text { UDP-D-glucose/UDP-D- } \\
\text { galactose 4-epimerase } 1\end{array}$ & 2.304708 & 0.020594 \\
\hline 130 & AT3G05360 & AtRLP30 & Receptor Like Protein 30 & 2.301642 & 0.021987 \\
\hline 131 & AT3G16470 & JR1 & $\begin{array}{l}\text { JASMONATE } \\
\text { RESPONSIVE } 1\end{array}$ & 2.269684 & 0.004786 \\
\hline 132 & AT4G33950 & $\begin{array}{l}\text { SRK2E, } \\
\text { SNRK2.6, } \\
\text { OST1 }\end{array}$ & $\begin{array}{l}\text { OPEN STOMATA 1; } \\
\text { calcium-dependent protein } \\
\text { serine/threonine kinase }\end{array}$ & 2.261583 & 0.00071 \\
\hline 133 & AT2G21110 & & $\begin{array}{l}\text { disease resistance- } \\
\text { responsive family protein }\end{array}$ & 2.25472 & 0.017517 \\
\hline 134 & AT3G17790 & $\begin{array}{l}\text { ATACP5, } \\
\text { PAP17 }\end{array}$ & acid phosphatase & 2.227106 & 0.007559 \\
\hline 135 & AT1G52000 & & jacalin lectin family protein & 2.201031 & 0.036732 \\
\hline 136 & $\begin{array}{l}\text { AT1G52030; } \\
\text { AT1G52040 }\end{array}$ & $\begin{array}{l}\text { at1g52040: } \\
\text { MBP1 } \\
\text { at1g52030: } \\
\text { MBP2 }\end{array}$ & $\begin{array}{l}\text { at1g52040: MYROSINASE- } \\
\text { BINDING PROTEIN } 1 \\
\text { at1g52030:MYROSINASE- } \\
\text { BINDING PROTEIN 2; } \\
\text { thioglucosidase binding }\end{array}$ & 2.195005 & 0.040268 \\
\hline 137 & AT1G74020 & SS2 & $\begin{array}{l}\text { STRICTOSIDINE } \\
\text { SYNTHASE } 2 \\
\end{array}$ & 2.108054 & 0.028429 \\
\hline 138 & AT1G70830 & MLP28 & MLP-LIKE PROTEIN 28 & 2.101261 & 0.018812 \\
\hline 139 & AT4G24220 & VEP1 & VEIN PATTERNING 1 & 2.086551 & 0.002036 \\
\hline 140 & AT5G46180 & DELTA-OAT & $\begin{array}{l}\text { ornithine-oxo-acid } \\
\text { transaminase }\end{array}$ & 2.049495 & 0.00153 \\
\hline \multicolumn{6}{|c|}{ Secondary metabolic process } \\
\hline 141 & AT3G13610 & & $\begin{array}{l}\text { 2OG-Fe(II) oxygenase } \\
\text { family protein }\end{array}$ & 5.134753 & 0.012592 \\
\hline 142 & AT1G72680 & ATCAD1 & $\begin{array}{l}\text { cinnamyl-alcohol } \\
\text { dehydrogenase, putative }\end{array}$ & 8.793325 & 0.00054 \\
\hline 143 & AT2G29460 & $\begin{array}{l}\text { ATGSTU4, } \\
\text { GST22 }\end{array}$ & $\begin{array}{l}\text { ARABIDOPSIS THALIANA } \\
\text { GLUTATHIONE S- } \\
\text { TRANSFERASE TAU } 4\end{array}$ & 5.629217 & 0.000318 \\
\hline 144 & AT5G48180 & NSP5 & $\begin{array}{l}\text { NITRILE SPECIFIER } \\
\text { PROTEIN } 5\end{array}$ & 5.026365 & 2.62E-06 \\
\hline 145 & AT1G09500 & & $\begin{array}{l}\text { cinnamyl-alcohol } \\
\text { dehydrogenase family }\end{array}$ & 4.804379 & 0.040677 \\
\hline 146 & AT2G02990 & RNS1 & RIBONUCLEASE 1 & 4.127582 & 0.019477 \\
\hline 147 & AT2G02390 & $\begin{array}{l}\text { ATGSTZ1, } \\
\text { GST18 }\end{array}$ & $\begin{array}{l}\text { ARABIDOPSIS THALIANA } \\
\text { GLUTATHIONE S- }\end{array}$ & 3.996039 & 0.001144 \\
\hline
\end{tabular}


Supplementary Material

\begin{tabular}{|c|c|c|c|c|c|}
\hline & & & $\begin{array}{l}\text { TRANSFERASE ZETA 1; } \\
\text { glutathione transferase }\end{array}$ & & \\
\hline 148 & AT5G25900 & $\begin{array}{c}\text { GA3, } \\
\text { CYP701A3, } \\
\text { ATKO1 }\end{array}$ & $\begin{array}{l}\text { GA REQUIRING 3; ent- } \\
\text { kaurene oxidase }\end{array}$ & 3.435863 & 0.001871 \\
\hline 149 & AT1G17170 & ATGSTU24 & $\begin{array}{l}\text { GLUTATHIONE S- } \\
\text { TRANSFERASE TAU } 24\end{array}$ & 2.862503 & 0.000643 \\
\hline 150 & AT3G57010 & & $\begin{array}{l}\text { strictosidine synthase family } \\
\text { protein }\end{array}$ & 2.571519 & 0.000279 \\
\hline 151 & AT2G33590 & & $\begin{array}{l}\text { cinnamoyl-CoA reductase } \\
\text { family }\end{array}$ & 2.480315 & 0.000322 \\
\hline 152 & AT2G25450 & & $\begin{array}{l}\text { 2-oxoglutarate-dependent } \\
\text { dioxygenase, putative }\end{array}$ & 2.466493 & 0.000827 \\
\hline 153 & $\begin{array}{l}\text { AT3G16410; } \\
\text { AT3G16390; } \\
\text { AT3G16400 }\end{array}$ & $\begin{array}{l}\text { at3g16410: } \\
\text { NSP4 } \\
\text { at3g16390: } \\
\text { NSP3 } \\
\text { at3g16400: } \\
\text { NSP1 }\end{array}$ & $\begin{array}{l}\text { NITRILE SPECIFIER } \\
\text { PROTEIN }\end{array}$ & 2.309807 & 0.019399 \\
\hline 154 & AT1G59700 & ATGSTU16 & $\begin{array}{l}\text { GLUTATHIONE S- } \\
\text { TRANSFERASE TAU } 16\end{array}$ & 2.272223 & 9.27E-05 \\
\hline \multicolumn{6}{|c|}{ Transcription factor } \\
\hline 155 & AT1G77450 & ANAC032 & $\begin{array}{l}\text { Arabidopsis NAC domain } \\
\text { containing protein } 32\end{array}$ & 115.4942 & 4.61E-09 \\
\hline 156 & AT1G10585 & & $\begin{array}{l}\text { bHLH-type transcription } \\
\text { factor }\end{array}$ & 43.08498 & $1.48 \mathrm{E}-06$ \\
\hline 157 & AT5G10140 & $\begin{array}{l}\text { FLC, FLF, } \\
\text { AGL25 }\end{array}$ & $\begin{array}{l}\text { FLOWERING LOCUS C; } \\
\text { specific transcriptional } \\
\text { repressor/ transcription } \\
\text { factor }\end{array}$ & 11.57218 & 0.000308 \\
\hline 158 & AT5G13330 & Rap2.6L & RELATED to AP2 6L & 7.978512 & 0.000715 \\
\hline 159 & $\begin{array}{l}\text { AT4G34590; } \\
\text { AT4G34588 }\end{array}$ & $\begin{array}{l}\text { at4g34590: } \\
\text { GBF6, } \\
\text { AtbZIP11 } \\
\text { at4g34588: } \\
\text { CPuORF2 }\end{array}$ & $\begin{array}{l}\text { at4g34590: G-BOX } \\
\text { BINDING FACTOR } 6 \\
\text { at4g34588: Conserved } \\
\text { peptide upstream open } \\
\text { reading frame } 2\end{array}$ & 6.264385 & 0.001517 \\
\hline 160 & AT3G04070 & ANAC047 & $\begin{array}{l}\text { Arabidopsis NAC domain } \\
\text { containing protein } 47\end{array}$ & 5.608168 & 0.013506 \\
\hline 161 & AT4G18170 & WRKY28 & $\begin{array}{l}\text { response to cyclopentenone, } \\
\text { toxin catabolic process }\end{array}$ & 4.432704 & $1.53 E-06$ \\
\hline 162 & AT3G29035 & $\begin{array}{l}\text { ANAC059,A } \\
\text { TNAC3 }\end{array}$ & $\begin{array}{l}\text { ARABIDOPSIS NAC } \\
\text { DOMAIN CONTAINING } \\
\text { PROTEIN } 3 \\
\end{array}$ & 4.009915 & 0.00449 \\
\hline 163 & AT5G39610 & $\begin{array}{l}\text { ATNAC2, } \\
\text { ORE1, } \\
\text { ANAC092, } \\
\text { ATNAC6 }\end{array}$ & $\begin{array}{l}\text { ARABIDOPSIS NAC } \\
\text { DOMAIN CONTAINING } \\
\text { PROTEIN } 6\end{array}$ & 3.812219 & 0.017287 \\
\hline 164 & AT5G24800 & BZIP9 & BASIC LEUCINE ZIPPER 9 & 3.721028 & 0.000381 \\
\hline 165 & $\begin{array}{l}\text { AT5G49450; } \\
\text { AT5G49448 }\end{array}$ & $\begin{array}{l}\text { at5g49450: } \\
\text { AtbZIP1 } \\
\text { at5g49448: } \\
\text { CPuORF4 }\end{array}$ & $\begin{array}{l}\text { at5g49450: Arabidopsis } \\
\text { thaliana basic leucine-zipper } \\
1 \\
\text { at5g49448: Conserved } \\
\text { peptide upstream open } \\
\text { reading frame } 4\end{array}$ & 3.532008 & 0.034164 \\
\hline 166 & AT1G06180 & ATMYB13 & MYB DOMAIN PROTEIN 13 & 3.43887 & 0.000615 \\
\hline 167 & AT2G36080 & & $\begin{array}{l}\text { DNA-binding protein, } \\
\text { putative }\end{array}$ & 3.259187 & 0.000885 \\
\hline 168 & AT5G67110 & ALC & ALCATRAZ & 2.925724 & 0.030792 \\
\hline 169 & AT3G04670 & WRKY39 & $\begin{array}{l}\text { calmodulin binding / } \\
\text { transcription factor }\end{array}$ & 2.902888 & $9.35 \mathrm{E}-06$ \\
\hline 170 & AT5G50915 & & $\begin{array}{l}\text { basic helix-loop-helix (bHLH) } \\
\text { family protein }\end{array}$ & 2.739857 & 0.018584 \\
\hline
\end{tabular}


Supplementary Material

\begin{tabular}{|c|c|c|c|c|c|}
\hline 171 & AT1G52890 & ANAC019 & $\begin{array}{l}\text { Arabidopsis NAC domain } \\
\text { containing protein } 19\end{array}$ & 2.554885 & 0.039508 \\
\hline 172 & AT4G36930 & SPT & $\begin{array}{l}\text { SPATULA, negative } \\
\text { regulation of seed } \\
\text { germination }\end{array}$ & 2.476109 & 0.002213 \\
\hline 173 & AT5G01200 & & $\begin{array}{l}\text { myb family transcription } \\
\text { factor }\end{array}$ & 2.4257 & 0.001789 \\
\hline 174 & AT2G42280 & & $\begin{array}{l}\text { basic helix-loop-helix (bHLH) } \\
\text { family protein }\end{array}$ & 2.342044 & 4.87E-05 \\
\hline 175 & AT1G01010 & ANAC001 & $\begin{array}{l}\text { Arabidopsis NAC domain } \\
\text { containing protein } 1\end{array}$ & 2.251101 & 0.000809 \\
\hline 176 & AT3G57800 & & $\begin{array}{l}\text { basic helix-loop-helix (bHLH) } \\
\text { family protein }\end{array}$ & 2.131992 & $5.55 \mathrm{E}-05$ \\
\hline 177 & AT5G65640 & BHLH093 & beta HLH protein 93 & 2.063423 & 0.004762 \\
\hline 178 & AT5G13180 & ANAC083 & $\begin{array}{l}\text { ARABIDOPSIS NAC } \\
\text { DOMAIN CONTAINING } \\
\text { PROTEIN } 83\end{array}$ & 2.049529 & 0.00015 \\
\hline \multicolumn{6}{|c|}{ Transporter } \\
\hline 179 & AT1G66570 & ATSUC7 & Sucrose-proton symporter 7; & 24.81859 & 0.000148 \\
\hline 180 & AT2G04040 & $\begin{array}{l}\text { ATDTX1, } \\
\text { TX1 }\end{array}$ & multidrug efflux pump & 14.20818 & 0.000732 \\
\hline 181 & AT5G13490 & AAC2 & $\begin{array}{l}\text { ADP/ATP carrier } 2 ; \\
\text { ATP:ADP antiporter }\end{array}$ & 10.32981 & $2.92 E-06$ \\
\hline 182 & AT2G17500 & & $\begin{array}{l}\text { auxin efflux carrier family } \\
\text { protein }\end{array}$ & 9.431891 & $4.26 \mathrm{E}-06$ \\
\hline 183 & AT5G17860 & CAX7 & $\begin{array}{l}\text { calcium exchanger } 7 ; \\
\text { calcium:sodium antiporter }\end{array}$ & 6.942018 & 2.77E-05 \\
\hline 184 & AT3G59140 & ATMRP14 & $\begin{array}{l}\text { ATPase, coupled to } \\
\text { transmembrane movement } \\
\text { of substances }\end{array}$ & 6.93742 & 0.001604 \\
\hline 185 & $\begin{array}{l}\text { AT3G60970; } \\
\text { AT3G60160 }\end{array}$ & $\begin{array}{l}\text { at3g60970: } \\
\text { ATMRP15 } \\
\text { at3g60160: } \\
\text { ATMRP9 } \\
\end{array}$ & $\begin{array}{l}\text { ATPase, coupled to } \\
\text { transmembrane movement } \\
\text { of substances }\end{array}$ & 6.129323 & 1.79E-05 \\
\hline 186 & AT1G08230 & & $\begin{array}{l}\text { gamma-aminobutyric acid } \\
\text { transmembrane transporter } \\
\text { activity }\end{array}$ & 6.072167 & $2.00 \mathrm{E}-05$ \\
\hline 187 & AT3G23560 & ALF5 & $\begin{array}{l}\text { ABERRANT LATERAL } \\
\text { ROOT FORMATION 5; drug } \\
\text { transporter }\end{array}$ & 5.590587 & 0.000172 \\
\hline 188 & AT1G71140 & & MATE efflux family protein & 5.231011 & 0.001079 \\
\hline 189 & AT3G23550 & & MATE efflux family protein & 3.633738 & 0.02648 \\
\hline 190 & AT1G30840 & ATPUP4 & $\begin{array}{l}\text { purine transmembrane } \\
\text { transporter }\end{array}$ & 3.44765 & 0.000305 \\
\hline 191 & AT3G21690 & & MATE efflux family protein & 3.134244 & 0.000123 \\
\hline 192 & AT1G61890 & & MATE efflux family protein & 3.074746 & 0.000923 \\
\hline 193 & AT5G13750 & ZIFL1 & $\begin{array}{l}\text { ZINC INDUCED } \\
\text { FACILITATOR-like 1; } \\
\text { tetracycline:hydrogen } \\
\text { antiporter }\end{array}$ & 3.073315 & $1.52 \mathrm{E}-05$ \\
\hline 194 & AT2G38290 & ATAMT2 & $\begin{array}{l}\text { AMMONIUM } \\
\text { TRANSPORTER 2; }\end{array}$ & 2.779288 & $6.18 \mathrm{E}-05$ \\
\hline 195 & AT2G47800 & ATMRP4 & $\begin{array}{l}\text { ARABIDOPSIS THALIANA } \\
\text { MULTIDRUG } \\
\text { RESISTANCE- } \\
\text { ASSOCIATED PROTEIN 4; } \\
\text { folic acid transporter }\end{array}$ & 2.728204 & 0.016759 \\
\hline 196 & AT3G55130 & ATWBC19 & $\begin{array}{l}\text { White-Brown Complex } \\
\text { homolog 19; ATPase, } \\
\text { coupled to transmembrane } \\
\text { movement of substances }\end{array}$ & 2.573647 & 0.000974 \\
\hline
\end{tabular}


Supplementary Material

\begin{tabular}{|c|c|c|c|c|c|}
\hline 197 & AT1G25530 & & $\begin{array}{l}\text { lysine and histidine specific } \\
\text { transporter, putative }\end{array}$ & 2.497767 & 0.000126 \\
\hline 198 & AT2G48020 & & sugar transporter, putative & 2.419541 & 0.000772 \\
\hline 199 & AT3G20660 & AtOCT4 & $\begin{array}{l}\text { Arabidopsis thaliana } \\
\text { ORGANIC } \\
\text { CATION/CARNITINE } \\
\text { TRANSPORTER4; } \\
\text { sugar:hydrogen symporter }\end{array}$ & 2.405715 & 4.14E-05 \\
\hline 200 & AT2G23150 & NRAMP3 & $\begin{array}{l}\text { NATURAL RESISTANCE- } \\
\text { ASSOCIATED } \\
\text { MACROPHAGE PROTEIN } \\
\text { 3; inorganic anion } \\
\text { transmembrane transporter }\end{array}$ & 2.385905 & 0.002785 \\
\hline 201 & AT5G57090 & $\begin{array}{c}\text { EIR1, } \\
\text { WAV6, } \\
\text { PIN2, AGR1 }\end{array}$ & $\begin{array}{l}\text { ETHYLENE INSENSITIVE } \\
\text { ROOT ); auxin efflux } \\
\text { transmembrane transporter }\end{array}$ & 2.364162 & 0.000354 \\
\hline 202 & AT1G74810 & BOR5 & anion exchanger & 2.341599 & 0.015416 \\
\hline 203 & AT5G15240 & & $\begin{array}{l}\text { amino acid transporter } \\
\text { family protein }\end{array}$ & 2.330684 & 0.004158 \\
\hline 204 & AT1G33110 & & MATE efflux family protein & 2.204309 & 0.001396 \\
\hline 205 & AT1G66760 & & MATE efflux family protein & 2.198126 & 0.00478 \\
\hline 206 & AT1G58360 & AAP1, NAT2 & $\begin{array}{l}\text { AMINO ACID PERMEASE } \\
1 ; \text { neutral amino acid } \\
\text { transmembrane transporter }\end{array}$ & 2.06958 & 0.002763 \\
\hline \multicolumn{6}{|c|}{ Other functions } \\
\hline 207 & AT3G60140 & $\begin{array}{c}\text { DIN2, } \\
\text { BGLU30 }\end{array}$ & $\begin{array}{l}\text { DARK INDUCIBLE 2; } \\
\text { hydrolase }\end{array}$ & 5.933911 & 0.022664 \\
\hline 208 & AT2G23810 & TET8 & TETRASPANIN8 & 2.239496 & 0.014333 \\
\hline 209 & AT1G69880 & ATH8 & thioredoxin H-type 8 & 25.1422 & 0.000349 \\
\hline 210 & AT1G02850 & BGLU11 & $\begin{array}{l}\text { BETA GLUCOSIDASE 11; } \\
\text { hydrolase }\end{array}$ & 19.66124 & $2.18 \mathrm{E}-06$ \\
\hline 211 & AT1G67810 & SUFE2 & $\begin{array}{l}\text { SULFUR E 2; enzyme } \\
\text { activator }\end{array}$ & 9.767296 & 0.00326 \\
\hline 212 & AT4G22530 & & $\begin{array}{l}\text { embryo-abundant protein- } \\
\text { related }\end{array}$ & 9.691002 & $9.94 \mathrm{E}-06$ \\
\hline 213 & AT2G39310 & JAL22 & $\begin{array}{l}\text { JACALIN-RELATED } \\
\text { LECTIN } 22\end{array}$ & 8.906152 & 0.000419 \\
\hline 214 & AT5G62110 & & DNA binding & 7.284636 & 0.0004 \\
\hline 215 & AT4G22490 & & $\begin{array}{l}\text { protease inhibitor/lipid } \\
\text { transfer protein (LTP) family } \\
\text { protein }\end{array}$ & 7.247641 & 0.011454 \\
\hline 216 & AT3G28007 & SWEET4 & nodulin MtN3 family protein & 6.922294 & 0.000184 \\
\hline 217 & AT5G38530 & & tryptophan synthase-related & 6.685648 & $5.52 \mathrm{E}-05$ \\
\hline 218 & AT1G09240 & NAS3 & $\begin{array}{l}\text { NICOTIANAMINE } \\
\text { SYNTHASE } 3\end{array}$ & 6.207736 & 0.004125 \\
\hline 219 & AT4G01430 & UMAMIT29 & nodulin MtN21 family protein & 6.067275 & 0.000352 \\
\hline 220 & AT4G28040 & UMAMIT33 & nodulin MtN21 family protein & 5.511548 & $2.13 \mathrm{E}-05$ \\
\hline 221 & AT5G17380 & & $\begin{array}{l}\text { pyruvate decarboxylase } \\
\text { family protein }\end{array}$ & 5.47592 & $6.20 \mathrm{E}-05$ \\
\hline 222 & AT5G54840 & SGP1 & GTP binding & 5.199143 & $2.76 \mathrm{E}-06$ \\
\hline 223 & AT5G16080 & AtCXE17 & $\begin{array}{l}\text { Arabidopsis thaliana } \\
\text { carboxyesterase } 17\end{array}$ & 4.549698 & 0.002053 \\
\hline 224 & AT4G31860 & & $\begin{array}{l}\text { protein phosphatase } 2 \mathrm{C}, \\
\text { putative }\end{array}$ & 4.533403 & 0.000599 \\
\hline 225 & AT2G42840 & PDF1 & $\begin{array}{l}\text { PROTODERMAL FACTOR } \\
1\end{array}$ & 4.445051 & 0.038263 \\
\hline
\end{tabular}


Supplementary Material

\begin{tabular}{|c|c|c|c|c|c|}
\hline 226 & AT4G22470 & & $\begin{array}{l}\text { protease inhibitor/ lipid } \\
\text { transfer protein (LTP) family } \\
\text { protein }\end{array}$ & 4.33971 & 0.0211 \\
\hline 227 & $\begin{array}{l}\text { AT3G16430; } \\
\text { AT3G16420 }\end{array}$ & $\begin{array}{l}\text { at3g16430: } \\
\text { JAL31 } \\
\text { at3g16420:P } \\
\text { BP1, JAL30 }\end{array}$ & $\begin{array}{l}\text { at3g16430: JACALIN- } \\
\text { RELATED LECTIN 31; } \\
\text { copper ion binding } \\
\text { at3g16420: PYK10- } \\
\text { BINDING PROTEIN } 1\end{array}$ & 4.299153 & 0.004253 \\
\hline 228 & AT5G47060 & & $\begin{array}{l}\text { senescence-associated } \\
\text { protein-related }\end{array}$ & 4.254011 & 0.002179 \\
\hline 229 & AT5G59510 & $\begin{array}{l}\text { RTFL5, } \\
\text { DVL18 }\end{array}$ & ROTUNDIFOLIA LIKE 5 & 4.19628 & 0.003787 \\
\hline 230 & AT1G63840 & & $\begin{array}{l}\text { zinc finger (C3HC4-type } \\
\text { RING finger) family protein }\end{array}$ & 4.149747 & 2.08E-05 \\
\hline 231 & AT4G27260 & $\begin{array}{l}\text { GH3.5, } \\
\text { WES1 }\end{array}$ & $\begin{array}{l}\text { indole-3-acetic acid amido } \\
\text { synthetase }\end{array}$ & 4.027045 & 0.000746 \\
\hline 232 & AT2G37870 & & $\begin{array}{l}\text { protease inhibitor/ lipid } \\
\text { transfer protein (LTP) family } \\
\text { protein }\end{array}$ & 3.746455 & 0.000342 \\
\hline 233 & AT5G65660 & & $\begin{array}{l}\text { hydroxyproline-rich } \\
\text { glycoprotein family protein }\end{array}$ & 3.715762 & 0.000399 \\
\hline 234 & AT4G14690 & ELIP2 & $\begin{array}{l}\text { EARLY LIGHT-INDUCIBLE } \\
\text { PROTEIN 2; chlorophyll } \\
\text { binding }\end{array}$ & 3.61221 & 0.003698 \\
\hline 235 & AT5G65390 & AGP7 & $\begin{array}{l}\text { arabinogalactan protein } 7 \\
\text { sterol biosynthetic process }\end{array}$ & 3.465446 & 0.000903 \\
\hline 236 & AT1G15670 & & $\begin{array}{l}\text { kelch repeat-containing F- } \\
\text { box family protein }\end{array}$ & 3.450734 & 0.029469 \\
\hline 237 & AT2G39330 & JAL23 & $\begin{array}{l}\text { JACALIN-RELATED } \\
\text { LECTIN } 23\end{array}$ & 3.411523 & 0.00193 \\
\hline 238 & AT3G19910 & & $\begin{array}{l}\text { zinc finger (C3HC4-type } \\
\text { RING finger) family protein }\end{array}$ & 3.375936 & 0.001933 \\
\hline 239 & $\begin{array}{l}\text { AT1G61330; } \\
\text { AT1G61320 }\end{array}$ & & $\begin{array}{l}\text { at1g61330: F-box family } \\
\text { protein } \\
\text { at1g61320: unknown }\end{array}$ & 3.367776 & 0.039321 \\
\hline 240 & AT2G02710 & PLPB & $\begin{array}{l}\text { PAS/LOV PROTEIN B; two- } \\
\text { component sensor }\end{array}$ & 3.255754 & 0.02996 \\
\hline 241 & AT3G10450 & SCPL7 & $\begin{array}{l}\text { SERINE } \\
\text { CARBOXYPEPTIDASE- } \\
\text { LIKE } 7\end{array}$ & 3.158142 & 0.010542 \\
\hline 242 & AT1G66480 & PMI2 & plastid movement impaired 2 & 3.131384 & 2.76E-05 \\
\hline 243 & AT1G23440 & & $\begin{array}{l}\text { pyrrolidone-carboxylate } \\
\text { peptidase family protein }\end{array}$ & 3.017379 & 0.000161 \\
\hline 244 & AT4G01870 & & tolB protein-related & 2.971778 & 0.019122 \\
\hline 245 & AT5G54510 & $\begin{array}{l}\text { GH3.6, } \\
\text { DFL1 }\end{array}$ & $\begin{array}{l}\text { DWARF IN LIGHT 1; indole- } \\
\text { 3-acetic acid amido } \\
\text { synthetase }\end{array}$ & 2.944273 & 0.018896 \\
\hline 246 & $\begin{array}{l}\text { AT1G31880; } \\
\text { AT2G21030 }\end{array}$ & $\begin{array}{l}\text { at1g31880: } \\
\text { NLM9, BRX }\end{array}$ & $\begin{array}{l}\text { at1g31880: BREVIS RADIX; } \\
\text { water channel at2g21030 }\end{array}$ & 2.941479 & 0.018305 \\
\hline 247 & AT1G76790 & & $\begin{array}{l}\text { O-methyltransferase family } 2 \\
\text { protein }\end{array}$ & 2.941472 & 0.000301 \\
\hline 248 & AT1G52690 & & $\begin{array}{l}\text { late embryogenesis } \\
\text { abundant protein, putative }\end{array}$ & 2.922277 & 0.038053 \\
\hline 249 & AT2G16700 & ADF5 & $\begin{array}{l}\text { ACTIN DEPOLYMERIZING } \\
\text { FACTOR } 5\end{array}$ & 2.832693 & 0.001892 \\
\hline 250 & AT5G37740 & & $\begin{array}{l}\text { C2 domain-containing } \\
\text { protein }\end{array}$ & 2.775706 & 0.009582 \\
\hline 251 & AT3G08860 & & $\begin{array}{l}\text { alanine--glyoxylate } \\
\text { aminotransferase, putative }\end{array}$ & 2.760281 & 0.002744 \\
\hline 252 & AT1G28130 & GH3.17 & $\begin{array}{l}\text { indole-3-acetic acid amido } \\
\text { synthetase }\end{array}$ & 2.75818 & 1.39E-05 \\
\hline 253 & AT1G04990 & & $\begin{array}{l}\text { zinc finger (CCCH-type) } \\
\text { family protein }\end{array}$ & 2.721602 & 0.00903 \\
\hline
\end{tabular}




\begin{tabular}{|c|c|c|c|c|c|}
\hline 254 & AT2G37080 & & myosin heavy chain-related & 2.695395 & 0.001345 \\
\hline 255 & AT4G24040 & TRE1 & TREHALASE 1 & 2.669742 & 0.004006 \\
\hline 256 & AT2G30400 & OFP2 & $\begin{array}{l}\text { OVATE FAMILY PROTEIN } \\
2\end{array}$ & 2.640737 & 0.005312 \\
\hline 257 & AT5G01210 & & transferase family protein & 2.634845 & 0.015089 \\
\hline 258 & AT5G16450 & & $\begin{array}{l}\text { dimethylmenaquinone } \\
\text { methyltransferase family } \\
\text { protein }\end{array}$ & 2.616874 & 0.000145 \\
\hline 259 & AT1G32940 & SBT3.5 & serine-type endopeptidase & 2.60018 & 0.048905 \\
\hline 260 & AT4G25835 & & $\begin{array}{l}\text { AAA-type ATPase family } \\
\text { protein }\end{array}$ & 2.582127 & 0.001425 \\
\hline 261 & AT2G04160 & AlR3 & serine-type endopeptidase & 2.581508 & 0.004246 \\
\hline 262 & AT3G17820 & $\begin{array}{l}\text { ATGSKB6, } \\
\text { GLN1.3 }\end{array}$ & glutamate-ammonia ligase & 2.578566 & 0.000295 \\
\hline 263 & AT4G19420 & & $\begin{array}{l}\text { pectinacetylesterase family } \\
\text { protein }\end{array}$ & 2.551852 & 5.86E-05 \\
\hline 264 & AT1G22500 & & $\begin{array}{l}\text { zinc finger (C3HC4-type } \\
\text { RING finger) family protein }\end{array}$ & 2.48845 & 0.03545 \\
\hline 265 & AT3G53210 & UMAMIT6 & nodulin MtN21 family protein & 2.438857 & 0.001289 \\
\hline 266 & AT2G28120 & & nodulin family protein & 2.393495 & 0.029096 \\
\hline 267 & AT5G24090 & $\mathrm{CHIA}$ & acidic endochitinase & 2.388647 & 0.005299 \\
\hline 268 & AT2G28320 & & $\begin{array}{l}\text { pleckstrin homology }(\mathrm{PH}) \\
\text { domain-containing protein }\end{array}$ & 2.371697 & 0.001786 \\
\hline 269 & AT1G70790 & & $\begin{array}{l}\text { C2 domain-containing } \\
\text { protein }\end{array}$ & 2.347914 & 0.000306 \\
\hline 270 & AT1G74790 & & $\begin{array}{l}\text { Catalytic acting on } \mathrm{CH}-\mathrm{OH} \\
\text { group of donors }\end{array}$ & 2.333346 & 0.000108 \\
\hline 271 & AT1G66180 & & $\begin{array}{l}\text { aspartyl protease family } \\
\text { protein }\end{array}$ & 2.33087 & 0.003705 \\
\hline 272 & $\begin{array}{l}\text { AT1G58889; } \\
\text { AT1G59265 }\end{array}$ & & transposable element gene & 2.327822 & 0.044887 \\
\hline 273 & AT5G23820 & & $\begin{array}{l}\text { MD-2-related lipid } \\
\text { recognition domain- } \\
\text { containing protein }\end{array}$ & 2.321514 & 0.00735 \\
\hline 274 & AT3G04010 & & $\begin{array}{l}\text { glycosyl hydrolase family } 17 \\
\text { protein }\end{array}$ & 2.281267 & 0.023084 \\
\hline 275 & AT3G03440 & & $\begin{array}{l}\text { armadillo/beta-catenin } \\
\text { repeat family protein }\end{array}$ & 2.254747 & 0.008427 \\
\hline 276 & AT4G36760 & ATAPP1 & $\begin{array}{l}\mathrm{N} \text {-1-naphthylphthalamic acid } \\
\text { binding }\end{array}$ & 2.209365 & 0.001041 \\
\hline 277 & AT1G30820 & & CTP synthase, putative & 2.183089 & 0.006337 \\
\hline 278 & AT2G27200 & & GTP-binding family protein & 2.181652 & 0.032579 \\
\hline 279 & AT4G16250 & PHYD & $\begin{array}{l}\text { PHYTOCHROME } \\
\text { DEFECTIVE D; G-protein } \\
\text { coupled photoreceptor }\end{array}$ & 2.180387 & $2.75 \mathrm{E}-05$ \\
\hline 280 & $\begin{array}{l}\text { AT1G70782; } \\
\text { AT1G70780 }\end{array}$ & $\begin{array}{c}\text { at1g70782:C } \\
\text { PuORF28 }\end{array}$ & $\begin{array}{l}\text { at1g70782: Conserved } \\
\text { peptide upstream open } \\
\text { reading frame } 28 \\
\text { at1g70780: unknown protein }\end{array}$ & 2.151836 & 0.001318 \\
\hline 281 & AT1G55500 & ECT4 & $\begin{array}{l}\text { EVOLUTIONARILY } \\
\text { CONSERVED C-TERMINAL } \\
\text { REGION } 4\end{array}$ & 2.142107 & 0.038379 \\
\hline 282 & AT1G44800 & & nodulin MtN21 family protein & 2.1393 & 0.00494 \\
\hline 283 & AT1G43590 & & transposable element gene & 2.11851 & 0.003507 \\
\hline 284 & AT1G30860 & & $\begin{array}{l}\text { protein binding / zinc ion } \\
\text { binding }\end{array}$ & 2.114061 & 0.002425 \\
\hline 285 & AT4G16540; & & heat shock protein-related & 2.113697 & 0.019747 \\
\hline
\end{tabular}


Supplementary Material

\begin{tabular}{|c|c|c|c|c|c|}
\hline & AT2G03020 & & & & \\
\hline 286 & AT3G54950 & $\begin{array}{c}\text { PLP7, PLA } \\
\text { IIIA }\end{array}$ & PATATIN-LIKE PROTEIN 6 & 2.10234 & 0.000386 \\
\hline 287 & AT3G29810 & COBL2 & $\begin{array}{l}\text { COBRA-LIKE PROTEIN } 2 \\
\text { PRECURSOR }\end{array}$ & 2.101852 & 0.01046 \\
\hline 288 & AT4G31590 & ATCSLC5 & $\begin{array}{l}\text { CELLULOSE-SYNTHASE } \\
\text { LIKE C5 }\end{array}$ & 2.093423 & 0.004987 \\
\hline 289 & AT2G06255 & ELF4-L3 & ELF4-Like 3 & 2.087513 & 0.000738 \\
\hline 290 & AT2G36400 & AtGRF3 & $\begin{array}{l}\text { GROWTH-REGULATING } \\
\text { FACTOR } 3\end{array}$ & 2.086138 & 0.016282 \\
\hline 291 & AT1G01070 & UMAMIT28 & nodulin MtN21 family protein & 2.064515 & 0.035635 \\
\hline 292 & AT4G21510 & & F-box family protein & 2.062487 & 0.022613 \\
\hline 293 & AT1G63010 & & $\begin{array}{l}\text { SPX (SYG1/Pho81/XPR1) } \\
\text { domain-containing protein }\end{array}$ & 2.037807 & 0.000255 \\
\hline 294 & AT3G10190 & & calmodulin, putative & 2.025874 & 0.001429 \\
\hline 295 & AT1G52080 & AR791 & actin binding & 2.022744 & 0.003086 \\
\hline 296 & AT3G53980 & & $\begin{array}{l}\text { protease inhibitor/lipid } \\
\text { transfer protein (LTP) family } \\
\text { protein }\end{array}$ & 2.021752 & 0.02841 \\
\hline 297 & AT3G02740 & & $\begin{array}{l}\text { aspartyl protease family } \\
\text { protein }\end{array}$ & 2.01532 & 0.000655 \\
\hline 298 & AT3G26690 & ATNUDX13 & $\begin{array}{l}\text { ARABIDOPSIS THALIANA } \\
\text { NUDIX HYDROLASE } \\
\text { HOMOLOG } 13\end{array}$ & 29.74907 & 3.83E-08 \\
\hline 299 & $\begin{array}{l}\text { AT1G34040; } \\
\text { AT1G34060 }\end{array}$ & & alliinase family protein & 13.44782 & $1.23 \mathrm{E}-05$ \\
\hline 300 & $\begin{array}{l}\text { AT3G10912; } \\
\text { AT3G10910 }\end{array}$ & $\begin{array}{l}\text { at3g10912: } \\
\text { CPuORF63 }\end{array}$ & $\begin{array}{l}\text { at3g10912: Conserved } \\
\text { peptide upstream open } \\
\text { reading frame } 63 \\
\text { at3g10910: zinc finger } \\
\text { (C3HC4-type RING finger) } \\
\text { family protein }\end{array}$ & 11.50478 & 1.89E-06 \\
\hline 301 & AT5G39050 & & $\begin{array}{l}\text { transferring acyl groups } \\
\text { other than amino-acyl } \\
\text { groups }\end{array}$ & 10.47903 & 3.81E-05 \\
\hline 302 & AT1G67820 & & $\begin{array}{l}\text { protein phosphatase } 2 \mathrm{C} \text {, } \\
\text { putative }\end{array}$ & 8.569184 & 0.000124 \\
\hline 303 & AT5G22860 & & $\begin{array}{l}\text { serine carboxypeptidase } \\
\text { S28 family protein }\end{array}$ & 8.229937 & 0.000128 \\
\hline 304 & $\begin{array}{l}\text { AT5G13370; } \\
\text { AT5G13360 }\end{array}$ & & $\begin{array}{l}\text { auxin-responsive GH3 family } \\
\text { protein }\end{array}$ & 7.306631 & $2.45 \mathrm{E}-05$ \\
\hline 305 & AT4G24000 & CSLG2 & $\begin{array}{l}\text { cellulose synthase/ } \\
\text { transferring glycosyl groups }\end{array}$ & 6.028111 & 0.001352 \\
\hline 306 & AT5G41070 & DRB5 & $\begin{array}{l}\text { DSRNA-BINDING PROTEIN } \\
5\end{array}$ & 5.179459 & 0.000115 \\
\hline 307 & AT4G27830 & BGLU10 & $\begin{array}{l}\text { BETA GLUCOSIDASE 10; } \\
\text { hydrolase }\end{array}$ & 4.506837 & 0.000157 \\
\hline 308 & AT1G69870 & & $\begin{array}{l}\text { proton-dependent } \\
\text { oligopeptide transport (POT) } \\
\text { family protein }\end{array}$ & 3.488548 & 0.000244 \\
\hline 309 & AT5G67480 & BT4 & $\begin{array}{l}\text { BTB AND TAZ DOMAIN } \\
\text { PROTEIN 4; protein binding } \\
\text { / transcription regulator }\end{array}$ & 2.752251 & 0.021153 \\
\hline 310 & AT3G10870 & MES17 & METHYL ESTERASE 17 & 2.59567 & 0.010281 \\
\hline 311 & AT1G78670 & ATGGH3 & $\begin{array}{l}\text { gamma-glutamyl hydrolase } \\
\text { 3; omega peptidase }\end{array}$ & 2.507317 & 0.000186 \\
\hline 312 & AT5G63140 & ATPAP29 & $\begin{array}{l}\text { ARABIDOPSIS THALIANA } \\
\text { PURPLE ACID } \\
\text { PHOSPHATASE } 29\end{array}$ & 2.39799 & 0.002376 \\
\hline 313 & AT3G14000 & ATBRXL2 & BRX-LIKE2 & 2.229507 & 0.000179 \\
\hline
\end{tabular}


Supplementary Material

\begin{tabular}{|c|c|c|c|c|c|}
\hline \multicolumn{6}{|c|}{ Unknown } \\
\hline 314 & AT1G29195 & & unknown protein & 9.785882 & 5.79E-06 \\
\hline 315 & AT5G57785 & & $\begin{array}{l}\text { response to sucrose } \\
\text { stimulus }\end{array}$ & 8.70065 & 0.000492 \\
\hline 316 & AT5G39520 & & unknown protein & 7.472651 & 0.001497 \\
\hline 317 & AT3G20300 & & $\begin{array}{l}\text { hyperosmotic salinity } \\
\text { response, response to } A B A \text {, } \\
\text { cold and water deprivation }\end{array}$ & 6.684753 & $1.62 \mathrm{E}-07$ \\
\hline 318 & AT5G18130 & & response to bacteria & 6.311842 & 0.000691 \\
\hline 319 & AT5G67600 & & $\begin{array}{l}\text { Involved in } \\
\text { megasporogenesis }\end{array}$ & 5.295142 & $1.51 \mathrm{E}-06$ \\
\hline 320 & AT1G15010 & & response to fungus & 5.087402 & 0.001343 \\
\hline 321 & AT1G62045 & & unknown protein & 3.655559 & 0.00033 \\
\hline 322 & AT1G05340 & & response to chitin & 3.602973 & 0.035809 \\
\hline 323 & AT5G44570 & & unknown protein & 3.595589 & 0.001261 \\
\hline 324 & AT2G37750 & & unknown protein & 3.409527 & 0.002835 \\
\hline 325 & AT1G27030 & & unknown protein & 3.267671 & 0.000779 \\
\hline 326 & AT5G57910 & & $\begin{array}{l}\text { response to phosphate } \\
\text { starvation and water } \\
\text { deprivation }\end{array}$ & 3.065675 & 0.008321 \\
\hline 327 & AT3G48550 & & unknown protein & 3.01456 & 0.002172 \\
\hline 328 & AT1G69760 & & unknown protein & 3.0009 & 0.000304 \\
\hline 329 & $\begin{array}{l}\text { AT1G53870; } \\
\text { AT1G53890 }\end{array}$ & & unknown protein & 2.775956 & 0.004817 \\
\hline 330 & AT2G28400 & & unknown protein & 2.76355 & 0.01528 \\
\hline 331 & AT1G07040 & & unknown protein & 2.727967 & 0.006837 \\
\hline 332 & AT2G24100 & ASG1 & $\begin{array}{l}\text { ALTERED SEED } \\
\text { GERMINATION } 1\end{array}$ & 2.722175 & 0.000111 \\
\hline 333 & AT4G16000 & & Unknown protein & 2.698386 & 0.021416 \\
\hline 334 & AT1G69160 & & unknown protein & 2.609614 & 0.00075 \\
\hline 335 & AT5G11070 & & response to brassinosteroid & 2.522679 & 0.005376 \\
\hline 336 & AT1G02470 & & $\begin{array}{l}\text { lipid transport superfamily } \\
\text { protein }\end{array}$ & 2.429294 & 0.025678 \\
\hline 337 & AT2G34070 & TBL37 & $\begin{array}{l}\text { TRICHOME } \\
\text { BIREFRINGENCE-LIKE } 37\end{array}$ & 2.365471 & 0.006245 \\
\hline 338 & AT3G10120 & & unknown protein & 2.337595 & 0.020093 \\
\hline 339 & AT3G19200 & & unknown protein & 2.276176 & 0.002032 \\
\hline 340 & AT3G27770 & & unknown protein & 2.217311 & 0.005692 \\
\hline 341 & AT1G28190 & & $\begin{array}{l}\text { response to phytohormones } \\
A B A, J A, S A \text { and } E T\end{array}$ & 2.215052 & 0.001976 \\
\hline 342 & AT5G51200 & & EMBRYO DEFECTIVE 3142 & 2.213379 & 0.000281 \\
\hline 343 & AT1G78170 & & unknown protein & 2.21131 & 0.000428 \\
\hline 344 & AT1G21010 & & $\begin{array}{l}\text { involved in N-terminal } \\
\text { protein myristoylation }\end{array}$ & 2.203696 & 0.025865 \\
\hline 345 & AT5G43180 & & unknown protein & 2.095066 & 0.008129 \\
\hline 346 & AT1G02816 & & unknown protein & 2.07257 & 0.00029 \\
\hline 347 & AT5G12420 & & $\begin{array}{l}\text { O-acyltransferase (WSD1- } \\
\text { like) family protein }\end{array}$ & 2.054012 & 0.00496 \\
\hline
\end{tabular}


Table S2: List of genes down-regulated in 35S:ANAC032 plants ( $>2$-fold; $\mathrm{P}<0.05$ )

\begin{tabular}{|c|c|c|c|c|c|}
\hline No. & Gene code & Symbol & Description & $\begin{array}{c}\text { Col-0/ } \\
\text { 35S:ANAC032 } \\
\text { (fold } \\
\text { suppression) }\end{array}$ & $p$-value \\
\hline \multicolumn{6}{|c|}{ Cell wall related } \\
\hline 1 & AT5G03350 & & legume lectin family protein & 3.765392 & 0.027743 \\
\hline 2 & AT3G16530 & & $\begin{array}{l}\text { legume lectin family protein } \\
\text { E5 }\end{array}$ & 3.107994 & 0.036902 \\
\hline 3 & AT1G65870 & & $\begin{array}{l}\text { disease resistance- } \\
\text { responsive family protein }\end{array}$ & 3.079823 & 0.032463 \\
\hline 4 & AT1G04040 & & $\begin{array}{l}\text { acid phosphatase class B } \\
\text { family protein }\end{array}$ & 2.866842 & 0.005916 \\
\hline 5 & AT3G22060 & & $\begin{array}{l}\text { receptor protein kinase- } \\
\text { related }\end{array}$ & 2.401016 & 0.012702 \\
\hline 6 & AT2G39850 & & $\begin{array}{l}\text { identical protein binding } \\
\text { /serine-type endopeptidase }\end{array}$ & 2.400638 & 0.001758 \\
\hline 7 & AT4G37800 & & $\begin{array}{l}\text { xyloglucan:xyloglucosyl } \\
\text { transferase, putative }\end{array}$ & 2.370646 & 0.003114 \\
\hline 8 & AT3G15400 & ATA20 & glycine-rich cell wall protein & 2.208898 & $9.50 \mathrm{E}-05$ \\
\hline 9 & AT2G26440 & & pectinesterase family protein & 2.11728 & 0.014366 \\
\hline 10 & AT4G01700 & & chitinase, putative & 2.107568 & 0.005514 \\
\hline 11 & AT5G53370 & PMEPCRF & $\begin{array}{l}\text { PECTIN } \\
\text { METHYLESTERASE PCR } \\
\text { FRAGMENT F; } \\
\text { pectinesterase }\end{array}$ & 2.050275 & 0.003018 \\
\hline 12 & AT5G65730 & & $\begin{array}{l}\text { xyloglucan:xyloglucosyl } \\
\text { transferase, putative }\end{array}$ & 2.298604 & 0.034813 \\
\hline \multicolumn{6}{|c|}{ Endomembrane system } \\
\hline 13 & AT3G47540 & & chitinase, putative & 2.053141 & 7.30E-05 \\
\hline 14 & AT2G35860 & FLA16 & $\begin{array}{l}\text { FASCICLIN-LIKE } \\
\text { ARABINOGALACTAN } \\
\text { PROTEIN } 16 \text { PRECURSOR }\end{array}$ & 2.034319 & 0.03553 \\
\hline 15 & AT5G50800 & SWEET13 & nodulin MtN3 family protein & 3.140465 & 0.021547 \\
\hline 16 & AT3G52720 & ACA1 & $\begin{array}{l}\text { ALPHA CARBONIC } \\
\text { ANHYDRASE 1; carbonate } \\
\text { dehydratase }\end{array}$ & 3.105561 & 0.021474 \\
\hline 17 & AT5G48540 & & $\begin{array}{l}33 \mathrm{kDa} \text { secretory protein- } \\
\text { related }\end{array}$ & 2.608235 & 0.000488 \\
\hline 18 & AT3G48460 & & $\begin{array}{l}\text { GDSL-motif lipase/hydrolase } \\
\text { family protein }\end{array}$ & 2.489515 & 0.043871 \\
\hline 19 & AT1G19940 & AtGH9B5 & $\begin{array}{l}\text { Arabidopsis thaliana } \\
\text { Glycosyl Hydrolase 9B5; } \\
\text { hydrolase }\end{array}$ & 2.272411 & 0.004566 \\
\hline 20 & AT3G52470 & & $\begin{array}{l}\text { harpin-induced family } \\
\text { protein }\end{array}$ & 2.240173 & 0.000395 \\
\hline 21 & AT3G29030 & $\begin{array}{l}\text { ATEXPA5, } \\
\text { EXPA5 }\end{array}$ & $\begin{array}{l}\text { EXPANSIN A5, plant-type } \\
\text { cell wall loosening }\end{array}$ & 2.23436 & 0.01626 \\
\hline 22 & AT1G78450 & & $\begin{array}{l}\text { SOUL heme-binding family } \\
\text { protein }\end{array}$ & 2.175728 & 0.002193 \\
\hline 23 & AT3G51450 & & $\begin{array}{l}\text { strictosidine synthase family } \\
\text { protein }\end{array}$ & 2.161901 & 0.005171 \\
\hline 24 & AT3G57630 & & exostosin family protein & 2.071314 & 0.009523 \\
\hline \multicolumn{6}{|c|}{ Hydrolase } \\
\hline 25 & AT5G58310 & MES18 & $\begin{array}{l}\text { METHYL ESTERASE 18; } \\
\text { hydrolase/ methyl indole-3- }\end{array}$ & 4.406805 & 0.006055 \\
\hline
\end{tabular}


Supplementary Material

\begin{tabular}{|c|c|c|c|c|c|}
\hline & & & acetate esterase & & \\
\hline 26 & AT4G12830 & & $\begin{array}{l}\text { hydrolase, alpha/beta fold } \\
\text { family }\end{array}$ & 2.261393 & 0.041191 \\
\hline \multicolumn{6}{|c|}{ Kinase activity } \\
\hline 27 & AT4G23130 & $\begin{array}{l}\text { CRK5, } \\
\text { RLK6 }\end{array}$ & $\begin{array}{l}\text { CYSTEINE-RICH RLK5; } \\
\text { kinase }\end{array}$ & 2.538395 & 0.011511 \\
\hline 28 & AT1G21270 & WAK2 & $\begin{array}{l}\text { ATP binding / calcium ion } \\
\text { binding / protein kinase }\end{array}$ & 2.013779 & 0.045028 \\
\hline 29 & AT5G59670 & & $\begin{array}{l}\text { leucine-rich repeat protein } \\
\text { kinase, putative }\end{array}$ & 6.372129 & 0.00176 \\
\hline 30 & AT5G60900 & RLK1 & $\begin{array}{l}\text { RECEPTOR-LIKE PROTEIN } \\
\text { KINASE 1; ATP binding / } \\
\text { kinase }\end{array}$ & 4.514457 & 0.00819 \\
\hline 31 & AT5G59680 & & $\begin{array}{l}\text { leucine-rich repeat protein } \\
\text { kinase, putative }\end{array}$ & 3.934956 & 0.000206 \\
\hline 32 & AT3G45860 & & $\begin{array}{l}\text { receptor-like protein kinase, } \\
\text { putative }\end{array}$ & 3.650749 & 0.009314 \\
\hline 33 & AT1G29720 & & protein kinase family protein & 2.99631 & 0.001562 \\
\hline 34 & AT4G21380 & ARK3 & $\begin{array}{l}\text { A. THALIANA RECEPTOR } \\
\text { KINASE } 3 \text {; transmembrane } \\
\text { receptor protein } \\
\text { serine/threonine kinase }\end{array}$ & 2.599056 & 0.00043 \\
\hline 35 & AT1G11330 & & $\begin{array}{l}\text { S-locus lectin protein kinase } \\
\text { family protein }\end{array}$ & 2.597267 & 0.001168 \\
\hline 36 & AT4G23320 & & protein kinase family protein & 2.57797 & 0.000182 \\
\hline 37 & AT4G23260 & & ATP binding / protein kinase & 2.431219 & 0.016496 \\
\hline 38 & AT1G78290 & & $\begin{array}{l}\text { serine/threonine protein } \\
\text { kinase, putative }\end{array}$ & 2.279841 & 0.001206 \\
\hline 39 & AT4G02420 & & $\begin{array}{l}\text { lectin protein kinase, } \\
\text { putative }\end{array}$ & 2.222469 & 0.037288 \\
\hline 40 & AT1G69730 & & protein kinase family protein & 2.20671 & 0.001366 \\
\hline 41 & AT1G51790 & & kinase & 2.175165 & 0.00227 \\
\hline 42 & AT1G16260 & & protein kinase family protein & 2.174017 & 0.000115 \\
\hline 43 & AT2G23770 & & $\begin{array}{l}\text { protein kinase family protein } \\
\text { / peptidoglycan-binding } \\
\text { LysM domain-containing } \\
\text { protein }\end{array}$ & 2.146823 & 0.000198 \\
\hline 44 & AT2G37710 & RLK & $\begin{array}{l}\text { RECEPTOR LECTIN } \\
\text { KINASE }\end{array}$ & 2.117521 & 0.019708 \\
\hline 45 & $\begin{array}{l}\text { AT5G38990;A } \\
\text { T5G39000 }\end{array}$ & & protein kinase family protein & 2.026729 & 0.000216 \\
\hline \multicolumn{6}{|c|}{ Methyltransferase activity } \\
\hline 46 & $\begin{array}{l}\text { AT3G44860;A } \\
\text { T3G44870 }\end{array}$ & $\begin{array}{l}\text { at3g44860: } \\
\text { FAMT }\end{array}$ & $\begin{array}{l}\text { FAMT (farnesoic acid } \\
\text { carboxyl-O- } \\
\text { methyltransferase) } \\
\text { at3g44870: S-adenosyl-L- } \\
\text { methionine:carboxyl } \\
\text { methyltransferase family } \\
\text { protein }\end{array}$ & 3.684674 & $5.71 \mathrm{E}-05$ \\
\hline 47 & $\begin{array}{l}\text { AT1G73602;A } \\
\text { T1G73600 }\end{array}$ & $\begin{array}{l}\text { at1g73602: } \\
\text { CPuORF32 }\end{array}$ & $\begin{array}{l}\text { Conserved peptide } \\
\text { upstream open reading } \\
\text { frame } 32 \\
\text { at } 1 \mathrm{~g} 73600 \text { : } \\
\text { phosphoethanolamine N- } \\
\text { methyltransferase }\end{array}$ & 3.010881 & 0.000382 \\
\hline \multicolumn{6}{|c|}{ Oxygen binding } \\
\hline 48 & AT2G30770 & CYP71A13 & $\begin{array}{l}\text { indoleacetaldoxime } \\
\text { dehydratase }\end{array}$ & 3.602751 & 0.0224 \\
\hline
\end{tabular}


Supplementary Material

\begin{tabular}{|c|c|c|c|c|c|}
\hline 49 & AT5G52320 & CYP96A4 & $\begin{array}{l}\text { heme binding / } \\
\text { monooxygenase }\end{array}$ & 2.935683 & 0.004136 \\
\hline 50 & AT3G26230 & CYP71B24 & $\begin{array}{l}\text { iron ion binding / } \\
\text { monooxygenase }\end{array}$ & 2.306404 & 0.000714 \\
\hline 51 & AT3G26320 & CYP71B36 & $\begin{array}{l}\text { iron ion binding / } \\
\text { monooxygenase }\end{array}$ & 2.242609 & 0.002329 \\
\hline 52 & AT1G13080 & CYP71B2 & $\begin{array}{l}\text { iron ion binding / } \\
\text { monooxygenase }\end{array}$ & 2.240076 & 0.024186 \\
\hline 53 & AT2G26170 & CYP711A1 & $\begin{array}{l}\text { iron ion binding / } \\
\text { monooxygenase }\end{array}$ & 2.102305 & 0.020876 \\
\hline 54 & AT5G36220 & CYP81D1 & $\begin{array}{l}\text { iron ion binding / } \\
\text { monooxygenase }\end{array}$ & 2.023514 & 0.043273 \\
\hline \multicolumn{6}{|c|}{ Response to stress } \\
\hline 55 & AT4G14400 & ACD6 & $\begin{array}{l}\text { ACCELERATED CELL } \\
\text { DEATH 6; protein binding }\end{array}$ & 4.38331 & 0.014703 \\
\hline 56 & AT2G14560 & LURP1 & $\begin{array}{l}\text { LATE UPREGULATED IN } \\
\text { RESPONSE TO } \\
\text { HYALOPERONOSPORA } \\
\text { PARASITICA }\end{array}$ & 4.220421 & 0.012204 \\
\hline 57 & AT1G19670 & $\begin{array}{l}\text { ATCLH1, } \\
\text { CORI1 }\end{array}$ & $\begin{array}{l}\text { A.THALIANA } \\
\text { CORONATINE-INDUCED } \\
\text { PROTEIN 1; chlorophyllase }\end{array}$ & 3.455888 & 4.54E-05 \\
\hline 58 & AT4G17090 & $\begin{array}{l}\text { CT-BMY, } \\
\text { BMY8, } \\
\text { BAM3 }\end{array}$ & $\begin{array}{l}\text { CHLOROPLAST BETA- } \\
\text { AMYLASE ; beta-amylase }\end{array}$ & 3.397184 & 0.017437 \\
\hline 59 & AT1G54040 & $\begin{array}{l}\text { ESP, } \\
\text { TASTY }\end{array}$ & $\begin{array}{l}\text { EPITHIOSPECIFIER } \\
\text { PROTEIN; enzyme regulator }\end{array}$ & 2.957499 & 0.000294 \\
\hline 60 & $\begin{array}{l}\text { AT1G76690;A } \\
\text { T1G76680 }\end{array}$ & $\begin{array}{l}\text { at1g76680: } \\
\text { OPR1 } \\
\text { at1g76690: } \\
\text { OPR2 } \\
\end{array}$ & $\begin{array}{l}\text { 12-oxophytodienoate } \\
\text { reductase | }\end{array}$ & 2.954008 & 0.002281 \\
\hline 61 & AT1G17610 & & $\begin{array}{l}\text { disease resistance protein- } \\
\text { related }\end{array}$ & 2.431586 & 8.31E-05 \\
\hline 62 & AT3G16670 & & unknown protein & 2.426182 & 0.007134 \\
\hline 63 & AT4G15440 & $\begin{array}{l}\text { HPL1, } \\
\text { CYP74B2 }\end{array}$ & $\begin{array}{l}\text { HYDROPEROXIDE LYASE } \\
\text { 1; electron carrier/ heme } \\
\text { binding/ monooxygenase }\end{array}$ & 2.376575 & 0.008187 \\
\hline 64 & AT4G26090 & RPS2 & $\begin{array}{l}\text { RESISTANT TO P. } \\
\text { SYRINGAE } 2\end{array}$ & 2.184328 & 0.001428 \\
\hline 65 & AT1G80850 & & $\begin{array}{l}\text { methyladenine glycosylase } \\
\text { family protein }\end{array}$ & 2.041256 & 0.012814 \\
\hline 66 & $\begin{array}{l}\text { AT1G72910;A } \\
\text { T1G72930 }\end{array}$ & $\begin{array}{l}\text { at1g72930: } \\
\text { IR }\end{array}$ & $\begin{array}{l}\text { at1g72910: disease } \\
\text { resistance protein (TIR-NBS } \\
\text { class), putative at1g72930: } \\
\text { TOLL /INTERLEUKIN-1 } \\
\text { RECEPTOR-LIKE }\end{array}$ & 2.037226 & 0.004886 \\
\hline \multicolumn{6}{|c|}{ Response to stimulus } \\
\hline 67 & AT3G22231 & PCC1 & $\begin{array}{l}\text { PATHOGEN AND } \\
\text { CIRCADIAN CONTROLLED } \\
1\end{array}$ & 5.211186 & 0.011547 \\
\hline 68 & AT2G40100 & LHCB4.3 & $\begin{array}{l}\text { light harvesting complex } \\
\text { PSII; chlorophyll binding }\end{array}$ & 4.624667 & 0.004588 \\
\hline 69 & AT5G54610 & ANK & ankyrin; protein binding & 4.096957 & 0.0028 \\
\hline 70 & AT4G13180 & & $\begin{array}{l}\text { short-chain dehydrogenase/ } \\
\text { reductase (SDR) family } \\
\text { protein }\end{array}$ & 3.731777 & 0.000547 \\
\hline 71 & AT5G55450 & & $\begin{array}{l}\text { protease inhibitor/ lipid } \\
\text { transfer protein (LTP) family } \\
\text { protein }\end{array}$ & 3.565105 & 0.013979 \\
\hline 72 & AT1G52770 & & $\begin{array}{l}\text { phototropic-responsive } \\
\text { NPH3 family protein }\end{array}$ & 3.416003 & 0.000182 \\
\hline 73 & AT1G78020 & & $\begin{array}{l}\text { Senescence-associated } \\
\text { protein-related }\end{array}$ & 2.266408 & 0.007507 \\
\hline
\end{tabular}


Supplementary Material

\begin{tabular}{|c|c|c|c|c|c|}
\hline 74 & AT1G30260 & & $\begin{array}{l}\text { response to cytokinin } \\
\text { stimulus }\end{array}$ & 2.262901 & 0.004016 \\
\hline 75 & AT1G70700 & $\begin{array}{l}\text { JAZ9, } \\
\text { TIFY7 }\end{array}$ & $\begin{array}{l}\text { JASMONATE-ZIM-DOMAIN } \\
\text { PROTEIN } 9\end{array}$ & 2.245812 & 0.048306 \\
\hline 76 & AT4G17670 & & $\begin{array}{l}\text { senescence-associated } \\
\text { protein-related }\end{array}$ & 2.20176 & 0.001727 \\
\hline 77 & AT4G36220 & $\begin{array}{l}\text { FAH1, } \\
\text { CYP84A1 }\end{array}$ & $\begin{array}{l}\text { FERULIC ACID 5- } \\
\text { HYDROXYLASE 1; ferulate } \\
\text { 5-hydroxylase }\end{array}$ & 2.1968 & 0.001008 \\
\hline 78 & AT1G56150 & & $\begin{array}{l}\text { auxin-responsive family } \\
\text { protein }\end{array}$ & 2.151447 & 0.017227 \\
\hline 79 & AT2G24540 & AFR & $\begin{array}{l}\text { ATTENUATED FAR-RED } \\
\text { RESPONSE }\end{array}$ & 2.053255 & 0.014936 \\
\hline 80 & AT3G21950 & & Methyltransferase & 2.049947 & 0.028911 \\
\hline 81 & AT3G62410 & $\begin{array}{l}\text { CP12-2, } \\
\text { CP12 }\end{array}$ & protein binding & 2.041587 & 0.021873 \\
\hline \multicolumn{6}{|c|}{ Transcription factor } \\
\hline 82 & AT5G63790 & ANAC102 & $\begin{array}{l}\text { ARABIDOPSIS NAC } \\
\text { DOMAIN CONTAINING } \\
\text { PROTEIN } 102\end{array}$ & 3.780047 & 0.0051 \\
\hline 83 & AT2G40750 & WRKY54 & $\begin{array}{l}\text { MAPK cascade, negative } \\
\text { regulation of defense } \\
\text { response }\end{array}$ & 3.290537 & 0.00141 \\
\hline 84 & AT5G53200 & TRY & TRIPTYCHON; DNA binding & 3.095995 & 0.034495 \\
\hline 85 & AT1G75250 & ATRL6 & ARABIDOPSIS RAD-LIKE 6; & 3.09007 & 0.011857 \\
\hline 86 & AT3G02380 & COL2 & $\begin{array}{l}\text { constans-like } 2 \text {; transcription } \\
\text { factor/ zinc ion binding }\end{array}$ & 2.702784 & 0.002375 \\
\hline 87 & AT5G07580 & & $\begin{array}{l}\text { DNA binding / transcription } \\
\text { factor }\end{array}$ & 2.433529 & 0.006766 \\
\hline 88 & AT2G21650 & MEE3 & $\begin{array}{l}\text { MATERNAL EFFECT } \\
\text { EMBRYO ARREST } 3\end{array}$ & 2.256903 & 0.030744 \\
\hline 89 & AT3G15270 & SPL5 & $\begin{array}{l}\text { SQUAMOSA PROMOTER } \\
\text { BINDING PROTEIN-LIKE } 5\end{array}$ & 2.129177 & 0.006874 \\
\hline 90 & AT3G56400 & WRKY70 & $\begin{array}{l}\text { transcription factor/ } \\
\text { transcription repressor }\end{array}$ & 2.091257 & 0.00114 \\
\hline 91 & AT1G19510 & ATRL5 & ARABIDOPSIS RAD-LIKE 5 & 2.033622 & 0.015531 \\
\hline \multicolumn{6}{|c|}{ Transporter } \\
\hline 92 & AT1G64780 & $\begin{array}{l}\text { AMT1;2 } \\
\text { ATAMT1;2 }\end{array}$ & $\begin{array}{l}\text { AMMONIUM } \\
\text { TRANSPORTER } 1 ; 2 ; \\
\text { transmembrane transporter }\end{array}$ & 3.805951 & 0.049804 \\
\hline 93 & AT3G46900 & COPT2 & $\begin{array}{l}\text { copper ion transmembrane } \\
\text { transporter/ high affinity } \\
\text { copper ion transmembrane } \\
\text { transporter }\end{array}$ & 3.161913 & 0.000458 \\
\hline 94 & AT1G55910 & ZIP11 & $\begin{array}{l}\text { ZINC TRANSPORTER } 11 \\
\text { PRECURSOR; cation } \\
\text { transmembrane transporter }\end{array}$ & 2.521367 & 0.003096 \\
\hline 95 & AT5G45380 & DUR3 & $\begin{array}{l}\text { sodium:solute symporter } \\
\text { family protein }\end{array}$ & 2.394784 & 0.028397 \\
\hline 96 & AT4G30110 & HMA2 & $\begin{array}{l}\text { cadmium-transporting } \\
\text { ATPasex }\end{array}$ & 2.262226 & 0.03795 \\
\hline 97 & AT4G13510 & ATAMT1;1 & $\begin{array}{l}\text { AMMONIUM } \\
\text { TRANSPORTER } 1 ; 1 ;\end{array}$ & 2.219013 & 0.00107 \\
\hline 98 & $\begin{array}{l}\text { ATMG00410;A } \\
\text { T2G07741;AT } \\
\text { MG01170;AT2 } \\
\text { G07699 }\end{array}$ & $\begin{array}{l}\text { atmg00410: } \\
\text { ATP6, } \\
\text { atmg01170: } \\
\text { ATP6-2 }\end{array}$ & $\begin{array}{l}\text { at2g07699: similar to } \\
\text { ATPase subunit } 6 \text {; } \\
\text { atmg00410: ATPase subunit } \\
6 \\
\text { at2g07741: ATPase subunit } \\
6 \text {, putative } \\
\text { atmg01170:ATPase subunit } \\
6-2\end{array}$ & 2.213852 & 0.020876 \\
\hline
\end{tabular}


Supplementary Material

\begin{tabular}{|c|c|c|c|c|c|}
\hline 99 & AT1G80760 & NIP6;1 & $\begin{array}{l}\text { NOD26-LIKE INTRINSIC } \\
\text { PROTEIN 6;1; boron } \\
\text { transporter/ glycerol } \\
\text { transmembrane transporter }\end{array}$ & 2.173673 & 0.011656 \\
\hline 100 & AT1G32450 & NRT1.5 & $\begin{array}{l}\text { NITRATE TRANSPORTER } \\
1.5\end{array}$ & 2.127833 & 0.003079 \\
\hline 101 & AT1G12110 & $\begin{array}{l}\text { NRT1.1, } \\
\text { CHL1, } \\
\text { B-1 }\end{array}$ & $\begin{array}{l}\text { nitrate transmembrane } \\
\text { transporter }\end{array}$ & 2.043714 & 0.00117 \\
\hline 102 & AT2G21540 & $\mathrm{SFH} 3$ & $\begin{array}{l}\text { SEC14-LIKE 3; } \\
\text { phosphatidylinositol } \\
\text { transporter }\end{array}$ & 2.02183 & 0.00107 \\
\hline \multicolumn{6}{|c|}{ Other functions } \\
\hline 103 & AT5G24150 & $\begin{array}{l}\text { SQP1, } \\
\text { SQE5 }\end{array}$ & squalene monooxygenase & 3.713257 & 0.045456 \\
\hline 104 & AT2G32290 & $\begin{array}{l}\text { BMY5, } \\
\text { BAM6 }\end{array}$ & $\begin{array}{l}\text { BETA-AMYLASE 6; cation } \\
\text { binding }\end{array}$ & 2.484569 & 0.037811 \\
\hline 105 & AT1G64400 & & $\begin{array}{l}\text { long-chain-fatty-acid--CoA } \\
\text { ligase, putative }\end{array}$ & 2.732873 & 0.00872 \\
\hline 106 & AT5G10170 & MIPS3 & $\begin{array}{l}\text { MYO-INOSITOL-1- } \\
\text { PHOSTPATE SYNTHASE } 3\end{array}$ & 2.496849 & 0.011415 \\
\hline 107 & AT2G41180 & & sigA-binding protein-related & 2.794774 & 0.003105 \\
\hline 108 & AT4G03450 & & ankyrin repeat family protein & 2.595286 & 0.008315 \\
\hline 109 & AT3G48080 & & $\begin{array}{l}\text { lipase class } 3 \text { family protein / } \\
\text { disease resistance protein- } \\
\text { related }\end{array}$ & 2.459949 & 0.02599 \\
\hline 110 & AT3G56710 & SIB1 & $\begin{array}{l}\text { SIGMA FACTOR BINDING } \\
\text { PROTEIN } 1\end{array}$ & 2.44967 & 0.006026 \\
\hline 111 & AT4G04840 & ATMSRB6 & $\begin{array}{l}\text { methionine sulfoxide } \\
\text { reductase domain- } \\
\text { containing protein }\end{array}$ & 2.374638 & 0.000339 \\
\hline 112 & AT3G57020 & & $\begin{array}{l}\text { strictosidine synthase family } \\
\text { protein }\end{array}$ & 2.368128 & 0.000295 \\
\hline 113 & AT2G39420 & & $\begin{array}{l}\text { esterase/lipase/thioesterase } \\
\text { family protein }\end{array}$ & 2.353474 & 0.000186 \\
\hline 114 & AT3G24503 & ALDH2C4 & $\begin{array}{l}\text { 3-chloroallyl aldehyde } \\
\text { dehydrogenase }\end{array}$ & 2.35122 & 0.007888 \\
\hline 115 & AT4G08300 & UMAMIT17 & nodulin MtN21 family protein & 2.350839 & 0.021292 \\
\hline 116 & AT1G01390 & & $\begin{array}{l}\text { UDP-glucoronosyl/UDP- } \\
\text { glucosyl transferase family } \\
\text { protein }\end{array}$ & 2.307895 & 0.007425 \\
\hline 117 & AT2G39210 & & nodulin family protein & 2.306359 & 0.006015 \\
\hline 118 & AT1G69720 & $\mathrm{HO} 3$ & HEME OXYGENASE 3 & 2.200228 & 0.000766 \\
\hline 119 & AT4G20780 & & $\begin{array}{l}\text { calcium-binding protein, } \\
\text { putative }\end{array}$ & 2.196002 & $9.55 \mathrm{E}-05$ \\
\hline 120 & AT1G24140 & & matrixin family protein & 2.126652 & 0.007713 \\
\hline 121 & AT1G22650 & & $\begin{array}{l}\text { beta-fructofuranosidase, } \\
\text { putative / invertase, putative }\end{array}$ & 2.060497 & 0.0098 \\
\hline 122 & AT4G22570 & APT3 & $\begin{array}{l}\text { ADENINE } \\
\text { PHOSPHORIBOSYL } \\
\text { TRANSFERASE } 3 \\
\end{array}$ & 2.042801 & 0.039514 \\
\hline 123 & AT1G64500 & & glutaredoxin family protein & 2.036543 & 0.023248 \\
\hline 124 & AT1G55850 & CSLE1 & $\begin{array}{l}\text { cellulose synthase/ } \\
\text { transferring glycosyl groups }\end{array}$ & 2.02917 & 0.004153 \\
\hline 125 & AT3G49580 & LSU1 & $\begin{array}{l}\text { RESPONSE TO LOW } \\
\text { SULFUR } 1\end{array}$ & 2.024903 & 0.033663 \\
\hline 126 & $\begin{array}{l}\text { AT2G32880;A } \\
\text { T2G32870 }\end{array}$ & & $\begin{array}{l}\text { meprin and TRAF homology } \\
\text { domain-containing protein, } \\
\text { MATH domain-containing } \\
\text { protein }\end{array}$ & 2.013923 & 0.001823 \\
\hline
\end{tabular}


Supplementary Material

\begin{tabular}{|c|c|c|c|c|c|}
\hline 127 & AT2G47130 & & $\begin{array}{l}\text { short-chain } \\
\text { dehydrogenase/reductase } \\
\text { (SDR) family protein }\end{array}$ & 2.563469 & 0.003639 \\
\hline \multicolumn{6}{|c|}{ Unknown } \\
\hline 128 & AT2G46630 & & unknown protein & 2.002048 & 0.001041 \\
\hline 129 & AT1G65490 & & unknown protein & 4.271573 & 0.005519 \\
\hline 130 & AT3G22240 & & unknown protein & 3.498544 & 0.011788 \\
\hline 131 & AT5G19240 & & unknown protein & 2.966056 & 0.000808 \\
\hline 132 & AT5G22390 & & unknown protein & 2.933623 & 0.000495 \\
\hline 133 & AT1G19960 & & unknown protein & 2.927 & 0.040121 \\
\hline 134 & AT3G51750 & & unknown protein & 2.918411 & 0.033997 \\
\hline 135 & AT1G74440 & & unknown protein & 2.900198 & 0.01844 \\
\hline 136 & AT2G15020 & & $\begin{array}{l}\text { myo-inositol } \\
\text { hexakisphosphate } \\
\text { biosynthetic process }\end{array}$ & 2.875841 & 0.024421 \\
\hline 137 & AT5G01790 & & unknown protein & 2.854305 & 0.008125 \\
\hline 138 & AT1G68600 & & $\begin{array}{l}\text { Aluminium activated malate } \\
\text { transporter family protein }\end{array}$ & 2.555495 & 0.000237 \\
\hline 139 & AT2G32160 & & $\begin{array}{l}\text { S-adenosyl-L-methionine- } \\
\text { dependent } \\
\text { methyltransferases } \\
\text { superfamily protein }\end{array}$ & 2.46698 & 0.008123 \\
\hline 140 & AT1G55960 & & $\begin{array}{l}\text { lipid transport superfamily } \\
\text { protein }\end{array}$ & 2.393015 & 0.047731 \\
\hline 141 & AT5G35490 & MRU1 & MTO1-RESPONDING UP 1 & 2.268254 & 0.027792 \\
\hline 142 & AT2G31110 & TBL40 & $\begin{array}{l}\text { TRICHOME } \\
\text { BIREFRINGENCE-LIKE } 40\end{array}$ & 2.218512 & 0.000361 \\
\hline 143 & AT4G00955 & & unknown protein & 2.19896 & 0.000711 \\
\hline 144 & AT5G42860 & & unknown protein & 2.156481 & 0.005854 \\
\hline 145 & AT1G11700 & & unknown protein & 2.128422 & 0.025579 \\
\hline 146 & AT5G44820 & & $\begin{array}{l}\text { Nucleotide-diphospho-sugar } \\
\text { transferase family protein }\end{array}$ & 2.076036 & 0.042788 \\
\hline 147 & AT5G01015 & & unknown protein & 2.056488 & 0.017074 \\
\hline
\end{tabular}


Table S3: List of common genes up-regulated by TIBA and by over-expression of 35S:ANAC032 (>2-fold, $\mathrm{P}<0.05$ )

\begin{tabular}{|c|c|c|c|c|c|}
\hline No. & Gene code & Symbol & Description & $\begin{array}{c}\text { 35S:ANAC032/ } \\
\text { Col-0 }\end{array}$ & $\begin{array}{c}\text { Col-0 } \\
\text { TIBA/mock }\end{array}$ \\
\hline 1 & AT1G77450 & ANAC032 & $\begin{array}{l}\text { NAC domain containing } \\
\text { protein } 32\end{array}$ & 115.4942 & 9.09966 \\
\hline 2 & AT2G37770 & AKR4C9 & $\begin{array}{l}\text { aldo/keto reductase family } \\
\text { protein }\end{array}$ & 56.89307 & 3.280615 \\
\hline 3 & AT1G10585 & & $\begin{array}{l}\text { bHLH type transcription } \\
\text { factor }\end{array}$ & 43.08498 & 18.91797 \\
\hline 4 & AT1G02850 & BGLU11 & $\begin{array}{l}\text { BETA GLUCOSIDASE 11; } \\
\text { hydrolase }\end{array}$ & 19.66124 & 5.033623 \\
\hline 5 & AT2G43820 & UGT74F2 & $\begin{array}{l}\text { UDP- } \\
\text { GLUCOSYLTRANSFERAS } \\
\text { E 74F2 }\end{array}$ & 18.93009 & 2.791824 \\
\hline 6 & AT3G04000 & & $\begin{array}{l}\text { short-chain dehydrogenase/ } \\
\text { reductase (SDR) family } \\
\text { protein }\end{array}$ & 13.73017 & 5.135259 \\
\hline 7 & AT2G37760 & AKR4C8 & $\begin{array}{l}\text { aldo/keto reductase family } \\
\text { protein }\end{array}$ & 12.63507 & 3.627012 \\
\hline 8 & AT4G15490 & UGT84A3 & $\begin{array}{l}\text { UDP-glycosyltransferase/ } \\
\text { sinapate } 1 \text { - } \\
\text { glucosyltransferase }\end{array}$ & 12.35113 & 3.503894 \\
\hline 9 & AT2G45210 & & $\begin{array}{l}\text { auxin-responsive protein- } \\
\text { related }\end{array}$ & 11.79464 & 2.066764 \\
\hline 10 & AT5G39050 & & $\begin{array}{l}\text { transferring acyl groups } \\
\text { other than amino-acyl } \\
\text { groups }\end{array}$ & 10.47903 & 2.80455 \\
\hline 11 & AT5G13490 & AAC2 & ADP/ATP carrier 2 & 10.32981 & 2.214483 \\
\hline 12 & AT1G67810 & SUFE2 & $\begin{array}{l}\text { SULFUR E 2; enzyme } \\
\text { activator }\end{array}$ & 9.767296 & 5.242495 \\
\hline 13 & AT4G22530 & & $\begin{array}{l}\text { embryo-abundant protein- } \\
\text { related }\end{array}$ & 9.691002 & 2.618454 \\
\hline 14 & AT1G05680 & UGT74E2 & $\begin{array}{l}\text { UDP-glucosyl transferase } \\
\text { family protein }\end{array}$ & 9.512384 & 20.43049 \\
\hline 15 & AT2G17500 & & $\begin{array}{l}\text { auxin efflux carrier protein } \\
\text { family }\end{array}$ & 9.431891 & 6.254818 \\
\hline 16 & AT5G13330 & Rap2.6L & $\begin{array}{l}\text { related to AP2 6L; } \\
\text { transcription factor }\end{array}$ & 7.978512 & 17.93513 \\
\hline 17 & AT1G26770 & ATEXPA10 & $\begin{array}{l}\text { ARABIDOPSIS THALIANA } \\
\text { EXPANSIN A 10; structural } \\
\text { constituent of cell wall }\end{array}$ & 7.724935 & 2.105974 \\
\hline 18 & AT3G46660 & UGT7E12 & $\begin{array}{l}\text { UDP-GLUCOSYL } \\
\text { TRANSFERASE 76E12 }\end{array}$ & 7.649356 & 2.246742 \\
\hline 19 & AT4G33540 & & $\begin{array}{l}\text { metallo-beta-lactamase } \\
\text { family protein }\end{array}$ & 7.213347 & 2.04123 \\
\hline 20 & AT5G17860 & CAX7 & $\begin{array}{l}\text { calcium exchanger } 7 ; \\
\text { calcium:sodium antiporter }\end{array}$ & 6.942018 & 3.505503 \\
\hline 21 & AT3G59140 & ATMRP14 & $\begin{array}{l}\text { ATPase, coupled to } \\
\text { transmembrane movement } \\
\text { of substances }\end{array}$ & 6.93742 & 2.140471 \\
\hline 22 & AT4G35770 & SEN1 & SENESCENCE 1 & 6.780057 & 2.129441 \\
\hline 23 & AT1G76470 & & $\begin{array}{l}\text { 3-beta-hydroxy-delta5- } \\
\text { steroid dehydrogenase }\end{array}$ & 6.669548 & 2.284777 \\
\hline 24 & $\begin{array}{l}\text { AT4G34590; } \\
\text { AT4G34588 }\end{array}$ & $\begin{array}{l}\text { at4g34590: } \\
\text { BZIP11 } \\
\text { GBF6 } \\
\text { at4g34588: } \\
\text { CPuORF2 }\end{array}$ & $\begin{array}{l}\text { At4g34590: G-BOX } \\
\text { BINDING FACTOR 6; } \\
\text { transcription factor } \\
\text { at4g34588: Conserved } \\
\text { peptide upstream open } \\
\text { reading frame } 2\end{array}$ & 6.264385 & 2.045682 \\
\hline 25 & AT2G29460 & ATGSU4 & $\begin{array}{l}\text { ARABIDOPSIS THALIANA } \\
\text { GLUTATHIONE S- }\end{array}$ & 5.629217 & 6.711621 \\
\hline
\end{tabular}


Supplementary Material

\begin{tabular}{|c|c|c|c|c|c|}
\hline & & & TRANSFERASE TAU 4 & & \\
\hline 26 & AT3G04070 & ANAC047 & $\begin{array}{l}\text { Arabidopsis NAC domain } \\
\text { containing protein } 47\end{array}$ & 5.608168 & 2.346065 \\
\hline 27 & AT2G34810 & & $\begin{array}{l}\text { FAD-binding domain- } \\
\text { containing protein }\end{array}$ & 5.385956 & 2.34858 \\
\hline 28 & AT2G03760 & ST1 & $\begin{array}{l}\text { brassinosteroid } \\
\text { sulfotransferase }\end{array}$ & 5.253201 & 2.854676 \\
\hline 29 & AT1G71140 & & MATE efflux family protein & 5.231011 & 2.105899 \\
\hline 30 & AT1G72680 & & $\begin{array}{l}\text { oxidoreductase, 2OG-Fe(II) } \\
\text { oxygenase family protein }\end{array}$ & 5.134753 & 2.251101 \\
\hline 31 & AT1G72900 & & $\begin{array}{l}\text { disease resistance protein } \\
\text { (TIR-NBS class), putative }\end{array}$ & 5.037367 & 4.303723 \\
\hline 32 & AT3G16450 & & Jacalin lectin family protein & 4.886648 & 2.194627 \\
\hline 33 & AT5G16080 & AtCXE17 & $\begin{array}{l}\text { Arabidopsis thaliana } \\
\text { carboxyesterase } 17\end{array}$ & 4.549698 & 3.021722 \\
\hline 34 & AT4G18010 & IP5PII & $\begin{array}{l}\text { MYO-INOSITOL } \\
\text { POLYPHOSPHATE 5- } \\
\text { PHOSPHATASE } 2\end{array}$ & 4.391116 & 2.468035 \\
\hline 35 & AT4G22470 & & $\begin{array}{l}\text { protease inhibitor/seed } \\
\text { storage/lipid transfer protein } \\
\text { (LTP) family protein }\end{array}$ & 4.33971 & 3.454267 \\
\hline 36 & AT5G22300 & NIT4 & $\begin{array}{l}\text { NITRILASE } 4 ; 3- \\
\text { cyanoalanine hydratase/ } \\
\text { indole-3-acetonitrile nitrilase }\end{array}$ & 4.251954 & 3.836168 \\
\hline 37 & AT5G59510 & $\begin{array}{l}\text { RTFL5 } \\
\text { DVL18 } \\
\end{array}$ & ROTUNDIFOLIA LIKE 5 & 4.19628 & 2.216006 \\
\hline 38 & AT1G63840 & & $\begin{array}{l}\text { zinc finger (C3HC4-type } \\
\text { RING finger) family protein }\end{array}$ & 4.149747 & 2.08117 \\
\hline 39 & AT2G02990 & RNS1 & RIBONUCLEASE 1 & 4.127582 & 2.23622 \\
\hline 40 & AT4G27260 & WES1 & $\begin{array}{l}\text { indole-3-acetic acid amido } \\
\text { synthetase }\end{array}$ & 4.027045 & 2.259881 \\
\hline 41 & AT2G30140 & & $\begin{array}{l}\text { UDP-glucoronosyl/UDP- } \\
\text { glucosyl transferase family } \\
\text { protein }\end{array}$ & 3.745069 & 2.280057 \\
\hline 42 & AT5G51830 & & $\begin{array}{l}\text { pfkB-type carbohydrate } \\
\text { kinase family protein }\end{array}$ & 3.66412 & 2.266256 \\
\hline 43 & $\begin{array}{l}\text { AT4G11320; } \\
\text { AT4G11310 }\end{array}$ & & cysteine proteinase, putative & 3.660721 & 3.876716 \\
\hline 44 & AT5G06860 & PGIP1 & $\begin{array}{l}\text { POLYGALACTURONASE } \\
\text { INHIBITING PROTEIN } 1\end{array}$ & 3.653244 & 2.665013 \\
\hline 45 & AT3G23550 & & MATE efflux family protein & 3.633738 & 9.949475 \\
\hline 46 & AT1G15670 & & $\begin{array}{l}\text { kelch repeat-containing F- } \\
\text { box family protein }\end{array}$ & 3.450734 & 2.036242 \\
\hline 47 & AT2G39330 & JAL23 & $\begin{array}{l}\text { JACALIN-RELATED } \\
\text { LECTIN } 23\end{array}$ & 3.411523 & 4.038976 \\
\hline 48 & AT4G14130 & XTR7 & $\begin{array}{l}\text { XYLOGLUCAN } \\
\text { ENDOTRANSGLYCOSYLA } \\
\text { SE } 7\end{array}$ & 3.401027 & 3.899549 \\
\hline 49 & AT1G32960 & SBT3.3 & $\begin{array}{l}\text { identical protein binding / } \\
\text { serine-type endopeptidase }\end{array}$ & 3.331092 & 2.419061 \\
\hline 50 & AT5G13750 & ZIFL1 & $\begin{array}{l}\text { ZINC INDUCED } \\
\text { FACILITATOR-like 1; } \\
\text { tetracycline:hydrogen } \\
\text { antiporter }\end{array}$ & 3.073315 & 3.235837 \\
\hline 51 & $\begin{array}{l}\text { AT1G54000; } \\
\text { AT1G54010 }\end{array}$ & MPL1 & $\begin{array}{l}\text { MYZUS PERSICAE- } \\
\text { INDUCED LIPASE } 1\end{array}$ & 3.016294 & 2.961967 \\
\hline 52 & AT3G16460 & & Jacalin lectin family protein & 3.006419 & 2.492469 \\
\hline 53 & AT4G01870 & & tolB protein-related & 2.971778 & 7.612111 \\
\hline 54 & $\begin{array}{c}\text { AT4G37530;A } \\
\text { T4G37520 }\end{array}$ & $\begin{array}{l}\text { at4g37520: } \\
\text { PER50 }\end{array}$ & $\begin{array}{l}\text { at4g37530: peroxidase, } \\
\text { putative } \\
\text { at4g37520: peroxidase } 50\end{array}$ & 2.956057 & 3.161199 \\
\hline
\end{tabular}




\begin{tabular}{|c|c|c|c|c|c|}
\hline 55 & AT1G76790 & & $\begin{array}{l}\text { O-methyltransferase family } 2 \\
\text { protein }\end{array}$ & 2.941472 & 3.815661 \\
\hline 56 & AT1G17170 & GSTU24 & $\begin{array}{l}\text { GLUTATHIONE S- } \\
\text { TRANSFERASE TAU } 24\end{array}$ & 2.862503 & 28.97755 \\
\hline 57 & AT5G67480 & BT4 & $\begin{array}{l}\text { BTB AND TAZ DOMAIN } \\
\text { PROTEIN } 4\end{array}$ & 2.752251 & 2.369505 \\
\hline 58 & AT5G50915 & & $\begin{array}{l}\text { basic helix-loop-helix (bHLH) } \\
\text { family protein }\end{array}$ & 2.739857 & 2.025977 \\
\hline 59 & AT2G24100 & & unknown protein & 2.722175 & 2.990254 \\
\hline 60 & AT3G14620 & CYP72A8 & $\begin{array}{l}\text { electron carrier/ heme } \\
\text { binding / monooxygenase/ } \\
\text { oxygen binding }\end{array}$ & 2.677795 & 2.137935 \\
\hline 61 & AT4G24040 & TRE1 & TREHALASE 1 & 2.669742 & 2.104687 \\
\hline 62 & AT3G55130 & ATWBC19 & $\begin{array}{l}\text { White-Brown Complex } \\
\text { homolog 19; coupled to } \\
\text { transmembrane movement } \\
\text { of substances }\end{array}$ & 2.573647 & 2.07274 \\
\hline 63 & AT1G52890 & ANAC019 & $\begin{array}{l}\text { Arabidopsis NAC domain } \\
\text { containing protein } 19\end{array}$ & 2.554885 & 2.966996 \\
\hline 64 & AT5G07010 & ST2A & SULFOTRANSFERASE 2A & 2.545133 & 2.246032 \\
\hline 65 & AT5G06870 & PGIP2 & $\begin{array}{l}\text { POLYGALACTURONASE } \\
\text { INHIBITING PROTEIN } 2\end{array}$ & 2.528479 & 3.956469 \\
\hline 66 & AT4G37410 & CYP81F4 & $\begin{array}{l}\text { electron carrier/ heme } \\
\text { binding / iron ion binding / } \\
\text { monooxygenase/ oxygen } \\
\text { binding }\end{array}$ & 2.516202 & 7.608564 \\
\hline 67 & $\begin{array}{l}\text { AT4G12290; } \\
\text { AT4G12280 }\end{array}$ & & $\begin{array}{l}\text { copper amine oxidase family } \\
\text { protein }\end{array}$ & 2.404675 & 2.090719 \\
\hline 68 & $\begin{array}{l}\text { AT2G02000;A } \\
\text { T2G02010 }\end{array}$ & $\begin{array}{l}\text { at2g02000: } \\
\text { GAD3 } \\
\text { at2g02010: } \\
\text { GAD4 }\end{array}$ & $\begin{array}{l}\text { at2g02000: glutamate } \\
\text { decarboxylase 3; } \\
\text { at2g02010: glutamate } \\
\text { decarboxylase 4) }\end{array}$ & 2.370822 & 2.607742 \\
\hline 69 & AT2G34070 & & unknown protein & 2.365471 & 2.225622 \\
\hline 70 & AT5G27600 & LACS7 & $\begin{array}{l}\text { LONG-CHAIN ACYL-COA } \\
\text { SYNTHETASE } 7\end{array}$ & 2.35029 & 2.325535 \\
\hline 71 & $\begin{array}{l}\text { AT3G16410; } \\
\text { AT3G16390; } \\
\text { AT3G16400 }\end{array}$ & $\begin{array}{c}\text { at3g16410: } \\
\text { NSP4 } \\
\text { at3g16390: } \\
\text { NSP3 } \\
\text { at3g16400: } \\
\text { NSP1 }\end{array}$ & $\begin{array}{l}\text { NITRILE SPECIFIER } \\
\text { PROTEIN }\end{array}$ & 2.309807 & 2.374808 \\
\hline 72 & АT3G05360 & AtRLP3 & Receptor Like Protein 30 & 2.301642 & 2.263713 \\
\hline 73 & AT3G16470 & JR1 & & 2.269684 & 2.125185 \\
\hline 74 & AT1G05560 & UGT75B1 & UDP-glycosyltransferase & 2.219308 & 11.38664 \\
\hline 75 & AT1G33110 & & MATE efflux family protein & 2.204309 & 3.47544 \\
\hline 76 & AT1G66760 & & MATE efflux family protein & 2.198126 & 3.801804 \\
\hline 77 & AT3G29810 & COBL2 & $\begin{array}{l}\text { COBRA-LIKE PROTEIN } 2 \\
\text { PRECURSOR }\end{array}$ & 2.101852 & 2.230228 \\
\hline 78 & AT5G12420 & & unknown protein & 2.054012 & 2.468399 \\
\hline
\end{tabular}


Table S4: List of common genes down-regulated by TIBA and by over-expression of 35S:ANAC032 (>2-fold, $\mathrm{P}<0.05$ )

\begin{tabular}{|c|l|l|l|r|r|}
\hline No. & Gene code & Symbol & \multicolumn{1}{|c|}{ Description } & $\begin{array}{c}\text { 35S:ANAC032/ } \\
\text { Col-0 }\end{array}$ & $\begin{array}{c}\text { Col-0 } \\
\text { TIBA/mock }\end{array}$ \\
\hline 1 & AT5G59670 & & $\begin{array}{l}\text { LRR protein kinase family } \\
\text { protein }\end{array}$ & 6.372129 & 3.020526 \\
\hline 2 & AT2G14560 & LURP1 & $\begin{array}{l}\text { LATE UPREGULATED IN } \\
\text { RESPONSE TO } \\
\text { HYALOPERONOSPORA } \\
\text { PARASITICA 1 }\end{array}$ & & \\
\hline 3 & AT5G03350 & WRKY54 & legume lectin family protein & 3.220421 & 2.165947 \\
\hline 4 & AT2G40750 & transcription factor & 3.290537 & 2.149989 \\
\hline 5 & AT3G52720 & ACA1 & $\begin{array}{l}\text { ALPHA CARBONIC } \\
\text { ANHYDRASE 1; carbonate } \\
\text { dehydrates activity }\end{array}$ & 3.105561 & 2.672328 \\
\hline 6 & AT1G19960 & AT2G39850 & unknown & 2.927 & 2.531967 \\
\hline 7 & AT27 & 2.400638 & 3.060939 \\
\hline 8 & AT1G80760 & NIP6;1, & $\begin{array}{l}\text { NLM7 } \\
\text { transporter/ glycerol } \\
\text { transmembrane transporter/ } \\
\text { urea transmembrane } \\
\text { transporter/ water channel }\end{array}$ & & 2.173673 \\
\hline
\end{tabular}


Figure S1: Sequence similarities between the ATAF-type NAC TFs
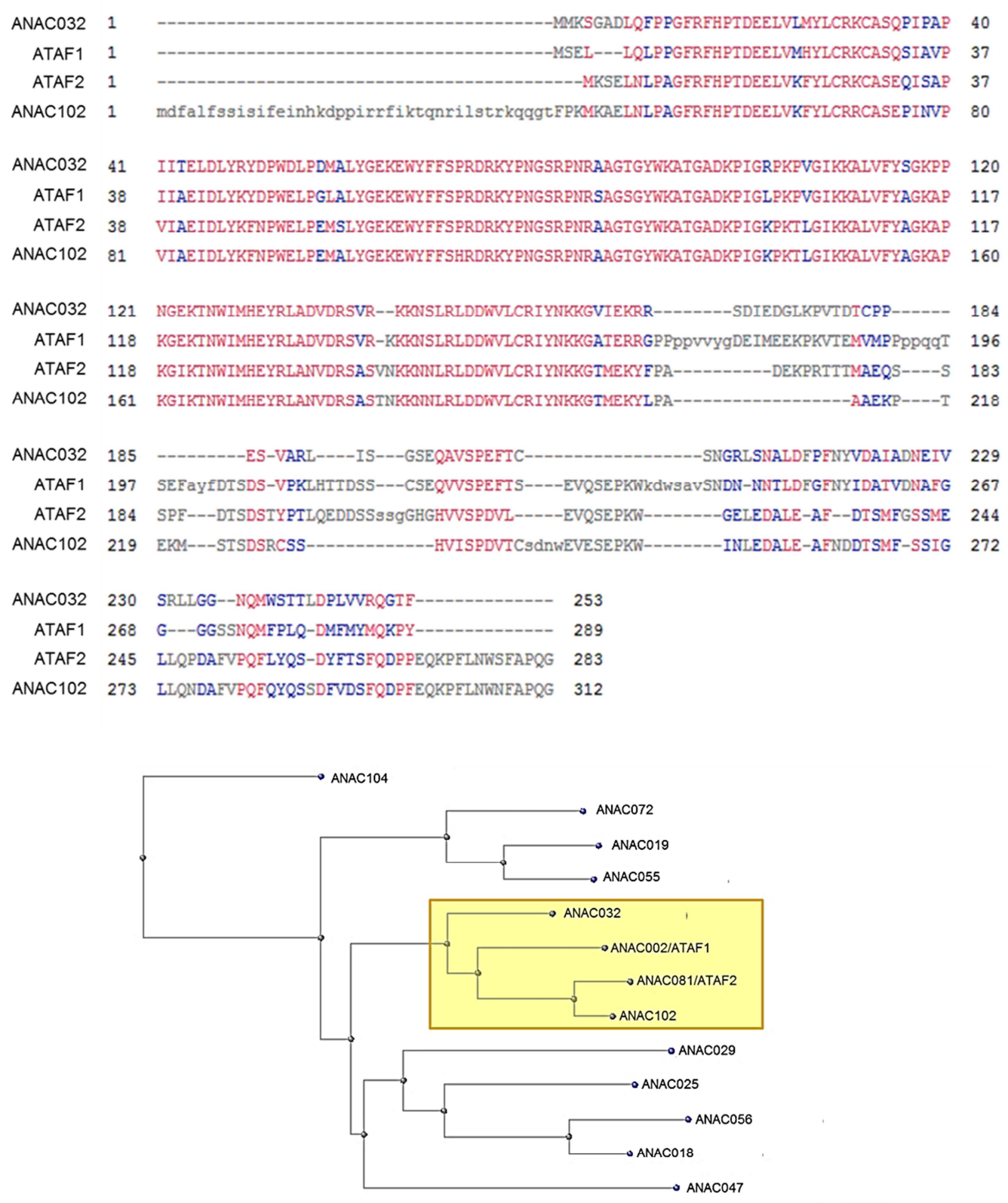

Multiple sequence alignment was performed using COBALT (Papadopoulos and Agarwala, 2007). In the top figure, columns with no gaps are colored in blue or red. The red color indicates highly conserved columns and blue indicates less conserved ones. The bottom figure indicates evolutionary distances between sequences modeled using the Neighbour-joining Tree method. The ATAF-type TFs (belonging to sub-group NAC-a-9) are within the yellow box while others are remaining members of the NAC-a sub-family. 
Figure S2: Induction of $A K R 4 C 9, b H L H 585$ and $A t 3 g 04000$ by TIBA requires

TGA256 and SCL14/33 proteins
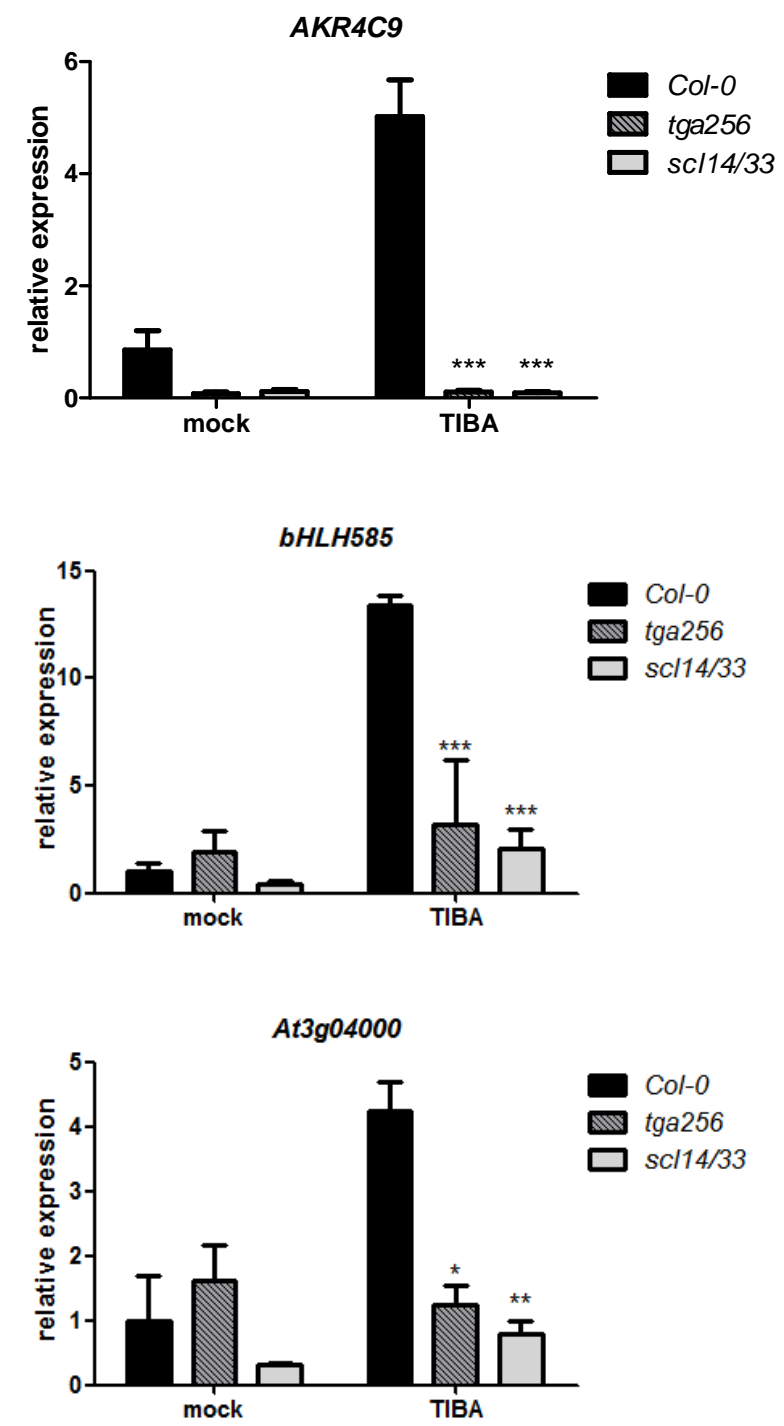

Six-week old soil-grown (under short day conditions) Col-O, tga256 and sc/14/33 plants were treated with $0.1 \mathrm{mM}$ TIBA for 8 hours. Treatment with $0.1 \%$ DMSO served as control. The relative transcript levels (normalized to house-keeping gene UBQ5) of AKR4C9, bHLH585 and At3g04000 were determined by qRT-PCR. The average relative expression in mock treated Col-O plants was set to 1 . The mean values $( \pm S E)$ from five individual plants are shown. Asterisks indicate significant differences compared with wild type (Two-way ANOVA; $\left.{ }^{* * *} \mathrm{P}<0.001,{ }^{* *} \mathrm{P}<0.01,{ }^{*} \mathrm{P}<0.05\right)$ 
Figure S3: Presence of ATAF1-binding consensus sequences as described by

Jensen et al., 2013 in the promoters of the three target genes

\begin{abstract}
AKR4C9 (AT2G37770)
TGTTTGGCAAATGTTGTTATTCTGCATTCTTCAAACAATAAAATGTTTTCAACTAGTTACAACTTCAACATGACATAGTCGATA GAACCTAAGACTATTTCCTTAGTTCGCGTCGGGAATTTT CTACATACCGCAAAAAAATACGTGTATGATAAAAAGTAAAATTC AAACCTTATTTCAAGACTAGGGAATTGCCTTCTTCTTTTTGATTCTATAACCTACTTACTGAATCCAAGGATCTTGATCAAATT AGTTATTTCTCATGAAAACTTACATTAACATTTCCTTAAATAAATAAAAACTTACATTAACAATTTAAAACATCCATTGTGAAG GGCCGGAATGAAGCATTATAGTAAGTGTTCCCAATTATTCTCCAATTTTTTCTCTTCAAAATGAATTACTACAAGCTCTCAAC CGTCGATTCTGCATTTCGCTCGGCGCAATATATATGCGTTCACCCAAAAACGTGTTACTTGGACGTTCACACTCGAGATAAT CTAAATGAACTCATATACACTCGAGATGTTATATAAACTCATCTACAATTTTGTTGTTGTTGTAAAACCACATAATTTTTCTTA TCACAAAGATTTTTGAAAAACCAATCACAATGTATAATATTCTACTATTGCTACATTATTTATGAAATATATAAAACTTTTTTCA TAATATGAAATGAATTATAAATCATGTACGAATTGTCTTGGTT GTTTGAGAGTTCTGTCTTCTGTGATACGTGTGAATT GTGG ACACAAAAAAGTGTCAGT CACACTCGAGATTAGCAAAGAGGAAATCTAAATGAACGAATTTAACTCAGATACGTCCACCGTC CATT GGTCCATGTAATGATCAATATCTGACGTGACAATATACTAACTAAGAAAGTACTAGTATTACAGAAAGAAGAAATCAAT TTGGCCACGAATCTCCCGCCTCTGTCGCTCTCTCACTTCTTCTCACCCTTTAATAGCTAGTGCCGAGTGCAGTGTGCGTTG AA
\end{abstract}

bHLH585 (AT1G10585)

CCTTTTACTTTTTATGTCAGTTTGCTCAGTGGCAAAGTTATGACCAACATCTACCTGGAGTACTCCAAGACTCAACAAAACTA GGCATGTTTAATTTTCTGTCTTTGTATTCACCTCCGGTGAACGTTTAGACGATCGGTCCATGTAGATCCCCTATCCGGTGAA CGATGTCGGCCATACGGCCAAAGAGAGTTGAGGGCCTTTAATAATTTATGTAAGGAATGCCGAATGTGTTGTGTCCTTTTC TTCTATGATAAT GATAGCTTGTTGAATAATCTTAGGTTATGGCGCCTTATGATACTTTCCTCGGATAATGAATACGTGCACCA AATTAATTGAACATGATGATACTATTTGATTTAGTGGTCCCGATTCTATCAGTATACAAAACAATTTTCCTTTTCTATTT GTTG ATAGAAACATATATAGTACTGTTGTAAGGAATTCATTTTTGTCTACCGTGGCTGTTGACTATTTTACGCCATTGAAATGATTTT TGATAATAATTTTCTCCAAACCTACTGTAAATCACAGGACTTAAACTCATGGTTAGTAATCTGAAAGAAGAAGAATCATATCT CTGAACGTTAGGAATCTCATCTCACACGGTAAGCATGATGCTATCTAAACTATGTCTTTGAACGTTAGAAATCTTACATCGA AATTATGATGCGTCCTAGTAATGTGTCAACCCACCAACAAATCTAATTTTTTTTTTTAATGATAAACAACATATCTAATTGTTTT GAAACTTTTGTATCTTTAAGAACGTGGAAATTCCGAAGTAAATAGTAAAATTTACTTGGTAGGAAAGATGCATGCATCTTATT AATTTAGTGTGTAAGCTCACGGACGCAATCACAAAAGCCATGACTTTCTTCCAAAACATCCCTTTCATCTAAATCACGTAGC TCTTTCTCTCAAAGTTGAGATTTGTGACTCTGTATCTCCCGGCCCTCTCTATCTCTTTAACTGTATATAAAGAGAGATGGATT TGAAAA

AT 3604000

CTGTGGAGACTCTTAAAACTGAAGGACATTTGCCGCAGCTTAGTGCTCCGGCGCAGCTTGCTCAGTTTCTCCGGCGAGCT CTTCCTCGGTGACTTTTITTTATAGATATAAAAAGAGAACAATAAAATATAATTGGTGGAATATGGGTTTAGTGGGGTCCACG TATCGAAGAAAAGAAGGGCCTCTATTTGTGGAGGACAGTTTGGCATTGTCACAAATCTAGTAAGATAAGATT GTTCACTTGA CACGTGACTTTCGCTTTTTTTATCACTTTTTTTCTTGCTCTCTTCATTAGTTTATAATCACAAGTTTATTTCATAAAATAATTGGA GAATAACCAAAAAAAACATTAAAAAATCCTATCTTATCTTTTACTTTCCTCTGAATATTTCTATCCATATTGTTGTTTCTTGTAA GTTCCTGGACCTTGTATTGATTGACGTCTAACAACACATCGATGCAACAACAATCTTTAGTCTCAACACTTTCGATTGTTTTC TCTAATAAAAT GATGGAGACAAAAAGATATAAAGTATACTAGAAAATTCTAGCATCACATCGTAAAAGTATCAACAACTAAAA TGAAGCAACTATGGCTGACATAATCTTGATTTAAGTTTTATAGTATGCAACTATGCATGTGTGTTCTAAATAATTTTAAAGTTA ATAAAATTGGTTAGTTGTATAATGTTGTTACCGTGCTATATATAATACAAGTTAAGATTTGAGAAAGTGAGTGTGTGAATTCT AGAAGACAATCACACAACGAAAACACGTCCTATCAATCTAAACTTTTGAGCAATTCAAAAT GCATACGAATTGACAGGTTAA GACAAATCTAAAAACATTTTCAGCAATTCAATTTGCTTACGAATTT GACAGCATAAGACAAATCTAACCATCACCACTACAAA TTGCTTGCTTACACTCTTTTAGCACGTTGTCATCATTTCTACCCTAAATATAGAAAAGTAAATTTATAGTAAAATCTACCTAAC AGT

The promoter sequences (-1000bp region) of the three target genes are shown. The highlighted sequences indicate conserved ATAF1-binding sequences as described by Jensen et al., 2013. Sequences highlighted in green are conserved 6-mers while those in yellow indicate conservation of $5 \mathrm{bp}$ out of the 6 -mer described. The consensus sequence described for ATAF1 is T[A/C/G]CGT[A/G] and TT[A/C/G]CGT. 
Figure S4: ANAC032 and ATAF1 without additional VP16 domain is unable to induce AKR4C9 and $b H L H 585$ promoter constructs
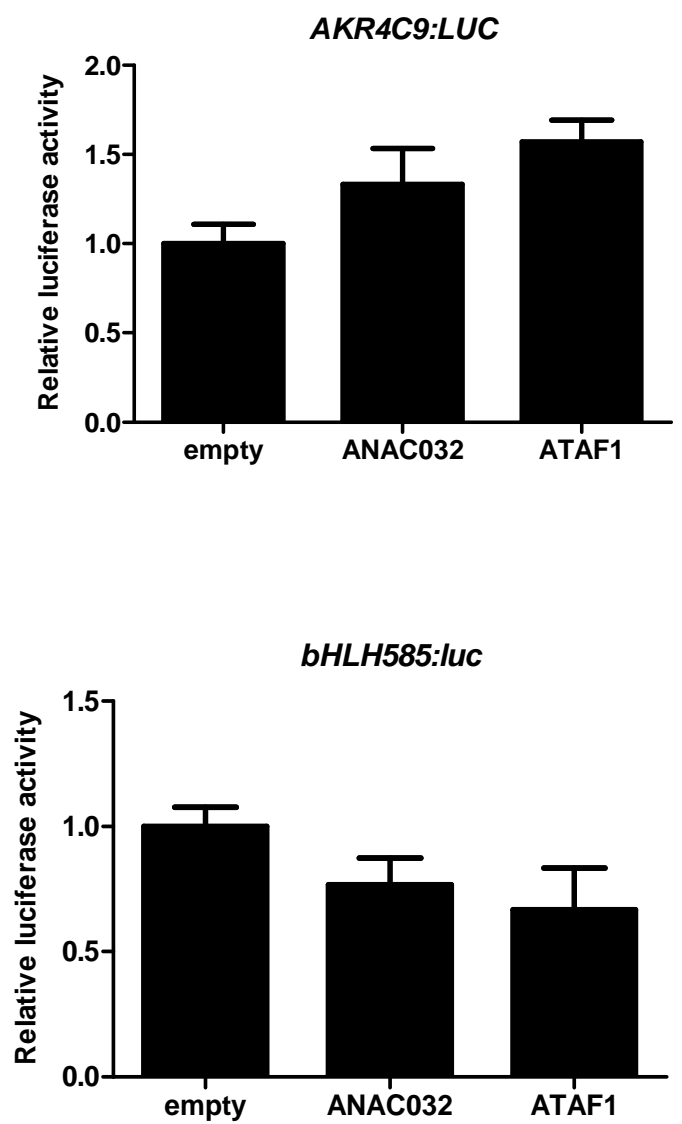

Leaves from four-week old soil-grown ataf1anac032 plants grown under 12-h light/12-h dark photoperiod were used for protoplast isolation and transformation with different effector and reporter constructs as indicated in the graphs. The values shown are means of two independent experiments, each with 4-5 reaction per effector construct. Statistical analysis using one-way ANOVA indicates no significant differences between the reactions. 


\section{Abbreviations}

\begin{tabular}{|c|c|}
\hline$\%$ & Percent \\
\hline${ }^{\circ} \mathrm{C}$ & degree Celsius \\
\hline$\mu \mathrm{l}$ & Microliter \\
\hline$\mu \mathrm{M}$ & micromolar \\
\hline A. thaliana & Arabidopsis thaliana \\
\hline A. tumefaciens & Agrobacterium tumefaciens \\
\hline ABA & Abscisic acid \\
\hline ACC & 1-aminocyclopropane-1-carboxylic acid \\
\hline AKR & Aldo-Keto Reductase \\
\hline AKR4C9 & ALDO KETO REDUCTASE FAMILY 4 MEMBER C9 \\
\hline ANAC032 & A. thaliana NAC DOMAIN CONTAINING PROTEIN 32 \\
\hline ANOVA & Analysis of Variance \\
\hline $\mathrm{AOS}$ & ALLENE OXIDE SYNTHASE \\
\hline as-1 & activation sequence-1 \\
\hline ATAF & ARABIDOPSIS THALIANA ACTIVATION FACTOR \\
\hline B. cinerea & Botrytis cinerea \\
\hline $\mathrm{bHLH}$ & basic Helix-Loop-Helix \\
\hline $\mathrm{bZIP}$ & basic domain/leucine zipper \\
\hline $\mathrm{CaCl}_{2}$ & calcium chloride \\
\hline cDNA & complementary DNA \\
\hline $\mathrm{cm}$ & centimeter \\
\hline COl1 & CORONATINE INSENSITIVE 1 \\
\hline COR78 & COLD REGULATED 78 \\
\hline $\mathrm{C}_{\mathrm{t}}$ & cycle threshold \\
\hline CUC2 & CUP-SHAPED COTYLEDON 2 \\
\hline DBD & DNA-binding domain \\
\hline DDE2 & DELAYED DEHISCENCE 2 \\
\hline DMSO & dimethyl sulfoxide \\
\hline DNA & deoxyribonucleic acid \\
\hline DNase & deoxyribonuclease \\
\hline dNTP & deoxynucleoside triphosphate \\
\hline dpi & day(s) post infection \\
\hline E.coli & Escherichia coli \\
\hline e.g. & for example (exempli gratia) \\
\hline EDTA & Ethylene di-amine tetra-acetic acid \\
\hline EIN3 & ETHYLENE INSENSITIVE 3 \\
\hline ET & ethylene \\
\hline $\mathrm{EtBr}$ & ethidium bromide \\
\hline EtOH & ethanol \\
\hline FLC & FLOWERING LOCUS C \\
\hline fwd & forward \\
\hline GA & gibberellic acid \\
\hline GO & Gene Ontology \\
\hline GRAS & GAI, RGA, SCR \\
\hline GUS & $\beta$-Glucuronidase \\
\hline $\mathrm{h}$ & hour \\
\hline $\mathrm{HCl}$ & hydrochloric acid \\
\hline HPLC-MS/MS & High Performance Liquid Chromatography-Tandem Mass Spectrometry \\
\hline
\end{tabular}




\begin{tabular}{|c|c|}
\hline HSPB & High Salt Precipitation Buffer \\
\hline JA & jasmonic acid \\
\hline JA-Ile & (+)-7-iso-Jasmonyl-L-isoleucine \\
\hline JAZ10 & JASMONATE ZIM DOMAIN PROTEIN 10 \\
\hline $\mathrm{KCl}$ & potassium chloride \\
\hline I & litre \\
\hline LB & Luria Bertani \\
\hline LD & long day \\
\hline M & Molarity \\
\hline MeJA & methyl jasmonate \\
\hline MES & 2-[N-Morpholino]-ethanesulfonic acid \\
\hline $\mathrm{mg}$ & milligram \\
\hline $\mathrm{MgCl}_{2}$ & magnesium chloride \\
\hline $\min$ & minute \\
\hline $\mathrm{ml}$ & milliliter \\
\hline $\mathrm{mM}$ & millimolar \\
\hline mRNA & messenger RNA \\
\hline MS & Murashige and Skoog medium \\
\hline MUG & 4-methyl-umbelliferyl-ß-D-glucuronide \\
\hline $\mathrm{Na}_{2} \mathrm{CO}_{3}$ & sodium carbonate \\
\hline NAC & NAM, ATAF1/2, CUC2 \\
\hline $\mathrm{NaCl}$ & sodium chloride \\
\hline NAM & NO APICAL MERISTEM \\
\hline ONPG & o-nitrophenyl- $\beta$-D-galactopyranoside \\
\hline OPDA & 12-oxo-phytodienoic acid \\
\hline $\mathrm{P}$ & $\begin{array}{l}\text { P-value (probability of obtaining a test statistic assuming that the null } \\
\text { hypothesis is true) }\end{array}$ \\
\hline P. xylostella & Plutella xylostella \\
\hline PCR & polymerase chain reaction \\
\hline PDB & potato dextrose broth \\
\hline PDF1.2 & PLANT DEFENSIN 1.2 \\
\hline $\mathrm{pH}$ & negative logarithm of the activity of the (solvated) hydronium ion \\
\hline PR-1 & PATHOGENESIS RELATED-1 \\
\hline qRT-PCR & quantitative Real-time PCR \\
\hline rev & reverse \\
\hline RNA & ribonucleic acid \\
\hline RNase & ribonuclease \\
\hline rpm & rotations per minute \\
\hline RT & reverse transcriptase \\
\hline RT & room temperature \\
\hline $\mathrm{s}$ & second \\
\hline S. cervisiae & Saccharomyces cervisiae \\
\hline SA & salicylic acid \\
\hline SAG & salicylic acid-2-O- $\beta$-D-glucoside \\
\hline SCL14 & SCARECROW LIKE-14 \\
\hline SD & short day \\
\hline SDS & sodium dodecylsulfate \\
\hline SE & standard error of mean \\
\hline TAE & Tris-acetate-EDTA \\
\hline taq & Thermus aquaticus \\
\hline TF & transcription factor \\
\hline TGA & TGACG motif binding protein \\
\hline
\end{tabular}




\begin{tabular}{l|l} 
TIBA & 2,3,4-triiodobenzoic acid \\
\hline TR domain & transcriptional regulatory domain \\
\hline UBQ5 & UBIQUITIN-5 \\
\hline VSP2 & VEGETATIVE STORAGE PROTEIN 2 \\
\hline w/v & weight per volume \\
\hline WT & wild-type \\
\hline X-Gluc & bromo-4-chloro-3-indolyl- $\beta$-D-glucuronide \\
\hline YPAD & Yeast extract-peptone-adenine-dextrose
\end{tabular}




\title{
11. Curriculum Vitae
}

\author{
Name: Neena Ratnakaran \\ Address: E /A-6 Sterling Park, \\ Near Drive-in cinema, Memnagar \\ Ahmedabad - 380052 \\ Gujarat, India \\ Date of Birth: $06^{\text {th }}$ July 1985 \\ Contact No: +917927435522 \\ Email id: neenarp@gmail.com
}

\section{Academic Qualifications and Research Experience}

$\mathrm{PhD}$ degree in Biology at Georg-August-Universität Göttingen, Germany

April 2010 - Research on

April 2014 "Identification of the role of Arabidopsis ATAF-type NAC transcription factors in plant stress and development"

\footnotetext{
Junior Research Fellow (CSIR-JRF) at Biochemistry Department,

Jan 2009 - National Chemical Laboratory, Pune, India

March 2010 Research on

"Application of RNAi technology as a means to control the pest Helicoverpa armigera"

\begin{tabular}{ll}
\hline & Master of Science (M.Sc) in Microbiology from University of Pune, India \\
(obtained 5.56 GPA on a scale of 6.0) \\
2006-2008 \\
$\begin{array}{l}\text { M.Sc Project: "Characterization of Extended-Spectrum- } \beta \text {-Lactamase } \\
\text { and Metallo- } \beta \text {-Lactamase producers from clinical isolates of } \\
\text { Acinetobacter sp." }\end{array}$ \\
\hline
\end{tabular}

2003-2006 Bachelor of Science (B.Sc) in Microbiology from Abasaheb Garware College, Pune, India (obtained 78.65\%)

2003 H.S.C (Higher Secondary Certificate) from Abasaheb Garware College, Pune, India (obtained $84.50 \%$ )

2001 S.S.C (Secondary School Certificate) from Vidya Bhavan High School, Pune, India (obtained 83.86\%)
} 